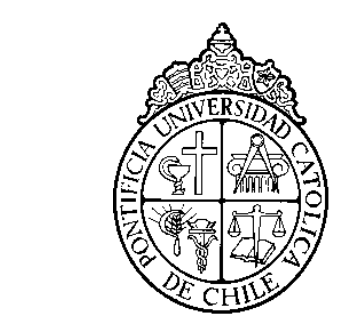

UNIVERSITAT POLITÈCNICA DE VALÈNCIA

ESCUELA DE DOCTORADO

PONTIFICIA UNIVERSIDAD CATOLICA DE CHILE

ESCUELA DE INGENIERÍA

\title{
IMPACT OF BIM/LEAN ON THE
}

INTERACTION OF CONSTRUCTION PROJECT

DESIGN TEAMS

\section{RODRIGO FERNANDO HERRERA VALENCIA}

Thesis submitted to the Office of Graduate Studies in partial fulfillment of the requirements for the Degree of "Doctorado en Ciencias de la Ingeniería" and "Doctorado en Infraestructuras de Transporte y Territorio".

Advisors:

DR. LUIS FERNANDO ALARCÓN, DR. CLAUDIO MOURGUES, DR. EUGENIO PELLICER

Santiago de Chile, July, 2020

(C) 2020, Rodrigo F. Herrera 
Dedicated to my lovely wife Cecilia, my children Amanda and Gabriel, my parents Carolina and Fernando, and my sister Daniela. 


\section{ACKNOWLEDGMENTS}

I want to thank all people who supported me during my stay at the Pontificia Universidad Católica de Chile and the Universitat Politècnica de València.

to my Advisors in Chile Luis Fernando Alarcón and Claudio Mourgues

to my Advisor in Spain Eugenio Pellicer

to Associate Professor Amalia Sanz

to Assistant Professor Laura Montalbán-Domingo

to Assistant Professor Tatiana García-Segura

to my PhD partners Luis Salazar, Tito Castillo, Zulay Giménez, Roberto Luna, María Calahorra and Jhonattan Martínez

to the Companies who collaborated in this research

to the School of Civil Engineering of the Pontificia Universidad Católica de Valparaíso, Chile.

to CONICYT, PCHA/National Doctorate/2018, 21180884, for funding the graduate research.

To VRI/PUC, for funding the graduate research the first two years 
TABLE OF CONTENTS

Pág.

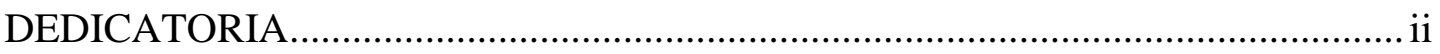

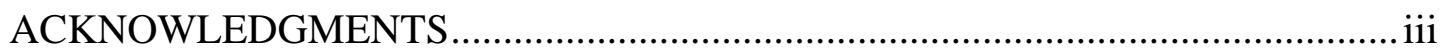

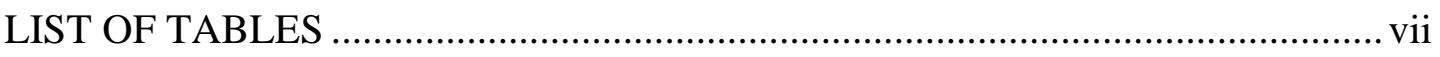

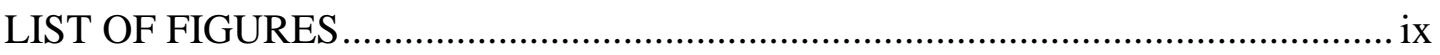

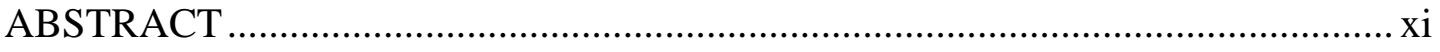

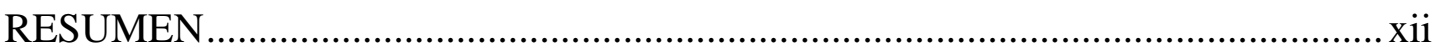

RESUM xiii

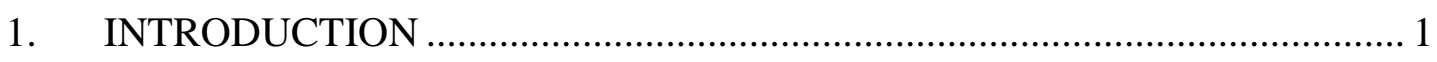

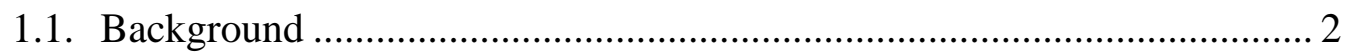

1.1.1. The design phase of construction projects ...................................... 2

1.1.2. Interaction in the design phase of construction projects ................... 3

1.1.3. Building Information Modeling uses ............................................. 5

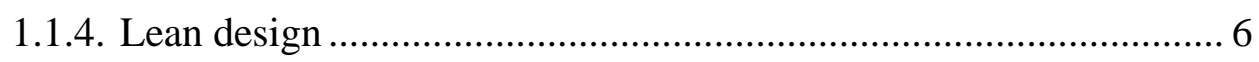

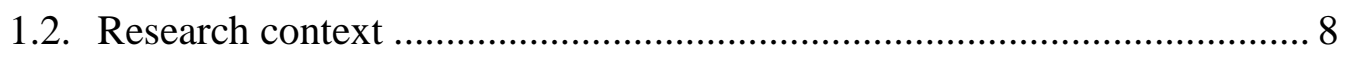

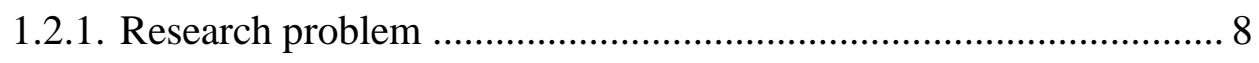

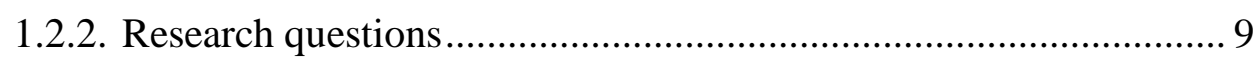

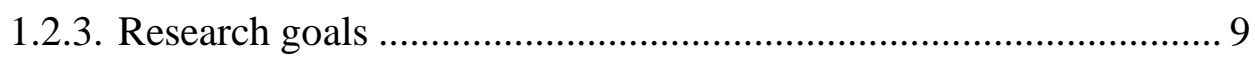

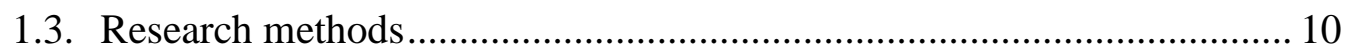

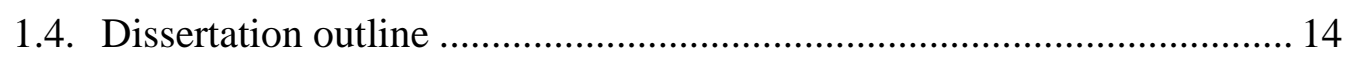

2. BIM USE ASSESSMENT (BUA) TOOL FOR CHARACTERIZING THE APPLICATION LEVELS OF BIM USES FOR THE PLANNING AND DESIGN

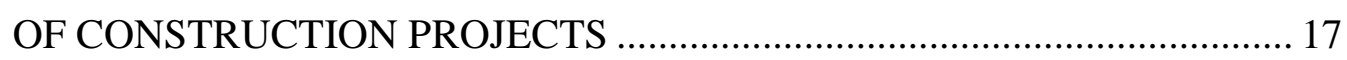

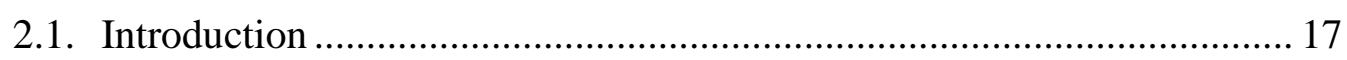

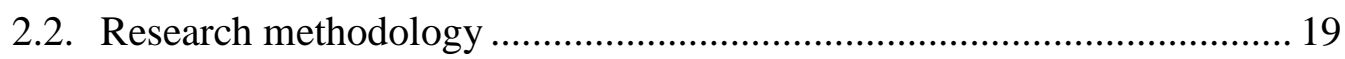

2.3. Identification, selection, and definition of BIM uses .............................. 23

2.4. Proposal of a BUA tool for measuring the level of BIM application ...... 27 
2.5. Validation of the BUA tool via the evaluation of the projects in the planning and design phases .......................................................................... 30

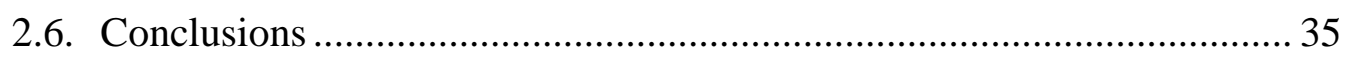

3. AN ASSESSMENT OF LEAN DESIGN MANAGEMENT PRACTICES IN CONSTRUCTION PROJECTS …............................................................ 37

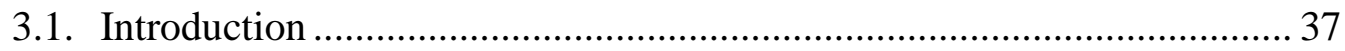

3.2. Research methodology ........................................................... 40

3.2.1. Stage 1: Lean design management practices - a literature review 41

3.2.2. Stage 2: Validation of Lean design management practices: practicesprinciples relationship............................................................... 42

3.2.3. Stage 3: Assessment of Lean design management practices ......... 46

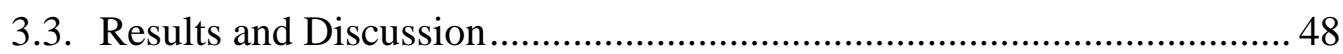

3.3.1. Identification of Lean design management practices from the literature 48

3.3.2. The relationship between Lean design management practices and Lean

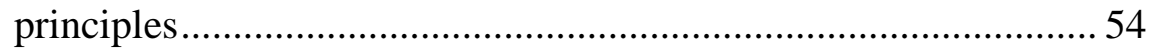

3.3.3. Assessment of Lean design management practices in construction projects 60

3.4. Conclusions 65

4. UNDERSTANDING INTERACTIONS BETWEEN DESIGN TEAM MEMBERS OF CONSTRUCTION PROJECTS USING SOCIAL NETWORK ANALYSIS69

4.1. Introduction 69

4.2. Research methodology 73

4.3. Literature review of interaction networks ........................................ 76

4.3.1. Dimensions of interaction in a work team ................................. 76

4.3.2. SNA experiences in the AEC industry .................................... 81

4.3.3. Gaps in SNA in the AEC industry .......................................... 85

4.4. Proposal for a network evaluation method: metrics and sociograms ....... 86

4.5. Pilot project: evaluation and analysis ................................................ 94

4.6. Conclusions .............................................................................. 104

5. ANALYZING THE ASSOCIATION BETWEEN LEAN DESIGN MANAGEMENT PRACTICES AND BIM USES IN THE DESIGN OF CONSTRUCTION PROJECTS ....................................................... 106

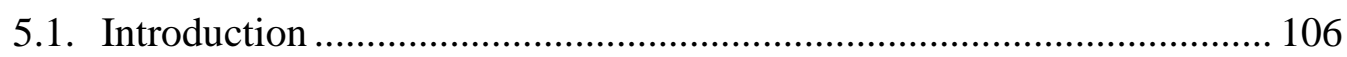




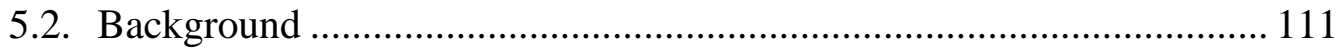

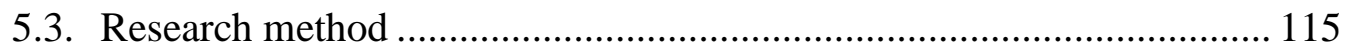

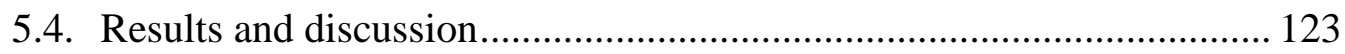

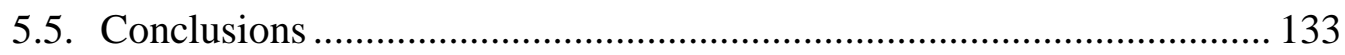

6. COMPARING TEAM INTERACTIONS IN TRADITIONAL AND BIM-LEAN DESIGN MANAGEMENT ………………………............................... 137

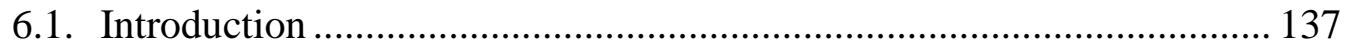

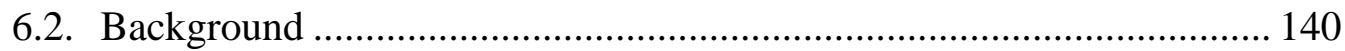

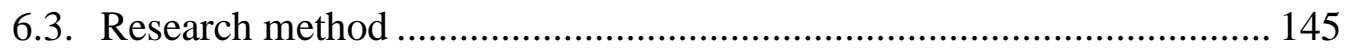

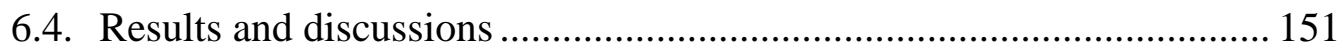

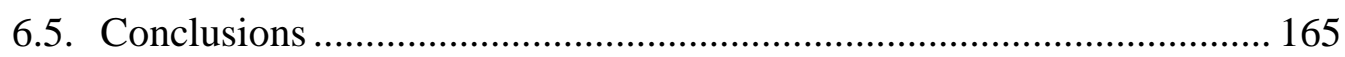

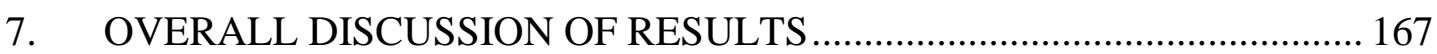

7.1. Phase 1: the creation of assessment tools ................................................. 168

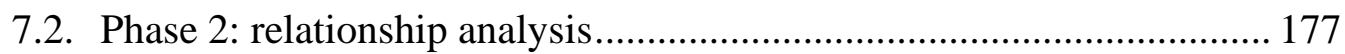

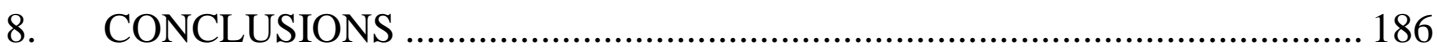

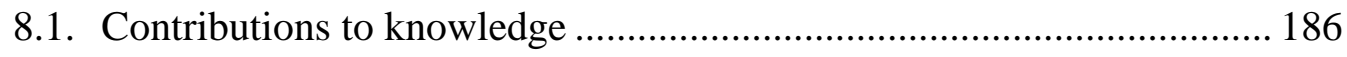

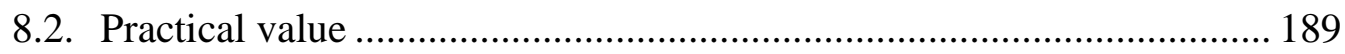

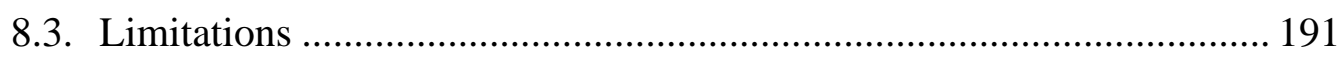

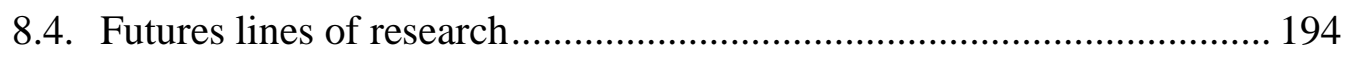

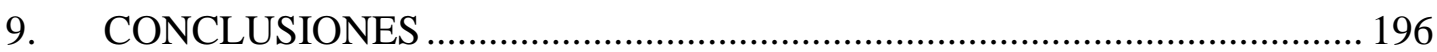

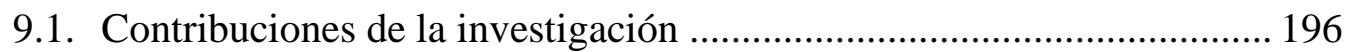

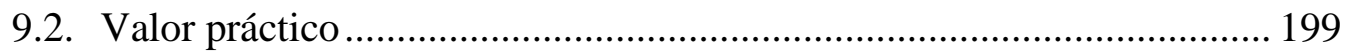

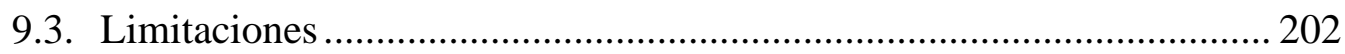

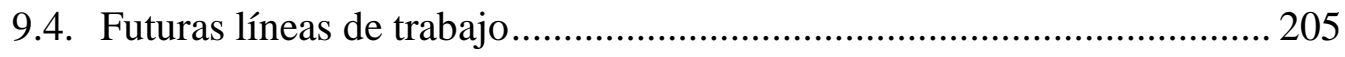

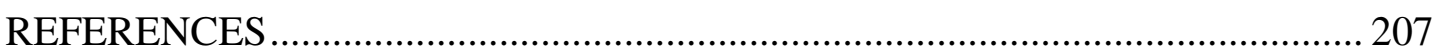

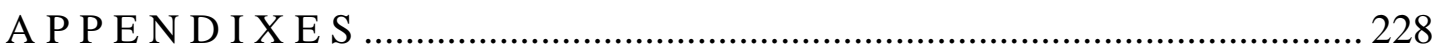

APPENDIX A: PUBLISHED PAPERS FIRST PAGE ………………………...... 229

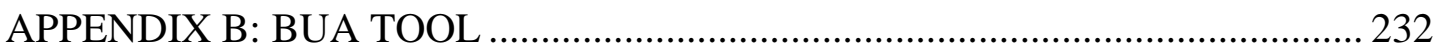

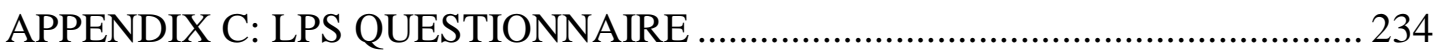




\section{LIST OF TABLES}

Pág.

Table 2-1: Characterization of expert panel ................................................................. 21

Table 2-2: BIM levels - a general description for each level ....................................... 22

Table 2-3: Characteristics of BIM use guides and manuals ........................................... 25

Table 2-4: Definitions of BIM uses for planning and design...................................... 26

Table 2-5: Uses and their characteristics................................................................. 28

Table 2-6: Summary of project characteristics ...................................................... 30

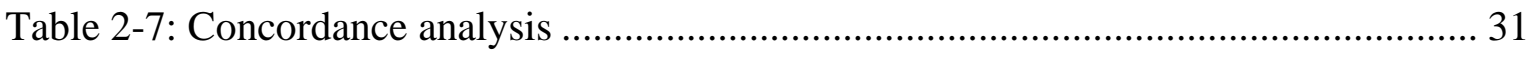

Table 3-1: Koskela's Lean Construction Principles (Herrera, Sanz, et al., 2019) (based on

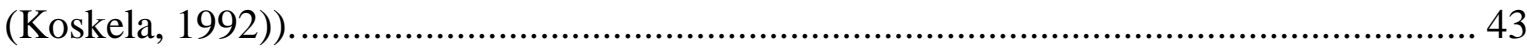

Table 3-2: Characterization of the experts who answered the matrix ............................... 44

Table 3-3: Characterization of the experts who created the questionnaire ....................... 46

Table 3-4: Summary of project characteristics ....................................................... 47

Table 3-5: Lean practices associated with stakeholder management............................. 50

Table 3-6: Lean practices associated with project planning and control .......................... 51

Table 3-7: Lean practices associated with problem solving and decision making ............ 53

Table 3-8: Practice-principle relationship matrix.......................................................... 55

Table 3-9: Spearman correlation matrix - lean design management practices .................. 63

Table 4-1: Dimensions that impact a work team - percentage of paper that mentions it ... 78

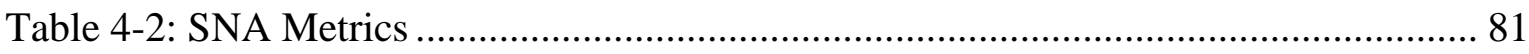

Table 4-3: SNA experiences in the AEC industry ...................................................... 83

Table 4-4: Descriptions of types of interactions - traditional ....................................... 87 
Table 4-5: Descriptions of types of interactions - commitment management 88

Table 4-6: Types of response for each type of interaction ....................................... 89

Table 4-7: Proposed metric for each network ......................................................... 91

Table 5-1: Lean design management (LDM) practices (Herrera et al., 2020a) .............. 112

Table 5-2: BIM uses for the planning and design of construction projects (Rojas et al.,

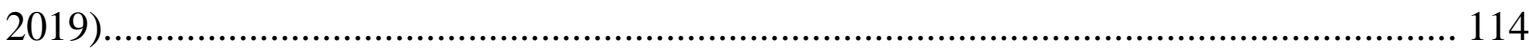

Table 5-3: BIM levels-a general description for each level ...................................... 118

Table 5-4: Summary of project characteristics ........................................................... 119

Table 5-5: Level of association according to the standardized contingency coefficient .. 121

Table 5-6: Pearson's chi-square test: related variables ............................................ 127

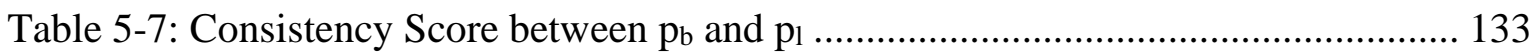

Table 6-1: Characteristics of projects A and B according to the selection criteria ........... 146

Table 6-2: Metrics for each network (Herrera et al., 2020b) ........................................ 150 


\section{LIST OF FIGURES}

Pág.

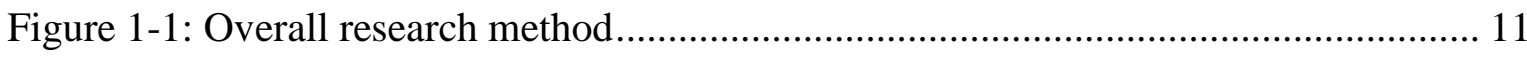

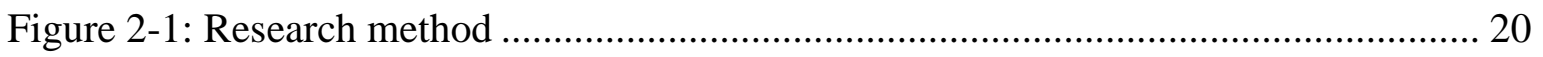

Figure 2-2: BUA-Cost Estimation............................................................................. 29

Figure 2-3: Cost estimation evaluations (example of an assessment) ............................. 31

Figure 2-4: BIM use application levels ................................................................... 34

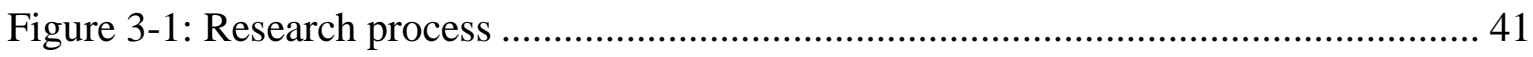

Figure 3-2: Relationships between lean design management practices and lean construction

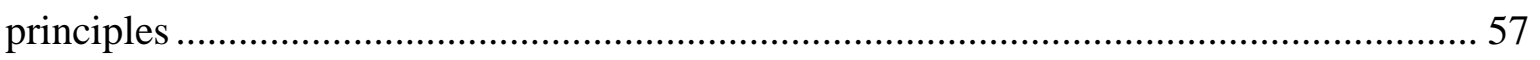

Figure 3-3: Number of lean principles related to each lean design management practice.. 59

Figure 3-4: Lean design management practices assessment. ......................................... 65

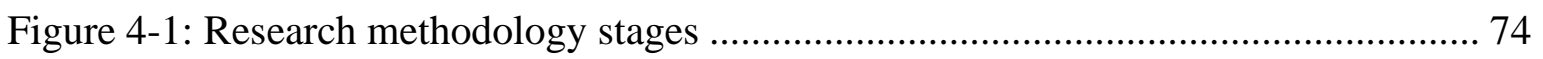

Figure 4-2: Proposed method for understanding interaction in design teams .................. 93

Figure 4-3: Knowledge of roles network (left)/ Global interaction network (middle)/

Relevant work information (right) .................................................................... 96

Figure 4-4: Collaboration network (left) / Planning and problem-solving network (right) 98

Figure 4-5: Trust network (left) / Learning network (right)........................................ 100

Figure 4-6: Commitment management networks...................................................... 102

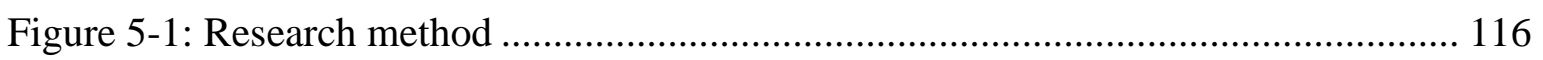

Figure 5-2: Association analysis in two hypothetical cases ..................................... 122

Figure 5-3: LDM practices assessment (Herrera et al., 2020a)..................................... 124

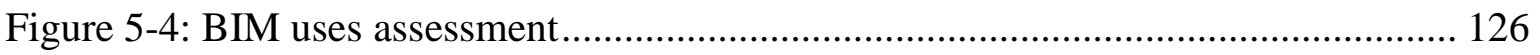


Figure 5-5: Association between LDM practices and BIM uses

Figure 5-6: LDM practices proportion and BIM uses proportion graph.......................... 132

Figure 6-1: BIM uses assessment: project A and project B .......................................... 152

Figure 6-2: LDM practices assessment: project A and project B …………………….... 154

Figure 6-3: Global interaction network and degree: project A and project B ................... 157

Figure 6-4: Relevant information flow network and degrees: project A and project B .... 158

Figure 6-5: Collaboration network and degree: project A and project B .......................... 159

Figure 6-6: Density according to interaction frequency: project A and project B ............ 161

Figure 6-7: Learning network and degrees: project A and project B .............................. 162

Figure 6-8: Commitment management metrics according to their interaction frequencies:

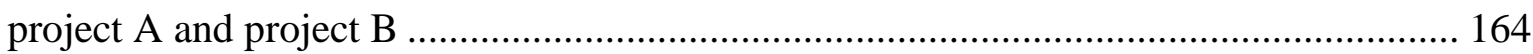

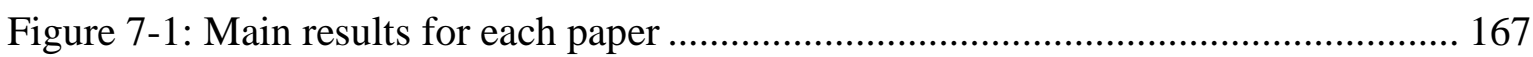




\begin{abstract}
Design teams of construction projects are composed of different stakeholders; this fact could make the interactions difficult. BIM and Lean methodologies have a positive impact on construction projects. Besides, there is evidence of the combined implementation of BIM and Lean; however, it is not known the empirical relationship between Lean practices and BIM uses in the design phase. Also, there is not a deeper understanding of the social phenomena that are generated among design teams when BIM-Lean management methodologies are implemented. Therefore, the objective of this research is to understand the impact of Lean design management (LDM) practices, and BIM uses in the interaction of construction project design teams. The research method has two phases: (1) the creation of tools to assess the level of implementation of LDM practices and BIM uses and to understand the interactions in a design team; and (2) the relationship analyses between BIM, Lean, and interaction, based on empirical information from construction projects in the design phase. The results present a BIM uses assessment tool and an LDM practices questionnaire to measure the design management and a method to understand the different types of interaction in a design team. Based on data from 64 projects, a chi-square analysis revealed 33 empirical relationships between BIM uses and LDM practices; also, the application of BIM uses implies a greater application of LDM practices. The project that applies BIM-Lean management achieves many interactions among its design team; transparent, orderly, and standardized information flows; a collaborative, trust, and learning environment; and commitment management. All these interaction elements are not visible in the project, where BIM-lean management was not applied.
\end{abstract}

Keywords: lean management practices, BIM uses, interaction, construction projects, design phase 


\section{RESUMEN}

Los equipos de diseño de los proyectos de construcción están compuestos por diferentes interesados; esto podría dificultar las interacciones. Las metodologías BIM y Lean tienen un impacto positivo en los proyectos de construcción. Además, hay pruebas de la aplicación conjunta de BIM y Lean; sin embargo, se desconoce la relación empírica entre las prácticas Lean y los usos de BIM en la fase de diseño. Tampoco existe una comprensión más profunda de los fenómenos sociales que se generan entre los equipos de diseño cuando se aplican las metodologías de gestión BIM-Lean. Por lo tanto, el objetivo de esta investigación es entender el impacto de las prácticas de gestión de diseño Lean (LDM) y los usos BIM en la interacción de los equipos de diseño de los proyectos de construcción. El método de investigación tiene dos fases: 1) la creación de herramientas para evaluar el nivel de aplicación de las prácticas LDM y los usos BIM, y para comprender las interacciones en un equipo de diseño; y 2) el análisis de las relaciones entre BIM, Lean y la interacción, basado en información empírica de proyectos de construcción en fase de diseño. Los resultados presentan un instrumento de evaluación de usos del BIM y un cuestionario de prácticas de LDM para medir la gestión del diseño, y un método para comprender los diferentes tipos de interacción en un equipo de diseño. Basados en los datos de 64 proyectos, un análisis chi cuadrado reveló 33 relaciones empíricas entre los usos del BIM y las prácticas LDM; además, la aplicación de los usos del BIM implica una mayor aplicación de las prácticas LDM. El proyecto que aplica la gestión BIM-Lean logra numerosas interacciones en su equipo de diseño; flujos de información transparentes, ordenados y estandarizados; un entorno de colaboración, confianza y aprendizaje; y una gestión del compromiso. Todos estos elementos de interacción no son visibles en el proyecto, en el que no se aplicó la gestión BIM-lean.

Palabras clave: prácticas de gestión lean, usos del BIM, interacción, proyectos de construcción, fase de diseño 


\section{RESUM}

Els equips de diseny dels projectes de construcción están compostos per diferents interesats; açó podría dificultar les interaccions. Les metodologies BIM i Lean tenen un impacte positiu en els projectes de construcció. A més, ni hi ha proves de l'aplicació conjunta de BIM i Lean; no obstant, es desconeix la relació empírica entre practiques Lean i els usos de BIM en fase de diseny. Tampoc existix una comprensió mes profunda dels fenómens socials que es generen entre els equips de diseny quan s'apliquen les metodologies de gestió BIM-Lean. Per tant, l'objectiu d'esta investigació es entendre l'impacte de les practiques de gestió de diseny Lean (LDM) i els usos BIM en l'interacció dels equips de diseny dels projectes de construcción. El métode de investigació te dos fases: 1) la creació de ferramentes per a evaluar el nivell d'aplicació de les practiques LDM i els usos BIM, i per a comprendre les interaccions en un equip de diseny; i 2) l'análisis de les relacions entre BIM, Lean i la interacció, basades en informació empírica de projectes de construcció en fase de diseny. Els resultats presenten un instrument d'evaluació d'usos del BIM i un questionari de practiques de LDM per a mesurar la gestió del diseny, i un método per a comprendre els diferents tipos d'interacció en un equip de diseny. Basades en les dades de 64 projectes, un análisis chi cuadrado va revelar 33 relacions empíricas entre els usos del BIM i les práctiques LDM; a més, l'aplicació dels usos del BIM implica una major aplicació de les práctiques LDM. El projecte que aplica la gestió BIM-Lean obté nombroses interaccions en el seu equip de diseny; fluxes d'informació transparents, ordenats i estandarizats; un entorn de colaboració, confiança i aprenentatge; i una gestió del compromis. Tots estos elements d'interacció no son visibles en el projecte, en el que no es va aplicar la gestió BIM-lean.

Paraules clau: practiques de gestió lean, usos del BIM, interacció, projectes de construcció, fase de diseny 


\section{INTRODUCTION}

The architecture, engineering, and construction industry (AEC) is characterized to be fragmented in several specialties, which appear in different stages during the project's life cycle (Dainty, Briscoe, \& Millett, 2001; Love, Irani, Cheng, \& Li, 2002). The high specialization of the different disciplines involved in a construction project generates a distance between professionals; therefore, their interaction is complex when the number of specialists increases ( $\mathrm{Ng} \&$ Tang, 2010).

A deficient interaction in work teams, in the AEC industry, can generate poor performance, in the execution of each one of its phases (design, construction, maintenance, operation, and deconstruction) and at global scope in the project's life cycle (Baiden, Price, \& Dainty, 2006). Poor performance is generated by activities that do not add value and are considered project waste, such as: rework, waiting times, among others (Aziz \& Hafez, 2013). Particularly, the design phase is critical in the project life cycle since decisions made at this phase can significantly impact the subsequent phases. Additionally, the costs of changes in the design phase are negligible in comparison to the cost of changes in future phases (AIA, 2007).

The philosophy of Lean management is focused on maximizing value for clients through the systematic reduction of waste in production processes (Ballard \& Howell, 2003; Pestana \& Gambatese, 2016). This philosophy has been adapted and applied in the construction industry (Lean Construction) in the last two decades, with successful results (Alsehaimi, Fazenda, \& Koskela, 2014), and also specifically in the design phase (Lean Design). Complementary, the Building Information Modeling (BIM) is a methodology with great potential in the design phases, being the architects the biggest users of this tool, 
highlighting that $82 \%$ of them believe that the use of BIM has a positive impact on the productivity of a project (Jones, Young Jr., \& Bernstein, 2008).

\subsection{Background}

\subsubsection{The design phase of construction projects}

The design phase of any construction project is cyclic, repetitive, and evolutionary, involving designers from various design groups such as architectural, structural, mechanical, electrical, plumbing, and others (Mujumdar \& Maheswari, 2018). The design process usually includes the following activities: product conception and feasibility analysis; product definition (preliminary design solution); interface coordination; detailing (final solution and constructive detailing) (Cambiaghi \& Amá, 2006). The design phase has a managerial perspective and a creative perspective (Dantas-Filho, Lima, Heineck, Tzortzopoulos, \& Barros Neto, 2017). Poor design management has been identified as an important factor in reducing the construction industry's overall performance and efficiency (Love \& Edwards 2004). Communication and the development of shared understanding in engineering design teams is an area of sustained importance for AEC industry (Cash, Dekoninck, \& Ahmed-Kristensen, 2017).

The design phase of any construction project involves several designers who exchange information with each other most often in an unstructured manner throughout the design phase (Mujumdar \& Maheswari, 2018). The effective workflow in the design phase can be defined as the information flow between the correct people at the correct times (Al Hattab \& Hamzeh, 2015). Traditional planning and management methods applied during the design phase do not consider workflows and the problem of workflow variability. The variability of flows, in the AEC industry, generates suboptimal cycle times, higher costs, 
and rework, affecting design and construction performance (Arashpour \& Arashpour, 2015; Hamzeh, Zankoul, \& Rouhana, 2015). Complementary, Svalestuen et al., (2015) identify twelve elements that influence the performance of a design team: contract models, elite feeling, commitment to the project, commitment to the team, former relation between team members, involvement in the goal-setting process, how difficult the goal is to reach, focus on team development, team building, good collaboration between al project leaders, identifying the design team member's roles, and trust between the team members. Some of these elements imply a high and effective interaction between members of the design team (Herrera, Mourgues, Alarcón, \& Pellicer, 2020b), which will directly influence the performance of the design team (Svalestuen et al., 2015).

\subsubsection{Interaction in the design phase of construction projects}

Managing information flow within design management is one of the critical aspects that affect the efficiency of the whole project (Dave, Kubler, Främling, \& Koskela, 2014). An increase in specialization requires greater interaction, and technological tools are not

enough to achieve it, because the information flow is not solved only with technology; it is necessary to understand the social phenomena generated in the organization, i.e., social factors, as well as technical ones, are fundamental to have an accurate information flow (Phelps, 2012). A project team with greater interaction generates an increase in trust and learning in the work teams, achieving high levels of commitment and understanding among the members (Phelps, 2012). Flores et al. (2014) declare that improving the connectivity of information flows between people results in higher project performance.

There are several key success factors to integrating the design teams effectively, for example: personal working attitude, team base accountability, team organization, 
management of leadership, transparent communication process, policy, procurement and contract, operation, and appropriate technology (Othman et al., 2016). A contracting strategy as Integrated Project Delivery (IPD) has the potential to enhance interaction, improve communication, align objectives, and improve project performance (Mesa, Molenaar, \& Alarcón, 2016).

Measuring the interaction of work teams is a challenge that has no single solution (Herrera, Mourgues, \& Alarcón, 2018). Valentine, Nembhard, \& Edmondson, (2015) present a literature review from 2012, where they found 39 instruments for assessing teamwork through surveys. Most of these instruments include dimensions such as: communication, coordination, and mutual respect. To analyze the interactions of work teams, different tools can be used, such as a survey, a frequency analysis, an $\mathrm{n} \times \mathrm{n}$ matrix, a social network analysis (SNA) (Yang \& Tang, 2004), and a design structure matrix (Rosas, 2013). SNA has attracted attention in the AEC industry because it can be used to examine the role of nonformal structures in their coexistence with formal structures (D. M. Alarcón, Alarcón, \& Alarcón, 2013).

Social networks are a set of relationships between actors who play different roles in an organization. Social Network Analysis (SNA) uses graph theory to explain these relationships using mathematical indicators such as density, length, and diameter of the network, among others (Marin \& Wellman, 2011). SNA has been used as an information flow diagnostic tool in the AEC industry (Alarcón, Alarcón, \& Alarcón, 2013). Flores et al., (2014) propose using SNA, in conjunction with inferential statistical analysis and roundtable discussions, to improve the interaction and connectivity of information flow in a project team. As an example, Hickethier, Tommelein, \& Lostuvali, (2013) present a case 
study on a construction project with IPD, where the research focused on the SNA of project members in a collaborative working environment.

\subsubsection{Building Information Modeling uses}

A technology-supported methodology that promotes the integration and collaboration among stakeholders in the AEC industry is Building Information Modeling (BIM) (Azhar, 2011). BIM per Eastman, Teicholz, Sacks, \& Liston, (2011) is "a new approach to design, construction, and facilities management, in which a digital representation of the building process [is used] to facilitate the exchange and interoperability of information in digital format". The most frequently reported benefits are related to the cost reduction and control through the project life cycle; significant time savings are also reported. By contrast, negative effects are mainly focused on the use of BIM software; cost/benefit analysis, awareness-raising, and education and training are important activities to address the challenges of BIM usage (Bryde, Broquetas, \& Volm, 2013). BIM refers to a set of interacting policies, processes, and technologies that generate a 'methodology to manage the essential building design and project data in digital format throughout the building's life-cycle (Penttilä, 2006). The use of BIM can strengthen collaboration and reduce fragmentation in AEC industry projects, improving performance, and reducing costs (Azhar, 2011).

The application of the BIM methodology to a particular project entails particular BIM uses, which are defined in various ways: The Penn State guide defines BIM use as "a method of applying Building Information Modeling during a facility's lifecycle to achieve one or more specific objectives" (Kreider \& Messner, 2013). According to Succar (2016), BIM uses "identify and collate the information, requirements that need to be delivered as - 
or embedded within - 3D digital models". Thus, while there is a consensus on the relationship of uses to project objectives, there is no agreement on whether uses are methods, applications, or actions; therefore, there is no universal definition for BIM uses. Although there is no universal definition, the definitions are aligned in that the BIM uses are present throughout the project lifecycle, as in each phase, it is possible to realize a specific benefit. The infrastructure lifecycle is defined as consisting of four phases: planning, design, construction, and operation (Azhar, 2011; C. M. Eastman et al., 2011). During all these phases, it is possible to apply various BIM uses according to the objectives established in the project, which increases the number of possible uses of this methodology (Hannele et al., 2012).

BIM has great potential in the early phases of the construction project. However, BIM cannot be seen only as a technology since a greater interaction cannot be resolved only with technology; it requires an advanced understanding of the social phenomena related to individual and collaborative information processing (Phelps, 2012). BIM is a methodology with technological support, which also includes aspects associated with people and processes; however, it does not describe how to address them. It is for this reason that certain Lean management practices can allow greater interaction because they encourage the management of commitment and trust among team members (Arkader, 2001; Perez, Castro, Simons, \& Gimenez, 2010; Simons \& Taylor, 2007).

\subsubsection{Lean design}

Two decades ago, Lean philosophy was proposed as a solution to improve the design process by applying each of the principles of this philosophy in the design of construction projects (Formoso, Tzotzopoulos, Jobim, \& Liedtke, 1998; Koskela, Ballard, \& 
Tanhuanpää, 1997). In these studies, the authors described the main causes of noncompliance of activities in the design process, such as: insufficient input information, insufficient time, optimistic estimation of the duration of activities, and delay in decision making. Later, Freire \& Alarcón (2002) presented the major waste in the design phases, that are: clarification of needs, rework, internal control of activities, interdisciplinary reviews, waiting times, and interruptions.

The principles of Lean management and some of its tools have been applied in the design process. For example, Fosse \& Ballard, (2016) present a case study that shows the change between traditional planning and planning using the Last Planner® System (LPS) in a design phase. Although the authors do not present evidence of changes in project performance, they conclude that the degree of satisfaction of project stakeholders increases when LPS is applied in work planning. Complementary, Knotten, Svalestuen, \& Hansen (2016) emphasize that the use of LPS® and collaborative planning in the design reinforces trust and commitment among team members, both of which are considered fundamental elements having an effective team (Svalestuen et al., 2015).

Lean Design introduces several elements that are part of the Lean philosophy and that are fundamental in the design phase, for instance, early client involvement, value maximization, identification of the needs and objectives of all stakeholders, a simultaneous realization of product and process design, and waiting in decision making until the last responsible moment, to reduce rework and unnecessary tasks (Gambatese, Pestana, \& Lee, 2017). Moreover, several tools can be used to support the application of Lean principles in the design, such as Target Value Design, Set-Based Design, Building Information Modeling, Choosing by Advantages, and Last Planner System (Gambatese et al., 2017; 
Munthe-kaas, Hjelmbrekke, \& Lohne, 2015; Tilley, 2005). Additionally, Lean has been implemented with other management methodologies; for instance, Lean and Six Sigma (Arnheiter \& Maleyeff, 2005), Lean and Agile Project Management (Mostafa, Chileshe, \& Abdelhamid, 2016), or Lean and BIM (Sacks, Koskela, Dave, \& Owen, 2010). Currently, Lean and BIM are central means of the ongoing transformation in the AEC industry (Sacks, Eastman, Lee, \& Teicholz, 2018).

There is a potential effect of integrating BIM with Lean to identify and reduce waste in the AEC industry (Sacks et al., 2010). Mollasalehi, Fleming, Talebi, \& Underwood (2016) present a literature review, interviews, and questionnaires, where it was possible to identify how waste can be reduced in the design process. Some of the potential benefits of using BIM and Lean together are: reducing design cycle time, reducing rework, increasing the number of value-added interactions, improving the ability to predict investment and cost lifecycles, and improving the ability to interact with stakeholders (Mandujano, Mourgues, Alarcón, \& Kunz, 2017).

\subsection{Research context}

\subsubsection{Research problem}

As mentioned in the previous section, the project teams in the design phase are composed of different stakeholders with various specialties, which in many cases do not belong to the same organization (Oloufa, Hosni, Fayez, \& Axelsson, 2017); this fact could make difficult the interactions between the different stakeholders, therefore generating deficiencies in information flows and project performance (Elmualim, 2010; Elmualim \& Gilder, 2014). There is also evidence that management based on BIM and Lean methodologies have a positive impact on the performance of construction projects 
(Hamzeh, Ballard, \& Tommelein, 2009; Mollasalehi et al., 2016). Besides, there is evidence of the combined implementation of BIM and Lean methodologies (Sacks et al., 2010); however, it is not known the empirical relationship between Lean practices and BIM uses in the design phase of construction projects. In addition, there is not a deeper understanding of the social phenomena that are generated among design teams when BIMLean management methodologies are implemented, and the differences that exist with other projects where these methodologies are not applied.

\subsubsection{Research questions}

The use of Building Information Modeling (BIM) in association with Lean management practices results in greater interaction between stakeholders at the design phase of construction projects. Considering this general statement, the research questions are:

(1) What is the relationship between Lean practices and BIM uses in the design phase of construction projects?

(2) What is the relationship between Lean and BIM with the interaction of construction project design teams?

\subsubsection{Research goals}

The main goal of this research is "to understand the impact of Lean design management (LDM) practices and Building Information Modeling (BIM) uses in the interaction of construction project design teams". The specific objectives are as follows:

- Specific Objective 1: To devise a tool for assessing the level of implementation of BIM uses in the design phase of construction projects. 
- Specific Objective 2: To devise a tool for assessing the degree of adoption of Lean design management (LDM) practices.

- Specific Objective 3: To understand the phenomenon of interaction between construction project design teams, through the use of Social Network Analysis (SNA).

- Specific Objective 4: To understand the relationship between the application of Lean design management (LDM) practices and the implementation of BIM uses during the design phase of construction projects.

- Specific Objective 5: To understand the relationship between the use of LDM practices and BIM uses, and the interaction of design teams of construction projects.

\subsection{Research methods}

In order to answer the research questions related to the relationship between Lean practices and BIM uses in the design phase of construction projects, and the impact of these methodologies on the interaction of a design team, it is necessary to create validated tools that allow: (1) assessing the level of implementation of lean practices and BIM uses in design; and (2) understanding the different types of interaction that are produced in a design team. Therefore, Phase 1 of this research seeks the generation of evaluation tools for assessing Lean practices, BIM uses, and interaction in design teams of construction projects. Subsequently, Phase 2 aims to get the relationships between these elements based on empirical information from construction projects in the design phase: first, the level of association between lean management practices and BIM uses in the design of construction projects, and second, the impact of BIM-Lean management on the interactions of a design 
team. Figure 1-1 presents phases 1 and 2. The different activities are displayed for each phase; furthermore, each one of these activities is described in a particular paper, published or under review in Web of Science indexed journals. Additionally, each paper addresses a specific objective of this research, having its own (also specific) research method, as displayed in Figure 1-1. Every one of these papers conforms to a later chapter of this document.

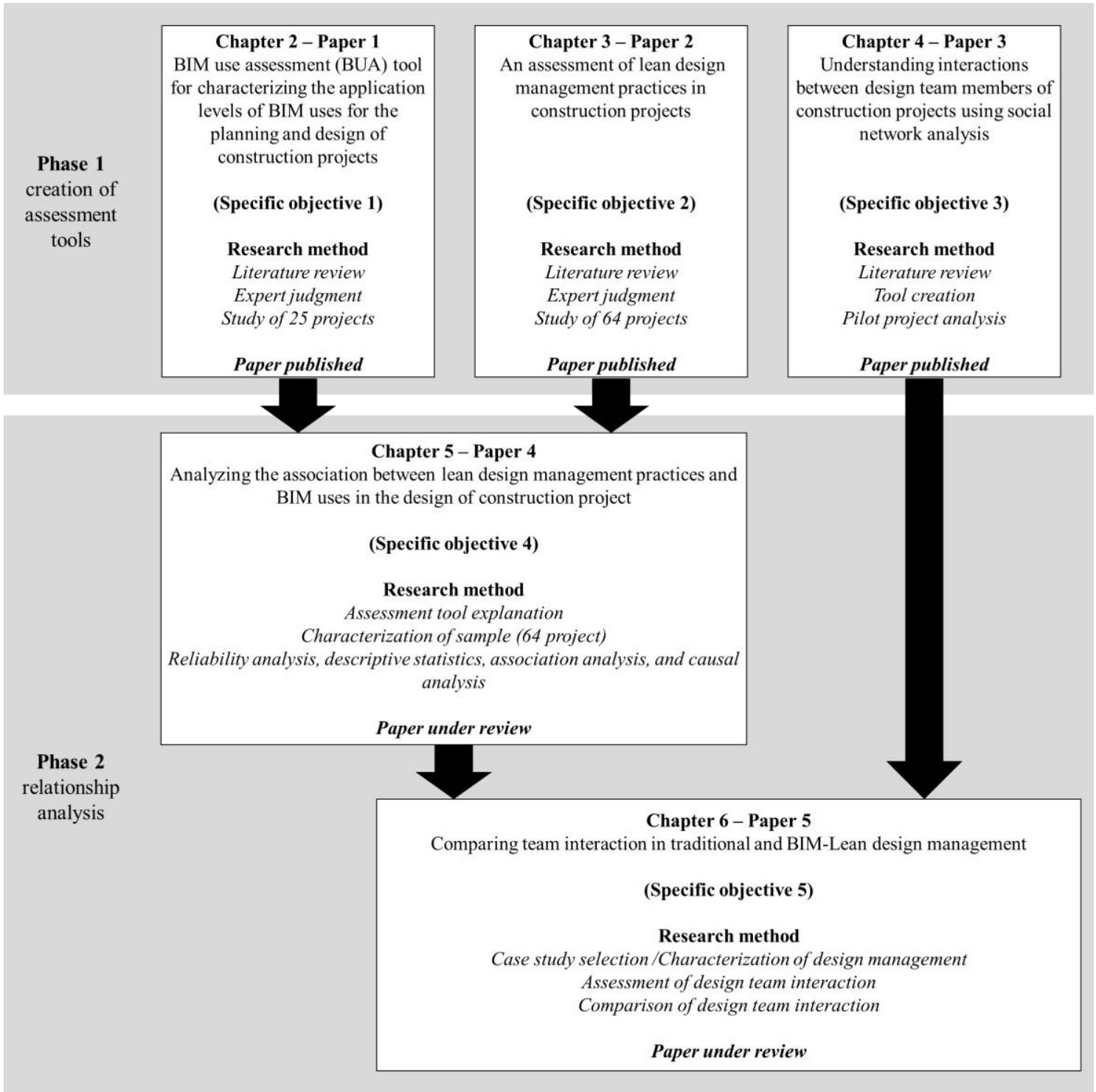

Figure 1-1: Overall research method 
Regarding Paper 1, its research method was organized into three stages: 1) identification, selection, and definition of BIM uses; 2) proposal of the BIM uses assessment (BUA) tool for characterizing the level of BIM use application; and 3) validation of the BUA tool. In the first stage, the user guides and manuals regarding BIM uses were identified to select the BIM uses to be evaluated in this research. Subsequently, each use was defined based on the selected guide and a review of the literature from the last ten years. Finally, a panel of experts validated the selection and definitions of BIM uses. In the second stage, the BUA tool is proposed for characterizing five-levels of application of BIM uses in construction projects in the planning and design phases. Then, the expert panel validated the combination of states that defined each level for each use. In the third stage, the BUA was validated by applying the proposed instrument to 25 construction projects in the planning and design phases. To validate the BUA tool, we conducted a concordance analysis of the evaluations of the two researchers and between each researcher and the final decision; we used the Kappa Cohen test to measure the level of concordance. Additionally, we conducted a reliability analysis of the BUA using the Cronbach alpha test to measure the level of internal consistency of the BUA tool.

The research method of Paper 2 was divided into three stages: (1) literature review of lean design management practices; (2) validation of the relationships between lean design management practices and lean principles; and, finally, (3) assessment of lean design management practices, where an analysis of the relationship among these practices is shown, as well as the identification of the main implementation gaps. In the first stage, the management practices that have been applied in the design phase of construction projects were identified from a literature review; then, categories were defined associated with 
common themes; and finally, the lean construction principles were identified. The second stage sought to validate management practices such as lean design management practices; the relationship between the practices and lean construction principles was defined through a survey of 15 experts from the academic and professional sectors. Finally, in the third stage, a questionnaire was proposed to evaluate the use of lean practices based on a scale of 1 to 5 ; the tool was created in collaborative meetings with five experts. This assessment was applied to 64 construction projects at the design phase.

Concerning Paper 3, its research method was divided into three stages: (1) a literature review of the dimensions of interactions evaluated in the AEC industry and different experiences of SNA implementation, (2) a proposal for an interaction network method (measurement and analysis) for construction project design teams, and (3) evaluation and analysis of a pilot project to exemplify the use of the tool. In the first stage, a literature review of specialized journals in engineering and construction project management and of the proceedings of major conferences held between 2008 and 2019 was carried out. In the second stage, the author proposed a method to assess the interaction in a design team of a construction project, using the design team as the unit of analysis. The list of interaction dimensions for this type of project was the input to develop this stage, and the team developed the interaction network method for the design teams of construction projects in four multidisciplinary work sessions that included engineers, architects, builders, consultants, and linguists. In the third stage, the proposed SNA method was applied to a pilot project to exemplify the use of this method in terms of implementation and analysis. The pilot project was a design team for a residential building project in Santiago, Chile. 
The research method of Paper 4 was organized into three stages:: (1) explanation of assessment tools to measure the level of implementation of BIM uses (Paper 1) and the lean design management (LDM) practices (Paper 2); (2) characterization of the sample of projects and data collection strategy; and (3) data exploration, including reliability analysis, descriptive statistics, association analysis using the Pearson chi-square test, and causal analysis using necessity and sufficiency relationships.

Finally, the research method of Paper 5 was organized into four stages: (1) case study selection, (2) description of the design management of the projects from the LDM (as

explained in Paper 2), and BIM perspectives (as explained in Paper 1), (3) assessment of design team interaction (as explained in Paper 3), and (4) comparison of design team interaction using SNA. The case study research method was used in Paper 5, following the recommendations of Yin (2009). Two case studies were analyzed, and their design management was assessed from a Lean BIM perspective while their team interactions were assessed using SNA. The selection of projects was intentional and aimed to facilitate literal and theoretical replication. The research team decided the opposing characteristic was the application of BIM methodology at the design phase.

\subsection{Dissertation outline}

Taking into consideration the overall research method displayed in Figure 1-1, the general structure of the dissertation is:

- CHAPTER 1 provides an overview of the thesis highlighting the research problem, knowledge gap, research questions, and research goals

- The intermediate chapters are either published manuscripts (chapters 2, 3, and 4) or under review for publication (chapters 5 and 6) in Web of Science indexed 
scientific journals. They correspond with papers 1 to 5, following Figure 1-1, which illustrates the process for each intermediate chapter. Given the independent format of each chapter, there is a certain degree of overlap in the review of the literature and methods used. The chapters and papers are:

- CHAPTER 2 - PAPER 1: Rojas, M.J., Herrera, R.F., Mourgues, C., PonzTienda, J.L., Alarcón, L.F., \& Pellicer, E. (2019). BIM Use Assessment (BUA) Tool for Characterizing the Application Levels of BIM Uses for the Planning and Design of Construction Projects. Advances in Civil Engineering, 2019, 9094254, 1-9 (already published in https://www.hindawi.com/journals/ace/2019/9094254/ (Q $Q_{3}$ indexed in Journal Citation Reports 2019).

- CHAPTER 3 - PAPER 2: Herrera, R.F., Mourgues, C., Alarcón, L.F., \& Pellicer, E. (2020). An Assessment of Lean Design Management Practices in Construction Projects. Sustainability, 12(1), 1-19 (already published in https://www.mdpi.com/2071-1050/12/1/19 (Q 2 indexed in Journal Citation Reports 2019).

- CHAPTER 4 - PAPER 3: Herrera, R.F., Mourgues, C., Alarcón, L.F., \& Pellicer, E. (2020). Understanding Interactions between Design Team Members of Construction Projects Using Social Network Analysis. Journal of Construction Engineering and Management, 146(6), 04020053, 1-13 (already published in https://doi.org/10.1061/(ASCE)CO.19437862.0001841 ( $\mathrm{Q}_{2}$ indexed in Journal Citation Reports 2019). 
- CHAPTER 5 - PAPER 4: Herrera, R.F., Mourgues, C., Alarcón, L.F., \& Pellicer, E. (2020). Analyzing the Association between Lean Design Management Practices and BIM Uses in the Design of Construction Projects. Journal of Construction Engineering and Management (currently under the third review) $\left(\mathrm{Q}_{2}\right.$ indexed in Journal Citation Reports 2019).

- CHAPTER 6 - PAPER 5: Herrera, R.F., Mourgues, C., Alarcón, L.F., \& Pellicer, E. (2020). Comparing Team Interactions in Traditional and BIMLean Design Management. Engineering, Construction, and Architectural Management (currently under the first review) $\left(\mathrm{Q}_{2}\right.$ indexed in Journal Citation Reports).

- CHAPTER 7 presents an integrated discussion of the five papers (previous chapters 2 to 6 ) that responds to the research objectives stated in the Introduction.

- Finally, CHAPTER 8 sets out the contributions, recommendations, limitations, and provides suggestions for future work in English. CHAPTER 9 is the Spanish translation of chapter 8 . 
2.

\section{BIM USE ASSESSMENT (BUA) TOOL FOR CHARACTERIZING \\ THE APPLICATION LEVELS OF BIM USES FOR THE PLANNING AND DESIGN OF CONSTRUCTION PROJECTS}

\subsection{Introduction}

Building information modeling (BIM) is becoming an essential methodology in the architecture, engineering, and construction (AEC) industry. Indeed, public agencies from several countries are encouraging the use of this methodology by issuing requirements, user guides and manuals regarding its use (NBS National Building Specification, 2018). There are several ways of using BIM (BIM uses), which lead to various benefits; as stated by (R. G. Kreider \& Messner, 2013), applications of BIM during the infrastructure lifecycle can enable the realization of one or more specific objectives. Therefore, it is important to understand the way that organizations apply BIM uses.

BIM uses are defined in various ways: The Penn State guide defines BIM use as "a method of applying Building Information Modeling during a facility's life-cycle to achieve one or more specific objectives" (R. G. Kreider \& Messner, 2013). According to (Succar, 2016), BIM uses "identify and collate the information, requirements that need to be delivered as - or embedded within - 3D digital models". Another definition comes from the New York Guide, which defines BIM uses as "the most common applications of BIM on the Department of Design and Construction Projects. BIM uses shall be considered and aligned with project goals" (D. Bloomberg, Bloomberg, Burney, \& Resnick, 2012). Thus, while there is a consensus on the relationship of uses to project objectives, there is no 
agreement on whether uses are methods, applications or actions; therefore, there is no universal definition for BIM uses.

Although there is no universal definition, the definitions are aligned in that the BIM uses are present throughout the project lifecycle, as in each phase it is possible to realize a specific benefit. The infrastructure lifecycle is defined as consisting of four phases: planning, design, construction and operation (Azhar, 2011; C. M. Eastman et al., 2011). During all these phases, it is possible to apply various BIM uses according to the objectives that are established in the project, which increases the number of possible uses of this methodology (Hannele et al., 2012). The initial stages, namely, planning and design, are considered instrumental in the development of the project. According to MacLeamy's curve (AIA, 2007), the planning and design phases have a significant impact on the entire project; early efforts in these phases can help to prevent cost overruns and time delays at the construction site (Talebi, 2014).

To realize the optimal applications of BIM, it is important to be aware of the BIM use level; in this way, it is possible to identify the possibility of improving the BIM in the project. However, it is possible to use a tool that enables the characterization of BIM level but, not each BIM use in a project. Moreover, measuring the BIM level is not the same as measuring the BIM uses. Those tools are BIM maturity models, because several BIM maturity models facilitate understanding regarding how companies apply the BIM methodology, where the term 'BIM maturity' refers to the quality, repeatability and degree of excellence within a BIM capability (Succar, Sher, \& Williams, 2012). Those maturity models can measure the BIM state but not specifically the BIM uses application. Likewise, it is possible to evaluate the capacity at a specific time ( $\mathrm{Wu}, \mathrm{Xu}, \mathrm{Mao}, \& \mathrm{Li}, 2017)$ in 
interorganizational project teams (specialists coming from different companies) (Sydow \& Braun, 2018), but it is not possible to evaluate the repeatability unless the client always works with the same project teams. Therefore, despite the existence of various BIM uses in the literature, there is no instrument to evaluate the level of implementation of them in construction projects.

Thus, addressing the lack of a tool to evaluate how BIM uses are performed in construction projects, this research proposes and validates a BIM Use Assessment (BUA) tool for characterizing the application levels of BIM uses in the planning and design phases

of building projects. The objective assessment enabled by the BUA tool yields benefits for both the industry and the academia. Organizations can use this assessment to perform a self-diagnosis that supports strategic implementation decisions, and to qualify/select other organizations in the context of future projects or joint ventures. The academia, on the other hand, can use this assessment tool for industry benchmarking and diagnosis.

\subsection{Research methodology}

The overall research methodology is organized into three stages: 1) identification, selection and definition of BIM uses; 2) proposal of the BUA tool for characterizing the level of BIM use application; and 3) validation of the BUA tool. Figure 2-1 specifies the activities, research tools and deliverables for each stage. 


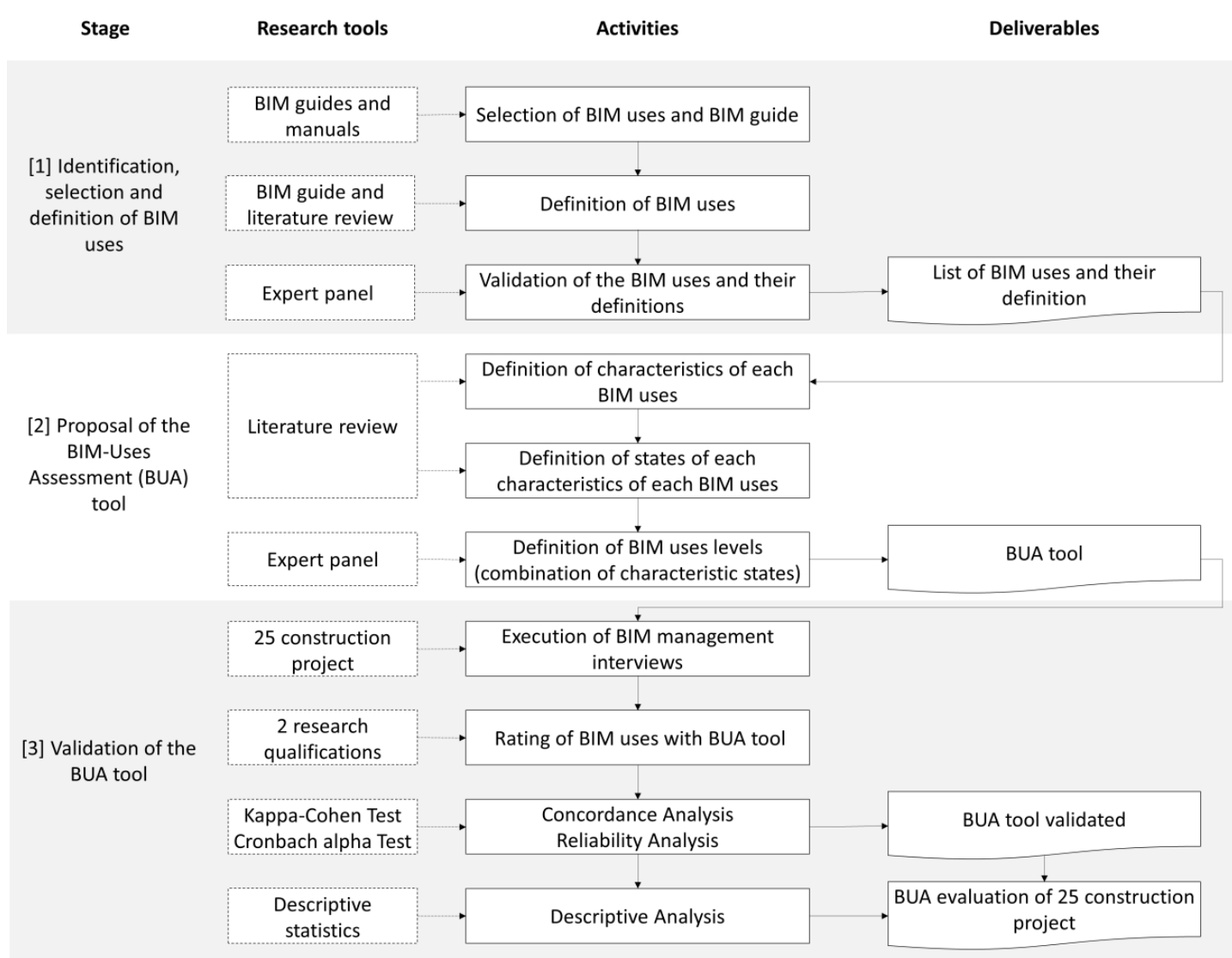

Figure 2-1: Research method

In the first stage, the user guides and manuals regarding BIM uses were identified to select the BIM uses to be evaluated in this research. The guides were classified according to three criteria: (1) definition of uses that are associated with an objective/application for the project, (2) classification of uses according to the phases of the project life cycle and (3) definition of uses that are supported by the scientific literature.

Subsequently, each use was defined based on the selected guide and a review of the literature from the last ten years. The search was carried out in the following libraries: Engineering Village, Web of Science and Scopus. In this review, 64 references regarding 
the application of the BIM uses were identified in the design and planning phases of construction projects.

Next, a panel of experts validated the selection and definitions of the BIM uses. Table 2-1 lists the experts who participated in the three sessions. Finally, we created a definitive list of BIM uses and their definitions for the design and planning phases of construction projects.

Table 2-1: Characterization of expert panel

\begin{tabular}{|c|c|c|c|}
\hline $\begin{array}{c}\text { Profession } \\
\text { (grade) }\end{array}$ & Occupation & Field of work & $\begin{array}{c}\text { Years of } \\
\text { experience }\end{array}$ \\
\hline $\begin{array}{l}\text { Architect, } \\
\text { Ph.D. }\end{array}$ & $\begin{array}{l}\text { Professor and } \\
\text { Consultant }\end{array}$ & $\begin{array}{l}\text { Construction management; Virtual } \\
\text { design and construction; Building } \\
\text { information modeling }\end{array}$ & $>30$ \\
\hline $\begin{array}{l}\text { Civil } \\
\text { Engineer, } \\
\text { Ph.D. }\end{array}$ & $\begin{array}{l}\text { Professor and } \\
\text { Consultant }\end{array}$ & $\begin{array}{l}\text { Construction management; Project } \\
\text { management; Lean construction; } \\
\text { Building information modeling }\end{array}$ & $>30$ \\
\hline $\begin{array}{l}\text { Civil } \\
\text { Engineer, } \\
\text { Ph.D. }\end{array}$ & $\begin{array}{l}\text { Professor and } \\
\text { Consultant }\end{array}$ & $\begin{array}{l}\text { Construction management; Virtual } \\
\text { design and construction; Building } \\
\text { information modeling }\end{array}$ & $>15$ \\
\hline $\begin{array}{c}\text { Civil } \\
\text { Engineer, } \\
\text { Ph.D.(c) }\end{array}$ & $\begin{array}{l}\text { Professor and } \\
\text { Consultant }\end{array}$ & $\begin{array}{l}\text { Construction management; Lean } \\
\text { construction; Building information } \\
\text { modeling }\end{array}$ & $>10$ \\
\hline $\begin{array}{l}\text { Civil } \\
\text { Engineer, } \\
\text { M.Sc. }\end{array}$ & $\begin{array}{l}\text { Researcher and } \\
\text { Consultant }\end{array}$ & $\begin{array}{l}\text { Construction management; Building } \\
\text { information modeling }\end{array}$ & $>5$ \\
\hline
\end{tabular}

In the second stage, the BUA tool is proposed for characterizing the levels of application of BIM uses in construction projects in the planning and design phases. A BIM use has various levels of complexity that are associated with its own characteristics, for example, the dimensionality of the model, the level of automation, and the number of associated systems. To establish each level, the researchers defined two or more 
characteristics for each use; those characteristics are elements that are associated with the objective or application of each BIM use. These characteristics were defined by analyzing the necessary factors for implementing each use successfully. Then, for each characteristic, a state was defined, which represents the level of complexity with which this characteristic is employed. Each characteristic and its state were defined in work sessions with the panel of experts.

Thereafter, combinations of states were defined according to characteristics that place a project in each level. Finally, the expert panel validated the combination of states that defined each level for each use. Therefore, in the BUA, evaluating each use on a scale from one to five is proposed, where the minimum level (1) does not use the BIM model and the maximum level (5) uses it in a way that realizes all its applications. The proposal of classification by levels allows having a structured and consistent tool. Table 2-2 presents a general description for each level; however, a detailed description of each level of each use is provided in the BUA (see Supplemental Data).

Table 2-2: BIM levels - a general description for each level

\begin{tabular}{|c|c|}
\hline Level & General description \\
\hline 1 & Traditional methods (2D model). \\
\hline 2 & Low use of BIM and little information in the model. \\
\hline 3 & Medium use of BIM and sufficient information for BIM. \\
\hline 4 & High use of BIM. \\
\hline 5 & Full use of BIM. The best tools are utilized to realize all its applications. \\
\hline
\end{tabular}

In the third stage, the BUA was validated by applying the proposed instrument to 25 construction projects in the planning and design phases. The only requirement for the evaluation is to declare that the company is using BIM. The evaluation process consisted 
of the following steps: First, a researcher conducted an interview with each BIM manager of each project. The interviews were conducted in a conversation-like manner to ensure that the interviewees would respond transparently (Iii, 2010); this avoided the bias of previously having examined the answer for each level. Then, based on a recording of the interviews, two researchers independently defined the level of the project for each BIM use. Next, in a collaborative session, the two researchers who qualified the projects were asked to discuss the final qualification of each use.

To validate the BUA tool, we conducted a concordance analysis of the evaluations of the two researchers and between each researcher and the final decision; we used the Kappa Cohen test to measure the level of concordance. Additionally, we conducted a reliability analysis of the BUA using the Cronbach alpha test to measure the level of internal consistency of the BUA tool.

Finally, a descriptive analysis of the results that were obtained for the 25 projects was conducted. Two measures, namely, central tendency and variability, for each of the uses were analyzed. Via this approach, the uses with highest and lowest levels of implementation in the sample of this study were identified. The interviews were carried out by project and not by company because even if a company has several ongoing projects, the demands of the client or the nature of the project can affect the specifications of the application of BIM uses.

\subsection{Identification, selection, and definition of BIM uses}

A BIM use is a set of actions and conditions that are associated with BIM, which together have a defined objective or application for the construction project. There are various guides or manuals that define BIM uses without specifying an 
objective/application or only as actions that are associated with the modeling process. Two examples are "existing condition modeling" and "record modeling", which are defined in the "BIM uses of Penn State" (R. G. Kreider \& Messner, 2013), because those uses are utilized for modeling without a defined application for the project. In applying a BIM use to a project, it is assumed that a BIM model exists. Other guides, such as "211 in model uses BIM" by (Succar, 2016), consider additional modeling uses. In this guide, several modeling actions are specified, such as "fire modeling" and "foundation modeling". However, actions of this type are not considered BIM uses in this research.

To select a guide on which to base the definition of BIM uses, five guides or manuals were characterized based on three criteria: definition of uses, classification of uses and literature background of uses (Table 2-3). The selected guide defined uses more in accordance with the definition that is proposed in this article, with a classification that is associated with the phases of the project's life cycle and with a more extensive literature background.

The BIM uses of Penn State were selected as the baseline guide in this research. This guide was selected for three main reasons: First, most BIM uses are aligned with an objective/application for the project, not just the modeling action. Other guides have BIM uses that are directly related to the modeling and not to the specified application; however, these are BIM tools, not BIM uses. Second, the classification of lifecycle phases is better suited to the requirements of this research. Third, every definition of BIM is strongly supported by the scientific literature. 
Table 2-3: Characteristics of BIM use guides and manuals

\begin{tabular}{|c|c|c|c|}
\hline Guide or manual & $\begin{array}{c}\text { BIM use definition } \\
\text { associated with } \\
\text { specific objective }\end{array}$ & Classification & $\begin{array}{c}\text { Literature } \\
\text { background }\end{array}$ \\
\hline $\begin{array}{c}211 \text { in Model Uses } \\
\text { List (Succar, 2016) }\end{array}$ & $\begin{array}{c}\text { General application } \\
\text { of BIM }\end{array}$ & $\begin{array}{c}\text { Type of information } \\
\text { use }\end{array}$ & High \\
\hline $\begin{array}{c}\text { BIM uses Penn State } \\
\text { (R. Kreider, 2013) }\end{array}$ & $\begin{array}{c}\text { With an objective or } \\
\text { application for } \\
\text { almost all uses }\end{array}$ & Lifecycle project & High \\
\hline $\begin{array}{c}\text { BIM Guidelines } \\
\text { NYC (D. Bloomberg } \\
\text { et al., 2012) }\end{array}$ & $\begin{array}{c}\text { General application } \\
\text { of BIM }\end{array}$ & No classification & Medium \\
\hline $\begin{array}{c}\text { Singapore BIM } \\
\text { Guide (Building and } \\
\text { Construction } \\
\text { Authority, 2013) }\end{array}$ & $\begin{array}{c}\text { Without a specified } \\
\text { objective or } \\
\text { application }\end{array}$ & Lifecycle project & Low \\
\hline $\begin{array}{c}\text { BIM Procurement } \\
\text { Guide Harvard } \\
\text { (Harvard University } \\
\text { Construction } \\
\text { Management } \\
\text { Council, 2010) }\end{array}$ & $\begin{array}{c}\text { General application } \\
\text { of BIM }\end{array}$ & Lifecycle project & Medium \\
\hline \multicolumn{2}{|c|}{} & & \\
\hline
\end{tabular}

Using this guide, an analysis was conducted on each of the uses that were specified in the planning and design phases of a construction project to determine which uses are considered in the evaluation tool. Fifteen uses are proposed in the planning and design phases by the Penn State guide; however, this research did not consider all the uses that are defined in the guide. The use "existing condition modeling" was deleted because it only considers the modeling and does not explain the associated benefit. In fact, the resulting model could be used, e.g., for cost estimation, 3D coordination, and site analysis. Moreover, "lighting analysis" and "energy analyses" are too specific in comparison with other uses; therefore, they were included in the use "sustainability analysis". Likewise, the uses "structural analysis" and "mechanical analyses were included into the "engineering 
analysis" use, along with other uses such as "hydraulic analysis" and "fire protection system". Both changes were made in order to simplify the evaluation of BIM uses, however, it is possible that those simplifications are too general for specific projects where illumination, sound, or any specific analysis are carried out. Finally, ten of the fifteen uses were selected for the planning and design phases (Table 2-4).

Once the uses to be evaluated had been selected, the next step was to define each of them based on the Penn State guide and the analyzed literature of 64 papers from the last ten years. Once the uses were defined, working sessions were held with the expert panel to provide feedback, implement the recommended corrections and validate each of the definitions of the BIM uses.

Table 2-4: Definitions of BIM uses for planning and design

\begin{tabular}{|c|c|c|c|}
\hline Stage & Use & Definition (proposal) & $\begin{array}{c}\# \\
\text { Papers }\end{array}$ \\
\hline $\begin{array}{c}\text { Planning } \\
\text { Design }\end{array}$ & $\begin{array}{c}\text { Cost } \\
\text { Estimation }\end{array}$ & $\begin{array}{c}\text { A BIM model is used to generate accurate quantity } \\
\text { take-offs and cost estimates. }\end{array}$ & 7 \\
\hline $\begin{array}{c}\text { Planning } \\
\text { Design }\end{array}$ & Phase Planning & $\begin{array}{c}\text { A 4D BIM model is utilized to effectively plan, } \\
\text { especially spatial planning, including spatial } \\
\text { clashes and paths. }\end{array}$ & 9 \\
\hline $\begin{array}{c}\text { Planning } \\
\text { Design }\end{array}$ & $\begin{array}{c}\text { Space } \\
\text { Programming }\end{array}$ & $\begin{array}{c}\text { A BIM model is used to design and analyze the } \\
\text { project's spaces and rooms and to assign to each } \\
\text { space a use and its measurements. }\end{array}$ & 6 \\
\hline $\begin{array}{c}\text { Planning } \\
\text { Design }\end{array}$ & Site Analysis & $\begin{array}{c}\text { BIM/GIS is used to select and evaluate a site } \\
\text { location and to select a building position on the } \\
\text { site. }\end{array}$ & 8 \\
\hline $\begin{array}{c}\text { Planning } \\
\text { Design }\end{array}$ & $\begin{array}{c}\text { Design } \\
\text { Authoring }\end{array}$ & $\begin{array}{c}\text { A process in which 3D software is used to develop } \\
\text { a Building Information Model. A project is } \\
\text { designed in a BIM model, where the typical } \\
\text { iterations of a project are made, and everything is } \\
\text { built directly in the BIM software. }\end{array}$ & 3 \\
\hline $\begin{array}{c}\text { Planning } \\
\text { Design }\end{array}$ & Design Review & $\begin{array}{c}\text { A process in which stakeholders interact with a } \\
\text { BIM model and provide their feedback to validate } \\
\text { multiple design aspects. }\end{array}$ & 5 \\
\hline
\end{tabular}




\begin{tabular}{|c|c|c|c|}
\hline Stage & Use & Definition (proposal) & $\begin{array}{c}\# \\
\text { Papers }\end{array}$ \\
\hline Design & $\begin{array}{c}\text { Engineering } \\
\text { Analysis }\end{array}$ & $\begin{array}{c}\text { A BIM model and specialized software are used to } \\
\text { conduct an engineering analysis to identify the } \\
\text { most efficient method or design. }\end{array}$ & 4 \\
\hline Design & $\begin{array}{c}\text { Sustainability } \\
\text { Evaluation }\end{array}$ & $\begin{array}{c}\text { A process in which the sustainability of a facility } \\
\text { is evaluated and tracked using a sustainability } \\
\text { metric system }\end{array}$ & 8 \\
\hline Design & $\begin{array}{c}\text { Code } \\
\text { validation }\end{array}$ & $\begin{array}{c}\text { A process in which code validation software is } \\
\text { utilized to check the model parameters against } \\
\text { project-specific design or construction codes or } \\
\text { norms. }\end{array}$ & 7 \\
\hline Coordination & $\begin{array}{c}\text { A process in which 3D coordination software is } \\
\text { used to identify 3D geometric conflicts by } \\
\text { comparing 3D models of building systems. }\end{array}$ & 7 \\
\hline
\end{tabular}

\subsection{Proposal of a BUA tool for measuring the level of BIM application}

Once the BIM uses were defined, the characteristics, which are the actions or conditions that are necessary for applying these uses, are identified. Table 2-5 lists the characteristics that are used to assess each use. Additionally, each characteristic use is defined in annexed Supplemental Data (BUA).

Each characteristic is evaluated in various states; for example, in the use "space programming", the characteristic "distribution analysis" has the following states: manuals, consults, report, and automatic. A characteristic can be evaluated in one or more states since the states are not necessarily mutually exclusive. For example, in the use "site analysis" and the characteristic "type of model", the states are BIM and GIS; therefore, a project can have one or both. In the annexed supplemental data, all the states of each characteristic are presented. 
Table 2-5: Uses and their characteristics

\begin{tabular}{|c|c|c|}
\hline Phase & BIM use & Characteristics \\
\hline \multirow{4}{*}{ Planning } & Cost estimation & Source of quantities, type of model, and applied systems \\
\hline & Phase planning & 4D model, type of use, and link type \\
\hline & Site analysis & Type of model and type of analysis \\
\hline & $\begin{array}{c}\text { Space } \\
\text { Programming }\end{array}$ & Type of model and distribution analysis \\
\hline \multirow{6}{*}{ Design } & Design review & Type of model, immersive lab, and list of requirements \\
\hline & Code validation & $\begin{array}{l}\text { Type of software, type of model, applied systems, and } \\
\text { level of mock-up }\end{array}$ \\
\hline & $\begin{array}{l}\text { Sustainability } \\
\text { analysis }\end{array}$ & Type of model, type of software, and applied systems \\
\hline & $\begin{array}{l}\text { Engineering } \\
\text { analysis }\end{array}$ & $\begin{array}{l}\text { Type of model, compatible software, applied systems, } \\
\text { and documentation }\end{array}$ \\
\hline & Design authoring & Type of models, generative models, and applied systems \\
\hline & 3D coordination & Type of models, analysis method, and applied systems \\
\hline
\end{tabular}

To clearly illustrate the characteristics of the uses, the example below presents the selected features for the use "cost estimation". The "cost estimation" use has three main characteristics: the type of model, the origin of the quantities, and the number of systems on which the use is applied (Figure 2-2). The characteristics were defined by answering the following question: What yields a higher benefit on the application of this use? Via this approach, it will be possible to analyze the current state of a project and to identify the next steps for improvement. In this example, the use of BIM to support the cost estimation is at its maximum level of application when the extraction of quantities is bidirectional between the cost's software and the model, and based on a BIM model, without distinguishing if this is applied to a large or small number of specialties.

The characteristic "applied systems" is used to analyze the number of systems in which a BIM use is applied. The feature is divided in two options: " $<50 \%$ " and " $\geq 50 \%$ ". In Figure 2-2, the feature "applied systems" corresponds to the two last columns; however, 
the number of systems depends on the characteristics of the project; hence, the tool cannot use a fixed number for each of the options. Therefore, it is necessary to calculate the number of systems to which a BIM use can be applied.

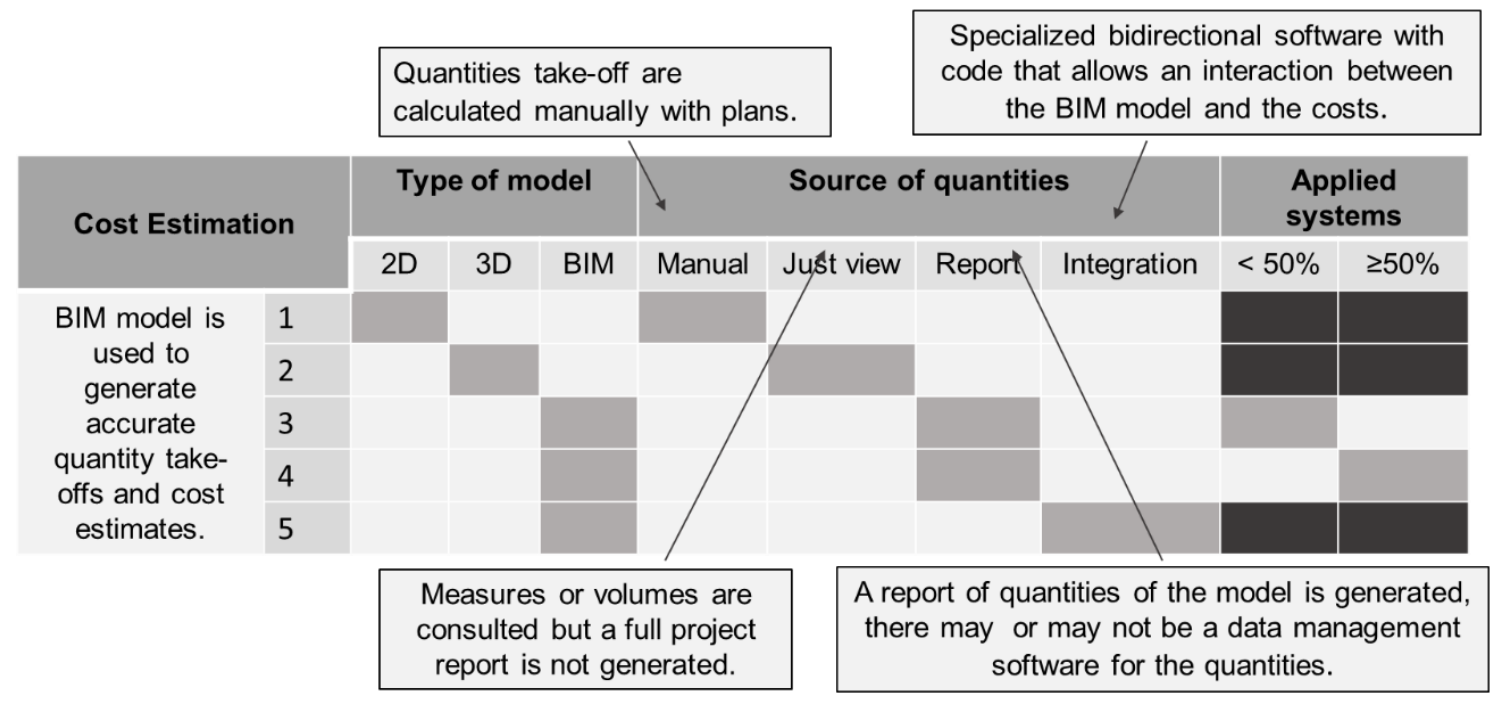

Figure 2-2: BUA-Cost Estimation

Once the levels have been defined, a BUA is constructed as a template for each use, which includes the use name, use definition, use levels (1 to 5) and use characteristics (Figure 2-2). This BUA tool serves as a rubric and should be read horizontally. The lightgrey squares indicate the conditions that must be satisfied to belong to a level. Likewise, the dark-grey squares indicate the possibilities within a level. The dark-grey color is applied with the objective of avoiding subjectivity to enable the analysis of various combinations at the same level. For example, a project is assigned a score of one for the "cost estimation" use if it uses a 2D model to calculate manually the quantities for over or under the $50 \%$ of the systems. 


\subsection{Validation of the BUA tool via the evaluation of the projects in the planning and design phases}

To validate the consistency resulting from the application of the proposed BUA tool, 25 civil infrastructure and building construction projects were considered, which were all in the first phases of the lifecycle (planning and design) (Table 2-6).

Table 2-6: Summary of project characteristics

\begin{tabular}{|c|c|c|c|c|c|c|}
\hline \multirow{2}{*}{ Country } & Project & Total & Public & Private & $\begin{array}{c}\text { External } \\
\text { client }\end{array}$ & $\begin{array}{c}\text { Internal } \\
\text { client }\end{array}$ \\
\hline \multirow{2}{*}{ Chile } & Building & 7 & 0 & 7 & 3 & 4 \\
\cline { 2 - 7 } & Infrastructure & 2 & 2 & 0 & 2 & 0 \\
\hline \multirow{2}{*}{ Colombia } & Building & 11 & 0 & 11 & 5 & 6 \\
\cline { 2 - 7 } & Infrastructure & 1 & 1 & 0 & 1 & 0 \\
\hline \multirow{2}{*}{ Spain } & Building & 3 & 0 & 3 & 3 & 0 \\
\cline { 2 - 7 } & Infrastructure & 1 & 0 & 1 & 1 & 0 \\
\hline \multicolumn{2}{|c|}{ Total } & $\mathbf{2 5}$ & $\mathbf{3}$ & $\mathbf{2 2}$ & $\mathbf{1 5}$ & $\mathbf{1 0}$ \\
\hline
\end{tabular}

To evaluate each project, interviews were conducted with the BIM manager and/or project manager. All the interviews were recorded with the interviewees' consent so that their answers could be later analyzed by two BIM researchers, who independently evaluated each use of the BUA.

Finally, the evaluators held a meeting to decide on the final score of the project for each use; they focused on the categories in which the scores differed between the two evaluators. In conducting this evaluation, the evaluators followed the format that is shown in Figure 2-3. The template must be filled by a BIM specialist who has been selected through an interview with the project leaders. 


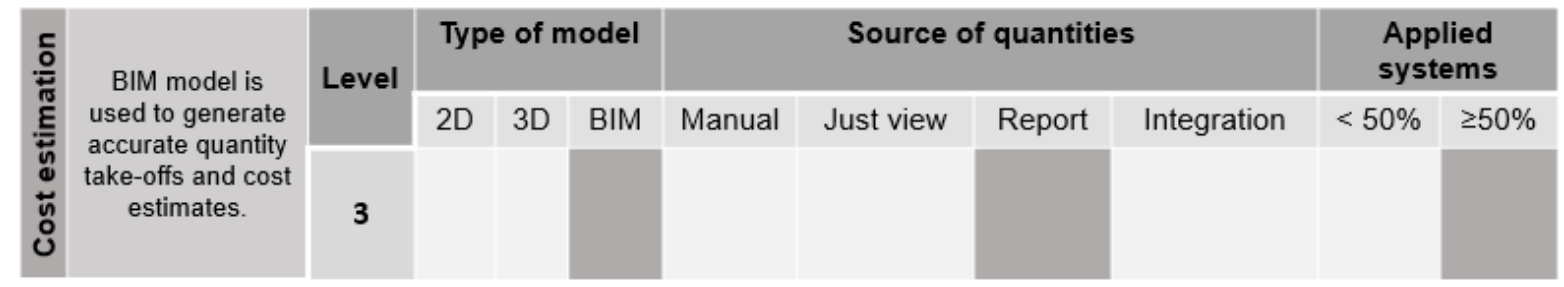

Figure 2-3: Cost estimation evaluations (example of an assessment)

To validate the BUA tool, three concordance analyses were performed: i) between the answers of the two researchers, ii) between the answers of Researcher 1 and the final decision for each use, and iii) between the answers of Researcher 2 and the final decision for each use. Cohen's Kappa was applied to each of these scenarios (Table 2-7) and an almost perfect level of agreement of over 93\% was reached in all three cases (Mchugh, 2012); hence, the tool is unbiased and precise.

Table 2-7: Concordance analysis

\begin{tabular}{|c|c|c|c|}
\hline & $\begin{array}{c}\text { Researcher 1 - } \\
\text { Researcher 2 }\end{array}$ & $\begin{array}{c}\text { Researcher 1 - Final } \\
\text { Decision }\end{array}$ & $\begin{array}{c}\text { Researcher 2 - Final } \\
\text { Decision }\end{array}$ \\
\hline $\begin{array}{c}\text { Agreement } \\
\text { percentage }\end{array}$ & $93.7 \%$ & $96.8 \%$ & $96.8 \%$ \\
\hline Kappa & 0.91 & 0.96 & 0.95 \\
\hline p-value & 0.02 & 0.01 & 0.01 \\
\hline
\end{tabular}

Then, as the next step in validating the BUA tool, the internal consistency of the measuring scale was analyzed using Cronbach's alpha coefficient. For the BUAs of 10 items and 25 test projects, a Cronbach's alpha coefficient of 0.8617 was calculated. Hence, the elements of the BUA tool assess the same characteristic for a project for each BIM use. From the high level of internal consistency (reliability) and the high level of agreement 
between the interviewers, it is concluded that the BUA is an objective and consistent tool for evaluating the levels of BIM uses in the design and planning phases of construction projects.

Based on the high measurement performance of the tool in the validation process, the BUA tool can systematically characterize the levels of application of the BIM uses in the planning and design phases of building projects. Thus, the proved trustiness of this tool to assess BIM uses in the early stages of the project, enables self-diagnosis of an organization's practices regarding how BIM is used in their projects. For example, an organization can understand that its cost estimation process (BIM use) consists of consulting quantities from 3D models in less than half of their main cost items, while its design review process (BIM use) is based on a non-immersive visualization of BIM models with an informal identification of design issues. This understanding can allow a company to formulate an improvement plan to take full advantage of BIM for its projects. Additionally, a company can use the BUA tool to assess the BIM use of potential partners or design consultants in future projects where certain BIM uses are required. Additionally, the results of the assessment done with the BUA tool in a particular project can be compared to successful cases of BIM application within the company or the industry (if available) to identify the most efficient practices for BIM uses.

Using the 25 evaluated test projects, a descriptive analysis was conducted to determine the distribution of the levels for each BIM use. Figure 2-4 shows a box plot for each BIM use. According to this Figure, the BIM use with the highest level of application is " $3 \mathrm{D}$ Coordination" and the BIM use with the lowest level of application is "Phase Planning", which is associated with Level 1 in almost all cases (three projects showed an application, 
which were represented as atypical dots, asterisks). This low application of "phase planning" is due, according to the interviewees, to the lack of a specific requirement for this use in the contract. "Sustainability Analysis" was another BIM use that has application level of 1; however, it has higher variability. For this BIM use, even if not all the projects required an environmental certification by the clients, some projects had their own environmental requirements to be satisfied, for which BIM was helpful.

BIM uses "Site Analysis", "Space Programming" and "Code Validation" were associated with Level 2 of application, while "Design Review" and "Engineering Analysis" were associated with Level 3. Regarding "Engineering Analysis", according to the interviewees, it is difficult to ask the external designers to develop the whole process in BIM software.

Finally, 6 out of the 10 evaluated BIM uses presented high variability in terms of the application levels. This is due to the differences among the projects in terms of their characteristics, the companies that execute them and their clients. For most of the projects, an improvement opportunity was identified in the BIM uses. 


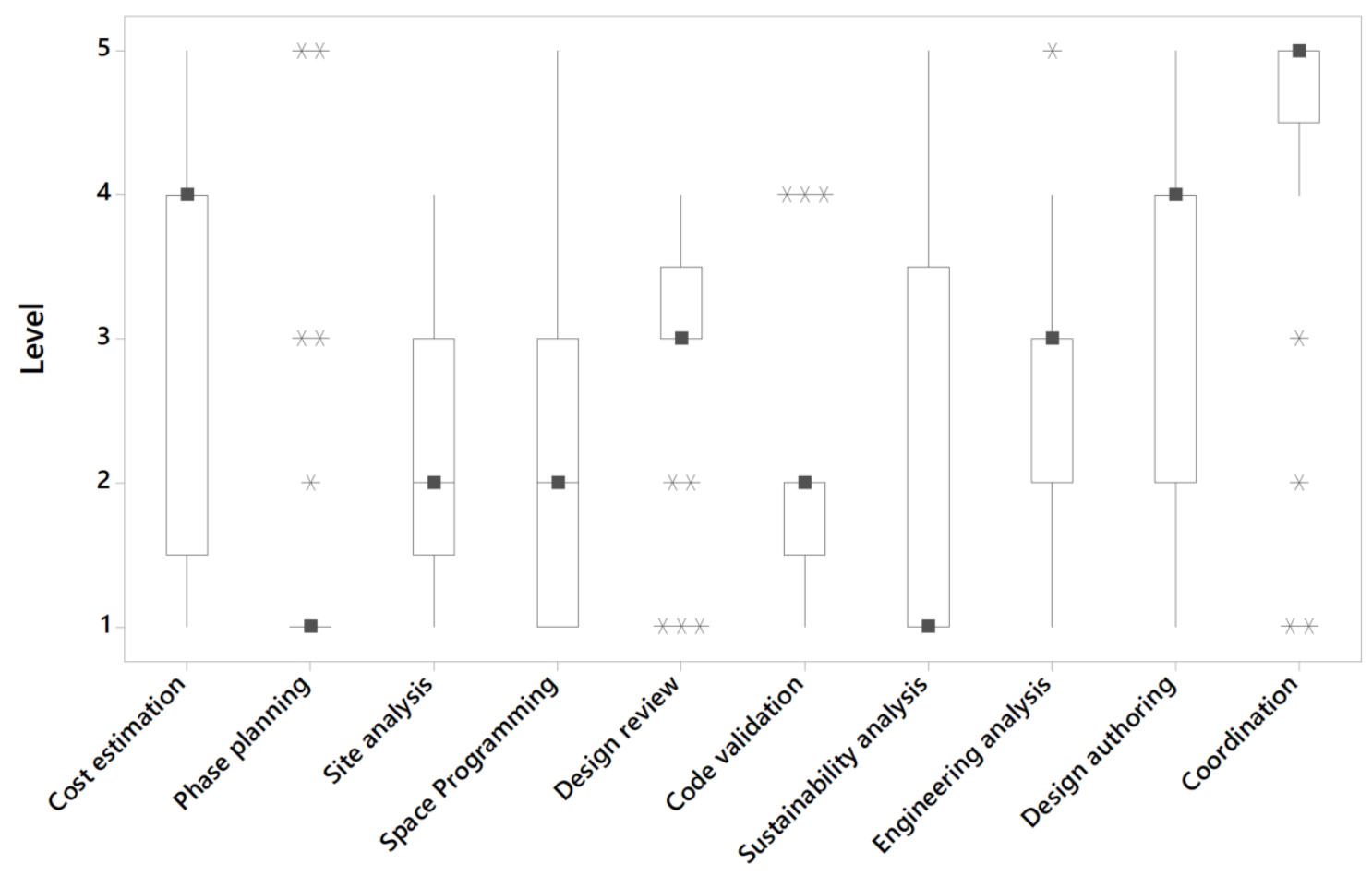

Figure 2-4: BIM use application levels

Additionality, hypothesis tests were conducted to identify significant differences according to the characteristics of the evaluated projects. Non-parametric hypothetical tests were applied with a significance level of $95 \%$ since the variable of each evaluation is ordinal qualitative. The Mann-Whitney U test was used to compare pairs of samples and the Kruskal-Wallis test was used to compare three samples. No significant differences were identified between projects with a public or private client. There are also no significant differences between projects with an internal or external client. There are no significant differences between infrastructure projects and building projects. Differences were identified in terms of the countries of origin of the projects; p-values of less than 0.05 were obtained between the pair Chile-Colombia and Spain, where in the latter country, the 
projects had significantly lower evaluations. No significant differences were identified between the projects in Chile and Colombia.

Therefore, from this initial evaluation, it can be noted that there is a high variability in the types of BIM uses in the design planning phases, where the most developed use is coordination between specialties, and the least developed is 4D planning. In addition, this sample shows high variability in the level of development and automation of each use, for example, in cost estimation or design authoring.

\subsection{Conclusions}

The proposed BUA tool that is presented in this study contributes to the diagnosis of the application of BIM uses, thereby enabling companies and clients to identify the BIM uses state of the project, the way in which the BIM uses are being implemented and opportunities for improvement. Via this approach, it is possible to realize higher benefits from the BIM methodologies when they are applied in the earliest stages of the projects. Since countries are encouraging the use of BIM methodologies, having a tool that enables the assessment of the application of BIM uses in projects is advantageous for those who are in the process of implementing or are seeking to implement this methodology efficiently. Then, the BUA tool becomes crucial for companies in evaluating how they are utilizing all the "uses" that BIM can offer. Likewise, BUA tool can be used to evaluate companies to be contracted seeking for specific BIM use level, or also to benchmarking the BIM uses level in the industry.

In the validation process of the BUA tool, a high consistency value was obtained; i.e. the tool is reliable and measures what is being measured. In addition, when the same project was evaluated by two researchers, a high percentage of agreement was obtained; 
therefore, it can be concluded that the tool is free from evaluator's bias. The BUA tool has high concordance and consistency values; however, it is recommended that external specialists evaluate a project to eliminate biases. The BUA can be used as a selfassessment tool if the examiner is knowledgeable regarding BIM. In addition, this evaluation enables the comparison between projects of the same company or of different companies and promotes benchmarking and continuous improvement in organizations.

The descriptive analysis and hypothesis tests were conducted with the pilot test of 25 projects. The use of a larger sample size is recommended for obtaining more general conclusions according to the characteristics of the project. The BUA defines each level as a combinatorial of states associated with each characteristic of each use, however, this combinatorial could be different. The uses "sustainability analysis" and "engineering analysis" group several specialties respectively, this simplification could generate an information gap if the objective of the assessment is to understand the use of each specialty individually.

Future work will focus on the extension of BUA, which was developed for implementation in the planning and design phases, to the other project lifecycle phases, namely, the construction and operation phases. In addition, it would be of substantial value to assess the level of socialization of each BIM use since, for effectively using BIM, the integration of information among all actors of the project is necessary. This would involve assessing the way in which the information is managed, shared and stored. Additionally, with a greater number of projects, a deeper descriptive analysis can be made of the states in which each characteristic of each BIM use is located. 


\section{AN ASSESSMENT OF LEAN DESIGN MANAGEMENT PRACTICES IN CONSTRUCTION PROJECTS}

\subsection{Introduction}

The infrastructure life cycle has several phases from the inception of the idea to the dismantlement of the facility (Pellicer, Yepes, Teixeira, Moura, \& Catalá, 2014; Project Management Institute, 2017). Within this life cycle, the design phase is key, because the decisions made during this phase can significantly affect the subsequent phase. In addition, the costs of changes in the design phase are negligible compared to the costs of changes in future phases (AIA, 2007). Poor interactions within the work teams of the AEC industry can result in poor performances (Baiden et al., 2006). Poor performance results from activities that do not add value and are considered project losses, such as reworks and waiting times, among others (Aziz \& Hafez, 2013). Therefore, it is essential to appropriately manage the design process. Design management is the discipline of planning, organizing and managing the design process to meet certain defined objectives (Knotten, Lædre, \& Hansen, 2017). Although there is no tradition of integral management of the design process, in recent years, several options have been studied: to evaluate its performance (Salvatierra et al., 2019), to implement integrated management systems and visual management tools (Abou-Ibrahim \& Hamze, 2017), as well as to optimize this process (Knotten et al., 2017).

Technological tools have great potential to improve the performance of projects, particularly in design phase. However, the problems generated in the design of construction projects cannot be solved with technology alone but require an understanding 
of the social phenomena related to the processing of individual and collective information (Phelps, 2012). For this reason, certain lean tools can allow higher interactions because they encourage the management of commitment and trust among team members (Arkader, 2001; Lamming, 1996; Perez et al., 2010; Simons \& Taylor, 2007).

Evidence exists for the application of lean management principles and some of its tools in the design management process (Kestle, Potangaroa, \& Storey, 2011; Reifi \& Emmitt, 2013). For example, (Fosse \& Ballard, 2016) presented a case study that demonstrated the change between traditional planning and planning using the last planner® system (LPS®) at the design phase. Although they did not present evidence of the changes in the project's performance, they concluded that the degree of satisfaction of the project's stakeholders increased when the LPS® was applied during the planning phase of the project. For their part, (Knotten et al., 2016) emphasized that the use of LPS® and collaborative planning in the design phase reinforced the trust and commitment among the members of the team, which are both considered fundamental elements of an effective team (Svalestuen et al., 2015). Additionally, the Integrated Project Delivery (IPD) has emerged as a new project delivery system and contractual strategy with the potential to provide more collaboration and better performance through more supply chain integration, where the owner, designer and constructor sign a single multiparty contract and they build a common culture in the organization that encourages team collaboration (Mesa et al., 2016)

Lean design introduces several elements that are part of the lean philosophy and that are fundamental in the design phase, for example, the active and systematic involvement of clients during early stages, maximization of the value, identification of the needs and objectives of all interested parties, simultaneous realization of the design of the product 
and the process, and postponement of the decision-making step until the last responsible moment, with the aim of reducing reworks and unnecessary tasks (Gambatese et al., 2017). It is remarkable that several of these elements are also proposed by other management tools in the design; however, Lean can group all elements into a single framework of best practices. In addition, several lean tools can be used in lean design, such as target value design (TVD) (Alves, Lichtig, \& Rybkowski, 2017; Gambatese et al., 2017; Munthe-kaas et al., 2015; Salgin, Arroyo, \& Ballard, 2016), set-based design (SBD) (Alves et al., 2017; Munthe-kaas et al., 2015; Salgin et al., 2016), building information modeling (BIM) (Alves et al., 2017; Munthe-kaas et al., 2015; Salgin et al., 2016), choosing by advantage (CBA) ) (Alves et al., 2017; Munthe-kaas et al., 2015; Salgin et al., 2016), and LPS® (Alves et al., 2017; Gambatese et al., 2017; Munthe-kaas et al., 2015; Salgin et al., 2016; Tilley, 2005) among others. In the BIM case, (Sacks et al., 2010) propose a matrix that links Lean Construction principles with BIM functionalities; they identify 56 issues that are presented as hypotheses being intended to guide and stimulate further research.

Although several experiences have been reported that reflect certain lean tools and principles in the design phase of construction projects, there is no systematic review that links some best design practices to the principles of lean construction; therefore, it is not known how these practices maximize the value of the design product of a construction project. Consequently, no evaluation tool is available, allowing the assessment of the level of using certain practices in a specific project. Therefore, the objective of this paper is to assess the lean management practices that are performed at the design phase of construction projects. 


\subsection{Research methodology}

To achieve the objective of this work, the research was divided into three stages: (1) literature review of lean design management practices; (2) validation of the relationships between lean design management practices and lean principles; and, finally, (3) assessment of lean design management practices, where an analysis of the relationship among these practices is shown, as well as the identification of the main implementation gaps. These stages are displayed in Figure 3-1 and explained in-depth as follows.

In the first stage, the management practices that have been applied in the design phase of construction projects were identified from a literature review; then, categories were defined associated with common themes; and finally, the lean construction principles as proposed by (Koskela, 1992) were identified. The second stage sought to validate management practices such as lean design management practices; the relationship between the practices and lean construction principles was defined through a survey of 15 experts from the academic and professional sectors. Finally, in the third stage, a questionnaire was proposed to evaluate the use of lean practices based on a scale of 1 to 5 ; the tool was created in collaborative meetings with five experts. This assessment was applied to 64 construction projects at the design phase. From this assessment, the authors analyzed the relationship among the lean design management practices, and also identified the main implementation gaps in the project evaluated. 


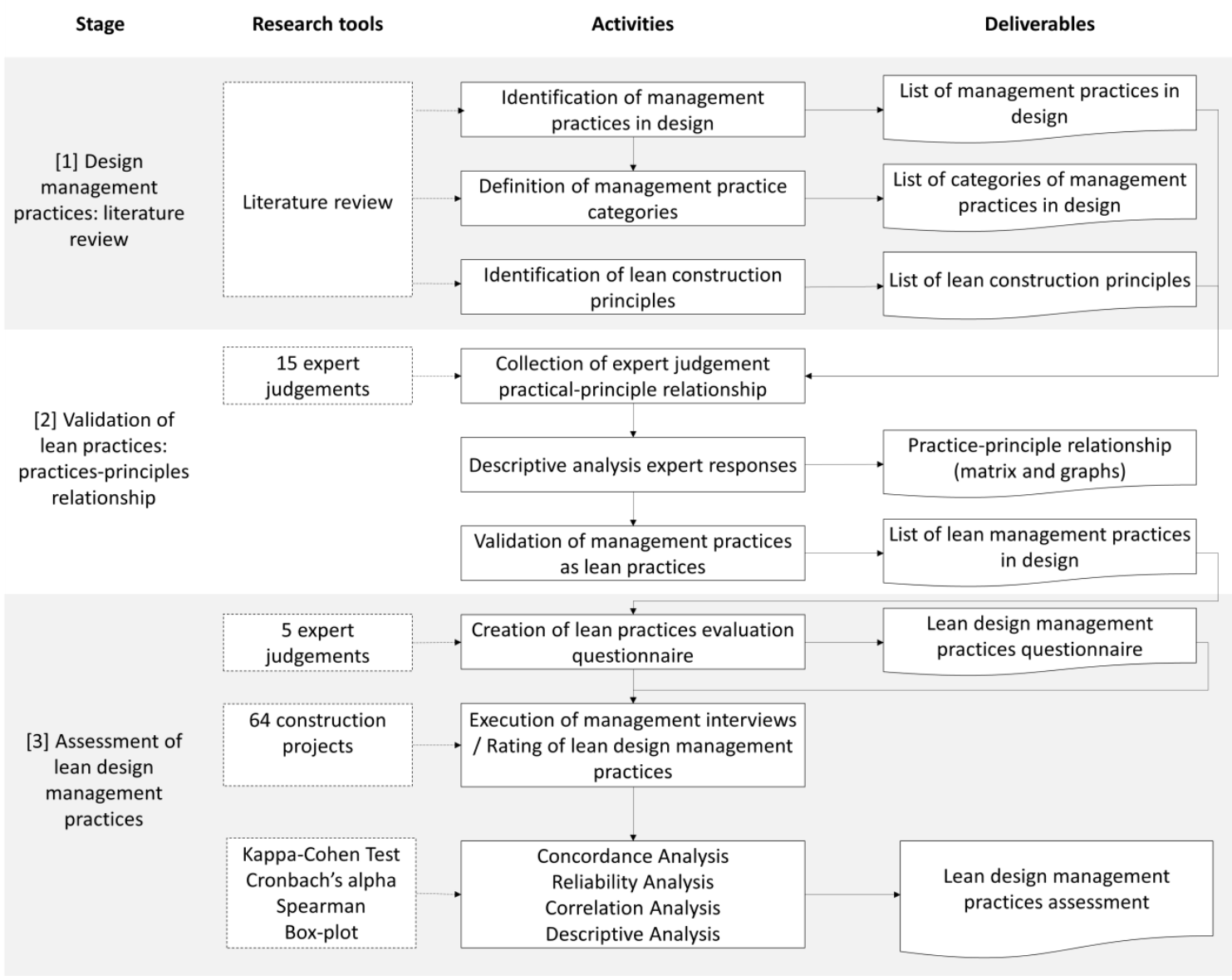

Figure 3-1: Research process

\subsubsection{Stage 1: Lean design management practices - a literature review}

A literature review was carried out of specialized journals on engineering and construction project management and of proceedings of main conferences between 1998 and 2018; the search was carried out in the following libraries: Engineering Village, Web of Science and Scopus. The search topics were lean design, design management, lean management, design team, design projects, and LPS® in design. Articles were selected applying three inclusion/exclusion criteria regarding the document: (1) focused on lean; (2) focused on design phase; and (3) reporting lean management practices in a case study. For 
control and information collection, a table was prepared using Microsoft Excel software; for each document, it comprised information related to title, authors, database, publication year and inclusion/exclusion criteria. In this review, 33 references of implementation or potential implementation of lean design management practices were found.

Based on the literature review, a set of lean design management practices was enumerated and classified into three major management areas: stakeholder management, planning and control, and problem solving and decision making. Practices associated with specific techniques, such as TVD, BIM, CBA, among others, were not considered in this study because the focus of this study was management practices and not the use of particular technologies or tools that could support this objective

\subsubsection{Stage 2: Validation of Lean design management practices: practices- principles relationship}

To validate the previously identified lean design management practices, the researchers assessed the relationship between these practices and the originals lean construction principles proposed by (Koskela, 1992), and adapted by (Herrera, Sanz, MontalbánDomingo, García-Segura, \& Pellicer, 2019) (Table 3-1). While these 11 principles were the first to be proposed, new principles have been developed (Sacks et al., 2010). However, all elements are taken up in the original eleven (Koskela, 1992), since the new principles are particular to the construction execution. 
Table 3-1: Koskela's Lean Construction Principles (Herrera, Sanz, et al., 2019) (based on (Koskela, 1992)).

\begin{tabular}{|c|c|c|}
\hline Id & Name & Description \\
\hline $\mathrm{IP}_{1}$ & Reduce waste & $\begin{array}{l}\text { Reduce the share of non-value-adding activities (also called } \\
\text { waste). These include activities that require time, resources, or } \\
\text { space but do not add value for the customer. }\end{array}$ \\
\hline $\mathrm{IP}_{2}$ & Increase value & $\begin{array}{l}\text { Increase output value through systematic consideration of } \\
\text { customer requirements. Value is generated through fulfilling } \\
\text { customer requirements, not as an inherent merit of conversion. }\end{array}$ \\
\hline $\mathrm{IP}_{3}$ & $\begin{array}{l}\text { Reduce } \\
\text { variability }\end{array}$ & $\begin{array}{l}\text { Production processes are variable. There are differences between } \\
\text { any two items, even though they are the same product, and the } \\
\text { resources needed to produce them (time, raw material, labor) vary. }\end{array}$ \\
\hline $\mathrm{IP}_{4}$ & Reduce time & $\begin{array}{c}\text { Time is a natural metric for flow processes. A production flow can } \\
\text { be characterized by cycle time, which refers to the time required } \\
\text { for a particular piece of material to traverse the flow. }\end{array}$ \\
\hline $\mathrm{IP}_{5}$ & Simplify steps & $\begin{array}{c}\text { Simplification can be understood as reducing the number of } \\
\text { components in a product or reducing the number of steps in a } \\
\text { material or information flow. }\end{array}$ \\
\hline $\mathrm{IP}_{6}$ & $\begin{array}{l}\text { Increase } \\
\text { flexibility }\end{array}$ & $\begin{array}{l}\text { Practical approaches to increasing flexibility include minimizing } \\
\text { lot sizes to closely match demand, reducing the difficulty of setups, } \\
\text { and customizing as late in the process as possible. }\end{array}$ \\
\hline $\mathrm{IP}_{7}$ & $\begin{array}{l}\text { Focus on the } \\
\text { whole process }\end{array}$ & $\begin{array}{l}\text { Focus control on the complete process. Segmented flow control } \\
\text { poses a risk of sub-optimization. }\end{array}$ \\
\hline $\mathrm{IP}_{8}$ & $\begin{array}{l}\text { Increase } \\
\text { transparency }\end{array}$ & $\begin{array}{l}\text { Lack of process transparency increases the propensity to err, } \\
\text { reduces the visibility of errors, and diminishes motivation for } \\
\text { improvement. }\end{array}$ \\
\hline $\mathrm{IP}_{9}$ & Kaizen & $\begin{array}{l}\text { Build continuous improvement into the process. The effort to } \\
\text { reduce waste and to increase value is an internal, incremental, and } \\
\text { iterative activity that can and must be carried out continuously. }\end{array}$ \\
\hline $\mathrm{IP}_{10}$ & $\begin{array}{l}\text { Balance flow } \\
\text { and conversion }\end{array}$ & $\begin{array}{c}\text { Balance flow improvement with conversion improvement. The } \\
\text { crucial issue is that flow improvement and conversion } \\
\text { improvement are intimately interconnected. }\end{array}$ \\
\hline $\mathrm{IP}_{11}$ & Benchmark & $\begin{array}{c}\text { Unlike technology for conversions, the best flow processes are not } \\
\text { marketed; each organization has to find world-class processes } \\
\text { themselves. Benchmarking includes knowing the process } \\
\text { (strengths and weaknesses), knowing industry leaders (finding, } \\
\text { understanding and comparing), and incorporating the best } \\
\text { practices. }\end{array}$ \\
\hline
\end{tabular}


The validation was performed based on the judgment of experts (academics and practitioners). The sample was selected from the research network of the Centre of Excellence of Production (GEPUC), complying with the following two requirements: (a) more than 10 years of practice, and (b) experience implementing or researching in lean management and design management. This way, twenty-five experts were invited to take part in this research; out of these twenty-five, fifteen experts agreed to participate (Table 3-2). The international experts completed a matrix whose columns contained the eleven lean principles and whose rows contained the lean design management practices obtained from the literature review.

Table 3-2: Characterization of the experts who answered the matrix

\begin{tabular}{|c|c|c|c|c|}
\hline $\begin{array}{c}\text { Profession } \\
\text { (grade) }\end{array}$ & Occupation & Field of work & $\begin{array}{l}\text { Country of } \\
\text { residence }\end{array}$ & $\begin{array}{l}\text { Years of } \\
\text { experience }\end{array}$ \\
\hline $\begin{array}{l}\text { Civil } \\
\text { Engineer, } \\
\text { PhD } \\
\end{array}$ & Professor & $\begin{array}{c}\text { Construction } \\
\text { management; project } \\
\text { management }\end{array}$ & Spain & $>25$ \\
\hline $\begin{array}{l}\text { Civil } \\
\text { Engineer, } \\
\text { PhD }\end{array}$ & Professor & $\begin{array}{l}\text { Procurement } \\
\text { management; } \\
\text { construction } \\
\text { management }\end{array}$ & Brazil & $>30$ \\
\hline $\begin{array}{l}\text { Civil } \\
\text { Engineer, } \\
\text { PhD }\end{array}$ & $\begin{array}{l}\text { Professor and } \\
\text { consultant }\end{array}$ & $\begin{array}{l}\text { Lean Construction; } \\
\text { project management }\end{array}$ & Ecuador & $>10$ \\
\hline $\begin{array}{l}\text { Architect, } \\
\text { PhD } \\
\end{array}$ & $\begin{array}{c}\text { Professor and } \\
\text { consultant }\end{array}$ & $\begin{array}{l}\text { Lean Construction; } \\
\text { theory of design }\end{array}$ & England & $>25$ \\
\hline $\begin{array}{l}\text { Architect, } \\
\text { PhD }\end{array}$ & $\begin{array}{c}\text { Professor and } \\
\text { consultant }\end{array}$ & $\begin{array}{l}\text { Lean Construction; } \\
\text { design management }\end{array}$ & Brazil & $>10$ \\
\hline $\begin{array}{l}\text { Architect, } \\
\text { PhD }\end{array}$ & Professor & $\begin{array}{l}\text { Lean Construction; } \\
\text { design management }\end{array}$ & Brazil & $>10$ \\
\hline $\begin{array}{l}\text { Architect, } \\
\text { PhD }\end{array}$ & $\begin{array}{c}\text { Professor and } \\
\text { consultant }\end{array}$ & BIM; integrated design & England & $>15$ \\
\hline $\begin{array}{l}\text { Civil } \\
\text { Engineer, } \\
\text { PhD }\end{array}$ & $\begin{array}{l}\text { Professor and } \\
\text { consultant }\end{array}$ & $\begin{array}{l}\text { Lean Construction; } \\
\text { project management }\end{array}$ & Brazil & $>30$ \\
\hline
\end{tabular}




\begin{tabular}{|c|c|c|c|c|}
\hline $\begin{array}{c}\text { Profession } \\
\text { (grade) }\end{array}$ & Occupation & Field of work & $\begin{array}{c}\text { Country of } \\
\text { residence }\end{array}$ & $\begin{array}{c}\text { Years of } \\
\text { experience }\end{array}$ \\
\hline $\begin{array}{c}\text { Civil } \\
\text { Engineer, } \\
\text { PhD }\end{array}$ & $\begin{array}{c}\text { Professor and } \\
\text { consultant }\end{array}$ & $\begin{array}{c}\text { Lean Construction; } \\
\text { project management }\end{array}$ & Lebanon & $>10$ \\
\hline $\begin{array}{c}\text { Civil } \\
\text { Engineer, } \\
\text { MSc }\end{array}$ & $\begin{array}{c}\text { Project } \\
\text { manager }\end{array}$ & $\begin{array}{c}\text { Project Management; } \\
\text { construction and design }\end{array}$ & Brazil & $>10$ \\
\hline $\begin{array}{c}\text { Civil } \\
\text { PhDineer, }\end{array}$ & $\begin{array}{c}\text { Researcher and } \\
\text { consultant }\end{array}$ & $\begin{array}{c}\text { Lean Construction; } \\
\text { virtual design }\end{array}$ & Mexico & $>10$ \\
\hline $\begin{array}{c}\text { Civil } \\
\text { Engineer, } \\
\text { PhD }\end{array}$ & $\begin{array}{c}\text { Researcher and } \\
\text { consultant }\end{array}$ & $\begin{array}{c}\text { Construction } \\
\text { Management; lean } \\
\text { construction }\end{array}$ & Brazil & $>10$ \\
\hline $\begin{array}{c}\text { Civil } \\
\text { Engineer, } \\
\text { MSc }\end{array}$ & $\begin{array}{c}\text { Professor and } \\
\text { consultant }\end{array}$ & $\begin{array}{c}\text { Construction } \\
\text { management; project } \\
\text { management }\end{array}$ & Chile & $>10$ \\
\hline $\begin{array}{c}\text { Civil } \\
\text { Engineer, } \\
\text { PhD }\end{array}$ & Professor & $\begin{array}{c}\text { Manstruction } \\
\text { procurement; } \\
\text { management }\end{array}$ & Chile & $>30$ \\
\hline $\begin{array}{c}\text { Civil } \\
\text { Engineer, } \\
\text { MSc }\end{array}$ & $\begin{array}{c}\text { Professor and } \\
\text { consultant }\end{array}$ & $\begin{array}{c}\text { Project management } \\
\text { Chile }\end{array}$ & \\
\hline
\end{tabular}

For each lean design management practice, it was requested to describe the level of relationship between the practice and each lean construction principle based on three levels: (0) the practice is not related to the lean principle; (1) the practice is partially related to the lean principle; and (2) the practice is completely related to the lean principle.

To obtain a single value of the practice-principle relationship, the median value of the experts' answers was used since the practice-principle relationship was of the ordinal type. In this way, a relationship matrix was generated between all the lean design management practices and the lean construction principles. A practice was considered a lean design management practice if it had a complete relationship with at least one lean principle or a partial relationship with two lean principles. 


\subsubsection{Stage 3: Assessment of Lean design management practices}

Given the lean design management practices that were systematically compiled from the literature, and their subsequent validation with lean construction principles, a tool was developed to assess these activities in construction projects at the design phase. Each practice was defined on a scale of five levels, that is, from null implementation to total implementation of lean design management practice in construction projects. A questionnaire was developed through collaboration with five academic experts and professionals, with at least ten years of experience in lean methodology or in the AEC industry (Table 3-3). The collaborative work of the experts consisted of five sessions in which the experts discussed and created a description for each of the five levels of the 19 lean design management practices.

Table 3-3: Characterization of the experts who created the questionnaire

\begin{tabular}{|c|c|c|c|c|}
\hline $\begin{array}{c}\text { Profession } \\
\text { (grade) }\end{array}$ & Occupation & Field of work & $\begin{array}{c}\text { Country of } \\
\text { residence }\end{array}$ & $\begin{array}{c}\text { Years of } \\
\text { experience }\end{array}$ \\
\hline $\begin{array}{c}\text { Civil Engineer, } \\
\text { PhD candidate }\end{array}$ & $\begin{array}{c}\text { Researcher and } \\
\text { consultant }\end{array}$ & $\begin{array}{c}\text { Construction } \\
\text { management; safety } \\
\text { management }\end{array}$ & Chile & $>10$ \\
\hline $\begin{array}{c}\text { Civil Engineer, } \\
\text { MSc }\end{array}$ & Consultant & $\begin{array}{c}\text { Construction } \\
\text { management }\end{array}$ & Chile & $>10$ \\
\hline $\begin{array}{c}\text { Civil Engineer, } \\
\text { PhD }\end{array}$ & $\begin{array}{c}\text { Professor and } \\
\text { consultant }\end{array}$ & $\begin{array}{c}\text { Lean construction; } \\
\text { project management }\end{array}$ & Ecuador & $>10$ \\
\hline $\begin{array}{c}\text { Civil Engineer, } \\
\text { PhD }\end{array}$ & $\begin{array}{c}\text { Professor and } \\
\text { consultant }\end{array}$ & $\begin{array}{c}\text { Virtual design; } \\
\text { construction } \\
\text { management }\end{array}$ & Chile & $>10$ \\
\hline $\begin{array}{c}\text { Civil Engineer, } \\
\text { PhD candidate }\end{array}$ & $\begin{array}{c}\text { Professor and } \\
\text { consultant }\end{array}$ & $\begin{array}{c}\text { Lean construction; } \\
\text { design management }\end{array}$ & Chile & $>$ \\
\hline
\end{tabular}

To assess the level of implementation of the lean design management practices, the researcher applied the questionnaire in 64 construction projects. The researchers invited to 
join all the companies who participate in its network of collaborating organizations, of which 64 projects of companies interested were assessed. All projects had a Design-BidBuild contracting system, so the design was in a contract prior to the construction. Additionally, the projects were divided between building and infrastructure projects and by the design's country of origin; the projects were from Colombia, Chile and Spain (Table 3-4). Given these classifications, hypothesis tests were carried out to check if there were significant differences by type of classification (country and type of project). The assessment of each project follows this process: first, the researchers conducted an interview, which was recorded, with the project coordinator considering all the points addressed in the questionnaire (audio was recorded with the consent of the interviewee). Then, two researchers listened to the recorded interviews and individually rated each project for each of the management practices defined in the questionnaire, using the 5point Likert scale explained above. Then, in a collaborative session, the two researchers who qualified the projects were asked to discuss the final qualification of each practice.

Table 3-4: Summary of project characteristics

\begin{tabular}{|c|c|c|c|}
\hline Country & Building project & Infrastructure project & Total \\
\hline Colombia & 12 & 2 & 14 \\
\hline Chile & 20 & 12 & 32 \\
\hline Spain & 12 & 6 & 18 \\
\hline Total & $\mathbf{4 4}$ & $\mathbf{2 0}$ & $\mathbf{6 4}$ \\
\hline
\end{tabular}

Finally, from the information of the 64 projects, the following analyses were carried out: (1) a concordance analysis using Cohen's Kappa test (Cohen, 1960) was performed in three scenarios (between the answer of the two researchers, between the answer of the first 
researcher and the final decision, and between the answer of the second researcher and the final decision); (2) a reliability analysis using Cronbach's alpha coefficient to assess the questionnaire internal consistency; (3) an analysis of significant differences of lean design management practices depending on country and type of project using the non-parametric Kruskal-Wallis Test and Mann-Whitney U test, respectively; (4) a relationship analysis among the lean design management practices using Spearman correlation coefficient; and (5) a descriptive analysis to know the main implementation gaps of lean design management practices in the project evaluated.

\subsection{Results and Discussion}

\subsubsection{Identification of Lean design management practices from the literature}

Affinity methods are used in Design Thinking to help in making sense of the information when data comes from diverse sources/contexts, such as facts, ethnographic research, brainstorming results, users' opinions and needs, insights, and design issues (Dam \& Siang, 2019). Considering the exploratory nature of this study and the mixed nature of the data collected, affinity methods were selected for information classification. From the literature review, 19 lean design management practices were identified and grouped into three categories, using the affinity method (Carnevalli \& Miguel, 2008; Foster \& Ganguly, 2007): stakeholder management, project planning and control, and problem solving and decision making. Below, the practices of each of the categories are presented; for each one of the practices, its supporting references are presented by category. 
The management of stakeholders (category 1) is one of the most important elements in the management of any type of project (Mok, Shen, \& Yang, 2015; Molwus, Erdogan, \& Ogunlana, 2017). As an example of its relevance, the project management body of knowledge (PMBOK) as proposed by the Project Management Institute (PMI), added stakeholder management, as the tenth area of knowledge to be considered by project managers (Project Management Institute, 2017). Within this category, requirement management is usually one of the critical elements for the management of construction projects (Molwus et al., 2017), where the identification and management must be conducted not only with external clients but also with all stakeholders of the project, while also considering internal clients (Mok et al., 2015; Project Management Institute, 2017). To correctly manage requirements, the systematic participation of a client as feedback agent of the proposition generated by designers is fundamental (C. Ko \& Chung, 2014; Reifi \& Emmitt, 2013; Salgin et al., 2016). Additionally, the early involvement of specialist designers and builders will generate a design with a comprehensive value proposal; furthermore, the design will consider the knowledge and experience of these actors as internal clients, allowing them to anticipate potential incompatibility problems among designers and even consider an optimal design for future construction (G. Ballard, Tommelein, Koskela, \& Howell, 2002; Franco \& Picchi, 2016; Knotten et al., 2017). Table 3-5 provides a summary of the main references found in the literature about lean management practices associated with stakeholder management. 
Table 3-5: Lean practices associated with stakeholder management

\begin{tabular}{|c|c|c|}
\hline ID & Definition & Sources \\
\hline $\mathrm{SM}_{1}$ & $\begin{array}{l}\text { Specialist designers are } \\
\text { involved during early stages of } \\
\text { the project. }\end{array}$ & $\begin{array}{l}\text { (G. Ballard \& Howell, 2003; G. Ballard et al., } \\
\text { 2002; Glenn Ballard \& Zabelle, 2000; Cohen, } \\
\text { 2010; Formoso et al., 1998; Franco \& Picchi, } \\
\text { 2016; Freire \& Alarcón, 2002; Hansen, Olsson, } \\
\text { Hansen, \& Olsson, 2011; Knotten et al., 2016; C. } \\
\text { Ko \& Chung, 2014; Koskela, Huovila, \& } \\
\text { Leinonen, 2002; Reifi \& Emmitt, 2013; Salgin et } \\
\text { al., 2016; Sødal, Lædre, Svalestuen, \& Lohne, } \\
\text { 2014) }\end{array}$ \\
\hline $\mathrm{SM}_{2}$ & $\begin{array}{l}\text { Builders are involved during } \\
\text { early stages of the project. }\end{array}$ & $\begin{array}{l}\text { (G. Ballard \& Howell, 2003; G. Ballard et al., } \\
\text { 2002; Glenn Ballard \& Zabelle, 2000; Cohen, } \\
\text { 2010; Formoso et al., 1998; Franco \& Picchi, } \\
\text { 2016; Freire \& Alarcón, 2002; Hansen et al., } \\
\text { 2011; Jaganathan, Nesan, Ibrahim, \& } \\
\text { Mohammad, 2013; Knotten et al., 2016; C. Ko \& } \\
\text { Chung, 2014; Koskela et al., 2002; Reifi \& } \\
\text { Emmitt, 2013; Salgin et al., 2016) }\end{array}$ \\
\hline $\mathrm{SM}_{3}$ & $\begin{array}{l}\text { The identification of } \\
\text { requirements of the } \\
\text { stakeholders is exhaustive, } \\
\text { where requirements, } \\
\text { constraints, technical } \\
\text { specifications and special } \\
\text { requirements are defined. }\end{array}$ & $\begin{array}{l}\text { (Alves et al., 2017; Bade \& Haas, 2015; G. } \\
\text { Ballard \& Howell, 2003; G. Ballard et al., 2002; } \\
\text { Glenn Ballard, 2002; Glenn Ballard \& Zabelle, } \\
\text { 2000; Cohen, 2010; Formoso et al., 1998; Franco } \\
\text { \& Picchi, 2016; Freire \& Alarcón, 2002; Hansen } \\
\text { et al., 2011; Knotten et al., 2016; C. Ko \& Chung, } \\
\text { 2014; Reifi \& Emmitt, 2013; Salgin et al., 2016) }\end{array}$ \\
\hline $\mathrm{SM}_{4}$ & $\begin{array}{l}\text { The participation of clients in } \\
\text { the design phase involves the } \\
\text { systematic participation and } \\
\text { support during meetings } \\
\text { concerning decision making } \\
\text { and resolution of problems. }\end{array}$ & $\begin{array}{c}\text { (G. Ballard \& Howell, 2003; G. Ballard et al., } \\
\text { 2002; Glenn Ballard \& Zabelle, 2000; Cohen, } \\
\text { 2010; Franco \& Picchi, 2016; Freire \& Alarcón, } \\
\text { 2002; Hansen et al., 2011; Knotten et al., 2016; C. } \\
\text { Ko \& Chung, 2014; Reifi \& Emmitt, 2013; Salgin } \\
\text { et al., 2016) }\end{array}$ \\
\hline $\mathrm{SM}_{5}$ & $\begin{array}{l}\text { The design of the product and } \\
\text { the construction process are } \\
\text { carried out simultaneously. }\end{array}$ & $\begin{array}{l}\text { (Alves et al., 2017; Arbulu \& Soto, 2006; G. } \\
\text { Ballard \& Howell, 2003; G. Ballard et al., 2002; } \\
\text { Glenn Ballard \& Zabelle, 2000; Franco \& Picchi, } \\
\text { 2016; Jaganathan et al., 2013; C. Ko \& Chung, } \\
\text { 2014; Salgin et al., 2016; Sødal et al., 2014) }\end{array}$ \\
\hline
\end{tabular}

The planning and monitoring (category 2) of projects are activities that require more time when managing a project; in the latest version of the PMBOK (Project Management Institute, 2017), $73.47 \%$ of the proposed processes for project management belonged to the 
planning and monitoring categories (Project Management Institute, 2017). In the AEC industry, there are certain standardized tools and practices that are commonly used for planning and control, specifically during the construction phase, such as the Earned Value Method (Bryde, Unterhitzenberger, \& Joby, 2018; Czemplik, 2014) or LPS® (Hamzeh et al., 2009; Herrera et al., 2018; Munthe-kaas et al., 2015). However, during the design phase, there are no common tools and practices for design teams (Herrera et al., 2018); currently, there have been reports and case studies about the application of certain management tools, such as the design structure matrix and LPS® (Rosas, 2013). Most of the practices compiled are related to the use of LPS® (Fosse \& Ballard, 2016; Hamzeh et al., 2009). Table 3-6 provides a summary of the main references encountered in the literature about lean management practices associated with project planning and control.

Table 3-6: Lean practices associated with project planning and control

\begin{tabular}{|c|c|c|}
\hline ID & Definition & Sources \\
\hline $\mathrm{PC}_{1}$ & $\begin{array}{l}\text { Project planning considers delivery } \\
\text { dates, phases, milestones, task } \\
\text { subdivision programs and control } \\
\text { instances. All of the above, immersed } \\
\text { in a scheme in which gaps, buffers } \\
\text { and points are clarified, can be used to } \\
\text { perform pull/push actions within the } \\
\text { program. }\end{array}$ & $\begin{array}{l}\text { (Alves et al., 2017; G. Ballard \& Howell, } \\
\text { 2003; G. Ballard et al., 2002; Glenn Ballard, } \\
\text { 2002; Glenn Ballard \& Zabelle, 2000; Fosse } \\
\text { \& Ballard, 2016; Franco \& Picchi, 2016; } \\
\text { Hamzeh et al., 2009; C. Ko \& Chung, 2014; } \\
\text { Koskela et al., 1997; Magalingam, Yadav, } \\
\text { \& Varaprasad, 2015; Rosas, 2013; } \\
\text { Tauriainen, Marttinen, Dave, \& Koskela, } \\
\text { 2016; UUsitalo, Olivieri, Seppänen, Pikas, } \\
\text { \& Peltokorpi, 2017; Wesz, Formoso, \& } \\
\text { Tzortzopoulos, 2018) }\end{array}$ \\
\hline $\mathrm{PC}_{2}$ & $\begin{array}{l}\text { With regard to project planning, this } \\
\text { is considered information of internal } \\
\text { and/or external projects of the } \\
\text { organization, generated through a } \\
\text { benchmarking exercise. }\end{array}$ & $\begin{array}{l}\text { (G. Ballard \& Howell, 2003; G. Ballard et } \\
\text { al., 2002; Glenn Ballard, 2002; Glenn } \\
\text { Ballard \& Zabelle, 2000; Formoso et al., } \\
\text { 1998; Fosse \& Ballard, 2016; Hamzeh et } \\
\text { al., 2009; Tauriainen et al., 2016; UUsitalo } \\
\text { et al., 2017) }\end{array}$ \\
\hline $\mathrm{PC}_{3}$ & Project planning is conducted & (Alves et al., 2017; G. Ballard \& Howell, \\
\hline
\end{tabular}




\begin{tabular}{|c|c|c|}
\hline ID & Definition & Sources \\
\hline & $\begin{array}{l}\text { collaboratively among various } \\
\text { stakeholders. }\end{array}$ & $\begin{array}{l}\text { 2003; G. Ballard et al., 2002; Glenn Ballard } \\
\text { \& Zabelle, 2000; Fosse \& Ballard, 2016; } \\
\text { Hamzeh et al., 2009; Hansen et al., 2011; } \\
\text { Knotten et al., 2016; C. Ko \& Chung, 2014; } \\
\text { Koskela et al., 1997; Magalingam et al., } \\
\text { 2015; Rosas, 2013; Tauriainen et al., 2016; } \\
\text { UUsitalo et al., 2017; Wesz et al., 2018) }\end{array}$ \\
\hline $\mathrm{PC}_{4}$ & $\begin{array}{l}\text { Project planning is carried out at } \\
\text { different levels (global, phase, } \\
\text { intermediate and weekly). }\end{array}$ & $\begin{array}{l}\text { (G. Ballard \& Howell, 2003; G. Ballard et } \\
\text { al., 2002; Glenn Ballard, 2002; Glenn } \\
\text { Ballard \& Zabelle, 2000; Formoso et al., } \\
\text { 1998; Fosse \& Ballard, 2016; Hamzeh et } \\
\text { al., 2009; Hansen et al., 2011; C. Ko \& } \\
\text { Chung, 2014; Koskela et al., 1997; } \\
\text { Magalingam et al., 2015; Rosas, 2013; } \\
\text { Tauriainen et al., 2016; UUsitalo et al., } \\
\text { 2017; Wesz et al., 2018) }\end{array}$ \\
\hline $\mathrm{PC}_{5}$ & $\begin{array}{l}\text { The constraints in the design process } \\
\text { are identified and registered } \\
\text { collaboratively and released by a } \\
\text { responsible person. Then, the } \\
\text { constraints are followed. }\end{array}$ & $\begin{array}{l}\text { (Arbulu \& Soto, 2006; G. Ballard \& } \\
\text { Howell, 2003; G. Ballard et al., 2002; Glenn } \\
\text { Ballard, 2002; Glenn Ballard \& Zabelle, } \\
\text { 2000; Cohen, 2010; Fosse \& Ballard, 2016; } \\
\text { Hamzeh et al., 2009; Koskela et al., 1997; } \\
\text { Magalingam et al., 2015; Rosas, 2013; } \\
\text { Tauriainen et al., 2016; UUsitalo et al., } \\
\text { 2017; Wesz et al., 2018) }\end{array}$ \\
\hline $\mathrm{PC}_{6}$ & $\begin{array}{l}\text { The coordination of project } \\
\text { information between the different } \\
\text { stakeholders is performed through a } \\
\text { single platform, which allows } \\
\text { systematic updates and continuous } \\
\text { communication between stakeholders. }\end{array}$ & $\begin{array}{l}\text { (G. Ballard et al., 2002; Glenn Ballard \& } \\
\text { Zabelle, 2000; Franco \& Picchi, 2016; } \\
\text { Magalingam et al., 2015; Reifi \& Emmitt, } \\
\text { 2013; Tauriainen et al., 2016; Tilley, 2005; } \\
\text { Tribelsky \& Sacks, 2011; UUsitalo et al., } \\
\text { 2017) }\end{array}$ \\
\hline
\end{tabular}

During the design phase, there are many iterations associated with both the creative process of design and the existence of problems of a different nature, such as incompatibilities between specialties, regulatory constraints, economic constraints, illdefined requirements, among others (C. Ko \& Chung, 2014). Therefore, these creative or problem iterations will generate instances of decision making and problem solving (category 3), which can be addressed individually and centrally or collaboratively and decentralized (Savolainen, Saari, Männistö, \& Kähkonen, 2018), and intuitively or with 
defined and standardized action protocols (Arroyo, Tommelein, \& Ballard, 2015; Salgin et al., 2016). The lean theory proposes collaborative, continuous and standardized management as appropriate practices to solve problems and make decisions, and using the resulting information as lessons learned (G. Ballard \& Howell, 2003; G. Ballard et al., 2002; Wesz et al., 2018). Table 3-7 provides a summary of the main references encountered in the literature about lean management practices associated with problem solving and decision making.

Table 3-7: Lean practices associated with problem solving and decision making

\begin{tabular}{|c|c|c|}
\hline ID & Definition & \\
\hline $\mathrm{DM}_{1}$ & $\begin{array}{l}\text { There exists a protocol to solve } \\
\text { problems collaboratively. }\end{array}$ & $\begin{array}{c}\text { (G. Ballard \& Howell, 2003; G. Ballard et al., } \\
\text { 2002; Glenn Ballard \& Zabelle, 2000; Cohen, } \\
\text { 2010; Fosse \& Ballard, 2016; Rahmawati, } \\
\text { Utomo, Anwar, Negoro, \& Nurcahyo, 2014; } \\
\text { Reifi \& Emmitt, 2013; Salgin et al., 2016; } \\
\text { Wesz et al., 2018) }\end{array}$ \\
\hline $\mathrm{DM}_{2}$ & $\begin{array}{l}\text { The } \\
\text { prob } \\
\text { analysi }\end{array}$ & $\begin{array}{l}\text { (G. Ballard \& Howell, 2003; G. Ballard et al., } \\
\text { 2002; Glenn Ballard \& Zabelle, 2000; Fosse } \\
\text { \& Ballard, 2016; Salgin et al., 2016) }\end{array}$ \\
\hline $\mathrm{DM}_{3}$ & $\begin{array}{l}\text { is } \\
\text { he }\end{array}$ & $\begin{array}{c}\text { (G. Ballard \& Howell, 2003; G. Ballard et al., } \\
\text { 2002; Glenn Ballard \& Zabelle, 2000; Cohen, } \\
\text { 2010; Fosse \& Ballard, 2016; Salgin et al., } \\
\text { 2016) }\end{array}$ \\
\hline $\mathrm{DM}_{4}$ & $\begin{array}{l}\text { In the decision-making process, } \\
\text { options are evaluated, designed, } \\
\text { and tested, and the results validated } \\
\text { and applied. }\end{array}$ & $\begin{array}{l}\text { (G. Ballard \& Howell, 2003; G. Ballard et al., } \\
\text { 2002; Glenn Ballard \& Zabelle, 2000; Cohen, } \\
\text { 2010; Franco \& Picchi, 2016; Kalsaas \& } \\
\text { Sacks, 2011; Kestle \& London, 2002; } \\
\text { Munthe-kaas et al., 2015; Salgin et al., 2016; } \\
\text { Wesz et al., 2018) }\end{array}$ \\
\hline $\mathrm{DM}_{5}$ & $\begin{array}{l}\text { The moment to make decisions is } \\
\text { the last responsible moment, and } \\
\text { all the information that could be } \\
\text { gathered at that moment is used. }\end{array}$ & $\begin{array}{l}\text { (G. Ballard \& Howell, 2003; G. Ballard et al., } \\
\text { 2002; Glenn Ballard \& Zabelle, 2000; Franco } \\
\text { \& Picchi, 2016; Munthe-kaas et al., 2015; } \\
\text { Salgin et al., 2016) }\end{array}$ \\
\hline & To make decisions, information of & (G. Ballard \& Howell, 2003; G. Ballard et al., \\
\hline
\end{tabular}




\begin{tabular}{|c|c|c|}
\hline ID & Definition & Sources \\
\hline & $\begin{array}{l}\text { internal and/or external projects of } \\
\text { the organization is used, generated } \\
\text { through a benchmarking exercise. }\end{array}$ & $\begin{array}{l}\text { 2002; Glenn Ballard \& Zabelle, 2000; Franco } \\
\text { \& Picchi, 2016; Kalsaas \& Sacks, 2011; } \\
\text { Kestle \& London, 2002; Reifi \& Emmitt, } \\
\text { 2013; Salgin et al., 2016) }\end{array}$ \\
\hline $\mathrm{DM}_{7}$ & $\begin{array}{l}\text { The decision-making mechanism is } \\
\text { a meeting with all stakeholders } \\
\text { involved, where a specific } \\
\text { technique is used, for example, } \\
\text { CBA or others. }\end{array}$ & $\begin{array}{l}\text { (G. Ballard \& Howell, 2003; G. Ballard et al., } \\
\text { 2002; Glenn Ballard \& Zabelle, 2000; } \\
\text { Kalsaas \& Sacks, 2011; Kestle \& London, } \\
\text { 2002; Koskela et al., 2002; Munthe-kaas et } \\
\text { al., 2015; Rahmawati et al., 2014; Reifi \& } \\
\text { Emmitt, 2013; Salgin et al., 2016; UUsitalo et } \\
\text { al., 2017) }\end{array}$ \\
\hline $\mathrm{DM}_{8}$ & $\begin{array}{l}\text { After making the decision, specific } \\
\text { actions are taken to verify whether } \\
\text { satisfactory results were obtained. } \\
\text { In addition, the lessons learned are } \\
\text { identified and documented. }\end{array}$ & $\begin{array}{l}\text { (G. Ballard et al., 2002; Glenn Ballard \& } \\
\text { Zabelle, 2000; Kalsaas \& Sacks, 2011; Kestle } \\
\text { \& London, 2002; Koskela et al., 2002; } \\
\text { Munthe-kaas et al., 2015; Salgin et al., 2016) }\end{array}$ \\
\hline
\end{tabular}

\subsubsection{The relationship between Lean design management practices and Lean principles}

To validate the 19 lean design management practices, their relationships with the 11 principles of lean construction were investigated. The judgment of 15 experts was used to consider whether the practical-principle relationship was nonexistent (0), a partial relationship (1) or a complete relationship (2). As each expert provided their judgment on each of the 209-possible practice-principle relationships, the median value of the experts' answers was used. All of the relationships were presented in a matrix of practical-principle relationships (Table 3-8), which could be visualized more compactly as a node diagram. In the node diagram, the nodes represented the principles and practices, while the edges represented relationships between the nodes (Figure 3-2). 
Table 3-8: Practice-principle relationship matrix

\begin{tabular}{|c|c|c|c|c|c|c|c|c|c|c|c|}
\hline & $\mathrm{IP}_{1}$ & $\mathrm{IP}_{2}$ & $\mathrm{IP}_{3}$ & $\mathrm{IP}_{4}$ & $\mathrm{IP}_{5}$ & $\mathrm{IP}_{6}$ & $\mathrm{IP}_{7}$ & $\mathrm{IP}_{8}$ & $\mathrm{IP}_{9}$ & $\mathrm{IP}_{10}$ & $\mathrm{IP}_{11}$ \\
\hline $\mathrm{SM}_{1}$ & 2 & 1 & 1 & 1 & 1 & 1 & 0 & 1 & 1 & 0 & 0 \\
\hline $\mathrm{SM}_{2}$ & 2 & 1 & 1 & 1 & 1 & 0 & 1 & 2 & 1 & 1 & 0 \\
\hline $\mathrm{SM}_{3}$ & 1 & 2 & 1 & 0 & 1 & 0 & 1 & 1 & 0 & 0 & 0 \\
\hline $\mathrm{SM}_{4}$ & 1 & 2 & 1 & 0 & 1 & 0 & 1 & 1 & 0 & 0 & 0 \\
\hline $\mathrm{SM}_{5}$ & 2 & 1 & 2 & 2 & 2 & 1 & 1 & 2 & 1 & 1 & 0 \\
\hline $\mathrm{PC}_{1}$ & 1 & 1 & 2 & 2 & 1 & 0 & 1 & 2 & 1 & 1 & 0 \\
\hline $\mathrm{PC}_{2}$ & 0 & 1 & 0 & 0 & 1 & 0 & 0 & 1 & 1 & 0 & 2 \\
\hline $\mathrm{PC}_{3}$ & 2 & 1 & 2 & 1 & 2 & 0 & 2 & 1 & 1 & 1 & 0 \\
\hline $\mathrm{PC}_{4}$ & 1 & 0 & 1 & 1 & 1 & 0 & 1 & 1 & 0 & 1 & 0 \\
\hline $\mathrm{PC}_{5}$ & 1 & 1 & 2 & 1 & 1 & 0 & 1 & 0 & 1 & 0 & 0 \\
\hline $\mathrm{PC}_{6}$ & 1 & 1 & 1 & 1 & 1 & 1 & 1 & 1 & 0 & 0 & 0 \\
\hline $\mathrm{DM}_{1}$ & 2 & 1 & 2 & 1 & 0 & 0 & 2 & 1 & 1 & 1 & 0 \\
\hline $\mathrm{DM}_{2}$ & 1 & 0 & 2 & 1 & 1 & 0 & 1 & 0 & 1 & 0 & 0 \\
\hline $\mathrm{DM}_{3}$ & 1 & 0 & 1 & 1 & 0 & 0 & 1 & 0 & 2 & 0 & 0 \\
\hline $\mathrm{DM}_{4}$ & 1 & 1 & 1 & 0 & 1 & 1 & 1 & 1 & 2 & 0 & 0 \\
\hline $\mathrm{DM}_{5}$ & 0 & 0 & 1 & 0 & 0 & 1 & 0 & 1 & 0 & 0 & 0 \\
\hline $\mathrm{DM}_{6}$ & 1 & 1 & 1 & 1 & 1 & 1 & 1 & 1 & 1 & 0 & 2 \\
\hline $\mathrm{DM}_{7}$ & 1 & 1 & 0 & 0 & 1 & 0 & 1 & 1 & 0 & 0 & 0 \\
\hline $\mathrm{DM}_{8}$ & 1 & 1 & 1 & 1 & 0 & 1 & 1 & 1 & 2 & 0 & 1 \\
\hline
\end{tabular}

Figure 3-2 depicts the network diagrams, where the white nodes represent the principles and the black nodes are the practices associated with the various categories of stakeholder management, planning and monitoring, and problem solving and decision making. The size of the practice nodes remains constant; however, the size of the principle nodes increases as additional practices contributed to each principle. The connections, represented by arrows, are continuous lines when complete relationships exist and dotted lines when connections are partial. Figure 3-2 allows visualization of the management practices that contributed to each principle; therefore, the visualization of management practices could serve as a guide for organizations to decide which practices have higher priorities than others. 
The 11 lean construction principles were linked by at least three practices and, at most, 17 of the 19 lean design management practices, that is, all of the lean construction principles were considered in the practices documented in this study. The principles that were most reinforced in the design phase of construction projects were as follows: increasing the output value through systematic consideration of customer requirements, reducing the amount of nonvalue adding activities, reducing the process variability, reducing the cycle times, increasing the process transparency, and continuously improving processes. This was a predictable result, since during the design phase, clients are provided with a first approximation of the final product that they expect to receive. The principles that were least reinforced were increasing the output flexibility, balancing the flow improvement with conversion improvement and benchmarking. The standard deviation of the number of practices connected to each principle was 4.68 practices; however, if the three least reinforced principles were not considered in the calculation, the standard deviation was 1.48; that is, without accounting for these three principles, it existed a greater level of homogeneity among the remaining eight principles, which was altered when considering the eleven lean construction principles. 


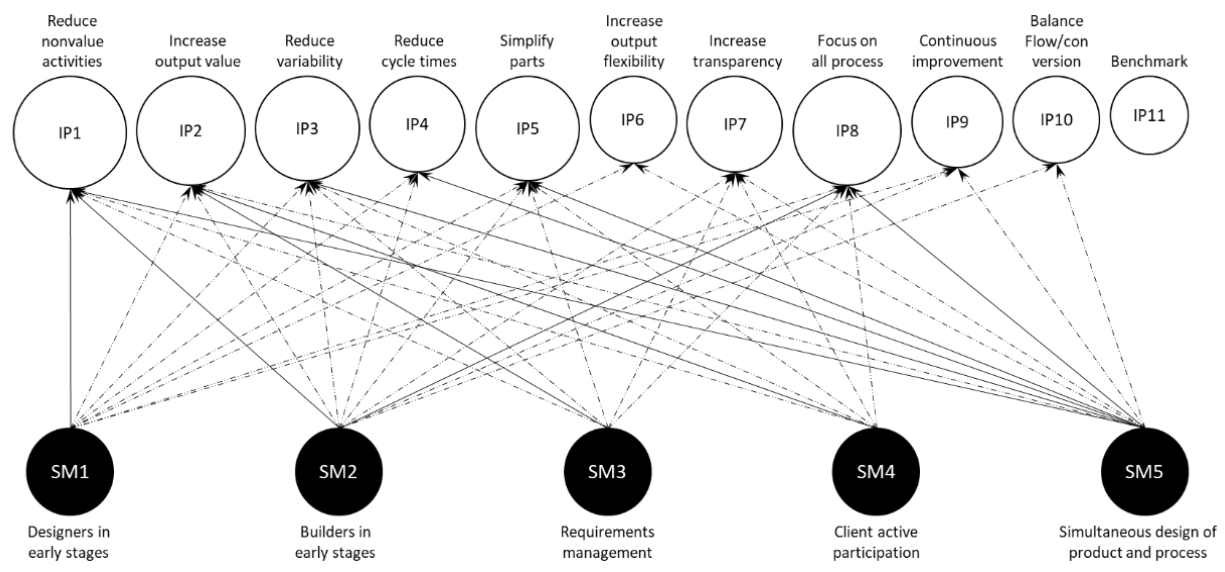

(a) Relationships between the stakeholder management practices and lean construction principles

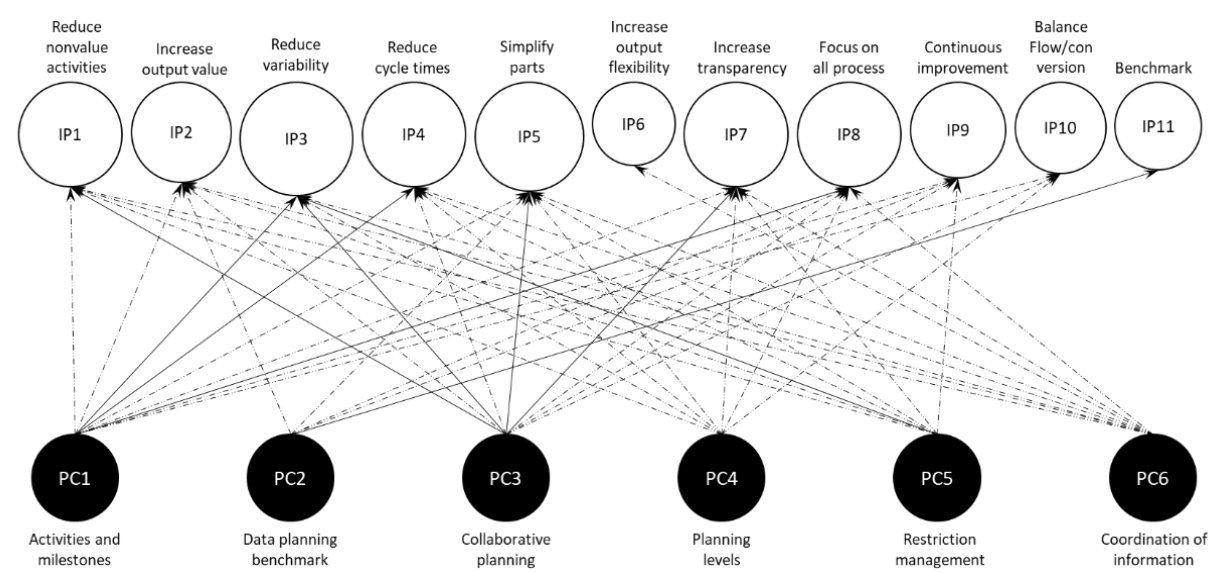

(b) Relationships between the planning and monitoring management practices and lean construction principles

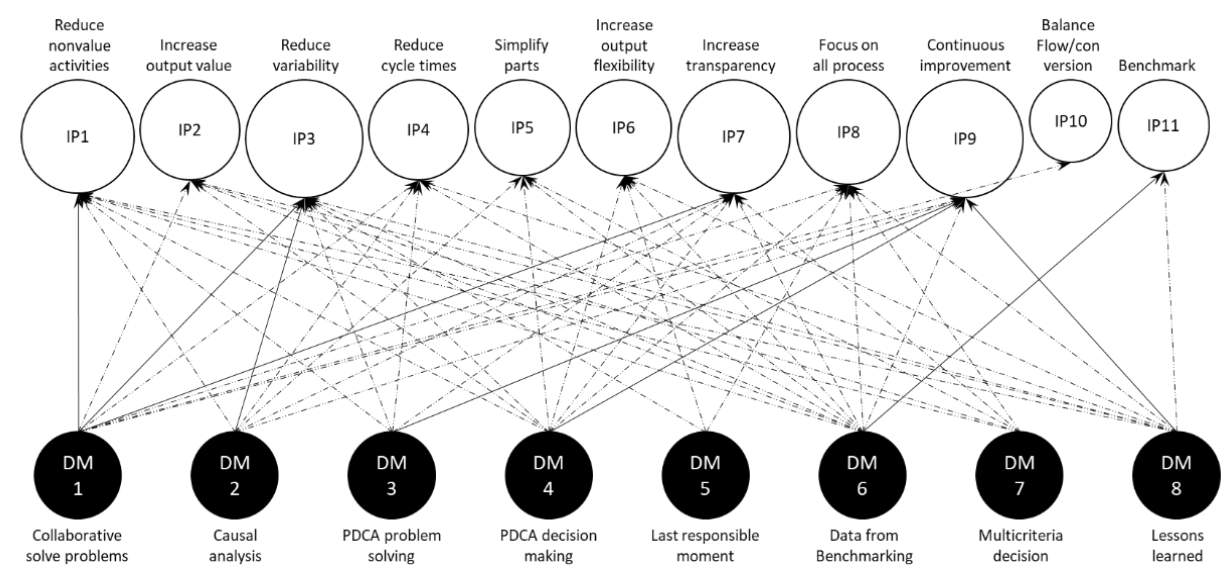

(c) Relationships between decision making and problem-solving management practices and lean construction principles

Figure 3-2: Relationships between lean design management practices and lean 
On average, each principle was connected with 12 of the 19 lean design management practices, which demonstrated a suitable level of compatibility between lean design management practices and lean construction principles. The number of total connections between practices and principles was 138 (including partial and complete relationships), which accounted for $66.03 \%$ of all potential relationships. However, of the total number of connections, $19.57 \%$ were complete relationships and $80.43 \%$ were partial relationships, which indicated that when applying lean construction principles during the design phase, there were on average two practices that would directly impact the management and application of these principles during the design phase. On average, there were six practices that only partially impacted the management and application of lean construction principles.

In addition, all practices were connected to each other through at least one principle; therefore, the implementation of lean practices in the design phase could be simple and gradual if the design team was clear about the lean construction principles that were being considered for implementation in the management process. However, each implementation process should be carried out gradually; therefore, it was important to identify which practices contributed to a greater number of lean construction principles. The identification would enable organizations to determine the rate at which practices would be gradually implemented. Figure 3-3 shows the number of principles that each of the practices contributed to: (A) partially and (B) completely. 


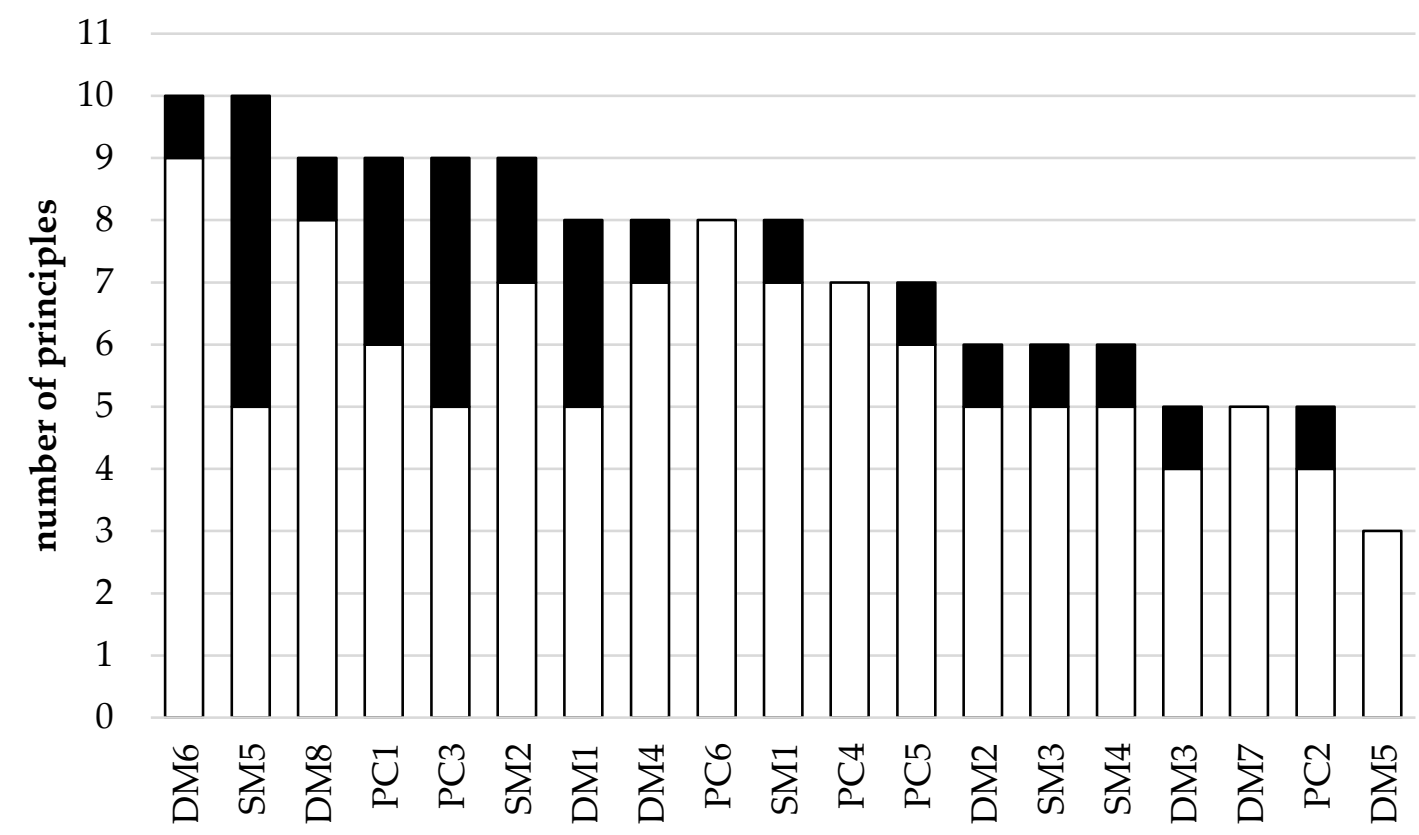

$\square$ A-Partial relationship $\quad$ B-Complete relationship

Figure 3-3: Number of lean principles related to each lean design management practice

The 19 defined lean design management practices were subject to at least three principles and a maximum of 10 out of 11 lean construction principles proposed by (Koskela, 1992). The practices that contributed to a larger number of principles were the simultaneous design of the product and construction process, use of benchmarking information to make decisions, definition of activities, milestones and control points and collaborative planning. Several of the aforementioned practices belonged to the planning and control category, which was in agreement with the literature review of lean construction principles in the design phase; most of the case studies in the literature reflected the implementation of LPS® during the design phase of construction projects. 
The practices that contributed to fewer principles were the making of decisions at the last responsible moment, plan-do-check-act (PDCA) problem solving, multicriteria decision making, and benchmarking to obtain information for planning. Three of these four practices corresponded to the problem solving and decision-making category; therefore, there would be a knowledge gap associated with the approach of this type of implementation of the lean construction principles. It is important to mention that the number of lean construction principles related to a practice does not imply that this practice is more or less important in the process of implementing lean to the design process.

On average, each practice contributed to 7.26 principles. Distinguishing this information by category, practices of the stakeholder management, planning and control, and problem solving and decision-making categories, contributed to, on average 7.80, 7.50 and 6.75 principles, respectively; therefore, none of the categories dominated over the others, although it was again observed that the problem solving and decision making category was the least related to the principles of lean construction.

\subsubsection{Assessment of Lean design management practices in construction projects}

Nick Bloom \& Van Reenen, (2007) developed a method to measure and explain management practices across firms and countries, which uses open-ended questions. This approach fits better to the current research than absolute scoring grids, and it is a proven model, which is highly cited in the literature. Based on the list of lean design management practices, a project management questionnaire was created that contained five levels (Bloom \& Van Reenen, 2007). For each practice, the collaborative team of experts (Table 3-3) proposed a description was defined for scores 1, 3 and 5, while scores 2 and 4 were defined as an intermediate point between 1-3 and 3-5, respectively: 
- Score 1: a traditional management practice

- Score 3: an initial lean design management practice

- Score 5: a developed lean design management practice

The researchers assessed 64 projects in design phase; each project was independently assessed by two researchers and then the final score was collaboratively defined. To evaluate the degree of agreement between the two researchers, the Cohen's Kappa test (Cohen, 1960) was used, where the null hypothesis (H0) was defined as that there was no agreement between the two researchers, and the alternative hypothesis (H1) was defined as that there was agreement between the two researchers. The test considered a level of significance of 5\%. When applying Cohen's Kappa test, a percentage of agreement of $75 \%$ was obtained, with a Cohen's Kappa value of 0.65 and p-value of 0.03 . Since the p-value was less than 0.05 , the null hypothesis could be rejected, while the alternative hypothesis that there existed agreement between the two researchers could not be rejected (Mchugh, 2012). When performing the Cohen's Kappa test considering the collaborative decision of the two independent researchers, Cohen's Kappa values of 0.81 and 0.82 were obtained, which indicated a high degree of agreement (Mchugh, 2012).

Then, the researcher analyzed the internal consistency of the questionnaire measuring scale using Cronbach's alpha coefficient. For the questionnaire of 19 items and 64 test projects, a Cronbach's alpha coefficient calculated was 0.918 . Hence, the element of the tool assesses the same characteristics for a project for each lean design management practices. From the high level of internal consistency (reliability) and the high level of agreement between the researchers, it is concluded that the questionnaire is an objective 
and consistent tool for evaluating the levels of lean design management practices in construction projects.

In addition, hypothesis tests were conducted to identify significant differences according to the characteristic of the evaluated projects. Nonparametric hypothesis tests were applied with a significance level of $95 \%$ since the variable of each evaluation of the 19 lean design management practice are ordinal qualitative. The Mann-Whitney U test was used to compare pairs of samples (building and infrastructure projects) and the KruskalWallis test was used to compare three samples (Colombia, Chile and Spain). Concerning the type of project, the p-value is not lower than 0.05 ; therefore, the authors do not have enough information to reject the hypothesis that building, and infrastructure projects have significant differences in their lean design management practices. About the difference by country of project design, when performing the test, it was observed that there are significant differences ( $\mathrm{p}$-value $<0.05$ ) in the lean design management practices SM1 and SM2, which correspond to the early incorporation of specialist designers and builders. This difference was generated specifically between the projects evaluated in Chile and Colombia, where the latter has a better developing in theses lean design management practices. In the other 17 practices, there are no significant differences among countries (pvalue $>0.05)$; therefore, the projects can be compared between them.

Then, in order to verify whether there is a correlation at the performance level between the 19 lean design management practices, the authors build a Spearman correlation matrix (Table 3-9), in which the researchers calculated the Spearman's Rho coefficient and the level of correlation significance between each pair of lean design management practices. In the matrix, it can be observed that the magnitudes of the correlations are moderate (around 
0.5 ); however, $74.85 \%$ of the correlations are significant ( $\mathrm{p}$-value $<0.05$ ). This highlights the connection that exists between the lean design management practices, given that the joint realization of these practices is a contribution to the fulfillment of the principles of lean construction.

Table 3-9: Spearman correlation matrix - lean design management practices

\begin{tabular}{|c|c|c|c|c|c|c|c|c|c|c|c|c|c|c|c|c|c|c|c|}
\hline & SM1 & SM2 & SM3 & SM4 & SM5 & PC1 & PC2 & PC3 & PC4 & PC5 & PC6 & DM1 & DM2 & DM3 & DM4 & DM5 & DM6 & DM7 & DM8 \\
\hline SM1 & 1,000 & & & & & & & & & & & & & & & & & & \\
\hline SM2 & 0,237 & 1,000 & & & & & & & & & & & & & & & & & \\
\hline SM3 &, $502^{*+*}$ & 0,121 & 1,000 & & & & & & & & & & & & & & & & \\
\hline SM4 & 0,208 & 0,175 & ,487 & 1,000 & & & & & & & & & & & & & & & \\
\hline SM5 & $322^{* *+}$ & $346^{* *}$ & , 403** & ,331" & 1,000 & & & & & & & & & & & & & & \\
\hline PC1 & 0,168 & 0,138 & ,488** & ,506" & $349^{* *+}$ & 1,000 & & & & & & & & & & & & & \\
\hline PC2 & 0,083 & 0,108 & ,358** & $274^{*}$ & , 321** & ,349" & 1,000 & & & & & & & & & & & & \\
\hline PC3 & 0,061 & 0,074 & ,393** & 0,233 & ,286" & ,527** & , $575^{* 1}$ & 1,000 & & & & & & & & & & & \\
\hline PC4 & ,339** & 0,231 & ,635* & , 457" & ,592.* & ,547* &, 586 &, $532^{* *}$ & 1,000 & & & & & & & & & & \\
\hline PC5 & $371^{* *}$ & ,289 & ,523** & ,488** & , 431"* & ,420" & ,348"* & ,442" & ,612 & 1,000 & & & & & & & & & \\
\hline PC6 & 0,126 & 0,229 & ,273* & 0,141 & 0,196 & 0,092 & ,296* & 0,213 & , 450" & , $380 "$ & 1,000 & & & & & & & & \\
\hline DM1 & 0,067 & 0,234 & ,340" &, $256^{\star}$ & 334 & , 446" & $477^{* \star *}$ & $366 "$ &, $595^{* \prime \prime}$ & $456 *$ & ,286* & 1,000 & & & & & & & \\
\hline DM2 & 0,115 & 0,223 & ,558** & ,570" & , 355 & ,461" & ,485" &, 594 & ,642"* & $637^{* *}$ & $300^{*}$ & ,588" & 1,000 & & & & & & \\
\hline DM3 & 0,156 & 0,160 & ,375* & $312^{*}$ & $280^{*}$ & , 424* & , 385"* & ,279" &, $488^{* *+}$ &, $561^{*}$ & 0,107 & ,676" &, $525^{4 *}$ & 1,000 & & & & & \\
\hline DM4 & 0,185 &, $283^{\star}$ & , 487 & ,502* &, $567^{* *}$ & , 419** & $365^{* *}$ & ,393* &, $525^{* *}$ & ,633" & 0,207 & , 465" & ,641" & ,642" & 1,000 & & & & \\
\hline DM5 & 0,088 & 324 & ,332** &, 534 & $313^{*}$ & $310^{*}$ & ,260* & 0,190 & 0,210 & , $405^{\prime \prime}$ & 0,208 & , 320" &, $413^{4 *+}$ & $247^{*}$ & , 464" & 1,000 & & & \\
\hline DM6 & 0,017 & $-0,008$ & ,256* & 0,192 & 0,241 & 0,221 & ,683" & , 458" & ,501" & ,396" & , $323^{* *+}$ & , 455" & , $443^{* 4}$ & ,527" & , 375" & 0,028 & 1,000 & & \\
\hline DM7 & 0,072 & ,278 & 0,241 & , $385^{* \prime}$ & 0,197 & 0,210 &, $551^{* 1 *}$ & ,389" & ,288* & 384 & 0,180 &, $315^{*}$ &, $508^{*+1}$ & , 444" & , 495" & ,398" & $421^{* *}$ & 1,000 & \\
\hline DM8 & $264^{*}$ & ,329" & ,524" & , 372" & ,394" & ,552" & ,538" & ,528" & ,631" & ,532" & $260^{\circ}$ & $649^{* *}$ & ,646" & ,679" & ,606" & , 356" & ,435 & , 442" & 1,000 \\
\hline
\end{tabular}

Using the 64 evaluated projects, a descriptive analysis was conducted to determine the distribution of the levels for each lean design management practice (Figure 4). According to this figure, the practices with the highest level of implementation are "requirements management (identification of constraints, technical specifications and special requirements)" and "client systematic participation and support during meetings concerning decision making and resolution of problems"; there are the only practices 
where a higher level than the initial lean design management practices implementation. Additionally, $75 \%$ of the projects are beginning to apply lean with the practices "planning in different levels" and "constrains management visualization", however, even at initial levels. The same happened with the lean design management practices "collaborative solving problems" and "PDCA problem solving". The practices with the lowest level of implementation are "builders in early stages", "decision-making until the last responsible moment", and "multicriteria decision-making", where lean implementation levels are practically non-existent in about $75 \%$ of the evaluated projects. In addition, high ranges of variability can be observed in Figure 4, since in most lean design management practices (15 of 19) there is a two-level difference between the 75 th percentile and the 25 th percentile. This variability reflects that lean design practices are not yet a standard in management at this stage of the project.

Finally, from Figure 3-4 it can also be seen that the practices that contribute most to the development of lean construction principles (Figure 3-3) have normal behavior in the range defined for each of the practices (DM6, SM5, DM8, PC1, PC3), i.e. the minimum value at level 1 , the 25 th percentile at level 2 , the median at level 3 , the 75 th percentile at level 4 , and the maximum value at level 5. Therefore, the variability of lean design management practice assessment is transferred to fulfillment of the lean construction principles. 


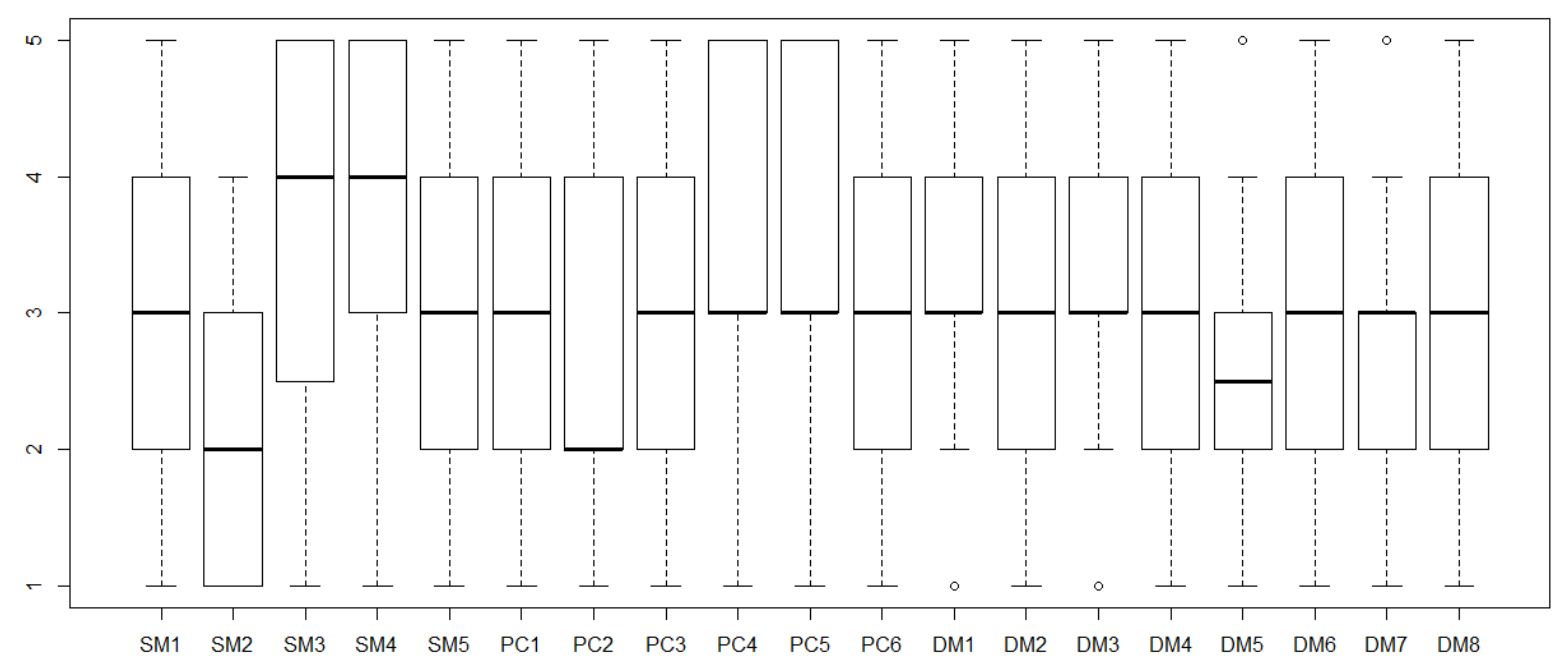

Figure 3-4: Lean design management practices assessment.

\subsection{Conclusions}

In this study, evidence was encountered in the literature about the implementation or potential implementation of at least 19 practices of the lean philosophy in the design process of construction projects. These practices were framed in three main areas: stakeholder management, planning and control, and problem solving and decision making. Each of the 19 practices had a high degree of relation with lean construction principles and revealed a balanced contribution to each of the principles of the lean philosophy; therefore, the defined practices could be regarded as lean practices in the design of construction projects. Some principles were most used during the design phase: increasing the output value through systematic consideration of customer requirements, reducing the amount of nonvalue adding activities, reducing the process variability, reducing the cycle times, increasing the process transparency, and continuously improving processes. On the other hand, the principles that were least used were: increasing the output flexibility, balancing 
the flow improvement with conversion improvement and benchmarking. The practices that contributed to a larger number of principles were: simultaneous design of the product and construction process, use of benchmarking information to make decisions, definition of activities, milestones and control points, and collaborative planning. The practices that contributed to fewer principles were: making of decisions at the last responsible moment, plan-do-check-act (PDCA) problem solving, multicriteria decision making, and benchmarking to obtain information for planning.

Furthermore, this research proposed a tool (questionnaire) to evaluate the degree of implementation of each of the practices at the project level, defining a taxonomy of lean design management practices. The tool consisted of two researchers individually qualifying project practices based on interviews with project managers and then making collaborative decisions. This way, the authors carried out an evaluation of the 19 lean design management practices to 64 construction projects at the design phase where a high variability in the levels of lean implementations could be observed. The most developed practices are: requirement management and active participation of the client; the least developed are: "builders in early stages", "decision-making until the last responsible moment", and "multicriteria decision-making". Therefore, there is a great opportunity to implement these practices in the design process and to continuously improve the implementation of lean design practices that are at the initial levels of development. Construction executives, project managers and designers can benefit from this tool as it helps them to identify the main development gaps in the best practices of design management. Additionally, they can use the data obtained in this study to benchmark their lean design management practice. 
Some limitations of this research are state next. The identified practices were not necessarily the only ones since the practices associated with information technology were not considered, such as the use of BIM or the cloud. The 64 projects evaluated are not a statistical sample, considering the number of projects in the design process in the countries where they were evaluated; hence a larger number of projects should be assessed. Also, the authors did not assess specific tools, such as, last planner system, target value design or others. Additionally, this study proposes a quantitative measure of the level of the lean design management practices in each project based on an interview with the project coordinator; this assessment may have a biased view. Therefore, as future work, it could be interesting to conduct an in-depth study of each project that involves the viewpoint of different actors carrying out a qualitative and quantitative assessment of the project. The qualification of each project has to be done with at least two researchers or specialized consultants to provide higher objectivity of the assessment; therefore, future studies could create a tool that would be used as self-evaluation for each project. In addition, this study did not measure the effect of the application of the lean design management practices on the performance of the 64 projects. Therefore, future research should aim to assess the performance of the design process and the organizational performance of the design team; in this way it will be possible to identify the effect of lean design management practices on the performance of the construction project, both during its design and in its execution. Future research should also consider practices associated with information technology, specifically, the collaborative work in the cloud and the use of BIM, to evaluate a larger number of projects of different types to understand and identify the gaps and opportunities 
for improvement that exist in the design phase of construction projects and understand the impacts of these practices on the performance of projects. 


\section{UNDERSTANDING INTERACTIONS BETWEEN DESIGN TEAM MEMBERS OF CONSTRUCTION PROJECTS USING SOCIAL NETWORK ANALYSIS}

\subsection{Introduction}

The architecture, engineering and construction industry (AEC) is fragmented into several specialties that correspond to the different phases of a project (Dainty et al., 2001; Love et al., 2002). A high degree of fragmentation requires better interaction between the specialties ( $\mathrm{Ng} \& \mathrm{Tang}, 2010)$. The interaction of a work team is generated through communication, coordination and collaboration among the participants (Schöttle, Haghsheno, \& Gehbauer, 2014). This interaction can be represented as the information flow between the right people at the right time (Al Hattab \& Hamzeh, 2015; Bhargav Dave et al., 2014).

Poor interactions in work teams can lead to poor performance, both in the implementation of each phase (design, construction, maintenance, operation and deconstruction) and globally in the life cycle of the project (Baiden et al., 2006). This phenomenon is particularly important at the design phase because decisions made at this phase can significantly affect the following phases, and the cost of making changes at this phase are insignificant compared with the cost of implementing changes in future phases (AIA, 2007).

The client usually chooses a project coordinator or design manager at the design phase of a construction project to lead this phase and manage the interaction between all the specialists, such as architects, structural, electrical and sanitary specialists, and others 
(Knotten et al., 2017; Oluwatayo \& Amole, 2013). Because the AEC industry is fragmented, the level of subcontracting of the specialties has been increasing in recent years (Oviedo-Haito, Jiménez, Cardoso, \& Pellicer, 2014).

More fragmentation requires more interaction, which must be approached by considering the social and technological factors. These factors together allow the information flows to be suitable for the desired interaction. A project team with greater interaction may generate an increase in trust and learning in work teams, achieving high levels of commitment and understanding between the participants (Phelps, 2012). (J. Flores et al., 2014) claim that by improving the interaction of information flows between people, improved project performance can be achieved. An interaction in a work team can be represented as a network of commitments among its members, who establish reliable commitments among themselves, to achieve the objectives of the project (Viana, Formoso, \& Isatto, 2011).

Evaluation of the interactions between members of a work team is challenging. One approach to this issue is to measure teamwork with instruments; (Valentine et al., 2015) present a literature review from 2012 in which 39 instruments are identified for measuring teamwork with surveys. Most of these instruments include dimensions such as communication, coordination and respect. Although the study by (Valentine et al., 2015) includes a large number of instruments that evaluate teamwork, these instruments carry out a general evaluation of an organization and thus do not allow the identification of the frequency and dimension of interaction that is generated between the people within the organization who participated in the surveys. In addition, many of the instruments that 
measure teamwork evaluates it from either an individual or a global perspective, but not both (Paris, Salas, \& Cannon-Bowers, 2000).

A tool for assessing interaction from an individual and a global perspective simultaneously is Social Network Analysis (SNA), which has been used to evaluate the information flow in AEC industry organizations (D. M. Alarcón et al., 2013). SNA uses graph theory to explain the relationships that exist among a group of people based on mathematical metrics, such as the density, length and diameter of the network and other metrics (Marin \& Wellman, 2011).

There are studies evaluating the social networks in the AEC at an organizational or company level (Castillo, Alarcón, \& Pellicer, 2018; Segarra, Herrera, Alarcón, \& Pellicer, 2017) or at the level of a construction project (Castillo, Alarcón, \& Salvatierra, 2018) in which all the participants are from the same workplace. These studies use standard social network metrics for all the dimensions of interactions without providing a specific interpretation for each network. In addition, such metrics are applicable to large organizations, and they are difficult to interpret in small work teams, such as temporary organizations created during the design phases of construction projects. A large organization is defined as one that exceeds the limits of medium-sized companies (250 people) and small companies (49 people) (European Commission, 2003); however, it is difficult to clearly define the size of a network to characterize it. (Richards \& Macindoe, 2010) propose that a small network is one with fewer than 100 members, while a large network has more than 1000 nodes. Therefore, design project teams are small social networks because the number of members is fewer than 50 people. According to a previous report (Segarra et al., 2017), when a network is small, there is a greater possibility of 
sharing important information because the network facilitates interaction among its members.

Previous studies on social networks in the construction industry provide valuable information mostly about large organizations (e.g., (J. Flores et al., 2014)) in construction companies of more than 100 employees. However, there are fewer studies analyzing small groups (fewer than 50 people); there are only preliminary studies of architecture (Segarra et al., 2017) and construction teams (Priven \& Sacks, 2013). In addition, these studies do not include an evaluation of the interaction from the perspective of the commitment network among the members of a team. SNA has been carried out in design teams with participants from different companies using information obtained from BIM log files that are registered in collaborative design software (Zhang \& Ashuri, 2018); however, this methodology can only be used in BIM design environments, and certain informal communicative actions typical of the design process are lost, such as telephone calls and face-to-face conversations.

SNA has not been used to study design project teams in which the full interactions have become more complex (formal and informal) because the team members are from different companies and no collocation obstructs the information flow. Design teams play a very important role because they create design concepts. During the design process, the teams adjust the client's requirements to the project before the planning phase (Oluwatayo \& Amole, 2013). To perform this task, the design offices form multidisciplinary working groups within their own or with other organizations, and these groups are divided into task teams (Sonnenwald, 1996). This project approach has evolved from a tool-oriented understanding of projects, in which it is compared with a production function that 
transforms inputs into outputs through mathematical formulation and planning (Turner \& Müller, 2003), to a consideration of the project as a temporary organization (Sydow \& Braun, 2018). In contrast to the social networks of construction companies, the social networks in design offices are generally small and have greater change dynamics due to the short duration of their production processes (Pryke, 2012).

Considering this knowledge gap, this study proposes a method to understand different dimensions of the interactions in construction project design teams through the analysis of social network metrics and sociograms generated within these types of temporary organizations, in which the members of the design teams are from different companies.

\subsection{Research methodology}

To achieve the objective of this work, the research was divided into three stages: (1) a literature review of the dimensions of interactions evaluated in the AEC industry and different experiences of SNA implementation, (2) a proposal for an interaction network method (measurement and analysis) for construction project design teams, and (3) an evaluation and analysis of a pilot project to exemplify the use of the tool. These stages are displayed in Figure 4-1. 


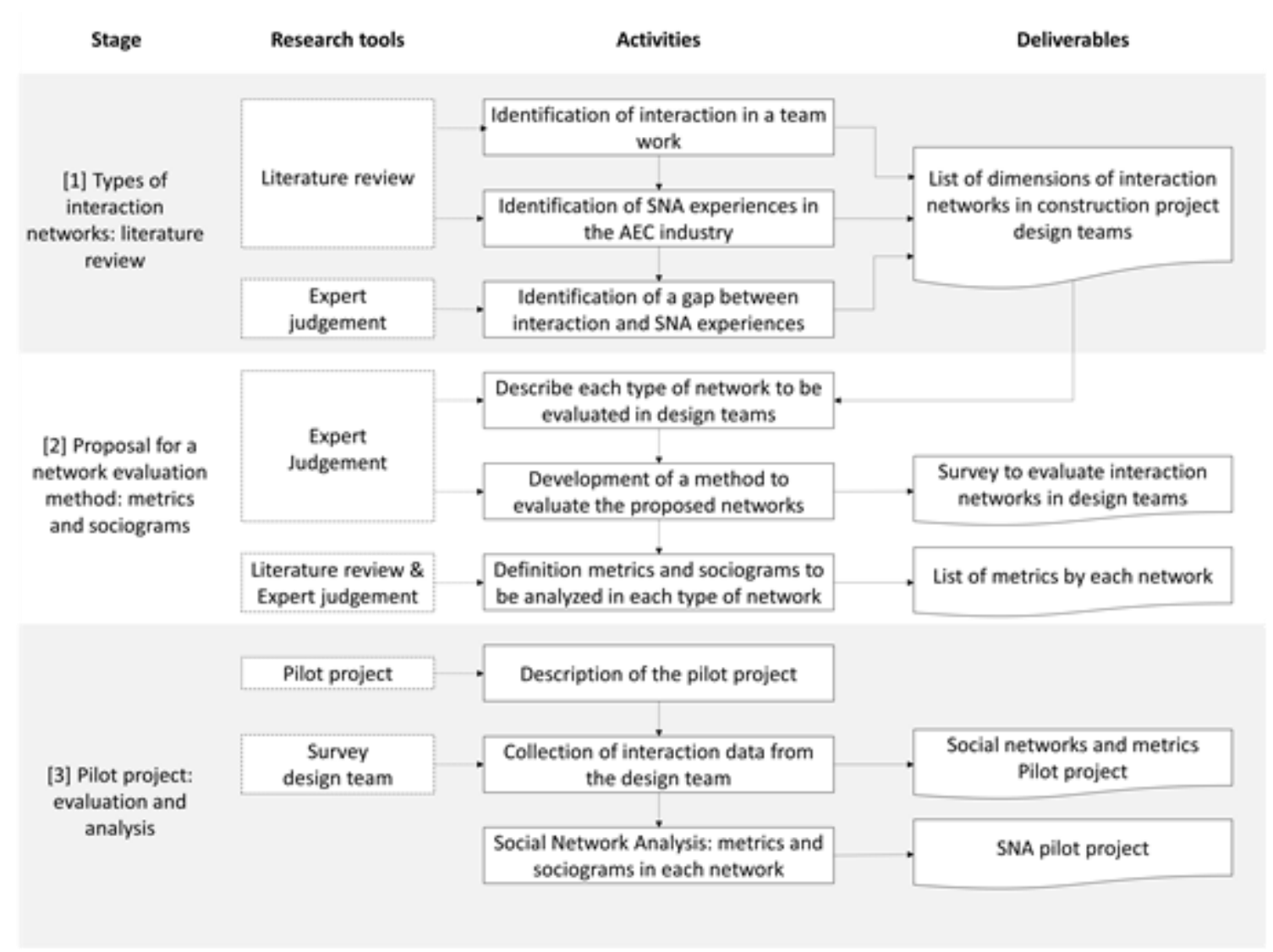

Figure 4-1: Research methodology stages

In the first stage, a literature review of specialized journals in engineering and construction project management and of the proceedings of major conferences held between 2008 and 2019 was carried out. The search was carried out in the following online libraries: Engineering Village, Web of Science and Scopus. The topics sought were interaction, teamwork, team effectiveness, SNA, team integration and team collaboration; all the papers selected were from the AEC industry. This first review aimed to identify the dimensions of teamwork, which can be defined as an interaction between two or more people in a design team. The literature review identified a perspective of the interaction of work teams associated with the commitment network generated among them. Therefore, a 
list of dimensions of interaction was compiled and grouped into two categories: traditional interaction and commitment management. In addition, a review of the literature associated with the use of SNA in the AEC industry was conducted. Some metrics and characteristics of this type of analysis were presented, exemplifying different case studies reported in the literature. Finally, the gap between the dimensions of the interactions associated with an effective team and the use of SNA in the AEC industry was identified.

In the second stage, the authors proposed a method to assess the interaction in a design team of a construction project, using the design team as the unit of analysis. The list of interaction dimensions for this type of project was the input to develop this stage, and the team developed the interaction network method for the design teams of construction projects in four multidisciplinary work sessions that included engineers, architects, builders, consultants and linguists. In the first session, the team described each dimension of interaction that would be evaluated in this type of project and the type of link framed in the SNA. In the second and third sessions, the team created the data collection survey and identified the objective of the instrument, potential survey participants and distribution method. In the fourth session, based on a review of the literature and its experience, the team defined the metrics and sociograms that should be analyzed in each of the networks, as well as the validation criteria. The final deliverable of this stage was the network evaluation method in construction project design teams, which included a description of the interaction dimensions, definitions of each interaction link type, the survey participants, the collection method and the questions for the data collection, data validation, and definitions of the metrics and sociograms to be analyzed for each interaction dimension. 
In the third stage, the proposed SNA method was applied to a pilot project with the objective of exemplifying the use of this method in terms of implementation and analysis. The pilot project was a design team for a residential building project in the city of Santiago, Chile. First, the main characteristics of the pilot project were described, e.g., project type, location, members of the design team and some specific characteristics. Then, the researchers collected interaction data from the design team through an online survey server (the survey created in phase 2 was used). The input data were validated according to the criteria proposed in the coherence analysis. Next, the metrics of each dimension of interaction were calculated, and the sociograms were graphed. Finally, the authors interpreted these metrics and graphs according to the literature review.

\subsection{Literature review of interaction networks}

This section is divided into three parts: the first part explains the different dimensions of interaction that are generated in a work team; the second part describes some experiences of using SNA in the AEC industry and identifies which dimensions of interaction were evaluated and which metrics were used to carry out the analysis; and the third part describes the gaps between the use of SNA in the AEC industry and the dimensions of interactions in a work team with the objective of proposing the application of SNA to other dimensions of interaction and analysis.

\subsubsection{Dimensions of interaction in a work team}

For a work team to be effective, several conditions associated with a compelling direction, an enabling structure, a supportive organizational context and team coaching must be present; teamwork has multiple dimensions that must be evaluated (Valentine et 
al., 2015). Specifically, some key performance elements of construction project design teams are as follows: the encouragement of collaboration, creation of a unique and challenging project, involvement of the team members in planning, commitment to the team, acceleration of the team-building process, commitment of the members to the goal, a sense of purpose, dedication to the time and effort required to form a team, opportunity for the team members to become familiar with each other and the project, increased collaboration in the whole project, identification of the design team member roles and trust between the team members (Svalestuen et al., 2015).

Several authors have reported a set of factors or dimensions that directly impact the effectiveness of a team in the AEC industry, and many of these factors are related to the concept of interaction. This review found that one of the first studies on teamwork in the AEC industry was that of (Baiden et al., 2006), who defined a list of 10 dimensions for an integrated work team. The list was recently updated in the literature with the following inclusion criteria: articles from the last five years; categories for the Web of Science including "multidisciplinary engineering", "civil engineering", "construction or building technology" and "architecture"; development of different dimensions or elements of teamwork and not only the generic concept; and papers in the AEC industry professional context. Educational papers were excluded from this study. Thus, the list was updated to 13 dimensions with the literature review of 17 papers from 2014 to 2019. Table 4-1 presents an updated list of dimensions that affect the integration of a work team. 
Table 4-1: Dimensions that impact a work team - percentage of paper that mentions it

\begin{tabular}{|c|c|c|}
\hline Dimensions & Description & $\%$ \\
\hline $\begin{array}{l}\text { Single team focus and } \\
\text { objectives }\end{array}$ & $\begin{array}{l}\text { All members have the same focus and work } \\
\text { together towards team objectives (Baiden et al., } \\
\text { 2006). }\end{array}$ & $100.00 \%$ \\
\hline $\begin{array}{l}\text { Seamless operation with no } \\
\text { organization defined } \\
\text { boundaries; coordination }\end{array}$ & $\begin{array}{l}\text { Members form a new single project team with no } \\
\text { individual member identity or boundaries, so } \\
\text { there is a high degree of coordination among team } \\
\text { members (Baiden et al., 2006). }\end{array}$ & $70.59 \%$ \\
\hline $\begin{array}{r}\text { Mutually be } \\
\text { outcom }\end{array}$ & $\begin{array}{c}\text { Achievement project goals that benefits all } \\
\text { members (Baiden et al., 2006). }\end{array}$ & $47.06 \%$ \\
\hline $\begin{array}{l}\text { Openly accessible design } \\
\text { and construction } \\
\text { information }\end{array}$ & $\begin{array}{l}\text { Increased time and cost predictability, through a } \\
\text { transparent information policy shared among all } \\
\text { members (Baiden et al., 2006). }\end{array}$ & $52.94 \%$ \\
\hline $\begin{array}{l}\text { Unrestricted cross-sharing } \\
\text { of information }\end{array}$ & $\begin{array}{l}\text { Availability and access to all project information } \\
\text { to all parties involved in the project (Baiden et al., } \\
\text { 2006). }\end{array}$ & $64.71 \%$ \\
\hline $\begin{array}{l}\text { Team flexibility and } \\
\text { responsiveness to change }\end{array}$ & $\begin{array}{l}\text { Require personnel join and leave the project team } \\
\text { as their skills are no longer required or are needed } \\
\text { (Baiden et al., 2006). }\end{array}$ & $17.65 \%$ \\
\hline $\begin{array}{r}\text { Creation of si } \\
\text { located }\end{array}$ & $\begin{array}{l}\text { A single project team with all } \mathrm{r} \\
\text { together in a common office (Ba }\end{array}$ & $47.06 \%$ \\
\hline $\begin{array}{l}\text { Equal opportunity for } \\
\text { project }\end{array}$ & $\begin{array}{l}\text { Consultation of members for contribution at all } \\
\text { phases of project before decisions are made, i.e. } \\
\text { all members collaborate (Baiden et al., 2006). }\end{array}$ & $58.82 \%$ \\
\hline $\begin{array}{c}\text { Equitable team } \\
\text { relationships and respect } \\
\text { for all, trust and team } \\
\text { chemistry }\end{array}$ & $\begin{array}{l}\text { All members are treated as having equal and } \\
\text { significant professional capability needed on the } \\
\text { project (Baiden et al., 2006). }\end{array}$ & $64.71 \%$ \\
\hline No blame culture & $\begin{array}{l}\text { Collective identification and resolution of } \\
\text { problems and collective responsibility for all } \\
\text { project outcomes (Baiden et al., 2006). }\end{array}$ & $58.82 \%$ \\
\hline $\begin{array}{l}\text { Learning among team } \\
\text { members }\end{array}$ & $\begin{array}{l}\text { Team members learn from each other about } \\
\text { technologies, methodologies and ways of working } \\
\text { (Herrera et al., 2018) }\end{array}$ & $41.18 \%$ \\
\hline $\begin{array}{l}\text { Contract models or type of } \\
\text { project delivery }\end{array}$ & $\begin{array}{l}\text { To have a relational type of contracting system, } \\
\text { where collaboration and integration of the project } \\
\text { is promoted from early stages (Svalestuen et al., } \\
\text { 2015) }\end{array}$ & $52.94 \%$ \\
\hline $\begin{array}{l}\text { Identification of the design } \\
\text { team members' roles }\end{array}$ & $\begin{array}{l}\text { All team members should have a clear } \\
\text { understanding of their roles and responsibilities, }\end{array}$ & $29.41 \%$ \\
\hline
\end{tabular}




\begin{tabular}{|c|c|c|}
\hline Dimensions & Description & \% \\
\hline & $\begin{array}{c}\text { and that of other team members (Savolainen et } \\
\text { al., 2018) }\end{array}$ & \\
\hline
\end{tabular}

From these dimensions, the following dimensions of interaction can be deduced: transfer of information, linking of trust, coordination and planning, and collaboration and learning among team members. Undoubtedly, one of the most characteristic elements of an effective team is associated with having and working for a common goal; however, this factor, along with others, is not considered an interaction among team members. Therefore, the researchers considered only the dimensions that can be represented as an interaction between two or more people.

Typically, design teams adopt a goal-oriented approach by prioritizing and sharing only what is necessary; therefore, they exhibit a distributed knowledge system, in which they rely on each person properly knowing his or her role and on the concept that not everyone needs to know everything to succeed in a design project (Kleinsmann, Deken, \& Dong, 2012). The collaborative approach of team members is accompanied by systematic discussion and negotiation (Kleinsmann et al., 2012); thus, a shared understanding among all the team members when they are making agreements is essential (Cash et al., 2017). This shared understanding implies that the interaction of team members must be based on continuous cycles of commitment (Viana et al., 2011).

Commitment cycles are understood as a network of commitments among the people in a team (F. Flores, 2015). The commitments network approach emphasizes what people do while communicating, how the language is used to create a common reality and how activities are coordinated through language (Viana et al., 2011). Basic elements of this perspective are speech acts, which are a set of rules for systematizing commitment 
management (Searle, 1969). According to Medina-Mora et al. (1992), one of the methods to model commitment management is the action workflow. These researchers state that two people are required to establish a commitment (a customer and a performer). The commitment cycle has four phases: (1) request/proposal, (2) negotiate/agreement, (3) declare compliance/performance and (4) declare acceptance/satisfaction (Medina-Mora, Winograd, Flores, \& Flores, 1992). The first phase is the request of a requirement from a customer (internal or external) to someone who will perform the request. The second phase is the negotiation and definition of satisfactory conditions and delivery dates between the customer and the performer. The third phase is the execution of the requirement according to the negotiated conditions and declaration of its completion (Searle, 1969).

Finally, the fourth stage is the assessment, declaration of acceptance and feedback from the customer (Searle, 1969). The structure is defined by the language acts through which people coordinate, not the action performed by individuals to meet the conditions of satisfaction. Therefore, each of these speech acts can be considered specific dimensions of interactions that are interconnected (F. Flores, 2015).

Consequently, from the literature review, dimensions of interaction can be defined from a traditional perspective and from a commitment management perspective. The traditional dimensions of interaction identified were the following: transfer of information, linking of trust, coordination, and collaboration and learning among team members. The dimensions of interaction associated with commitment management are associated with each of the speech acts, i.e., requirements, negotiation, declaration of completion and declaration of acceptance (Long \& Arroyo, 2018). In addition, a basic element for all work teams is that all members know each other's roles and responsibilities. 


\subsubsection{SNA experiences in the AEC industry}

SNA uses sociograms to represent relationships between different people (Hickethier et al., 2013). People are represented by nodes, and the line between them constitutes a connection or edge. Each network can be represented graphically with a sociogram and with mathematical metrics, which can be classified into organizational or network metrics and individual or node metrics (Al Hattab \& Hamzeh, 2015) (Table 4-2).

Table 4-2: SNA Metrics

\begin{tabular}{|c|c|c|}
\hline Type & Metric & Definition \\
\hline \multirow{3}{*}{ Node } & Degree & $\begin{array}{l}\text { How many other nodes a node is connected to (D. M. Alarcón } \\
\text { et al., 2013). }\end{array}$ \\
\hline & Betweenness & $\begin{array}{l}\text { How many pairs of individuals are connected through a node } \\
\text { with the least number of steps: brokerage role (Hickethier et } \\
\text { al., 2013). }\end{array}$ \\
\hline & Closeness & $\begin{array}{l}\text { How close a node is to other nodes: depends on the shortest } \\
\text { average length (Al Hattab \& Hamzeh, 2015). }\end{array}$ \\
\hline \multirow{6}{*}{ Network } & Density & $\begin{array}{l}\text { How many actual links exist between nodes divided by the } \\
\text { number of total possible links in the network Alarcon } 2013\end{array}$ \\
\hline & Mean Degree & $\begin{array}{l}\text { How many other nodes a node is connected to, on average (D. } \\
\text { M. Alarcón et al., 2013) }\end{array}$ \\
\hline & Clustering & $\begin{array}{l}\text { How clustered groups of people are compared to the rest of } \\
\text { the network, the existence of closed triads and small } \\
\text { communities (Hickethier et al., 2013). }\end{array}$ \\
\hline & $\begin{array}{l}\text { Average path } \\
\text { length }\end{array}$ & $\begin{array}{l}\text { How many steps, on average, nodes require to reach each } \\
\text { other (Al Hattab \& Hamzeh, 2015). }\end{array}$ \\
\hline & Diameter & $\begin{array}{l}\text { How many steps, nodes require to reach each other } \\
\text { (maximum) (Al Hattab \& Hamzeh, 2015). }\end{array}$ \\
\hline & Modularity & $\begin{array}{l}\text { How dense are the connections between nodes within groups } \\
\text { compared to nodes with another group (Hickethier et al., } \\
\text { 2013). }\end{array}$ \\
\hline
\end{tabular}

Another interesting indicator to assess project teams is the number of connected components. Components are sets of nodes that are linked to one another through 
continuous chains of connections; a connected network simply comprises a single component (Scott, 2017). The members of a component can communicate with one another, either directly or through chains of intermediaries. On the other hand, isolated nodes have no such opportunities; the number of connected components can be taken as an indication of the opportunities and obstacles to communication or the transfer of resources in the associated network (Scott, 2017).

Social networks can be characterized as directed or undirected links. Undirected links occur when two people have a bidirectional interaction obligation; in contrast, directed links imply that the interaction flows from person A to person B. Therefore, directed links can be unidirectional or bidirectional (Hoppe \& Reinelt, 2010) depending on the dimension of interaction being analyzed. Except for their degree, the metrics presented in Table 4-2 do not change based on whether the links are directed or undirected. In directed networks, there is a degree of input or indegree (number of connections reaching the node) and a degree of output or outdegree (number of connections leaving the node); the metric degree is obtained as the sum of both (Scott, 2017). In addition, connected components can be searched for in both undirected and directed graphs. However, there are important differences between the two situations (Marin \& Wellman, 2011).

In the case of directed graphs, two distinct types of components can be identified: strong components and weak components. A strong component is one in which the lines that make up the paths are aligned in a continuous chain without any change of direction; thus, it represents a set of agents among which such resources can easily and freely flow (Scott, 2017). On the other hand, in a weak component, it can be assumed that the mere presence of a relationship, regardless of its direction, allows some possibility for 
communication; thus, weakly connected components represent semi paths in the network (Scott, 2017). In the case of undirected graphs, because no directions are attached to the lines, all paths constitute acceptable connections (Scott, 2017).

The relevant characteristics to carry out an SNA are the following: type of organization, dimension of interaction and metrics. Table 4-3 exemplifies each of these characteristics from prior research that used SNA in AEC organizations. All these studies present case studies in which an SNA was carried out, with the exception of the work of (Al Hattab \& Hamzeh, 2015), who present a theoretical analysis of an organization. In all the case studies presented in Table 4-3, data capture is carried out through surveys (paper or online) conducted on the participants of the analysis (J. Flores et al., 2014; Herrera et al., 2018); therefore, it must be assumed that there may be some subjectivity in the input data of the SNA.

Table 4-3: SNA experiences in the AEC industry

\begin{tabular}{|c|c|c|c|}
\hline Source & $\begin{array}{c}\text { Type of } \\
\text { organization }\end{array}$ & Types of interactions & Metrics \\
\hline $\begin{array}{c}\text { (Hickethier et } \\
\text { al., 2013) }\end{array}$ & $\begin{array}{l}\text { Design team } \\
\text { (complex } \\
\text { project) }\end{array}$ & Information flow & $\begin{array}{l}\text { Clustering; } \\
\text { centrality }\end{array}$ \\
\hline $\begin{array}{c}\text { (D. M. Alarcón } \\
\text { et al., 2013) }\end{array}$ & $\begin{array}{c}\text { Mining } \\
\text { companies }\end{array}$ & $\begin{array}{c}\text { Interaction; information flow; } \\
\text { problem solving; planning; } \\
\text { trust }\end{array}$ & $\begin{array}{c}\text { Mean degree; } \\
\text { diameter; density; } \\
\text { average path length }\end{array}$ \\
\hline $\begin{array}{c}\text { (Priven \& } \\
\text { Sacks, 2013) }\end{array}$ & $\begin{array}{l}\text { Construction } \\
\text { complex } \\
\text { projects } \\
\end{array}$ & Information flow; trust & Density \\
\hline $\begin{array}{c}\text { (J. Flores et al., } \\
\text { 2014) }\end{array}$ & $\begin{array}{c}\text { Construction } \\
\text { Companies }\end{array}$ & $\begin{array}{l}\text { Interaction; information flow; } \\
\text { problem solving; planning; } \\
\text { innovation; trust }\end{array}$ & $\begin{array}{c}\text { Mean degree; } \\
\text { diameter; density; } \\
\text { average path length }\end{array}$ \\
\hline $\begin{array}{c}\text { (Al Hattab \& } \\
\text { Hamzeh, 2015) }\end{array}$ & Design teams & Interaction; information flow & $\begin{array}{l}\text { Density; average } \\
\text { path length; } \\
\text { modularity; }\end{array}$ \\
\hline
\end{tabular}




\begin{tabular}{|c|c|c|c|}
\hline Source & $\begin{array}{c}\text { Type of } \\
\text { organization }\end{array}$ & Types of interactions & Metrics \\
\hline $\begin{array}{c}\text { (Segarra et al., } \\
\text { 2017) }\end{array}$ & $\begin{array}{c}\text { Architecture } \\
\text { offices }\end{array}$ & $\begin{array}{c}\text { Interaction; information flow; } \\
\text { innovation }\end{array}$ & $\begin{array}{c}\text { Mean degree; } \\
\text { density; average } \\
\text { path length }\end{array}$ \\
\hline $\begin{array}{c}\text { (Schröpfer, } \\
\text { Tah, Kurul, } \\
\text { 2017) }\end{array}$ & $\begin{array}{c}\text { Construction } \\
\text { complex } \\
\text { projects }\end{array}$ & Knowledge transfer & $\begin{array}{c}\text { Density, degree, } \\
\text { betweenness }\end{array}$ \\
\hline $\begin{array}{c}\text { (Herrera et al., } \\
2018)\end{array}$ & $\begin{array}{c}\text { Designs team } \\
\text { (complex } \\
\text { projects) }\end{array}$ & $\begin{array}{c}\text { Interaction; information flow; } \\
\text { planning; learning; trust }\end{array}$ & Density \\
\hline $\begin{array}{c}\text { Alarcón, \& } \\
\text { Salvatierra, } \\
2018)\end{array}$ & $\begin{array}{c}\text { Ponstruction } \\
\text { companies }\end{array}$ & $\begin{array}{c}\text { innovation development, } \\
\text { interaction, relevant } \\
\text { information exchange, } \\
\text { planning and problem solving }\end{array}$ & $\begin{array}{c}\text { Diameter, density, } \\
\text { average path length, } \\
\text { and average degree }\end{array}$ \\
\hline
\end{tabular}

From the examples presented in the AEC industry (Table 4-3), the networks most frequently measured are those of interaction and information flow, and the metrics most analyzed are those linked to the organization (density, diameter, average path length) and not to the people (degree, centrality, betweenness). In addition, the analyses are performed on companies (D. M. Alarcón et al., 2013; J. Flores et al., 2014; Segarra et al., 2017) or complex projects (Hickethier et al., 2013; Priven \& Sacks, 2013; Schröpfer et al., 2017), where the number of participants is high (50 people or more). Furthermore, in these studies, it is not specified whether the links of the networks are directed or undirected, with the exception of (Al Hattab \& Hamzeh, 2015), who clarify that the interaction has undirected links. In addition, none of these studies include a study carried out on the number of connected components. 


\subsubsection{Gaps in SNA in the AEC industry}

Two perspectives are identified within the dimensions of interaction: traditional interaction and commitment management. According to the experiences found regarding the use of SNA in the AEC industry, there is evidence of evaluations of dimensions of traditional interaction in this industry, for example, interaction, information flow, problem solving, planning, innovation, trust and learning. However, interactions such as knowledge of roles and collaboration are not explicitly included because these elements have been broadly studied as key elements in the effectiveness of a work team (Baiden et al., 2006; Savolainen et al., 2018; Svalestuen et al., 2015). In addition, (Kereri \& Harper, 2019) recently proposed to use SNA for the evaluation of collaboration in construction project teams. Furthermore, based on similar experiences in the AEC industry, there is no evidence of interaction assessments associated with the perspective of commitment management, although this element is key to a shared understanding in multidisciplinary teams in which discussion and negotiation are common (Kleinsmann et al., 2012).

For each dimension of interaction, an analysis of the social network can be performed; therefore, for each interaction, the links must be defined as directed or undirected, according to the nature of the interaction (Hoppe \& Reinelt, 2010). According to the SNA experiences in the AEC industry, this definition is not explicit; however, it is fundamental to the analysis of metrics and input data filtering because some metric calculations are affected depending on the characteristics of the link (Scott, 2017).

Because data capture is conducted through a survey of project team members, there will always be some amount of subjectivity of the input data; therefore, an analysis of the coherence of the input data must be performed before the SNA (Cisterna, 2017). This 
coherence analysis can be performed in undirected networks in which, theoretically, there is a correspondence between the responses of the people involved, so that if person A wishes to interact with person B, then person B must indicate the same (Cisterna, 2017).

Although there are metrics for SNA that have mathematical interpretations, a practical interpretation should be provided for the construction project design teams (less than 50 people) (Castillo, Alarcón, \& Pellicer, 2018). In addition, new metrics should be proposed for the dimensions of interaction associated with commitment management because these networks interact with each other as part of a cycle, even though there are no SNA metrics linking two or more networks. The definition of the link types (directed or undirected), the coherence analysis to validate the input data and the definition of new dimensions of interaction, and their metrics and interpretation must be included in the existing SNA methodology (e.g., (D. M. Alarcón et al., 2013; J. Flores et al., 2014)).

\subsection{Proposal for a network evaluation method: metrics and sociograms}

The objective of this evaluation method is to capture data from different dimensions of interaction in construction project design teams. To develop the method, the following steps were followed: (1) definition of the interaction dimensions and description and definition of the link type for each interaction, (2) definition of the participants involved in the data capture and the data capture method, (3) definition of the questions (and type of answer) to capture information for each interaction, (4) definition and analysis of the metrics and sociograms for each dimension of interaction and validation data criteria and (5) data collection and analysis.

Based on the literature review, the dimensions of interaction to be assessed were defined. Table 4-4 and Table 4-5 present the description for each dimension of interaction 
and the type of link associated with each from the perspective of traditional interaction and commitment management, respectively. The description of each dimension of interaction and the type of link (directed or undirected) was determined by a multidisciplinary team of professionals. This team included engineers, builders, researchers, architects and linguists; all with experience in SNA and teamwork assessment in the AEC industry.

Table 4-4: Descriptions of types of interactions - traditional

\begin{tabular}{|c|c|c|c|}
\hline $\begin{array}{c}\text { Type of } \\
\text { interaction }\end{array}$ & Description & $\begin{array}{l}\text { Type of } \\
\text { link }\end{array}$ & Source \\
\hline $\begin{array}{l}\text { Knowledge of } \\
\text { roles and } \\
\text { responsibilities }\end{array}$ & $\begin{array}{l}\text { When person A knows the role and } \\
\text { responsibility of person B, a one-way } \\
\text { link is created between the two people. } \\
\text { This network is fundamental, since if } \\
\text { the link does not exist, it is difficult to } \\
\text { make another type of interaction. }\end{array}$ & Directed & Proposal \\
\hline Global interaction & $\begin{array}{c}\text { Refers to any type of interaction } \\
\text { between two people, these include } \\
\text { telephone conversations, mail } \\
\text { exchanges, conversations or business } \\
\text { meetings. }\end{array}$ & Undirected & $\begin{array}{l}\text { (D. M. } \\
\text { Alarcón et al., } \\
\text { 2013) }\end{array}$ \\
\hline $\begin{array}{l}\text { Relevant work } \\
\text { information }\end{array}$ & $\begin{array}{l}\text { Relevant work information is that flow } \\
\text { where person A sends necessary } \\
\text { information to person B that adds value } \\
\text { to the project but is not openly } \\
\text { available. }\end{array}$ & Directed & $\begin{array}{l}\text { (Castillo, } \\
\text { Alarcón, \& } \\
\text { Salvatierra, } \\
\text { 2018) }\end{array}$ \\
\hline Collaboration & $\begin{array}{l}\text { Collaboration refers to the act of joint } \\
\text { work between two or more people. It is } \\
\text { considered that working together } \\
\text { implies working with another person on } \\
\text { the same task and at the same time, } \\
\text { either in person or virtually. }\end{array}$ & Undirected & Proposal \\
\hline $\begin{array}{l}\text { Planning and } \\
\text { problem solving }\end{array}$ & $\begin{array}{l}\text { Collaborative planning and problem } \\
\text { solving refer to the joint act of two or } \\
\text { more people to define and redefine } \\
\text { tasks, schedules, resources, costs, risks, } \\
\text { etc. }\end{array}$ & Undirected & $\begin{array}{c}\text { (Castillo, } \\
\text { Alarcón, \& } \\
\text { Salvatierra, } \\
\text { 2018) }\end{array}$ \\
\hline Trust & $\begin{array}{l}\text { When a person } A \text { trusts the work of a } \\
\text { person } \mathrm{B} \text {, a one-way bond of trust }\end{array}$ & Directed & $\begin{array}{c}\text { (Priven \& } \\
\text { Sacks, 2013) }\end{array}$ \\
\hline
\end{tabular}




\begin{tabular}{|c|c|c|c|}
\hline $\begin{array}{c}\text { Type of } \\
\text { interaction }\end{array}$ & Description & $\begin{array}{c}\text { Type of } \\
\text { link }\end{array}$ & Source \\
\hline & between A-B is created. & & \\
\hline Learning & $\begin{array}{c}\text { When a person A learns something new } \\
\text { from a person B, a learning link } \\
\text { between A-B is created. What is } \\
\text { learned can be something technical } \\
\text { related to knowledge, some skill or } \\
\text { competence, or even an attitude at } \\
\text { work. }\end{array}$ & Undirected & $\begin{array}{c}\text { (Herrera et al., } \\
\text { 2018) }\end{array}$ \\
\hline
\end{tabular}

Table 4-5: Descriptions of types of interactions - commitment management

\begin{tabular}{|l|l|l|l|}
\hline $\begin{array}{l}\text { Type of } \\
\text { interaction }\end{array}$ & Description & $\begin{array}{l}\text { Type of } \\
\text { link }\end{array}$ & Source \\
\hline $\begin{array}{l}\text { Request for } \\
\text { requirement }\end{array}$ & $\begin{array}{l}\text { The speaker (customer) is asking a potential } \\
\text { performer for action around a requirement. }\end{array}$ & Directed & $\begin{array}{l}\text { (Long \& } \\
\text { Arroyo, } \\
\text { 2018) }\end{array}$ \\
\hline $\begin{array}{l}\text { Requirement } \\
\text { negotiation }\end{array}$ & $\begin{array}{l}\text { The customer and the performer clarify the } \\
\text { requirement and define conditions of } \\
\text { satisfaction, based on time cost and } \\
\text { performance. }\end{array}$ & Undirected & $\begin{array}{l}\text { (Viana et } \\
\text { al., 2011) }\end{array}$ \\
\hline $\begin{array}{l}\text { Declaration of } \\
\text { compliance }\end{array}$ & $\begin{array}{l}\text { The performer reports facts and is prepared } \\
\text { to offer evidence about the compliance of } \\
\text { the requirement. }\end{array}$ & Directed & $\begin{array}{l}\text { (Long \& } \\
\text { Arroyo, } \\
\text { 2018) }\end{array}$ \\
\hline $\begin{array}{l}\text { Declaration of } \\
\text { satisfaction }\end{array}$ & $\begin{array}{l}\text { The customer reports a level of satisfaction } \\
\text { and feedback about the compliance of the } \\
\text { requirement. }\end{array}$ & Directed & $\begin{array}{l}\text { (Long \& } \\
\text { Arroyo, } \\
\text { 2018) }\end{array}$ \\
\hline
\end{tabular}

The people involved in the analysis are all those involved in the design phase, which may vary depending on the nature of the project. The roles that may be stakeholders are the project manager, architect, structural engineer, client, client representative, geotechnical engineer, MEP engineer, BIM manager, planning engineer, general contractor and others (Al Hattab \& Hamzeh, 2015). The interaction data capture tool is a survey that must be answered by those involved in the design phase. Because these stakeholders typically do 
not work in the same place, it is easier to use an online survey server. It is recommended to have a meeting with the project manager to discuss the scope and benefits of the analysis and to list the participants and their roles before sending the survey to all the participants.

The data capture survey has a question for each dimension of interaction. For each question, the respondents are asked to identify the other people and the dimension of interaction they had in a defined period of time; this time depends on the context of the project being assessed and the purpose of the assessment, e.g., if a design team wants to evaluate only the detailed design phase, then the period of time should correspond to the duration of this phase of the project. In this case, the researchers used "the last twelve weeks", based on previous experiences (Segarra et al., 2017). In addition, examples are provided to ensure the question is understood. There are three types of answer for each question: yes/no per person, number of times per person and frequency per person. Table 4-6 shows the answers associated with each type of network.

Table 4-6: Types of response for each type of interaction

\begin{tabular}{|l|l|}
\hline Type of interaction & Response \\
\hline $\begin{array}{l}\text { Knowledge of roles and responsibilities } \\
\text { Global Interaction } \\
\begin{array}{l}\text { Trust } \\
\text { Learning }\end{array}\end{array}$ & Yes/No \\
\hline $\begin{array}{l}\text { Relevant work information } \\
\text { Collaboration }\end{array}$ & $\begin{array}{l}\text { Always (1 or more times per day) / Often (1 to } \\
\text { Planning and problem solving } \\
\text { per month) / Never (less than } 1 \text { time per } \\
\text { month) }\end{array}$ \\
\hline Request for requirement & Yes/No \\
\hline $\begin{array}{l}\text { Requirement negotiation } \\
\text { Declaration of compliance } \\
\text { Declaration of satisfaction }\end{array}$ & $\begin{array}{l}\text { Always (over } 80 \% \text { of the time) / Often }(60 \% \text { to } \\
80 \% \text { of the time) / Sometimes (20\% to } 60 \% \text { of } \\
\text { the time) / Never (less } 20 \% \text { of the time) }\end{array}$ \\
\hline
\end{tabular}


After capturing the data, it is necessary to validate their reliability. Therefore, a coherence analysis is carried out on the undirected network "global interaction". Coherence analysis in undirected networks differentiates between valid and invalid interactions: if person $\mathrm{A}$ wishes to interact with person $\mathrm{B}$, and person $\mathrm{B}$ wishes to interact with person $\mathrm{A}$, then the interaction is valid; if person $\mathrm{A}$ wishes to interact with person $\mathrm{B}$, and person $\mathrm{B}$ does not wish to interact with person $\mathrm{A}$, then the interaction is invalid. Therefore, it is possible to calculate a percentage of valid connections (PVC) as the proportion between the valid connections and the total connections (valid and invalid). It is recommended to define a sufficiency condition or limit for this percentage, which ensures that the input data are reliable and thus allows the SNA to continue (PVC must be defined by the assessment team). The PVC has been obtained in other studies, and these values varied between $50 \%$ and $90 \%$ (Cisterna, 2017); however, there are no studies that provide information on the definition of the PVC limit. In this case, the researchers used a pragmatic vision based on general rules such as the concept of Pareto, which considers $80 \%$ predominant to explain a phenomenon (Craft \& Leake, 2002), or such a typical confidence level value $(80 \%)$ used in risk analysis of the construction industry (L. F. Alarcón, Ashley, Sucre de Hanily, Molenaar, \& Ungo, 2011). Therefore, the team defined a limit percentage of $80 \%$ of valid connections for the data to be reliable; if the percentage was less than this condition, it may have meant that the question was understood differently by the different survey participants.

If the validation of input data has a positive result, then the networks are represented through an adjacency matrix. This matrix represents the link between pairs of people through a weight; the weight depends on the type of response. Ones and zeros correspond 
to responses of yes and no, respectively, and for answers of frequency, "never" is scored with a zero, and the different levels are classified either in an ascending scale $(1,2,3)$ or with the value of 1 for all responses other than "never". In directed networks, it does not matter whether the links are unidirectional or bidirectional, but in undirected networks, there must be a unique link between person $\mathrm{A}$ and person $\mathrm{B}$. Therefore, it is necessary to make a prior filter eliminating all the invalid interactions. Then, the adjacency matrix must be loaded on to software that allows SNA, which provides metrics and sociograms for each dimension of interaction.

The sociogram analysis makes it possible to visually identify people or groups of people who are disconnected or isolated, central people and people who serve as brokers or bridges. It is interesting to analyze the changes generated in pairs or groups of networks: knowledge of roles-global interaction, global interaction-work information, collaborationplanning, trust-learning and all commitment management networks. To perform metrics analysis, it is not necessary to analyze all the social network metrics in each type of network; thus, depending on the network, the metrics to be analyzed are selected. Furthermore, in some cases, it is interesting to analyze metrics with data from different networks. Table 4-7 presents the list of metrics for each network. In the next section, an interpretation of each metric is performed using a pilot project.

Table 4-7: Proposed metric for each network

\begin{tabular}{|c|c|}
\hline Type of network & Metrics \\
\hline $\begin{array}{c}\text { Knowledge of roles } \\
\text { and responsibilities }\end{array}$ & In-degree of each node; Mean in-degree of the network \\
\hline Global interaction & $\begin{array}{r}\text { Degree of each node; Mean and range degree of the network; } \\
\text { Network density; \# connected components }\end{array}$ \\
\hline
\end{tabular}




\begin{tabular}{|c|c|}
\hline $\begin{array}{c}\text { Type of network } \\
\text { Relevant work } \\
\text { information }\end{array}$ & $\begin{array}{c}\text { Percentage of bidirectional links; In-degree and out-degree of } \\
\text { each node; Mean and range degree of the network; Network } \\
\text { density; \# weakly and \# strongly connected components }\end{array}$ \\
\hline \begin{tabular}{c|c|} 
Learning \\
Collaboration \\
solving
\end{tabular} & $\begin{array}{c}\text { Percentage of bidirectional links; Degree of each node; Mean and } \\
\text { range degree of the network; Network density; \# connected } \\
\text { components }\end{array}$ \\
\hline $\begin{array}{c}\text { Pranning and problem } \\
\text { Request for } \\
\text { requirement }\end{array}$ & \# links trust network / \# links knowledge of roles network \\
\hline $\begin{array}{c}\text { Requirement } \\
\text { negotiation }\end{array}$ & In-degree and out-degree of each node and the sum \\
\hline $\begin{array}{c}\text { Declaration of } \\
\text { compliance }\end{array}$ & Compliance declaration links / requirements links \\
\hline $\begin{array}{c}\text { Declaration of } \\
\text { satisfaction }\end{array}$ & Satisfaction declaration links / requirements links \\
\hline
\end{tabular}

To apply the proposed method, the activities outlined in Figure 4-2 should be carried out. For the creation of the survey, it is first necessary to establish the initial conditions, such as (1) the definition of the interaction time period (e.g., the 12 weeks used in this pilot project); (2) definition of the data collection method, which, for no collocated teams, is usually an online survey server or an in-person survey; (3) definition of the study participants (client, architect, specialist engineers, project manager, etc.); (4) definition of the limit for the PVC for validation of the reliability of the answers obtained; and (5) selection of the software to carry out the SNA (there are several free software packages such as Gephi and iGraph). Second, the survey should be created considering all the previous information, the descriptions of the interaction dimensions (Table 4-4 and Table 4-5) and the questions and answers for the evaluation (Table 4-6). Third, the survey should be sent to the defined participants and the data collected; for small teams, it is recommended that $100 \%$ of the defined participants respond. Then, with the information collected, the data are processed using the selected software, according to the type of link 
of each interaction dimension, directed or undirected (information available in Table 4-4 and Table 4-5). Then, the metrics are calculated according to the definitions in Table 4-7, and the PVC limit criterion is reviewed to determine whether the analysis can continue. If the PVC criterion is satisfied, then the sociograms are created and the analysis proceeds. Finally, the analysis consists of two parts: an analysis of the metrics and sociograms according to the project context, which can be done between the assessor and project manager, and a comparative analysis with other experiences in the AEC industry reported in the literature (Table 4-3).

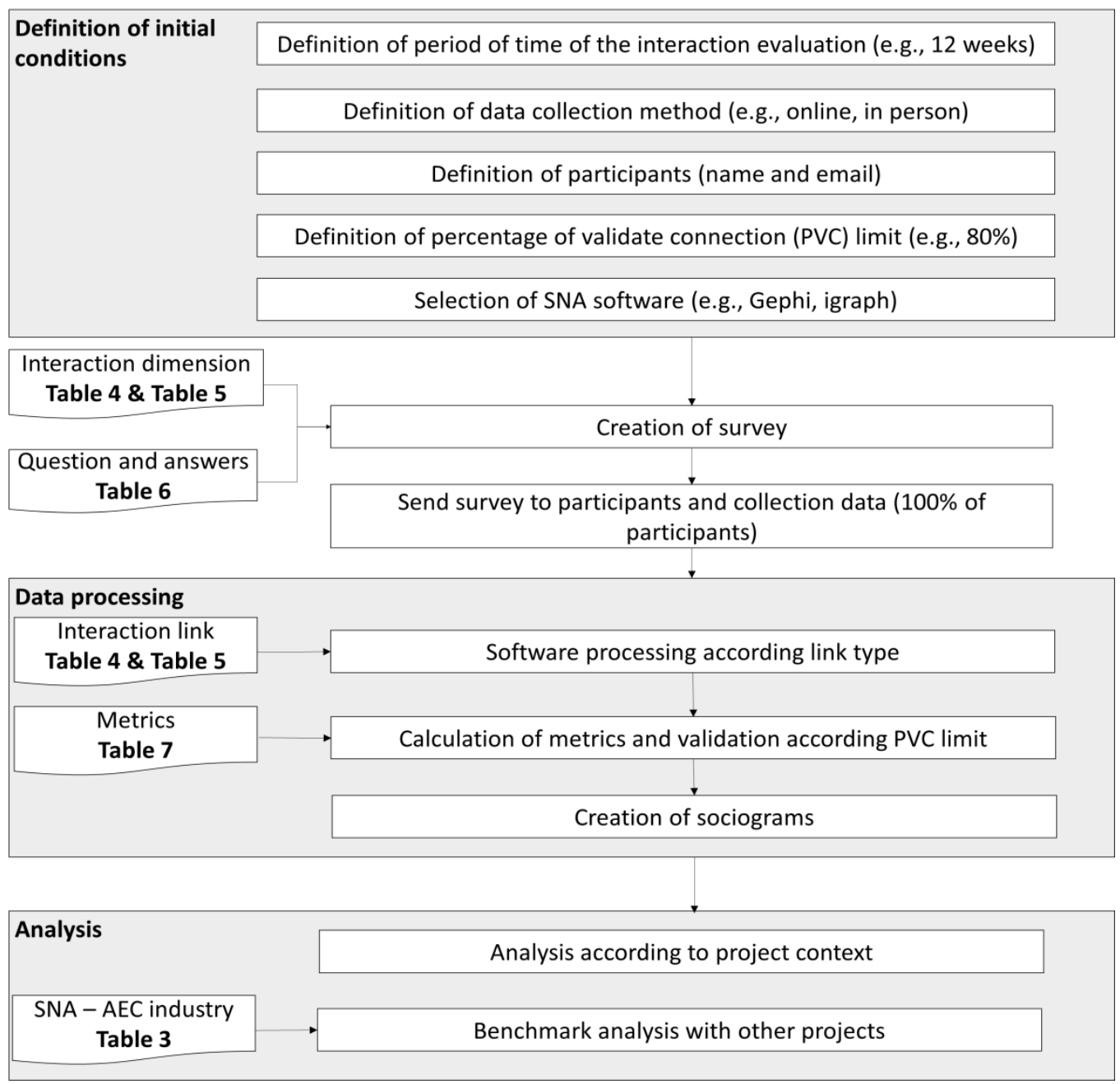

Figure 4-2: Proposed method for understanding interaction in design teams 


\subsection{Pilot project: evaluation and analysis}

A pilot project was used to exemplify the use of the tool. The pilot project involved the design team of a project to build a $28,500 \mathrm{~m}^{2}$ residential building consisting of 22 floors and two sublevels, located in the city of Santiago, Chile. This project had two important characteristics: (1) the client was the same company as the builder, which led to the expectation of a global vision for the project in its design and construction phases; and (2) all the specialties of the design phase were contracted to different companies, which was the opposite of a collocated situation.

During the design, 12 people participated in the following roles: project manager (PM), client representative (CR), architect (A), geotechnical engineer (GE), structural designer (SD), structural reviewer (SR), electrical specialist (E), plumbing specialist (P), gas specialist (G), pool designer (PD), irrigation designer (ID) and landscape designer (LD). The PM and CR were part of the client's company, and the rest of the personnel were from different companies, so much of the interaction was through emails and phone calls. In this project, only the architecture office worked on a BIM platform and the specialties in a traditional way (2D drawing and specialized analysis software) (Rojas et al., 2019), so it was not possible to capture the interaction data that were logged in the BIM environments. All the stakeholders answered the online survey to provide data about the team interaction. The analysis of the consistency of the responses of the global interaction network gave a percentage of valid interaction of $85.71 \%$; thus, the input data were reliable for performing the SNA, according to the $80 \%$ limit proposed by the research team.

Currently, there are no studies that define the ideal range for the metrics; however, a comparative analysis was performed using the values obtained from projects of similar size 
(number of participants). Because a project is a temporary organization in which all the participants have the common objective of carrying out the design, it is expected that all the participants know their roles, and the mean degree must be close to the number of participants minus one. In the pilot project, the average grade was 4.33 , i.e., one person knew the role of approximately four other people. Figure 4-3 (left) shows the role knowledge network, in which the size of the nodes is proportional to the level of knowledge of the entire organization toward that node (indegree). Therefore, in this organization, the knowledge toward the project manager was at the first level, with the area of architecture and structures at the second level and other design specialties at the third level. In a small team such as the one in this project, one would expect all the specialists to know the roles and responsibilities of the others (Svalestuen et al., 2015). However, on average in this project, each person knew the role of only one-third of the team.

In the global interaction network (Figure 4-3 center), all the nonreciprocal connections first needed to be eliminated because it was an undirected network. The density of this network was 0.273 with a mean degree of 3 , i.e., an average person connected with three others. However, there was also a high variability (range equal to 9). Thus, the lowest degree was 1 , and the highest degree was 10 . This density value was low compared to the value obtained in the airport design teams in which the density of the interaction network was approximately 0.5 (Herrera et al., 2018). This phenomenon may have been due to the context of the typology of the project, e.g., in architecture offices the density varies between 0.4 and 0.5 in teams of this size (Segarra et al., 2017), or in construction teams on the worksite, the density varies between 0.4 and 0.7 (Priven \& Sacks, 2013). The project manager is the node with the highest number of connections, and from this node there is a 
connected group (number of connected components equal to 1). In this work, the project manager was an important node of articulation, because if it was taken out of the network, then the number of connected components increased to five, leading to a team with two or more subgroups (in this case five), in which the interaction between the specialists and other team members might be difficult. Note that in this case, the global interaction network is a subnetwork of the role knowledge network, i.e., for people who can interact, first the roles of each of the team participants must be presented and defined. Therefore, the kick-off meetings are essential to initiate the expected interaction between the different professionals (Koo, Park, Yi, \& Kwon, 2013), and they should be utilized in all project teams.
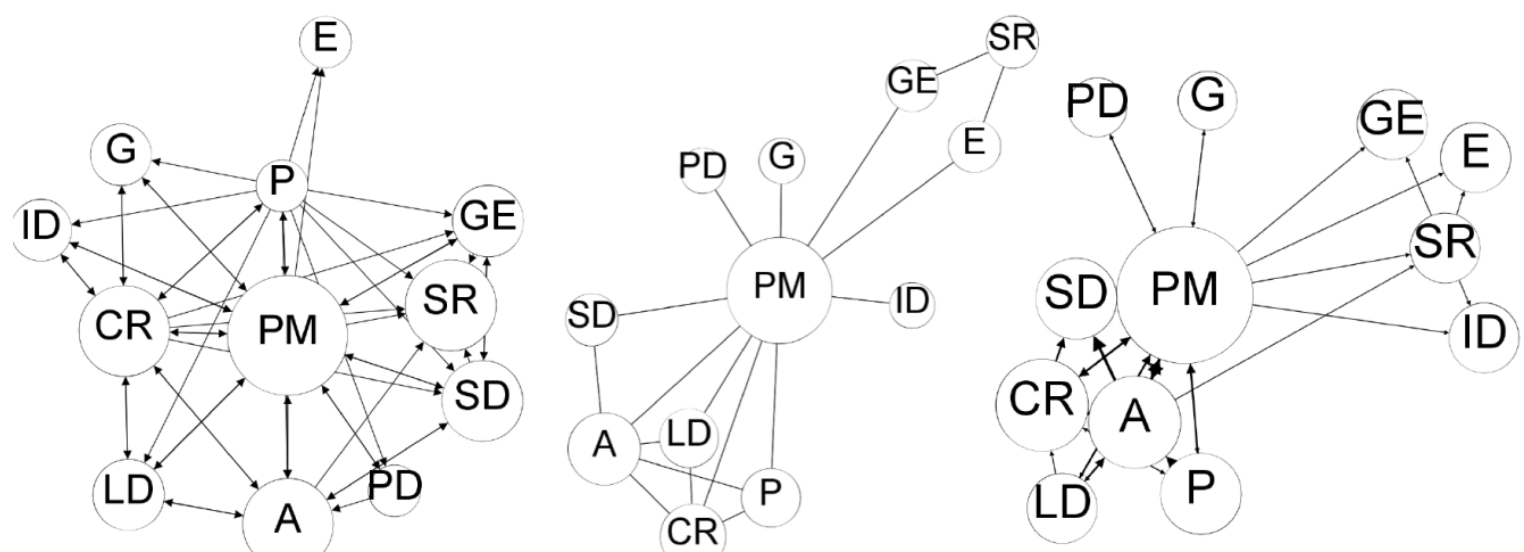

Figure 4-3: Knowledge of roles network (left)/ Global interaction network (middle)/ Relevant work information (right)

Figure 4-3 (right) shows the relevant work information network in the pilot project, and the thickness of the arrow represents the frequency of the information flow, i.e., the network. A thicker arrow shows a higher frequency of information. The reciprocal connections, which constituted $67.65 \%$ of the information network, included the 
participation of the client's representative, the project manager, the architect, the structural designer and a few specialist designers. The density was 0.258 , which was low compared to the value obtained in airport design teams in which the density of the interaction network was approximately 0.4 (Herrera et al., 2018). Moreover, in larger design teams (between 40 and 60 people) the integrated density was approximately 0.1 (Al Hattab \& Hamzeh, 2015). Thus, a team four or five times larger than the pilot project only reduced the density by half. The mean indegree was 2.83 , and its range was 7 ; the mean outdegree was 2.830 , and its range was 10 . Therefore, there was high variability regarding the sharing of work information, which demonstrated an inhomogeneous flow of information that focused on the project manager and the architect. There was one weakly connected component and five strongly connected components. Thus, the network was weakly connected, and, as in the interaction network, it was strongly dependent on the project manager, which was contrary to the goals of lean management practices regarding the transparency of information (Wesz et al., 2018) and was greater among the specialists through technology (AIA, 2007). 

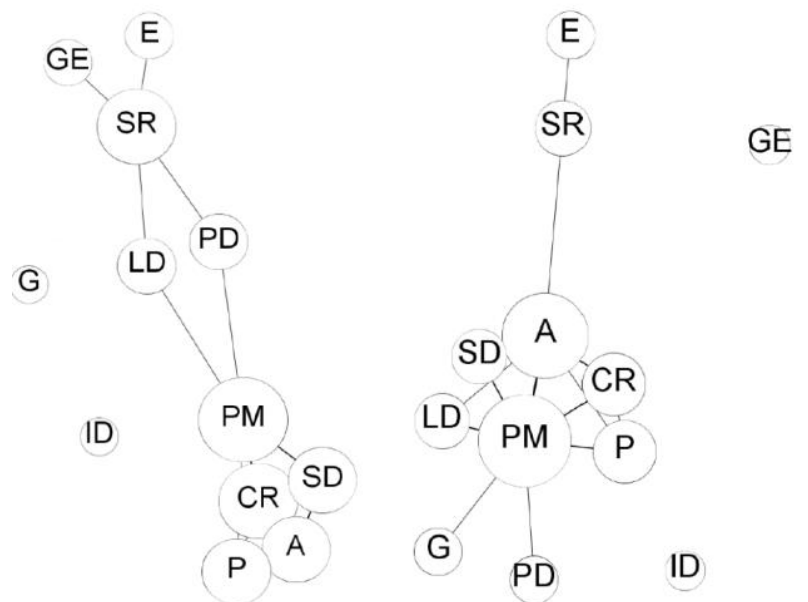

Figure 4-4: Collaboration network (left) / Planning and problem-solving network (right)

Collaboration and planning are strongly related to problem-solving networks because planning can be a type of collaboration. Therefore, the planning network should be a subnet of the collaboration network. Both types of networks have undirected links, and all invalid connections must first be removed. In the case study, both networks had similar characteristics, which was evidenced by their indicators. The proportion of reciprocal connections was $90.32 \%$ in both cases, which explained the high reliability of the input data. Additionally, in both networks, there were two disconnected people (three related components), meaning there was no collaborative planning. Finally, the collaboration and planning had a density of 0.212 and a mean degree of 2.330 . Thus, there were 10 people who were connected; however, for most of the opportunities the project manager was the intermediary (Figure 4-4). Therefore, in this project, there were no planning activities and collaborative work because the planning was carried out in meetings of two or three people and not among the 12 people who made up the work team. Current technologies and 
design methodologies support collaborative work and planning among the specialists to achieve greater understanding and time efficiency in projects, which produces better results in the designed product (Rahmawati et al., 2014).

The level of trust between members of a team is fundamental for a team to be effective (Austin, Pishdad-Bozorgi, \& de la Garza, 2015). In the pilot project, the trust network was created (Figure 4-5). In this project, there were 36 connections of trust and 52 connections of knowledge of roles, which meant that the relative level of trust was 0.690 in the network and that there was a high degree of trust between the people who knew each other. However, note that the level of knowledge of roles in this organization was low (density 0.394); of the four people a team member knew, he or she trusted two or three, on average. Therefore, in this team, there was no problem of trust but rather of knowledge of the team and greater collaboration. However, there was no evidence that an increase in the links of knowledge would result in an increase in the network of trust, but it is known that through collaboration and collaborative planning, trust can be strengthened (J. Flores et al., 2014). To learn from another person, it is necessary to trust that person (Karp, Hauer, \& Sheu, 2019); therefore, the learning network is a subnet of the trusted network (Herrera et al., 2018). In the case study, a small learning network was obtained, in which only 9 of the 12 stakeholders of the project participated and in which their level of connectivity was weak because their mean degree was 1.083 , their density was 0.247 and the percentage of reciprocal connections was $7.69 \%$. Thus, an average person learned from only one person, although there was an opportunity to learn from 11 others. Therefore, in this project, there was an important growth gap in the learning network, given that organizations need to be 
constantly learning, especially with the implementation of new technologies (Wong, Demertjis, Hardie, \& Lo, 2014).

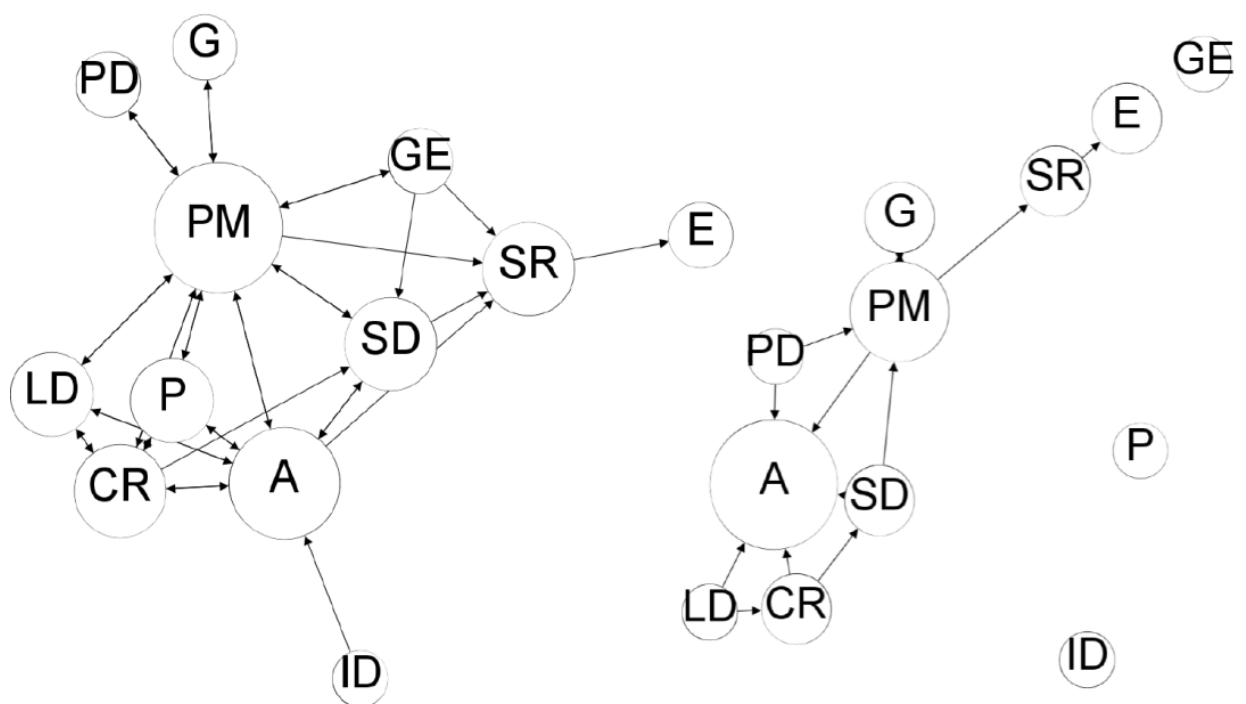

Figure 4-5: Trust network (left) / Learning network (right)

The multidisciplinary design process involves continuous discussions and negotiations among the participants, so it is essential to manage the commitments correctly (Cash et al., 2017). A network was created to allow for each step to have a reliable commitment (Figure 4-6). The request for requirements network is a measure of the requests made by the people involved for some task or document. The indegree of person A represents the number of people who request something from person $\mathrm{A}$ and not the number of requirements that person A has, and the outdegree of person A represents the number of people to whom person $\mathrm{A}$ is sending a request. In the pilot project, the sum of the input degrees of each node was 27, which meant that there were 27 connections between people, of which 7 were unidirectional and 20 were bidirectional. In the negotiation requirements network, the connections can be visualized as a negotiation between those involved. With this 
information, the percentage of negotiated requirements in the pilot project was calculated to be $51.85 \%$.

After a request, the requirements correspond to a declaration of completion. In the pilot project, the percentage of declaration of compliance was $59.25 \%$, and when only the negotiated requirements were reviewed, the percentage reached $100 \%$. Therefore, the discussion generated in the negotiation required a "following compliance declaration". The percentage of declarations of acceptance was $62.96 \%$; the customer declared satisfaction in approximately 6 out of 10 requirements. For cases in which the only declared requirement was fulfillment, the percentage increased to $93.75 \%$. This result confirms the need to include these four steps in the process of creating the correct management commitment requirements and to ensure a shared understanding among the participants. 


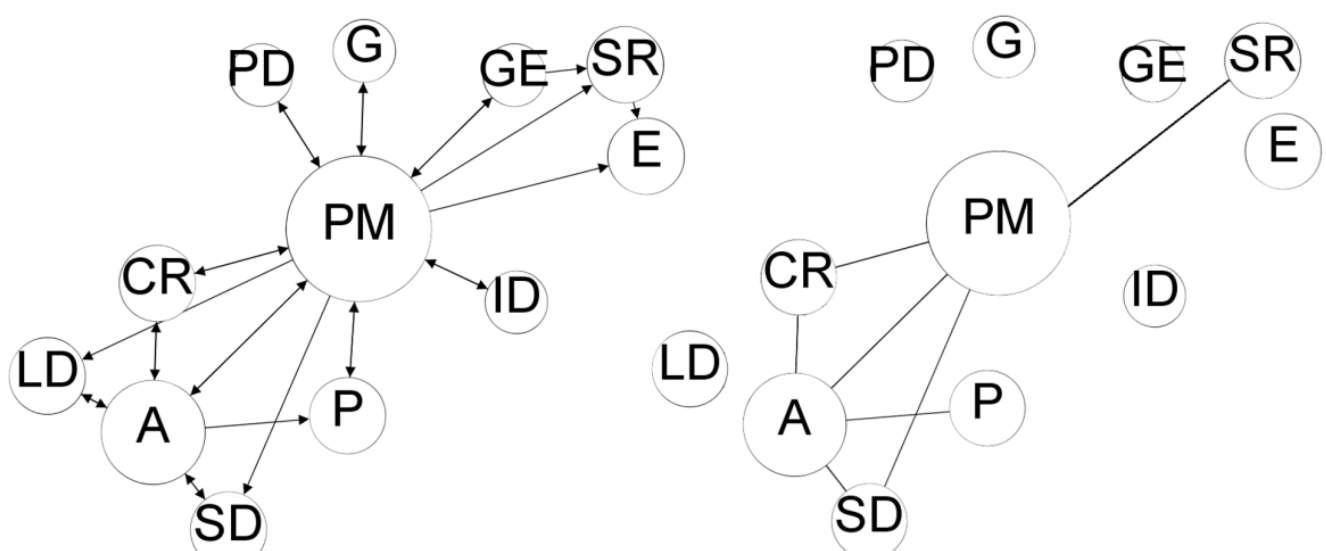

Request for requirement network

Negotiation network

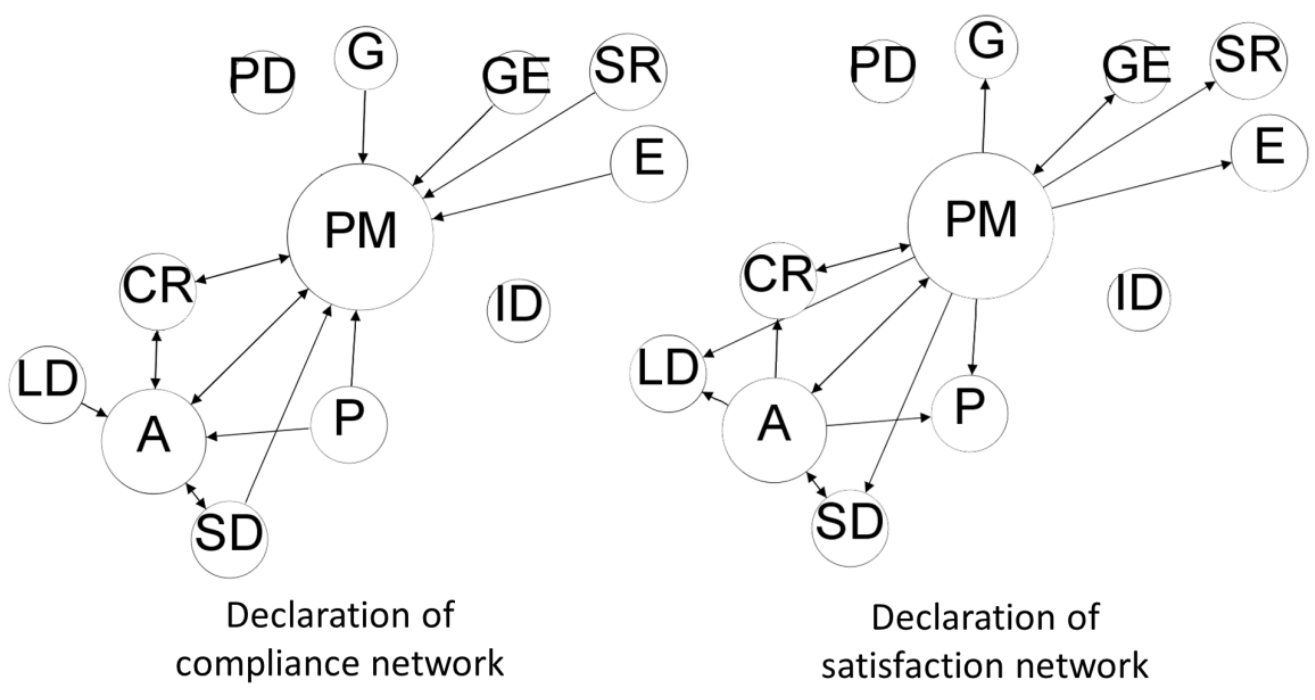

Figure 4-6: Commitment management networks

To summarize, in the pilot project, weak interactions were identified that were strongly centered on the project manager, with low interactions between different designers. This low interaction was initially caused by a lack of knowledge of the roles of the members of the team, a critical element in the project, in which each designer was from a different company. Thus, the kick-off meeting was fundamental in this project (Koo et al., 2013). Regarding commitment management, a low level of negotiation of requirements (clarifying 
deadlines, resources, scope, etc.) was identified, which affected the declarations of compliance and satisfaction without achieving the cycle for correct commitment management. Therefore, there was no continuous cycle of commitments affecting the shared understanding among the team members (Viana et al., 2011), which may have affected the design process, generating more rework or other wastes (Cash et al., 2017).

The application of the method involves three major efforts: (1) obtain answers from all the participants of the survey, (2) process the data with software, and (3) analyze the data and understand the context. To obtain answers from all the participants of the survey, the evaluator must have an internal organizational partner to facilitate the process. In addition, the people should understand the questions equally, so the coherence analysis is fundamental. In the pilot project, a PVC of over $80 \%$ was achieved, demonstrating that there was a good understanding of the questions by the respondents. Additionally, the creation of the questions for each type of interaction should be done with an understanding of the industry context and the language used by the design team being evaluated. In this case, the survey was created by a multidisciplinary team of engineers, architects, builders, consultants, and linguists, which allowed a broad and contextualized view of the characteristics of a design team. Then, to process and analyze the data, the evaluator must understand that, with this method, the results of the analysis give no answers but reveal where to ask questions (D. M. Alarcón et al., 2013), so it is essential to understand the context of the organization. There are two main limitations to the application of this method: first, there is no willingness on the part of the work team to respond judiciously to the survey; and second, the study has a punitive purpose. These limitations affect the objective of understanding the design team interaction that would allow it to improve and 
strengthen the channels in which the team interacts. In future studies, new types of interaction and new metrics can be added to analyze and understand the interactions of design teams in construction projects. In addition, assessments could be done in conjunction with other techniques for evaluating interaction and teamwork.

\subsection{Conclusions}

For a design team to be successful, the design participants must have high levels of interaction. To evaluate the interaction, a method was proposed to understand the interactions in this type of work team using SNA as a tool and evaluating the interaction from a multidimensional point of view. The key dimensions of interaction in a design team were identified and grouped into two groups: traditional interaction and commitment management. The latter group is fundamental in design teams because there are instances of systematic discussion and negotiation that oblige the team to have a shared understanding of the actions to be followed. In addition, this was the first time that speech acts were modeled using SNA. The SNA is a tool that allows global and individual analysis in a visual format and with mathematical indicators. Each dimension of interaction is represented as a network and may have an individual analysis; however, it is also necessary to perform an analysis between two or more networks. The proposed method has the following practical applications: (a) understanding the interactions of the design team from several perspectives; (b) taking corrective actions to improve the interaction to make it more efficient and less dependent on a single person; (c) recognizing the causes that generate a shared misunderstanding among the members of the team; and (d) taking actions in this matter, such as generating knowledge of roles, meetings for collective planning, and opportunities for collaborative work. These benefits can improve the 
common understanding of project requirements, reduce waste and increase the value of the design process. The application of the method requires that all the members of the design team respond to the survey; therefore, there must be a commitment from the organization that is being assessed. In addition, respondents should equally understand the questions, so the evaluation team should write the questions in context and verify the PVC limit through coherence analysis. In addition, the evaluation team and the design team should understand this method as a tool for continuous improvement and not as a punitive mechanism.

There are some limitations to this method. The tool is used for evaluation over time; therefore, comparisons should be made between projects with similar levels of progress. In addition, the researchers only assessed a pilot project with the SNA tool. For future research, it is recommended to perform assessments with this method on a large number of design teams with different compositions, e.g., collocated/no collocated teams, different numbers of companies, different management systems and different technology application levels (BIM environments), to understand how the context, management and technology affects interactions between team members. In addition, it would be interesting to evaluate new dimensions of interaction, study new metrics for small networks and analyze their quality and evaluate the metrics between different networks. Furthermore, in projects that work in BIM environments, it would be interesting to contrast the networks obtained from the log files and the networks obtained with the proposed method. 


\section{ANALYZING THE ASSOCIATION BETWEEN LEAN DESIGN MANAGEMENT PRACTICES AND BIM USES IN THE DESIGN OF CONSTRUCTION PROJECTS}

\subsection{Introduction}

Building Information Modeling (BIM) per (Eastman et al. 2008, p.491) is "a new approach to design, construction, and facilities management, in which a digital representation of the building process [is used] to facilitate the exchange and interoperability of information in digital format". For this reason, BIM has been related to the development of lean approaches to project management, as improved collaboration and information exchange can contribute to the lean management goal of reducing waste (Olatunji, 2011). There is a strong synergy between lean construction and BIM (C. M. Eastman et al., 2011), which has been documented in many case studies where it is possible to visualize the interaction between both methodologies (Sacks et al., 2010). The interactions between BIM and Lean are mutual, i.e. the development of BIM contributes to the development of Lean, and also the development of Lean contributes to the development of BIM (Nascimento, Caiado, Tortorella, Ivson, \& Meiriño, 2018; Sacks et al., 2010). In particular, BIM has a high technological component that has been extensively studied in recent years; however, its implementation has several challenges from the perspective of people and organizational processes (Arayici et al., 2011). For instance, BIM requires

profound process changes of the involved parties, and a higher team communication (Fakhimi, Majrouhi Sardroud, \& Azhar, 2016).

On the other hand, the foundation of Lean construction is based on the theory of production (Koskela, 2000), and it is people- and process-focused. Therefore, BIM with its 
technology capability and Lean with its theoretical foundation can complement each other for better project efficiency (Al Hattab \& Hamzeh, 2015). Sacks et al. (2010) presented 56 distinct interactions between lean construction principles and BIM functionalities, which were grouped in a Lean/BIM matrix. This study initiated extensive research into the synergies between Lean and BIM in the architecture, engineering and construction industry (AEC), being cited in more than 500 scientific papers, and it is also a foundation for the research introduced in this paper.

BIM in fact will become increasingly essential and an inextricably linked component to a Lean construction process, especially within the context of abundant geometric and semantic project information (Schimanski, Monizza, Marcher, \& Matt, 2019). For example, Schimanski et al. (2019) describe three practical case studies through BIM-based objectives and outcomes and map these outcomes to the taxonomy of interactions described by Sacks et al. (2010). All three case studies have demonstrated advances in the core tenet of delivering increased value to clients while significantly reducing waste in the form of time, material, and financing. In these examples, the implementation was primarily BIM-based methods, and secondarily, incremental inclusion of Lean definitions. Based on the synergies of BIM and Lean, specific tool applications have been developed, such as the Digital Obeya Room framework (Nascimento et al., 2018); "VisiLean", which uses BIM as the visual platform and enables pull flow scheduling on the construction site (B. A. Dave, 2013); “BeaM!”, which allows a joint application of BIM and the Last Planner ${ }^{\circledR}$ System (LPS) (Schimanski et al., 2019); and "KanBIM", which mixes Kanban and BIM (Sacks, Barak, Belaciano, \& Gurevich, 2011). A Lean tool can be defined as an structured technique or instrument that facilitates the implementation of the Lean principles 
(O’Connor \& Swain, 2013), such as, the last planner system, 5S, big rooms, and collaborative process mapping, among others. On the other hand, a management practice refers to concrete actions associated with increasing productivity (Bloom \& Van Reenen, 2007), such as, specialist designers and builders involvement during early stages of the project, the systematic participation or support of the clients, and the collaborative planning among various stakeholders, among others (Herrera, Mourgues, Alarcón, \& Pellicer, 2020a).

In addition, some authors have indicated that lean practices can enable BIM adoption (Gerber, Becerik-Gerber, \& Kunz, 2010). For instance, Arayici et al. (2011) have used lean-inspired action research interventions to enhance the adoption of BIM in an architectural company, from which the researchers developed detailed, operational-level guidelines to be used during implementations in this type of organization. Gerber et al. (2010) present qualitative evidence that indicates using lean and BIM in conjunction with each other can significantly improve BIM adoption and, consequently, project performance in India and perhaps elsewhere. Therefore, some lean practices reduce coordination-related issues within the project organization, paving the way for BIM adoption (Magalingam et al., 2015). By understanding the benefits of BIM and lean interactions, the design errors can be handled better in an attempt to reduce both their incidence and their dissemination (Magalingam et al., 2015). Some of the benefits of using an integrated BIM and Lean approach in the design stage of construction were summarized by Dave et al. (2013): reducing the design development lifecycle, reducing rework, increasing the number of iterations for value improvement, improving predictability of investment and lifecycle costs (4D scheduling), and enhancing the ability to engage with stakeholders. However, 
applying BIM alone as a technology and failing to employ it as a lean process does not bring about the desired benefits dissemination (Magalingam et al., 2015). To realize the full potential benefit of BIM and Lean methods, both need to be used collaboratively in a project (Fakhimi et al., 2016). However, both methodologies have been studied in depth on their own, and contributions about their synergies are quite recent; hence, the available assessment instruments used to measure the level of implementation of both methods so far are unrelated (Peralta, 2019). For example, on the one hand, there are many uses of BIM reported by various authors (M. R. Bloomberg, Burney, \& Resnick, 2012; Building and Construction Authority, 2013; Harvard University Construction Management Council, 2010; Succar, 2016), which can be implemented during the project life cycle (R. G. Kreider \& Messner, 2013); therefore, a BIM use is a set of actions and conditions that are associated with BIM, which together have a defined objective or application for the construction project during its life cycle (Rojas et al., 2019). On the other hand, there are also many Lean practices and tools that can be applied from design to project demolition (G. Ballard, 2008; Forbes \& Ahmed, 2011). However, Lean practices applied to BIM uses (defined in the BIM execution plan) are not known up to now.

An unexplored perspective on these synergies concerns the relationship between the specific uses of BIM and Lean practices. While some of this can be seen in the matrix proposed by Sacks et al. (2010), this study is limited to an analysis of the literature focused on Lean principles, not practices. Additionally, there are empirical studies that provide evidence of the potential of the application of BIM and Lean (Gerber et al., 2010; Matta, Herrera, Baladrón, Giménez, \& Alarcón, 2018; Schimanski et al., 2019); however, these are limited to the application of particular Lean tools and BIM uses in a limited number of 
case studies. Hence, a comprehensive understanding of BIM/Lean management is needed. Also, there are instruments to assess the gradualness of implementation of lean practices and BIM uses on their own, but there are no experiences that present the joint evaluation of both methodologies.

This is particularly important in the design phase of construction projects because the decisions made during this phase can significantly affect the subsequent phase, and the costs of changes in the design phase are negligible compared to the costs of changes in future phases (AIA, 2007). Then, particularly the Lean design management (LDM) practices are processes or methods related to Lean philosophy that are usually applied in the design phase of a construction project. Herrera et al. (2020) developed an instrument to assess 19 LDM practices; however, this instrument has not yet been compared to BIM uses applied in early project phases. Furthermore, Rojas et al. (2019) designed a instrument to assess ten BIM uses during the planning and design of construction projects; nevertheless, this instrument has not yet been compared to the Lean management practices implemented on those projects. Thus, there is no empirical evidence of the relationship between BIM uses and LDM practices. Additionally, there is also no evidence of causality between Lean and BIM, i.e., it is not known whether companies with high levels of Lean implementation are using BIM extensively or whether projects using BIM are applying Lean practices on actual projects.

Therefore, the purpose of this study is to analyze the relationships between Lean Design Management (LDM) practices and the uses of BIM in the early stages of construction projects, i.e., during the planning and design phases. The analysis of the relationship between LDM practices and BIM uses will allow having empirical evidence of 
the LDM practices that are present in each BIM use in the design phase of construction projects. To achieve this, the LDM practices and the BIM uses is explained in the Background section. Then, in the Research Method section, the relationship analysis is explained in depth. Finally, in the Results and Discussion section, the assessing of the LDM practices and BIM uses of 64 construction projects in the design phase are discussed.

\subsection{Background}

\section{$\underline{\text { Lean Design Management (LDM) practices }}$}

Lean design introduces several elements that are part of the Lean philosophy and that are fundamental in the design phase, for example, the active and systematic involvement of clients during early stages, maximization of value, identification of the needs and objectives of all interested parties, simultaneous realization of the design of the product and the process, and postponement of the decision-making step until the last responsible moment, with the aim of reducing reworks and unnecessary tasks (Gambatese et al., 2017). Better management practices are significantly associated with higher productivity, profitability, sales growth rates and firm survival rates (Bloom \& Van Reenen, 2007). Therefore, the Lean design management (LDM) practices will be the best management practices according to Lean philosophy, which will allow having a better performance in the design phase of a construction project. While Lean has been applied in the design phase of construction projects for more than 20 years (Formoso et al., 1998; Koskela et al., 1997), recently a framework has been proposed that integrates LDM practices and that allows an assessment of the level of implementation of each practice on a scale of 1 to 5 (Herrera et al., 2020a). 
Lean implementation in the design phase could be applied through multiple tools (e.g., set-based design, choosing by advantages, target value design, the last planner system, or big room), which could include one or several LDM practices. However, this research did not study particular tools because it was determined to have a comprehensive approach to Lean design management though LDM practices. Herrera et al. (2020) proposed 19 LDM practices in the design phase of construction projects. These practices were classified into three main categories: stakeholder management, planning and control, and problem solving and decision making. These authors proposed a questionnaire to assess the degree of implementation of each of the practices at the project level, defining a taxonomy of LDM practices in a scale of five levels (Herrera et al., 2020a). The present research used this questionnaire to assess LDM practices. Table 5-1 presents a definition of these 19 LDM practices.

Table 5-1: Lean design management (LDM) practices (Herrera et al., 2020a)

\begin{tabular}{|l|l|}
\hline ID & Definition \\
\hline STAKEHOLDER MANAGEMENT \\
\hline SM$_{1}$ & Specialist designers are involved during early stages of the project. \\
\hline SM$_{2}$ & Builders are involved during early stages of the project. \\
\hline $\mathbf{S M}_{3}$ & $\begin{array}{l}\text { The identification of requirements of the stakeholders is exhaustive, where } \\
\text { requirements, constraints, technical specifications and special requirements are } \\
\text { defined. }\end{array}$ \\
\hline SM$_{4}$ & $\begin{array}{l}\text { The participation of clients in the design phase involves the systematic participation } \\
\text { and support during meetings concerning decision making and resolution of } \\
\text { problems. }\end{array}$ \\
\hline SM$_{5}$ & $\begin{array}{l}\text { The design of the product and the construction process are carried out } \\
\text { simultaneously. }\end{array}$ \\
\hline PLANNING AND CONTROL \\
\hline PC $_{1}$ & $\begin{array}{l}\text { Project planning considers delivery dates, phases, milestones, task subdivision } \\
\text { programs and control instances. All of the above, immersed in a scheme in which } \\
\text { gaps, buffers and points are clarified, can be used to perform pull/push actions } \\
\text { within the program. }\end{array}$ \\
\hline PC $_{2}$ & $\begin{array}{l}\text { With regard to project planning, this is considered information of internal and/or } \\
\text { external projects of the organization, generated through a benchmarking exercise. }\end{array}$ \\
\hline
\end{tabular}




\begin{tabular}{|c|c|}
\hline $\mathbf{P C}_{3}$ & Project planning is conducted collaboratively among various stakeholders. \\
\hline $\mathrm{PC}_{4}$ & $\begin{array}{l}\text { Project planning is carried out at different levels (global, phase, intermediate and } \\
\text { weekly). }\end{array}$ \\
\hline PC5 & $\begin{array}{l}\text { The constraints in the design process are identified and registered collaboratively } \\
\text { and released by a responsible person. Then, the constraints are followed. }\end{array}$ \\
\hline PC6 & $\begin{array}{l}\text { The coordination of project information between the different stakeholders is } \\
\text { performed through a single platform, which allows systematic updates and } \\
\text { continuous communication between stakeholders. }\end{array}$ \\
\hline \multicolumn{2}{|r|}{ DECISION MAKING } \\
\hline DM1 & There exists a protocol to solve problems collaboratively. \\
\hline $\mathbf{D M}_{2}$ & $\begin{array}{l}\text { The last planner identifies the problem and performs a causal analysis (e.g., the } 5 \\
\text { why's method). }\end{array}$ \\
\hline DM3 & $\begin{array}{l}\text { The solution to the problem is implemented, monitored and documented, to verify } \\
\text { that the problem was solved. }\end{array}$ \\
\hline $\mathbf{D M}_{4}$ & $\begin{array}{l}\text { In the decision-making process, options are evaluated, designed, and tested, and the } \\
\text { results validated and applied. }\end{array}$ \\
\hline DM5 & $\begin{array}{l}\text { The moment to make decisions is the last responsible moment, and all the } \\
\text { information that could be gathered at that moment is used. }\end{array}$ \\
\hline DM6 & $\begin{array}{l}\text { To make decisions, information of internal and/or external projects of the } \\
\text { organization is used, generated through a benchmarking exercise. }\end{array}$ \\
\hline $\mathbf{D M}_{7}$ & $\begin{array}{l}\text { The decision-making mechanism is a meeting with all stakeholders involved, where } \\
\text { a specific technique is used, for example, Choosing By Advantages (CBA) or } \\
\text { others. }\end{array}$ \\
\hline DM8 & $\begin{array}{l}\text { After making the decision, specific actions are taken to verify whether satisfactory } \\
\text { results were obtained. In addition, the lessons learned are identified and } \\
\text { documented. }\end{array}$ \\
\hline
\end{tabular}

BIM uses in the planning and design phase

BIM use is defined as "a method of applying building information modeling during a facility's lifecycle to achieve one or more specific objectives" (Kreider and Messner 2013, p. 6). BIM maturity models could be used to measure the level of application of BIM in a project. However, they allow the assessment of BIM capability and BIM status in an organization (Succar et al., 2012), but not specifically the application of BIM uses. Additionally, there are several guidelines that define BIM uses in the project life cycle (M. R. Bloomberg et al., 2012; Building and Construction Authority, 2013; Harvard University Construction Management Council, 2010), Penn State's guide being the one that stands out 
for its high level of theoretical and empirical support (R. G. Kreider \& Messner, 2013). Originally, these guidelines did not propose a scale of gradual implementation of each BIM use; however, Rojas et al. (2019) recently proposed an instrument to diagnose some of the BIM uses proposed in the Penn State guidelines (R. G. Kreider \& Messner, 2013). Rojas et al. (2019) designed a BIM uses assessment (BUA) instrument, which allows companies and clients to identify the status of BIM uses of the project, the way that BIM uses are being implemented, and the design team's opportunities for improvement. With this approach, it is possible to realize higher benefits from the BIM methodologies when they are applied in the earliest stages of the projects (planning and design). Table 5-2 presents a definition of the ten BIM uses for the planning and design of construction projects considered in this study.

Table 5-2: BIM uses for the planning and design of construction projects (Rojas et al., 2019)

\begin{tabular}{|l|l|l|}
\hline ID & Use & Definition \\
\hline U1 & Cost Estimation & $\begin{array}{l}\text { A BIM model is used to generate accurate quantity take-offs and } \\
\text { cost estimates. }\end{array}$ \\
\hline $\mathbf{U}_{2}$ & 4D Planning & $\begin{array}{l}\text { A 4D BIM model is utilized to effectively plan, especially spatial } \\
\text { planning, including spatial clashes and paths. }\end{array}$ \\
\hline U3 & Site Analysis & $\begin{array}{l}\text { BIM/GIS is used to select and evaluate a site location and to } \\
\text { select a building position on the site. }\end{array}$ \\
\hline $\mathbf{U}_{4}$ & $\begin{array}{l}\text { Space } \\
\text { Programming }\end{array}$ & $\begin{array}{l}\text { A BIM model is used to design and analyze the project spaces } \\
\text { and rooms and to assign to each space a use and its } \\
\text { measurements. }\end{array}$ \\
\hline U5 & Design Review & $\begin{array}{l}\text { A process in which stakeholders interact with a BIM model and } \\
\text { provide their feedback to validate multiple design aspects }\end{array}$ \\
\hline U6 & Code Validation & $\begin{array}{l}\text { A process in which code validation software is utilized to check } \\
\text { the model parameters against project-specific design or } \\
\text { construction codes or norms. }\end{array}$ \\
\hline U7 & $\begin{array}{l}\text { Sustainability } \\
\text { Evaluation }\end{array}$ & $\begin{array}{l}\text { A process in which the sustainability of a facility is evaluated } \\
\text { and tracked using a sustainability metric system. }\end{array}$ \\
\hline U8 & $\begin{array}{l}\text { Engineering } \\
\text { Analysis }\end{array}$ & $\begin{array}{l}\text { A BIM model and specialized software are used to conduct an } \\
\text { engineering analysis to identify the most efficient method or }\end{array}$ \\
\hline
\end{tabular}




\begin{tabular}{|l|l|l|}
\hline ID & Use & Definition \\
\hline U9 & $\begin{array}{l}\text { Design } \\
\text { Authoring }\end{array}$ & $\begin{array}{l}\text { A process in which 3D software is used to develop a building } \\
\text { information model. A project is designed in a BIM model, where } \\
\text { the typical iterations of a project are made, and everything is } \\
\text { built directly in the BIM software. }\end{array}$ \\
\hline U10 & $\begin{array}{l}\text { 3D } \\
\text { Coordination }\end{array}$ & $\begin{array}{l}\text { A process in which 3D coordination software is used to identify } \\
\text { 3D geometric conflicts by comparing 3D models of building } \\
\text { systems. }\end{array}$ \\
\hline
\end{tabular}

\subsection{Research method}

\section{Overall Approach}

To achieve the objective of this work, the research was organized into three stages, displayed in Figure 5-1, in the following way: (1) explanation of assessment instruments to measure the level of implementation of BIM uses and the lean design management (LDM) practices; (2) characterization of the sample of projects and data collection strategy; and (3) data exploration, including reliability analysis, descriptive statistics, association analysis using the Pearson chi-square test, and causal analysis using necessity and sufficiency relationships between both elements through a fuzzy set analysis. 


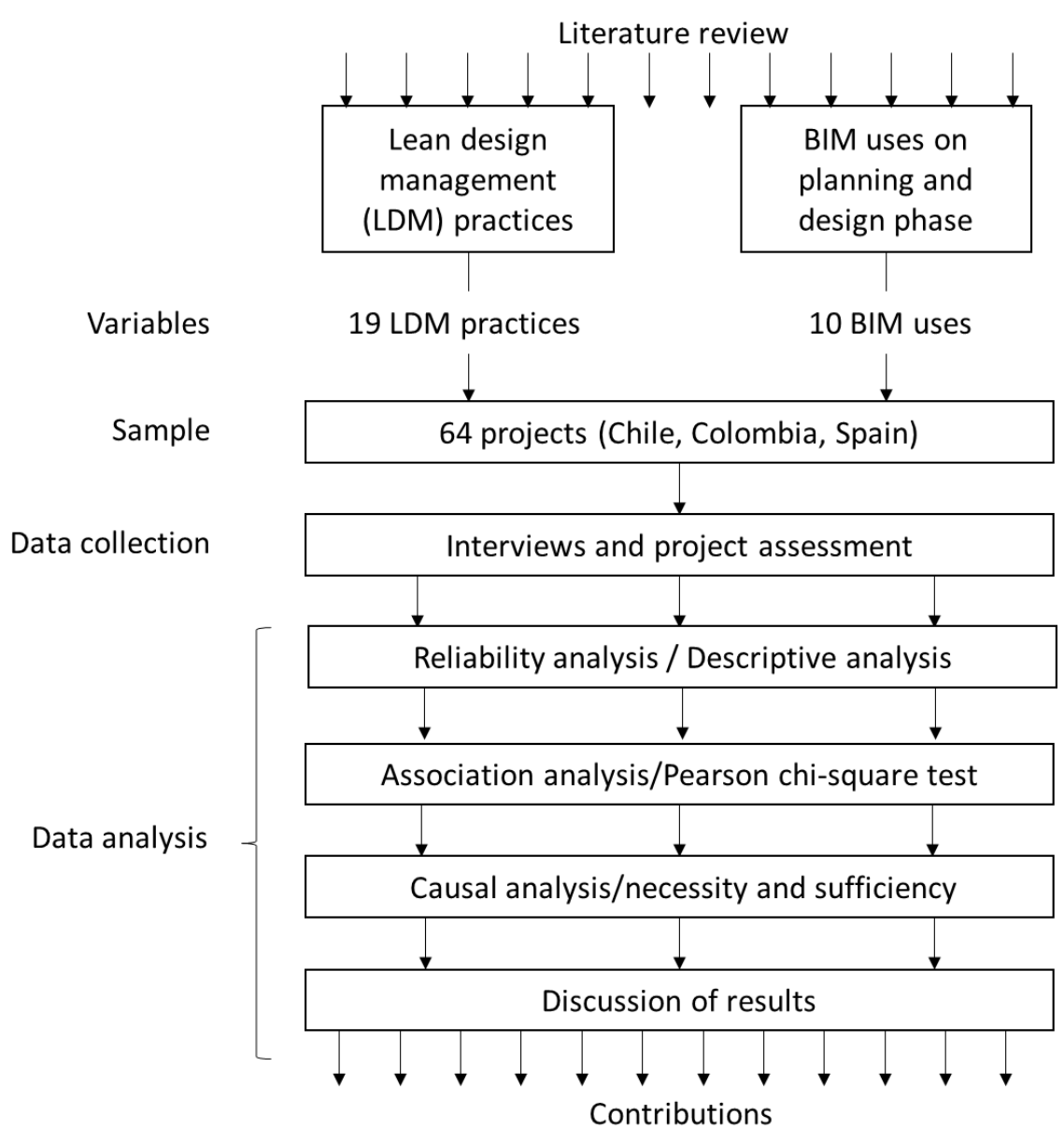

Figure 5-1: Research method

\section{Explanation of LDM Practices and BIM Uses instruments}

In the first stage, a literature review was conducted to identify the Lean design management (LDM) practices and BIM uses in the planning and design phases of the infrastructure lifecycle. This is based on previous work of the research team, who identified LDM practices and BIM uses in two previous papers (Herrera et al., 2020a; Rojas et al., 2019). The study by Herrera et al. (2020) was selected because it brings together several Lean design management practices applied in real projects in a single document. In addition, this study offers a questionnaire that allows the evaluation of the level of application of each practice on a scale of 1 to 5. On the other hand, the study by 
Rojas et al. (2019) was selected, since it allows the evaluation of the gradualness of application of 10 BIM uses proposed by the Penn state guide on a scale of 1 to 5 . These two previous contributions aimed to identify the level of application of LDM practices and BIM uses in construction through assessment instruments.

The implementation of the LDM practices and BUA instruments was done in the following way. In each project, two semi-structured interviews were conducted. In the first interview, LDM practices were assessed, whereas in the second interview, BIM uses were assessed. The duration of each interview was from 40 to 60 minutes. The interviewer was the main researcher of the study, who also participated in the creation of both instruments. The interviewees were people with extensive knowledge of the projects assessed (project manager, BIM manager, and client representative), and more than 15 years of expertise in the field; the interviewees had the authorization of their superior to provide information as well as documents supporting this information. For each interview the procedure was as follows: First, the researchers conducted a recorded interview (audio was recorded with the consent of the interviewee), with the project manager and the BIM manager, considering all the points addressed in the questionnaires. Then, to maintain objectivity, two researchers (also co-authors of this paper) listened to the recorded interviews and individually rated each project according to each of the management practices that were defined in the questionnaire, using the 5-point Likert scale explained below. Rojas et al. (2019) introduced the BUA questionnaire, and Herrera et al. (2020) presented the LDM practices questionnaire. Then, in a collaborative session, the two researchers who revised the in the interviews were asked to discuss the final qualification of each practice. Finally, to maintain the objectivity of the ratings, a concordance analysis of the evaluations of the 
two researchers was conducted using the Kappa Cohen test to measure the level of concordance.

The LDM practices questionnaire has five levels for the 19 practices. Each LDM practice follows the method of Bloom and Van Reenen (2010), i.e., there is a description for scores 1, 3 and 5, while scores 2 and 4 are defined as intermediate points between 1-3 and 3-5, respectively. The score descriptions are (1) a traditional management practice, (3) an initial lean design management practice, and (5) a developed lean design management practice (Herrera et al., 2020a). The BUA questionnaire qualifies each use on a scale from one to five, where the minimum level (1) means that there is no use of the BIM model and the maximum level (5) means that the organization uses it in a way that realizes all its applications. The proposal of classification by levels allows having a structured and consistent instrument. Table 5-3 presents a general description for each level (Rojas et al., 2019).

Table 5-3: BIM levels-a general description for each level

\begin{tabular}{|c|c|}
\hline Level & General description \\
\hline 1 & Traditional methods (2D model). \\
\hline 2 & Low use of BIM and little information in the model. \\
\hline 3 & Medium use of BIM and sufficient information for BIM. \\
\hline 4 & High use of BIM. \\
\hline 5 & Full use of BIM. The best tools are utilized to realize all its applications. \\
\hline
\end{tabular}

\section{$\underline{\text { Sample and Data Collection }}$}

In the second stage, the researchers invited all the companies collaborating with the Production Management Centre (GEPUC) in Santiago (Chile) to join in research; 64 projects of companies interested were assessed, which had the following characteristics: (1) the contracting system was design-bid-build; (2) BIM methodology was being used; 
and (3) the project manager and/or BIM manager agreed to provide actual project information. The infrastructure projects used in this research were hospitals and airports; thus, it was possible to compare BIM uses between building and infrastructure projects. The assessment of the 64 construction projects was carried out using the LDM practices instrument (Herrera et al., 2020a) and the BUA instrument (Rojas et al., 2019).

Table 5-4: Summary of project characteristics

\begin{tabular}{|c|c|c|c|}
\hline Country & Building project & Infrastructure project & Total \\
\hline Colombia & 12 & 2 & 14 \\
\hline Chile & 20 & 12 & 32 \\
\hline Spain & 12 & 6 & 18 \\
\hline Total & $\mathbf{4 4}$ & $\mathbf{2 0}$ & $\mathbf{6 4}$ \\
\hline
\end{tabular}

\section{Data Analysis}

In the third stage, the authors performed a descriptive analysis from the data of the 64 projects. First, to measure whether the scale of the BUA questionnaire and the LDM practices questionnaire consistently reflect the construct it is measuring, a reliability analysis of the two instruments was carried out using Cronbach's alpha test. Second, to understand the level of application of LDM practices and BIM uses of the sample of the 64 projects, the authors performed a frequency and percentile analysis for each LDM practice and BIM use. Third, to understand the relationship between LDM practices and BIM uses, the researchers performed an association analysis using Pearson's chi-square test. Finally, to understand the causality between LDM practices and BIM uses, a necessity and sufficiency analysis between both elements was performed using a fuzzy set analysis. A necessity and sufficiency analysis allows evaluating the degree of consistency of the causal relationship between two variables (Rihoux \& Ragin, 2009). 
For the association analysis, the authors built 19x10 (190) contingency tables between each LDM practice and each BIM use. The researchers decided to apply the original scale of five levels for LDM practices, while for the BIM uses, they defined a binary scale, i.e., (0) when the project did not apply the BIM use (levels 1 and 2 in the original scale) and (1) when the project applied the BIM use (levels 3 to 5 in the original scale). Therefore, each contingency table had 5 columns and 2 rows. Then, the authors defined the hypothesis test: $\left(\mathrm{H}_{0}\right)$ there is no association between the LDM practice $(\mathrm{n})$ and the BIM use $\mathrm{U}(\mathrm{m})$; and $\left(\mathrm{H}_{1}\right)$ there is an association between the LDM practice (n) and the BIM use U (m). Finally, the researchers performed Person's chi-square test for each contingency table with a level of significance of $5 \%$; a degree of freedom (df) $d f=(r-1)(c-1)$, where $\mathrm{r}$ is the number of rows (2) and c is the number of columns (5); therefore, the degree of freedom for each test was four.

The chi-square was calculated for each contingency table (190 in total) using the following procedure. Each contingency table had an observed value $(\mathrm{O})$. Then, the researchers calculated the expected frequency $(\mathrm{E})$, which represents the expected value of the two variables that are independent of one another. Later, the authors calculated each chi-square according to Equation 1.

$$
\chi^{2}=\sum \frac{\left(O_{i}-E_{i}\right)^{2}}{E_{i}}(\mathrm{Eq}, 1)
$$

Given the degree of freedom $(\mathrm{df}=4)$ and each chi-square statistic value, the level of significance ( $p$-value) can be found with the chi-square distribution. If the p-value $<0.05$, then the null hypothesis can be rejected. Therefore, there is a relationship between the LDM practice (n) and the BIM use $\mathrm{U}(\mathrm{m})$. If the p-value $>0.05$, then the null hypothesis 
cannot be rejected. Therefore, there is not a relationship between the LDM practice (n) and the BIM use $\mathrm{U}(\mathrm{m})$.

If the correlation exists, then the level of association with the contingency coefficient standardized (C stand) has to be computed as indicated in Equation 2, where " $\mathrm{N}$ " is the size of the sample (64 projects) and " $\mathrm{k}$ " is the minimum between the numbers of rows and columns (2). Then, the level of association can be defined using Table 5-5 (Akoglu, 2018).

$$
C_{\text {stand }}=\sqrt{\frac{\chi^{2} \cdot k}{\left(\chi^{2}+N\right) \cdot(k-1)}} \text { (Eq. 2) }
$$

Table 5-5: Level of association according to the standardized contingency coefficient

\begin{tabular}{|l|l|}
\hline C stand & Level of association \\
\hline+0.70 or higher & Very strong relationship \\
\hline 0.40 to 0.69 & Strong relationship \\
\hline 0.30 to 0.39 & Moderate relationship \\
\hline 0.20 to 0.29 & Weak relationship \\
\hline 0.01 to 0.19 & No or negligible relationship \\
\hline 0.00 & No relationship \\
\hline
\end{tabular}

Therefore, to understand the application of the association analysis between an LDM practice and a BIM use, two hypothetical cases are presented below in Figure 5-2. . This figure shows first (a) when an LDM practice and a BIM use are totally independent, i.e., there is no association between BIM use and LDM practice. This is reflected with a chisquare and a standardized contingency coefficient equal to 0.00 ; in other words, the use of BIM in a project may or may not perform the lean management practice with the same probability. Figure 5-2, in (b), shows an LDM practice and a BIM use with a high association. In this case, there is a very strong relationship between the existence of the BIM use and the LDM practice. This is reflected by a chi-square of 37.25 (p-value<0.05) and a standardized contingency coefficient equal to 0.85 , i.e.; if BIM is used in a project, 
there is also a high probability that lean management practice is being applied in the design phase.

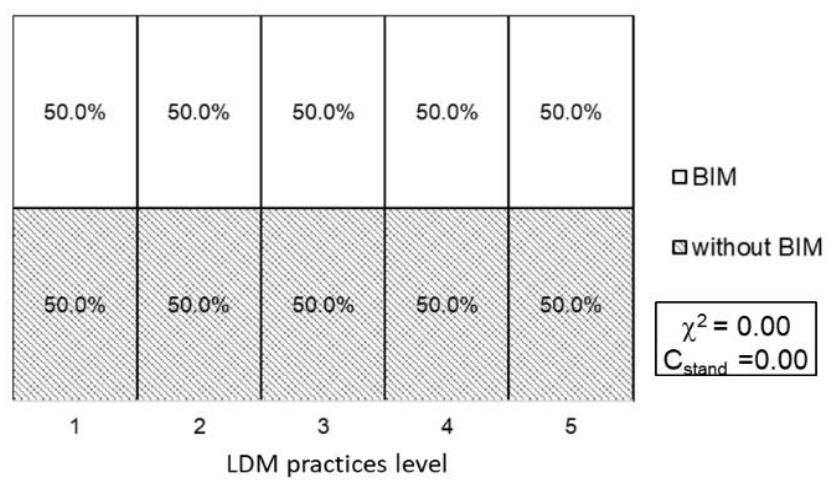

(a)

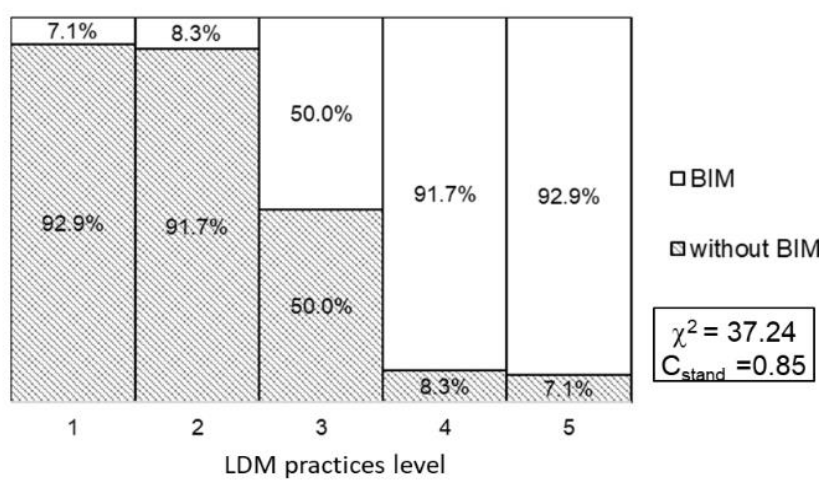

(b)

Figure 5-2: Association analysis in two hypothetical cases

Finally, to understand the causality between LDM practices and BIM uses, a necessity and sufficiency analysis between both elements was performed using a fuzzy set analysis. For this analysis, two variables were defined: (1) the proportion between the number of LDM practices with an initial or higher lean application (score three or higher) and the total of 19 LDM practices, and (2) the proportion between the number of BIM uses with an initial or higher BIM application (score three or higher) and the total of 10 BIM uses. The LDM practices proportion $\left(p_{l}\right)$ and the BIM uses proportion $\left(p_{b}\right)$ have a range between 0 and 1. 
Then, the causal relationship between $p_{l}$ and $p_{b}$ was defined through an analysis of necessity and sufficiency. A condition is necessary if it is present every time the outcome of interest occurs (although in some cases where the condition is present, the outcome of interest does not occur). On the other hand, a condition is sufficient if the outcome of interest is present whenever the condition is present (although it may also be present in the absence of the condition) (Rihoux \& Ragin, 2009).

With fuzzy sets, the consistency of the necessary condition relationship depends on the degree to which it can be shown that membership in the outcome is consistently less than or equal to memberships in this cause (Outcome $\mathrm{i} \leq$ Condition $_{\mathrm{i}}$ ). This inequality is the reverse of the inequality defining the consistency of the sufficient condition relationships (Outcome $_{\mathrm{i}} \geq$ Condition $_{\mathrm{i}}$ ) (Ragin, 2006). In this case, researchers assessed the necessity and sufficiency relationship between the LDM practices proportion $\left(p_{l}\right)$ and the BIM uses proportion $\left(p_{b}\right)$ through the consistency score. A perfect consistency score will take a value of 1.0; however, when there are more than 20 cases (projects), a consistency score of 0.75 or higher has a strong causal relationship (Schneider \& Wagemann, 2012).

\subsection{Results and discussion}

From the 64 evaluated projects, the authors analyzed the internal consistency of the LDM practices and the BUA instruments using Cronbach's alpha coefficient. For the LDM practices instrument, which has 19 items, the researchers calculated a Cronbach's alpha coefficient of 0.918 ; hence, the LDM practices have a high reliability. In the same way, for the BUA instrument, which has 10 items, the authors obtained a Cronbach's alpha coefficient of 0.867 , i.e., a high reliability. Therefore, both instruments present a high level of internal consistency. In addition, Cohen's kappa values are 0.81 and 0.92 in the LDM 
practices questionnaire and BUA instrument, respectively. Therefore, the consistency between the assessment between the two evaluators indicated a high degree of agreement on both instruments.

The LDM practices with the highest level of implementation are $\mathrm{SM}_{3}$ "requirements management (identification of constraints, technical specifications and special requirements)" and $\mathrm{SM}_{4}$ "client systematic participation and support during meetings concerning decision making and resolution of problems"; they are the only LDM practices where a higher level than the initial LDM practices implementation exists. Both LDM practices belong to the stakeholder management category, this category being one of the most important in any kind of project (Mok et al., 2015; Molwus et al., 2017). This result is good news for design projects, since requirements management is usually one of the critical elements in construction project management (Molwus et al., 2017).

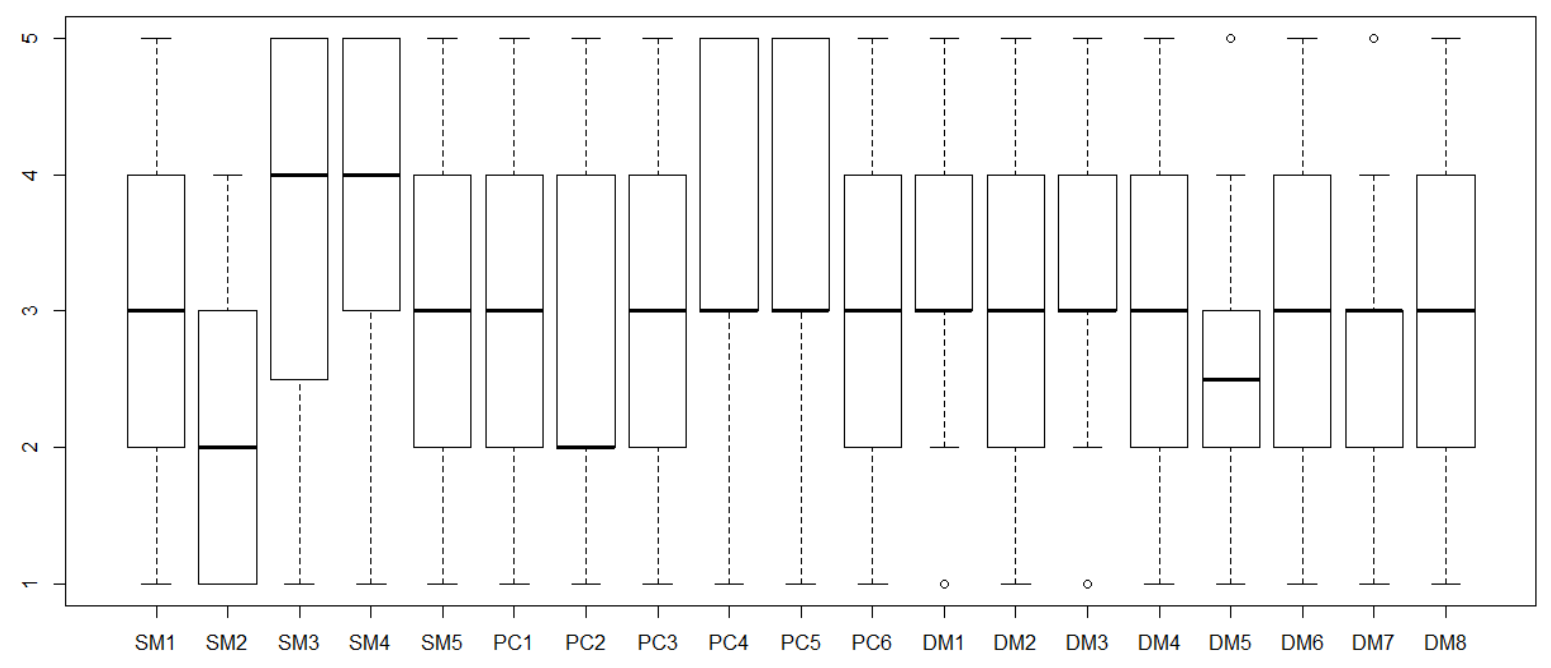

Figure 5-3: LDM practices assessment (Herrera et al., 2020a)

In addition, $75 \%$ of the projects are beginning to apply lean with the practices $\mathrm{PC}_{4}$ "planning in different levels" and $\mathrm{PC}_{5}$ "constrains management visualization", even at initial levels. The same happens with the LDM practices $\mathrm{DM}_{1}$ "collaborative solving 
problems" and $\mathrm{DM}_{3}$ "PDCA problem solving". The academy has focused on the process, collaboration and planning of the design phase to reduce waste in this phase of the construction project (Munthe-kaas et al., 2015). Thus, the implementation of these LDM practices implies that there has been an increase in awareness around excellent processes and planning.

On the other hand, the LDM practices with the lowest level of implementation are $\mathrm{SM}_{2}$ "builders in early stages", $\mathrm{DM}_{5}$ "decision-making until the last responsible moment", and $\mathrm{DM}_{7}$ "multicriteria decision-making", where lean implementation levels are practically nonexistent in approximately $75 \%$ of the evaluated projects. The early involvement of builders in the design phase represents the best opportunities for a successful project (Reifi \& Emmitt, 2013); however, it is difficult to implement LDM practices in a project with a design-bid-build delivery system (Mesa et al., 2016), as shown in the 64 projects that were evaluated in this study. On the other hand, LDM practices associated with the decisionmaking process are increasingly being implemented in Lean projects; choosing by advantages (CBA) is the most commonly used technique in those projects (Arroyo, Fuenzalida, Albert, \& Hallowell, 2016). Additionally, there are high ranges of variability, since in most LDM practices (15 of 19), there is a two-level difference between the 75th percentile and the 25th percentile. This variability reflects that lean design practices are not yet a standard in management at this stage of the project.

The BIM uses with the highest level of implementation are $\mathrm{U}_{5}$ "design review", $\mathrm{U}_{9}$ "design authoring", and $\mathrm{U}_{10}$ "3D coordination". 3D coordination is limited to visualization and clash detection (Shafiq, Matthews, \& Lockley, 2013); however, there are many possibilities for coordination to be missed in this process, especially with specialists with 
different disciplines who often do not think about the other disciplines' responsibilities (Liu, van Nederveen, Hertogh, Nederveen, \& Hertogh, 2017). Design authoring is a process in which software is used to develop a building information model, and the project is designed in a BIM model, where the typical iterations of a project are made, and everything is built directly in the BIM software (R. Kreider, 2013; Rojas et al., 2019). A design review between different specialists is essential for BIM to become a collaborative methodology that facilitates decision making and improves the design process (Liu et al., 2017). Thus, the high level of execution of these BIM uses is aligned with the first BIM implementation efforts in the AEC industry (Gu \& London, 2010).

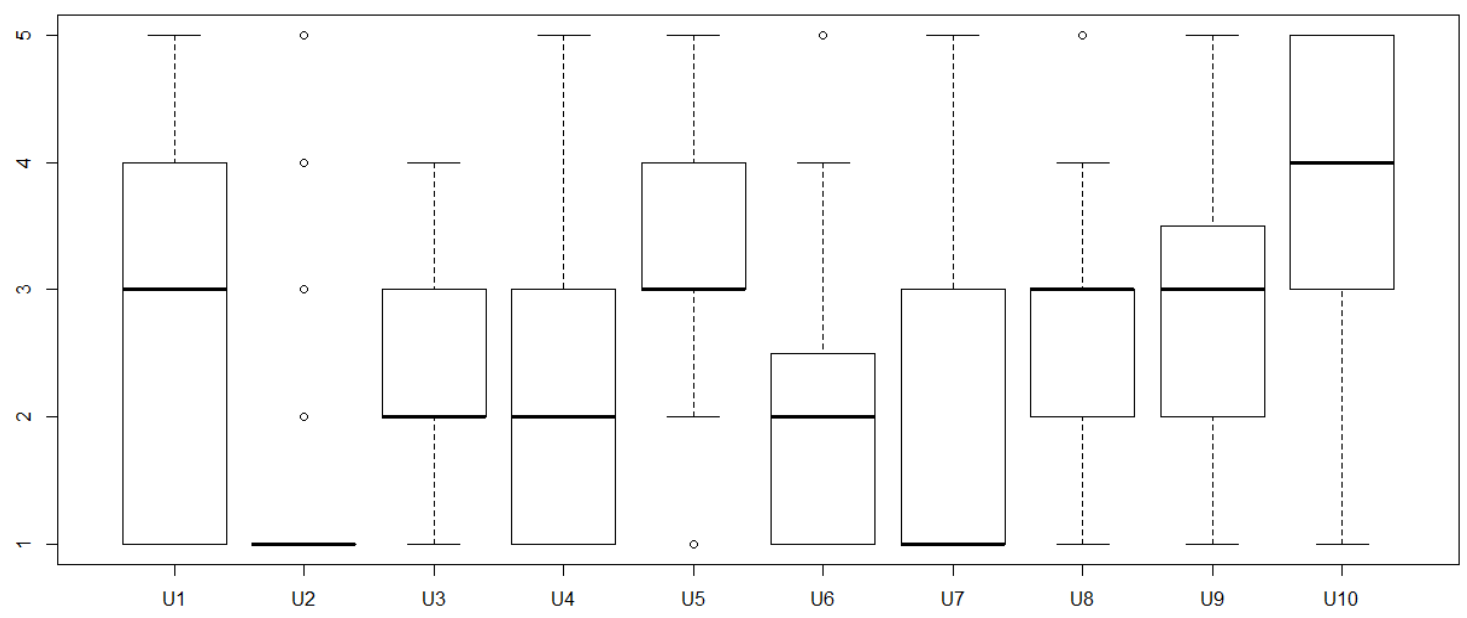

Figure 5-4: BIM uses assessment

The BIM uses with a medium level of implementation are $\mathrm{U}_{1}$ "cost estimation", $\mathrm{U}_{3}$ "site analysis", $\mathrm{U}_{4}$ "space planning", and $\mathrm{U}_{8}$ "engineering analysis". The estimation of quantities and subsequent estimation of the project budget is a basic activity that is carried out in all types of projects with or without BIM (Porwal \& Hewage, 2013); however, the use of BIM allows the project budget to be estimated more quickly and accurately (Rojas et al., 2019). This and other activities in the planning phase of the construction project are 
beginning to be implemented in their early stages, as are the LDM practices associated with planning and analysis.

On the other hand, the BIM uses with the lowest level of implementation are $\mathrm{U}_{2}$ "4D planning”, $\mathrm{U}_{6}$ “code validation", and $\mathrm{U}_{7}$ "sustainability analysis". 4D planning, also known as 4D modeling, is one of the least used applications, which is consistent with a study that indicates this use as important but under a baseline of 74 other key factors of BIM implementation (Tsai, Mom, Hsieh, Tsai, \& Hsieh, 2014). In the case of sustainability analysis and code validation, in the countries that were studied, it is still difficult to ask external designers to develop the whole process on a BIM platform (Rojas et al., 2019).

Then, a Pearson's chi-square test of independence was performed to examine relationships between BIM uses and the LDM practices of the 64 projects. The main results are summarized in Table 6 . The chi-square test showed no significant association between the BIM use $\mathrm{U}_{8}$ "engineering analysis" and any LDM practices ( $p$-values>0.05). This means that engineering analysis is being used as a technique. However, there are no structured management practices that allow these agents to be actively involved in planning and decision making in the engineering process. Therefore, it is essential that in schools of design and engineering, students be trained to explore state-of-the-art computersupported collaborative devices and to collaborate across disciplines ( $\mathrm{Gu} \&$ London, 2010).

Table 5-6: Pearson's chi-square test: related variables

\begin{tabular}{|c|c|c|c|}
\hline Var & $\chi \mathbf{2}$ & p-value & Coef. Cont. Stand. \\
\hline $\mathrm{U}_{1}-\mathrm{SM}_{1}$ & 13.135 & 0.011 & 0.5840 \\
\hline $\mathrm{U}_{1}-\mathrm{PC}_{4}$ & 10.033 & 0.040 & 0.5200 \\
\hline $\mathrm{U}_{1}-\mathrm{DM}_{1}$ & 14.756 & 0.005 & 0.6124 \\
\hline $\mathrm{U}_{2}-\mathrm{PC}_{4}$ & 11.298 & 0.023 & 0.5473 \\
\hline
\end{tabular}




\begin{tabular}{|c|c|c|c|}
\hline Var & $\chi \mathbf{2}$ & p-value & Coef. Cont. Stand. \\
\hline $\mathrm{U}_{3}-\mathrm{PC}_{2}$ & 11.375 & 0.023 & 0.5487 \\
\hline $\mathrm{U}_{3}-\mathrm{PC}_{6}$ & 12.105 & 0.017 & 0.5643 \\
\hline $\mathrm{U}_{3}-\mathrm{DM}_{4}$ & 9.486 & 0.050 & 0.5077 \\
\hline $\mathrm{U}_{4}-\mathrm{SM}_{4}$ & 10.590 & 0.032 & 0.5332 \\
\hline $\mathrm{U}_{4}-\mathrm{PC}_{1}$ & 9.603 & 0.048 & 0.5105 \\
\hline $\mathrm{U}_{4}-\mathrm{PC}_{3}$ & 10.815 & 0.029 & 0.5374 \\
\hline $\mathrm{U}_{4}-\mathrm{PC}_{4}$ & 15.694 & 0.003 & 0.6279 \\
\hline $\mathrm{U}_{4}-\mathrm{PC}_{5}$ & 14.378 & 0.006 & 0.6053 \\
\hline $\mathrm{U}_{4}-\mathrm{PC}_{6}$ & 13.117 & 0.011 & 0.5827 \\
\hline $\mathrm{U}_{4}-\mathrm{DM}_{1}$ & 10.677 & 0.030 & 0.5346 \\
\hline $\mathrm{U}_{4}-\mathrm{DM}_{2}$ & 9.849 & 0.043 & 0.5162 \\
\hline $\mathrm{U}_{4}-\mathrm{DM}_{6}$ & 13.320 & 0.010 & 0.5869 \\
\hline $\mathrm{U}_{4}-\mathrm{DM}_{8}$ & 14.261 & 0.007 & 0.6039 \\
\hline $\mathrm{U}_{5}-\mathrm{SM}_{4}$ & 10.722 & 0.040 & 0.5360 \\
\hline $\mathrm{U}_{5}-\mathrm{SM}_{5}$ & 10.972 & 0.027 & 0.5416 \\
\hline $\mathrm{U}_{5}-\mathrm{DM}_{2}$ & 13.915 & 0.008 & 0.5982 \\
\hline $\mathrm{U}_{6}-\mathrm{SM}_{2}$ & 15.291 & 0.002 & 0.6208 \\
\hline $\mathrm{U}_{6}-\mathrm{SM}_{5}$ & 9.680 & 0.046 & 0.5119 \\
\hline $\mathrm{U}_{6}-\mathrm{PC}_{1}$ & 20.868 & 0.000 & 0.7014 \\
\hline $\mathrm{U}_{6}-\mathrm{PC}_{2}$ & 11.994 & 0.017 & 0.5614 \\
\hline $\mathrm{U}_{6}-\mathrm{PC}_{3}$ & 17.103 & 0.002 & 0.6491 \\
\hline $\mathrm{U}_{6}-\mathrm{PC}_{4}$ & 13.797 & 0.008 & 0.5954 \\
\hline $\mathrm{U}_{6}-\mathrm{DM}_{6}$ & 11.964 & 0.018 & 0.5614 \\
\hline $\mathrm{U}_{7}-\mathrm{SM}_{5}$ & 27.676 & 0.000 & 0.7764 \\
\hline $\mathrm{U}_{7}-\mathrm{PC}_{2}$ & 11.423 & 0.022 & 0.5501 \\
\hline $\mathrm{U}_{9}-\mathrm{PC}_{4}$ & 10.130 & 0.038 & 0.5233 \\
\hline $\mathrm{U}_{9}-\mathrm{DM}_{1}$ & 10.461 & 0.033 & 0.5303 \\
\hline $\mathrm{U}_{10}-\mathrm{DM}_{1}$ & 15.112 & 0.004 & 0.6180 \\
\hline $\mathrm{U}_{10}-\mathrm{DM}_{2}$ & 10.983 & 0.027 & 0.5416 \\
\hline & & & \\
\hline
\end{tabular}

In addition, the chi-square test showed no significant association between any BIM use and the LDM practices: $\mathrm{SM}_{3}$ "requirements management (identification of constraints, technical specifications and special requirements)", $\mathrm{DM}_{3}$ "PDCA problem solving", $\mathrm{DM}_{5}$ "decision-making until the last responsible moment", and $\mathrm{DM}_{7}$ "multicriteria decisionmaking". The accurate requirements definition is a key factor in any construction project (Molwus et al., 2017). Therefore, the independence of this variable with or without the use of BIM demonstrates that the AEC industry has considered this a basic factor for the 
development of projects. Similarly, problem solving using PDCA is a widely used technique. In this study, $75 \%$ of projects apply these LDM practices at level 3 or higher; thus, its application is independent of the use of BIM. However, there is evidence of the joint application of PDCA and BIM in the context of the Digital Obeya Room, which promotes activities that use BIM-Lean approaches aiming at continuous flow and Jidoka (Nascimento et al., 2018). The practices associated with decision making $\left(\mathrm{DM}_{5}\right.$ and $\left.\mathrm{DM}_{7}\right)$ are not related to any use of BIM, since both LDM practices have a low level of application, it is not possible to make strong conclusions about this relationship; however, it can be summarized that applying certain uses of BIM by themselves does not imply that any LDM practice aligned with decision making is being carried out.

Table 6 shows the chi-square test results for the pair of variables that are related. In addition, this table presents the calculated chi-square, the associated p-value and the standardized contingent coefficient of each pair of variables. The 33 relationships found have a standardized contingent coefficient between 0.50 and 0.63 , i.e., the associativity between all pairs of variables has a strong relationship, as shown in Table 5.

The 33 significant relationships presented in Table 6 are equivalent to $17.36 \%$ of the potential relationships between the $19 \mathrm{LDM}$ practices and the $10 \mathrm{BIM}$ uses. There are four LDM practices and one use of BIM that are not present in any relationship, so the relationship between the fifteen LDM practices and the nine uses of BIM can be visualized in Fig. 5. In this figure, a graph can be visualized where the nodes are the variables LDM practices and BIM uses in white and black, respectively; the size of the nodes is equivalent to the number of links that this variable has. The link between variables is represented with a line that indicates a weight equivalent to the standardized contingency coefficient. Then, 
through an attraction and repulsion algorithm between the nodes called Force Atlas (Thangaraj \& Amutha, 2018), the variables with the highest relative relationship are grouped.

From the graph, it can be observed that $\mathrm{U}_{4}$ "space programming" and $\mathrm{U}_{6}$ "code validation" are the BIM uses that are most related to LDM practices. On the other hand, the LDM practices associated with more $\mathrm{BIM}$ uses are $\mathrm{PC}_{4}$ "gradual planning", $\mathrm{PC}_{1}$ "use of database for planning", $\mathrm{DM}_{1}$ "collaborative problem solving" and $\mathrm{DM}_{2}$ "causal analysis of problems". Each LDM practice is connected on average to two or three BIM uses, and through a clustering analysis, five groupings can be identified that include one or two BIM uses. Ten years ago, Sacks et al. (2010) proposed a framework with 56 potential interactions between BIM functionalities and Lean Construction principles, where they argued that at that time, companies and professionals were still in the process of learning BIM and Lean. Currently, the actual interaction between Lean and BIM is still low in the planning and design phase of construction projects in relation to the potential interactions between Lean and BIM. 


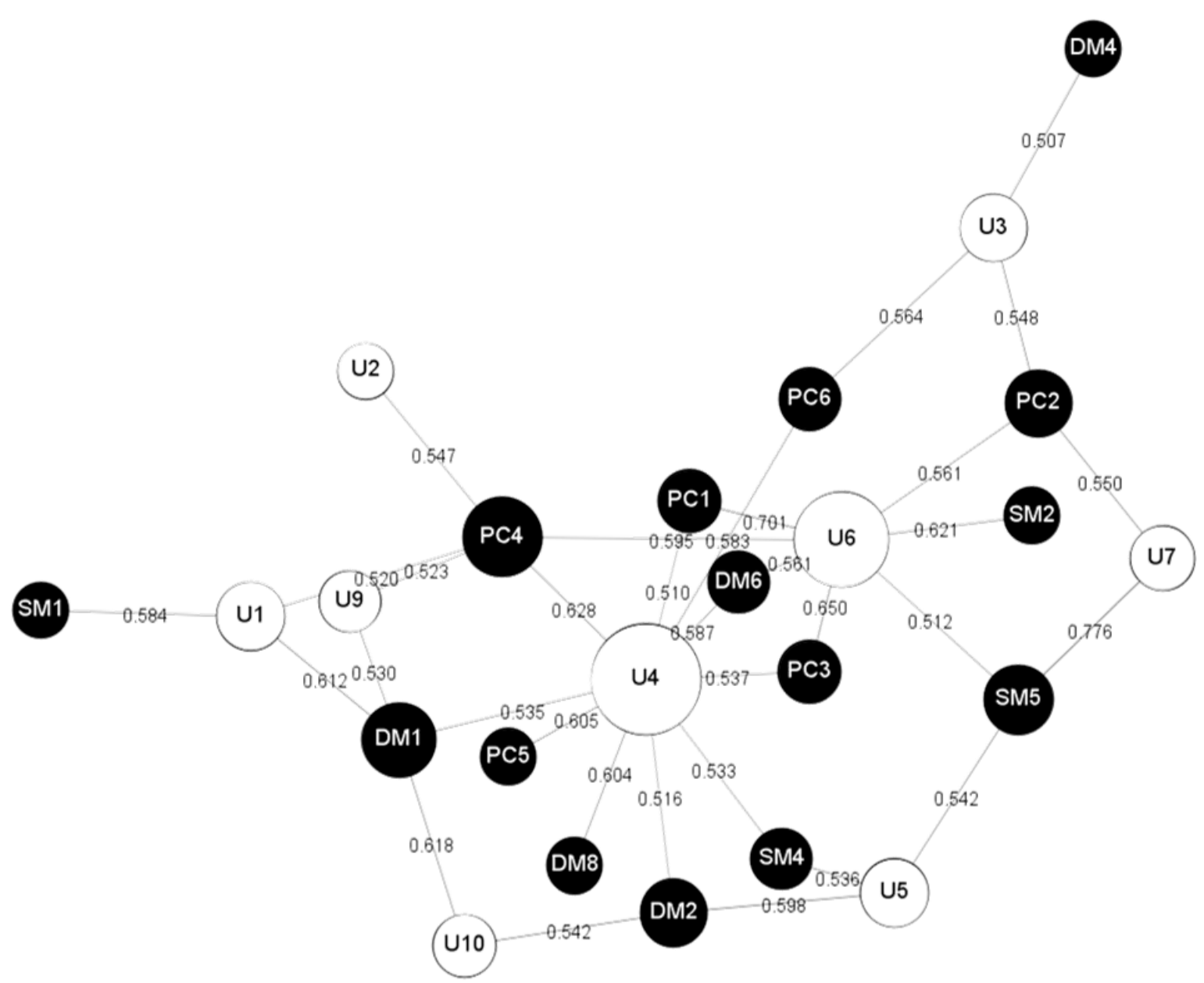

Figure 5-5: Association between LDM practices and BIM uses

Finally, a necessity and sufficiency analysis was performed to assess the causal relationship between the LDM practices proportion ( $\mathrm{pl}$ ) and the BIM uses proportion ( $\mathrm{pb}$ ) using the data of the 64 evaluated projects. Figure 5-6 shows on the x-axis the BIM use proportion of each project, and on the y-axis the corresponding LDM practices proportion of that project. The graph shows a higher density of points in the upper-left triangle, which means that more projects have a higher proportion of LDM practices than the proportion of BIM uses; i.e., a higher proportion of BIM uses is a sufficient condition to result in a higher proportion of LDM practices. 


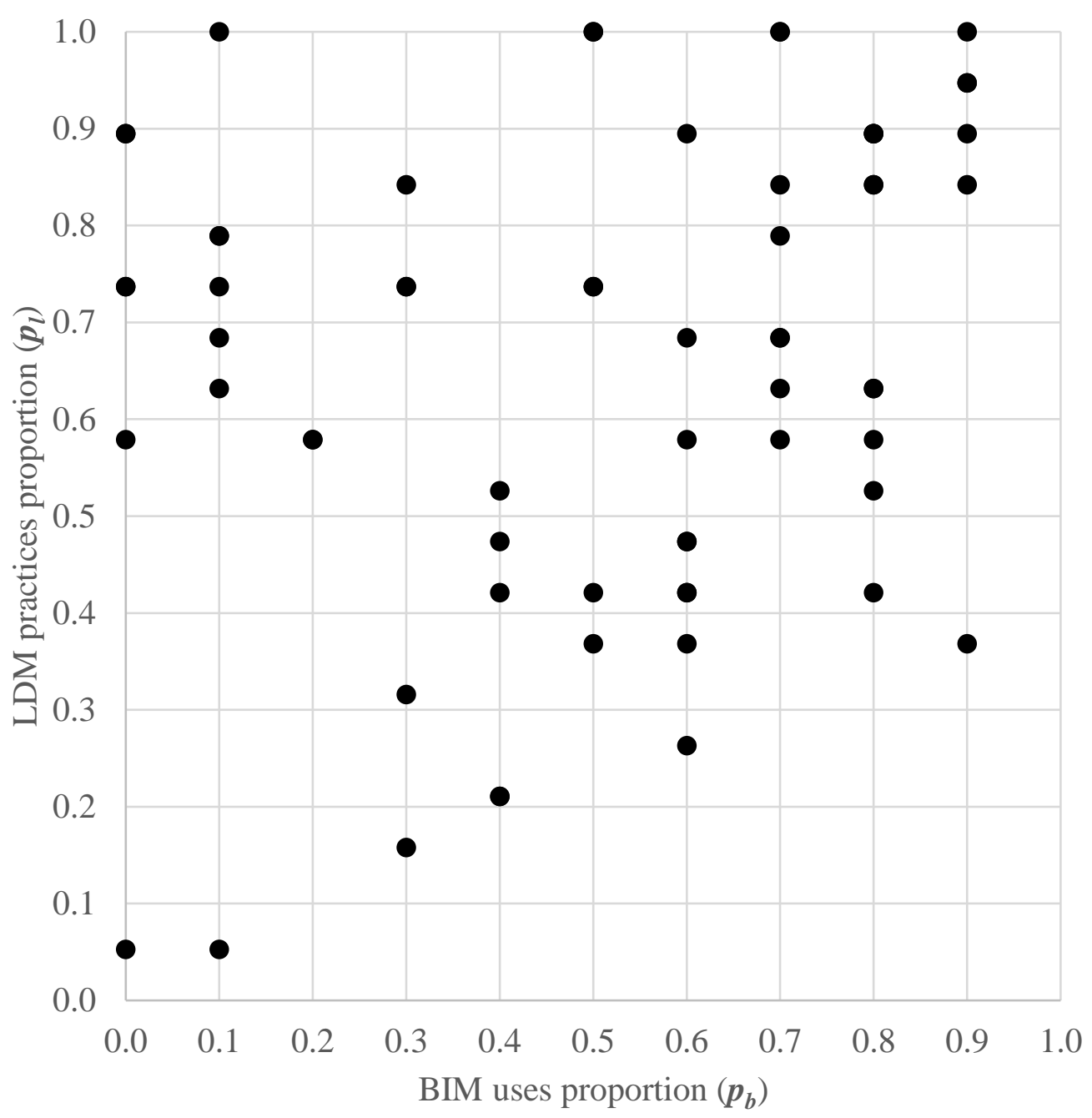

Figure 5-6: LDM practices proportion and BIM uses proportion graph

To confirm the graphical interpretation of Figure 5-6, it is necessary to calculate the consistency score of the relationship between the two variables. Table 5-7 presents the consistency index for the necessity and sufficiency relationship between the LDM practices proportion $\left(\boldsymbol{p}_{l}\right)$ and the BIM uses proportion $\left(\boldsymbol{p}_{\boldsymbol{b}}\right)$. From the consistency analysis, it can be interpreted that a higher LDM practices proportion is a necessary condition to have a higher BIM use proportion as a result. In contrast, a higher proportion of BIM uses is a sufficient condition to have a higher proportion of LDM practices as a result. That is, 
whenever a project performs a high proportion of BIM uses, this implies that a high proportion of LDM practices is being applied; however, a high proportion of LDM practices does not ensure that a high proportion of BIM uses is being applied. In other words, when an organization develops more BIM uses in its projects, teams tend to adopt more lean practices to manage the project.

Table 5-7: Consistency Score between $\mathrm{p}_{\mathrm{b}}$ and $\mathrm{p}_{\mathrm{l}}$

\begin{tabular}{|c|c|c|c|}
\hline Condition & Outcome & Necessity & Sufficiency \\
\hline$p_{l}$ & $p_{b}$ & 0.8738 & 0.6733 \\
\hline$p_{b}$ & $p_{l}$ & 0.6733 & 0.8748 \\
\hline
\end{tabular}

\subsection{Conclusions}

This study examined the association among BIM uses and lean design management practices in the planning and design of construction projects through the BUA instrument and the LDM practices questionnaire, respectively. Based on data from 64 projects, this study performed an association analysis between each pair of variables, i.e., 10 BIM uses and 19 LDM practices. A chi-square analysis revealed 33 significant relationships between BIM uses and lean design management practices, which is equivalent to $17.36 \%$ of the potential relationships between the variables measured with these instruments. The associations found have a standardized contingent coefficient between 0.50 and 0.63 ; i.e., the associativity between all pairs of variables has a strong relationship. No association was found between the use of BIM U "engineering analysis" and any LDM practices. There was also no association between $\mathrm{SM}_{3}$ (requirements management) and $\mathrm{SM}_{4}$ (client systematic participation) practices with any of the ten BIM uses. On the other hand, the BIM uses $\mathrm{U}_{4}$ "space programming" and $\mathrm{U}_{6}$ "code validation" were the BIM uses that are 
most related to LDM practices. In addition, the LDM practices associated with more BIM uses were $\mathrm{PC}_{4}$ "gradual planning", $\mathrm{PC}_{1}$ "use of database for planning", $\mathrm{DM}_{1}$ "collaborative problem solving", and $\mathrm{DM}_{2}$ "causal analysis of problems". The analysis of the relationship between LDM practices and BIM uses allows having empirical evidence of the LDM practices that are present in each BIM use in the design phase of construction projects. LDM practices from the categories "planning and control" and "problem solving and decision making" are more related to BIM uses than LDM practices from the category "stakeholder management". Additionally, it can be concluded that if a project applies a higher proportion of BIM uses, it will tend to apply a higher proportion of LDM practices; however, this relationship is not as clear in the other way around.

The results confirm that the implementation of BIM uses and LDM practices, at the design phase, are at a nascent stage, given that the relationship between Lean and BIM and their potential have not been explored extensively. In this learning phase, BIM uses are still applied as isolated technological implementations of collaborative management and other best management practices aligned with Lean. Therefore, this study reinforces the need to apply BIM as a whole to LDM, and even more at the design and planning phases of the infrastructure lifecycle. Additionally, it is concluded that there is no double implication between BIM uses and the application of LDM, since with the causal analysis, it was found that the application of BIM uses implies a greater application of LDM practices; however, a greater application of such practices does not imply a greater application of BIM uses. This means that organizations that are more advanced in the development of BIM in their projects tend to apply design management practices aligned 
with lean, which encourages collaboration, transparency of information and better planning, problem solving and decision making in the design of the construction project.

Moreover, since several countries are defining a regulatory framework that promotes the use of BIM, organizations that manage their projects under Lean principles will naturally be able to apply the BIM methodology. The results obtained allow project managers and executives to carry out a benchmark study of the practices and uses of BIM applied in their projects in comparison with other projects in the planning design phase. Additionally, it allows the identification of sets of design management practices associated with certain BIM uses, allowing the adopter of these methodologies to prioritize efforts in the combined implementation of Lean and BIM in their projects.

Some limitations of this study are stated next. The 64 projects evaluated are not a statistical sample, considering the number of projects in the design process in the countries where they were evaluated; hence, a larger number of projects should be assessed. The qualification of each project has to be done with at least two researchers or specialized consultants to provide higher objectivity of the assessment; therefore, future studies could create a instrument that would be used as a self-evaluation for each project. In addition, this study did not measure the effect of the application of LDM practices and BIM uses on the performance of the 64 projects. Therefore, future research should aim to assess the performance of the design process and the organizational performance of the design team; in this way, it will be possible to identify the effect of LDM practices on the performance of the construction project, both during its design and in its execution. In addition, this study did not include particular tools, such as, set-based design, target value design, the last planner system, choosing by advantages, or big room, among others. Within these 
tools one or more of the LDM practices are applied; therefore, it would be interesting to study the impact of the application of BIM with one of them in the design phases of construction projects. 


\section{COMPARING TEAM INTERACTIONS IN TRADITIONAL AND BIM-LEAN DESIGN MANAGEMENT}

\subsection{Introduction}

The architecture, engineering, and construction (AEC) industry has been criticized for its fragmented approach to project delivery and its failure to form effective teams (Baiden et al., 2006). Additionally, the AEC industry has an adversarial nature, which has resulted in poor project performance and a lack of innovation (Love et al., 2002). This fragmentation, caused by the isolation of professionals and a lack of coordination between the individuals involved in the design and those involved in building, has impacted construction performance, leading to a lack of integration, waste, low productivity, and low efficiency (Othman et al., 2016). Additionally, certain barriers to improved integration seem to stem from the historical fragmentation of project delivery systems and the contractual and adversarial nature of construction project relationships (Dainty et al., 2001).

Addressing this high degree of fragmentation requires better interaction between the specialties of the industry ( $\mathrm{Ng} \&$ Tang, 2010); this improved interaction depends on coordination and communication (Schöttle et al., 2014). Full integration occurs when individual team members view themselves as equals in the process, and when the initial collaboration among them is focused on exploring and defining the problem. Hence, the building process cannot be optimized without full collaboration and, ultimately, integration among all its project members (Fakhimi et al., 2016). Therefore, team integration is critical 
to developing projects and achieving value for the clients and stakeholders involved in these projects (Kestle \& London, 2002).

Poor interaction among specialists, clients, and other team members can have negative consequences, such as an inappropriate synthesis of the needs analysis of the project that results in a lack of value generation for the client and the end-users (Kestle \& London, 2002). Consequently, poor interactions among work teams can lead to poor performance, both in the implementation of each phase (namely, the phases of design, construction, maintenance, operation, and deconstruction) and in the overall life cycle of the infrastructure (Baiden et al., 2006). This is particularly important during the design phase because decisions made during this phase can significantly affect the following phases, and the cost of making changes during this phase is insignificant compared with the cost of implementing changes during future phases (AIA, 2007).

As the interdependence and complexity of design tasks increase, the need for synchronous communication becomes vital; therefore, the efficacy and challenge of design management is rooted in the appropriate management of its workflow (Knotten et al., 2017). It is critical to consider the interactions within design teams and those between the design teams of different disciplines due to the interdependent nature of the design phase (Al Hattab \& Hamzeh, 2015). Therefore, managing the design workflow includes managing the people involved in the design process as well as the flow of information among them to enable the progression of design solutions (Knotten et al., 2017). The interactions among the professionals involved in the design team of a construction project is fundamental to the performance of the project (Svalestuen et al., 2015). To analyze the interactions of work teams, different tools can be used, such as a survey, a frequency 
analysis, an $\mathrm{n} \times \mathrm{n}$ matrix, a social network analysis (SNA) (Yang \& Tang, 2004), and a design structure matrix (Rosas, 2013). SNA has attracted attention in the AEC industry because it can be used to examine the role of nonformal structures in their coexistence with formal structures (D. M. Alarcón et al., 2013).

One of the challenges faced in this study is determining the methodologies used to achieve this higher level of interaction. Many studies have recommended Building Information Modeling (BIM) as a workable option to address this issue (Baiden et al., 2006), and Lean has also been applied to the design phase (C.-H. Ko \& Chung, 2014). Additionally, Lean practices and BIM functionalities can enable a better design workflow through their focus on teamwork and information integration and sharing (Knotten et al., 2017). One of the theoretical benefits of BIM and Lean is that errors in design can be better addressed in a way that reduces both their incidence and their dissemination. Additionally, BIM and lean principles improve the exchange of information and create a more cohesive social network with increased collaboration and connections within teams and between different teams (Al Hattab \& Hamzeh, 2015).

There is qualitative evidence showing that design teams that use BIM and Lean have higher levels of interaction than design teams that do not use these management and technology support methodologies (Becerik-Gerber, Kihonh, Jazizadek, Ku, \& Jazizadeh, 2012; Fakhimi et al., 2016). However, there does not seem to be any quantitative empirical evidence of this higher level of interaction. Additionally, this concept is not studied indepth to examine the dimensions of interaction in which this theoretical increase exists, since there are multiple types of interaction within the design process, such as work information flows, planning and solving problems, collaboration, and learning (Herrera et 
al., 2020b). Therefore, the objective of this paper is to present quantitative empirical evidence of the differences that exist among the various types of interactions of a design team through a comparative analysis of two case studies involving high-rise building construction projects in Chile. To assess the interactions among the design teams of these projects, the researchers involved in this study used social network analysis (SNA) since it allows for the extraction of qualitative and quantitative information from each type of interaction through sociograms and graph theory metrics that explain the behavior of the design team (Pryke, 2012).

\subsection{Background}

\section{Design management}

The design phase of any construction project involves several designers who exchange information with each other, most often in an unstructured manner, throughout the design phase (Mujumdar \& Maheswari, 2018). Like any project, the design management process involves planning, organizing, and managing people, knowledge, and flows of information to achieve specific project goals and objectives (Knotten et al., 2017). Additionally, design management is fundamentally concerned with value generation for the customer or client, which involves integrating various specialists' knowledge and the accurate timing of critical decisions. These objectives are achieved through an integrated team approach to the design, construction, implementation, and management of a project (Kestle et al., 2011).

Traditionally, the design phase of a project is characterized by a high level of uncertainty due to the ill-defined nature of its requirements, solutions, or outputs. The design requirements of a project can be well understood, whereas the solutions and 
resulting outputs cannot be defined in advance and are generally vague at the beginning of a project (Al Hattab \& Hamzeh, 2017). Recent research has proposed that the design process should be studied through an evaluation of its performance (Herrera, Mourgues, Alarcon, \& Pellicer, 2019; Salvatierra et al., 2019), an implementation of integrated management systems and visual management tools (Abou-Ibrahim \& Hamze, 2017), and its optimization (Knotten et al., 2017). Nevertheless, there are still several challenges in the design management of construction projects, for instance, the challenges posed by the collaborative methodologies of various specialties and the use of technology (Whyte \& Tombesi, 2013). Thus, it is important to facilitate the application of collaborative technologies and methodologies to design management, considering that the extensive interdependence of design information and the tasks of many trades that are involved in design increases the complexity of this process. Furthermore, the design environment is built upon interaction and communication among various multidisciplinary teams whose processes and information are constantly dependent on one another (Al Hattab \& Hamzeh, 2017).

Lean design introduces several elements of the Lean philosophy that are fundamental to the design phase, for example, the active and systematic involvement of clients during the early stages of a project, the maximization of the value generated, the identification of the needs and objectives of all interested parties, the simultaneous design of the product and the process, and the postponement of the decision-making step until the last responsible moment to reduce reworks and unnecessary tasks (Gambatese et al., 2017). Herrera et al. (2020b) summarized 19 lean design management (LDM) practices for the design phase of construction projects, namely, the early involvement of specialist designers 
and builders, the exhaustive definition of all the requirements of stakeholders, systematic client participation, the simultaneous design of the product and the process, the implementation of design planning activities, the collection of data for planning, collaborative and systematic planning, gradual planning, constraint management, coordination among specialist designers, collaborative problem-solving, the causal analysis of problems, monitoring problem-solving processes, multiple option decision making, the examination of all available information for decision making, the collection of data for decision making, collaborative decision making, and monitoring decision-making processes. The same study also proposes a questionnaire that assesses the degree of implementing each of these practices and defines a taxonomy of LDM practices.

Moreover, BIM has positioned itself as a technology-supported methodology that promotes the integration of and collaboration among work teams through its multiple uses (Kapogiannis \& Sherratt, 2018). A BIM use is defined as a method of applying building information modeling during a facility's lifecycle to achieve one or more specific objectives. Some examples of BIM uses that are relevant for the planning, and design phases of construction projects include cost phase planning, site analysis, design review and authoring, and 3D coordination (R. G. Kreider \& Messner, 2013). Rojas et al. (2019) designed a BIM uses assessment (BUA) tool to diagnose the application of BIM uses; this tool allows companies and clients to identify the status of the BIM uses of the project, i.e., how BIM uses are being implemented, and the design team's opportunities for improvement. 


\section{Dimensions of design team interaction}

The interactions among work teams have been studied from the perspectives of several dimensions, such as those of information flows, planning, coordination, collaboration, innovative ideas, and learning. For instance, Herrera et al. (2020a) identified two perspectives of interaction dimensions: traditional interaction and commitment management. On the one hand, the traditional interaction perspective includes the concepts of social interaction, information flow, problem-solving interaction, planning interaction, collaboration, innovative idea interaction, trust, and learning. On the other hand, the commitment management perspective is critical to the design phase because this approach facilitates the shared understanding in multidisciplinary teams, thus supporting the discussion and negotiation that are common during the design process (Kleinsmann et al., 2012). All of these types of interaction can be measured and evaluated through social network analysis (SNA) (Herrera et al., 2020b).

SNA is the product of collaboration between mathematicians, anthropologists, and sociologists. This tool involves representing organizational relationships as a system of nodes or actors linked by precisely defined connections (networks) (Pryke, 2012). Each network can be represented graphically with a sociogram and mathematical metrics such as density, length, and diameter (Marin \& Wellman, 2011). There are directed and undirected networks. In directed networks, the relationship between two actors can be unidirectional or bidirectional. In contrast, the relationships in an undirected network must be bidirectional (Pryke, 2012). Some of the types of interactions that can be evaluated through SNA are explained below. 
Global interaction refers to any type of interaction between two people, for example, telephone conversations, mail exchanges, social conversations, or business meetings (D. M. Alarcón et al., 2013); therefore, the use of a bidirectional link (i.e., an undirected network) is necessary. Relevant work information flows from person A to person B. This information is necessary to the project and adds value to it but is not freely available (Castillo, Alarcón, \& Salvatierra, 2018); therefore, it is not necessarily a reciprocal link (i.e., a directed network). Collaboration refers to work jointly accomplished by two or more people (Herrera et al., 2020b); therefore, it is a necessary reciprocal link (i.e., an undirected network). In the same way, planning and problem-solving is an undirected network that refers to two or more people jointly defining and redefining tasks, schedules, and resources, among other tasks (Castillo, Alarcón, \& Salvatierra, 2018). Additionally, when a person trusts in the work of another person, a one-way link of trust is created (Priven \& Sacks, 2013), i.e., a directed network. In the same way, when a person learns something new from another person, a one-way link is created (Herrera et al., 2018).

The commitment network approach emphasizes the actions that people take while communicating, how language is used to create a common reality, and how activities are coordinated through language (Viana et al., 2011). The basic elements of this perspective are speech acts, which comprise a set of rules for systematizing commitment management (Searle, 1969). The commitment cycle has four phases: (1) the request and proposal, (2) the negotiation and agreement, (3) the declaration of compliance and performance, and (4) the declaration of acceptance and satisfaction (Medina-Mora et al., 1992). The request for requirements, the declaration of compliance and performance, and the declaration of acceptance and satisfaction can be depicted as directed networks, as they do not represent 
obligatory links between two people. However, the negotiation and agreement phase should be considered an undirected network since at least two people must always be included (Herrera et al., 2020b).

\subsection{Research method}

The case study research method was used in this paper, following the recommendations of Yin (2009). Two case studies were analyzed, and their design management was assessed from a Lean BIM perspective while their team interactions were assessed using SNA. To achieve the objective of this paper, four steps were performed: (1) case study selection, (2) description of the design management of the projects from the LDM and BIM perspectives, (3) assessment of design team interaction, and (4) comparison of design team interaction using SNA.

\section{$\underline{\text { Case study selection }}$}

The selection of projects was intentional and aimed to facilitate literal and theoretical replication. The authors defined a list of 10 comparative criteria to select the two case studies (Table 6-1). To facilitate literal replication, two projects with similar features concerning the first nine criteria in Table 6-1 were chosen. To facilitate theoretical replication, the research team ensured that the two selected projects exhibited opposing characteristics in relation to at least one characteristic criterion (Yin, 2009). The research team decided to use the application of BIM methodologies during the design phase (see criterion 10 in Table 6-1) as the opposing characteristic; however, during the research process, the researchers characterized the actual application of LDM practices, and BIM uses in both projects to validate the project manager's reporting regarding Lean BIM 
management. Project A was chosen due to its use of traditional, informal design management without the methodological and technological support of BIM, while project B was chosen because of its use of BIM methodology. Both projects had the following design team members: client representative (CR), project manager (PM), architect (A), geotechnical engineer (GE), structural designer (SD), electrical specialist (E), plumbing specialist (P), gas specialist (G), irrigation designer (ID), and landscape designer (LD). Additionally, project B included a BIM manager (BM) and a construction company representative $(\mathrm{CO})$; therefore, there are ten and twelve design team members in projects $\mathrm{A}$ and $\mathrm{B}$, respectively.

Table 6-1: Characteristics of projects A and B according to the selection criteria

\begin{tabular}{|l|c|c|}
\hline Selection criteria & Project A & Project B \\
\hline 1. Type of project: high-rise building & $\checkmark$ & $\checkmark$ \\
\hline 2. Delivery method: design-bid-build & $\checkmark$ & $\checkmark$ \\
\hline 3. Client and constructor are the same corporative group & $\checkmark$ & $\checkmark$ \\
\hline $\begin{array}{l}\text { 4. Size of client company (according to European } \\
\text { Commission 2003): large }\end{array}$ & $\checkmark$ & $\checkmark$ \\
\hline $\begin{array}{l}\text { 5. All specialists and designers are from different } \\
\text { organizations }\end{array}$ & $\checkmark$ & $\checkmark$ \\
\hline 6. All design team members are located in Santiago, Chile & $\checkmark$ & $\checkmark$ \\
\hline 7. Project location: Santiago, Chile & $22(14,200)$ & $24(15,000)$ \\
\hline 8. Project size: numbers of floors (m $\left.{ }^{2}\right)$ & $x$ & $x$ \\
\hline $\begin{array}{l}\text { 9. Explicit Lean application (as reported by the client } \\
\text { company) }\end{array}$ & $\checkmark$ & $\checkmark$ \\
\hline $\begin{array}{l}\text { 10. Explicit BIM application (as reported by the client } \\
\text { company) }\end{array}$ & & $\checkmark$ \\
\hline
\end{tabular}

The number of projects studied is related to the complexity of the expected results (Yin, 2009). Yin's (2009) approach shows that for a descriptive theory, such as the theory used in this research, two cases can suffice. Based on the projects studied, the domains to 
which the research results can be generalized are: (1) the design phase of the infrastructure life-cycle; (2) building construction; (3) large and medium-sized companies; (4) small temporary organization of fewer than 50 people (European Commission, 2003); and (5) varying degrees of application of LDM practices and BIM uses.

\section{Description of design management}

To describe the design management of each project, the researchers conducted interviews with the client representative $(\mathrm{CR})$, the project manager $(\mathrm{PM})$, and the BIM manager; the latter was only interviewed in project $B$. The instruments used for these interviews were the LDM practices questionnaire (Herrera et al., 2020a), and the BIM uses assessment (BUA) tool for design and planning (Rojas et al., 2019).

These tools were applied using recorded interviews (audio was recorded with the consent of the interviewee) with the CR, PM, and BIM manager, covering all the topics addressed in each questionnaire and following the criteria established by Woodside (2010). Then, the researchers listened to these recorded interviews and rated each item on each questionnaire for both projects using a 5-point Likert scale, as explained below.

The LDM practices questionnaire uses a five-point scale to measure the 19 practices. Each LDM practice follows the method of Bloom and Van Reenen (2010); namely, a description is provided for scores 1, 3, and 5, while scores 2 and 4 are defined as intermediate points between scores 1 and 3 and 3 and 5, respectively. The general descriptions for each score are (1) traditional management practice, (3) initial lean design management practice, and (5) developed lean design management practice (Herrera et al., 2020a). The BUA questionnaire also rates each use on a scale from one to five, where the first level (1) denotes a traditional method with a 2D model, i.e., no use of BIM; the second 
level (2) denotes a low use of BIM and includes little BIM-related information in the model; the third level (3) denotes a medium use of BIM and sufficient information for its implementation; the fourth level (4) denotes a high use of BIM; and the fifth level (5) denotes a full use of BIM, i.e., the best methods and tools are utilized. The above is a general description of each BUA level; however, different features and levels of automation were evaluated for each BIM use in the planning and design of the projects (Rojas et al., 2019). Finally, a benchmark was established for projects A and B using other projects evaluated with the same instruments. The projects used for the benchmark in this study were derived from the studies of Rojas et al. (2019) (who assessed the BIM uses in 25 projects) and Herrera et al. (2020b) (who assessed the LDM practices in 64 projects).

\section{$\underline{\text { Interaction assessment and case study comparison }}$}

An interaction assessment was conducted, although the method for understanding the interaction in the design follows that of Herrera et al. (2020a). This method recommends the use of SNA to analyze the data obtained via surveys conducted with all the members of the design team. The interactions evaluated in this study were knowledge of roles and responsibilities, global interaction, the flow of relevant information, planning and problem solving, collaboration, trust, learning, and commitment management. The method consisted of four main stages: (1) definition of the initial conditions, (2) information capture, (3) data processing, and (4) information analysis.

During the step involving the definition of the initial conditions, the researchers detailed the assessment procedure. First, a 12-week interaction evaluation period was defined, including representatives from both projects; this period was consistent with the detailed design stages of both projects. Then, for both projects, the use of online surveys 
was chosen as the method to be used for collecting data, given the non-collocated nature of the various members of the design team. Third, the participants of the study were defined; as mentioned before, projects $\mathrm{A}$ and $\mathrm{B}$ had 10 and 12 members in their design teams, respectively. Fourth, given the subjective nature of the information source employed (namely, individuals' perceptions), a coherence analysis was carried out on the global interaction network to validate the quality of this information, since the network was undirected and correspondence among the responses of the different participants was expected. Therefore, the minimum percentage of valid connections (PVC) to consider the responses valid was set at $80 \%$, given that this is a typical confidence level used in risk analyses involving the construction industry. Finally, Gephi was selected as the software to be used to calculate metrics and the realization of sociograms, given the precedence set by prior researchers regarding the use of this tool.

The second stage (information capture) consisted of two activities: the design of the survey and the actual data collection. Certain types of interactions, namely, knowledge of roles and responsibilities, global interaction, trust, learning, and request for requirements allowed for yes or no responses. Other types of interaction, namely, relevant information flow, planning and problem-solving, and collaboration, were answered using the following frequencies: never, monthly, weekly, and daily. The remaining types of interaction, namely, requirements negotiation, declaration of compliance and performance, and declaration of acceptance and satisfaction, were answered using the following frequencies: never, sometimes, frequently, and always. Each participant in the study responded according to the type of interaction he/she had experienced with all the other design team 
members. Finally, the survey was required to have a 100\% response rate to be used for the analysis.

In the third stage of data processing, the first step is to verify that the PVC exceeds the minimum of $80 \%$ and that the response rate is $100 \%$. Then, the metrics are calculated (Table 6-2), and the sociograms for each type of network are created. Finally, in the fourth stage, a comparative analysis of both projects is carried out.

Table 6-2: Metrics for each network (Herrera et al., 2020b)

\begin{tabular}{|c|c|}
\hline Type of network & Metrics \\
\hline $\begin{array}{l}\text { Knowledge of roles } \\
\text { and responsibilities }\end{array}$ & In-degree of each node; mean in-degree of the network \\
\hline Global interaction & $\begin{array}{l}\text { Degree of each node; mean and range degree of the network; \# of } \\
\text { connected components }\end{array}$ \\
\hline $\begin{array}{l}\text { Relevant work } \\
\text { information }\end{array}$ & $\begin{array}{l}\text { Percentage of bidirectional links; in-degree and out-degree of } \\
\text { each node; mean and range degree of the network; \# of weakly }\end{array}$ \\
\hline $\begin{array}{l}\text { Learning } \\
\text { Collaboration }\end{array}$ & Percentage of bidirectional links; degree of each node; mean and \\
\hline $\begin{array}{l}\text { Planning and problem } \\
\text { solving }\end{array}$ & range degree of the network; \# of connected components \\
\hline Trust & $\begin{array}{l}\text { \# of links in the trust network/\# of links in the knowledge of roles } \\
\text { network }\end{array}$ \\
\hline $\begin{array}{l}\text { Request for } \\
\text { requirements }\end{array}$ & Requirement links \\
\hline $\begin{array}{c}\text { Requirement } \\
\text { negotiation }\end{array}$ & Negotiated links/requirement links \\
\hline $\begin{array}{l}\text { Declaration of } \\
\text { compliance }\end{array}$ & Compliance declaration links/requirement links \\
\hline $\begin{array}{l}\text { Declaration of } \\
\text { satisfaction }\end{array}$ & Satisfaction declaration links/requirement links \\
\hline
\end{tabular}




\subsection{Results and discussions}

Figure 6-1 shows the results of the BUA application in both projects. The evaluation of project A shows that BIM uses were not applied in this project, as was mentioned by its project manager during the project description. The unique application of BIM at the initial level corresponds to a 3D coordination between the architecture and the structural model. Therefore, project A was entirely designed using traditional methodologies, i.e., the use of CAD and non-BIM technologies. On the other hand, project B shows some level of BIM application for each of the BIM uses considered in this study, as mentioned by the project manager and the client representative during the project description. All the BIM uses in the planning, and design phases were applied at the initial level, 5 out of 10 were applied at an intermediate level, 2 out of 10 were applied at a high level, and one was applied at a comprehensive level.

Projects A and B can be contrasted with the results of a study regarding 25 projects in Chile, Colombia, and Spain (Rojas et al., 2019). Project A consistently corresponded to the minimum application of BIM exhibited by the projects in the aforementioned study. However, project B in the maximum values of application in the BIM uses: "4D planning" and "3D coordination"; it was in the 75th percentile in the uses of "cost estimation", "site analysis", "space programming", "design review", and "engineering analysis"; and it was in the 50th percentile in the uses of "code validation", "sustainability evaluation", and "design authoring". Therefore, the results of the BIM use assessment demonstrate that project A 
did not use BIM methodology in its planning and design; however, project B used BIM methodology and stood out in its use of these methods even among similar projects.

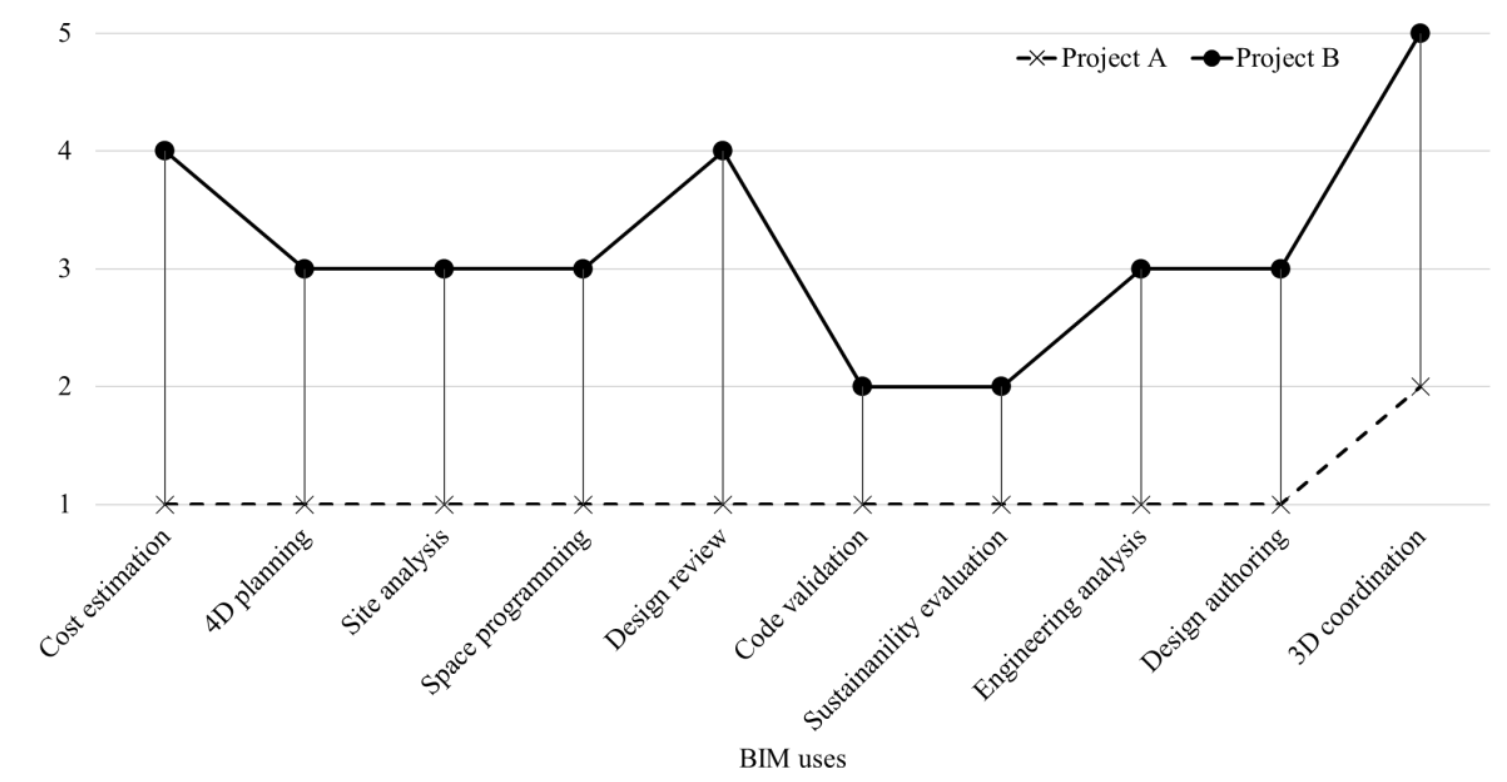

Figure 6-1: BIM uses assessment: project A and project B

Neither project explicitly applied lean design methodologies to manage the project during the design stage. However, the researchers assessed the LDM practices in both projects since BIM methodology indirectly involves the application of certain lean principles (Fakhimi et al., 2016); thus, projects that apply BIM methods could be expected to apply some lean practices as well. Figure 6-2 presents the results obtained from the assessment of the LDM practices in projects A and B. Project B had a higher level of implementation of all the LDM practices than did project A, confirming that the application of BIM methodology entails the application of some lean principles as well.

Project A did not apply the practices of the early involvement of builders and the simultaneous design of the product (building) and the production (construction) process. Considering that the client's company and the construction company belong to the same 
corporate group and are even physically located in the same place, both of these lean practices could have been applied to project A without significant complications. The LDM practices of the exhaustive collection of requirements from all stakeholders and the client's systematic participation were implemented at the initial level of lean application; given the company's experience with this type of project and their closeness to the client, they could have used both of these conditions to improve the design process in addition to implementing other LDM practices. Project A did not exhibit any LDM practices at the 4th and fifth application levels, and only 7 of the 19 LDM practices were implemented at the initial level of lean application. The project manager and the client representative responded that their company does not have standardized practices that facilitate the management of their projects in design phases, and each project manager manages according to his/her level of experience. In addition, they were not familiar with the concept of lean design, although they were familiar with lean construction due to their application of the last planner system during the construction phase of other projects.

The project manager of project B did not know if he was applying lean practices in his management; however, this project applied several lean practices at a high level of implementation. Six out of the 19 LDM practices were fully implemented, including exhaustive requirements management, systematic client participation, gradual planning, coordination of specialists, and monitoring problem solving and decision-making processes. At the beginning of project $\mathrm{B}$, the design team, which was led by the project manager and the BIM manager, defined the workflow using the participation times of each designer and/or specialist, and they scheduled weekly meetings for planning and problemsolving. Additionally, a BIM common virtual data environment was used in project B, in 
which all the team members could make notes and propose changes to the project. All of these factors allowed the team to exhibit high levels of implementation of lean practices. However, two LDM practices were implemented at a low level: the simultaneous design of the product and the construction process and the use of a database to record the lessons learned regarding planning and decision making. This project was the first in the company that had involved the builders in the early stages of the project. According to the client and construction company representatives, this project provided a useful experience that they planned to standardize to be used in other projects. In addition, they stated that the next project would implement the simultaneous design of the product and the construction process as a pilot test. However, the company did not yet have an organized database of lessons learned regarding project planning and decision making, so both of these practices were assessed at the initial levels of implementation.

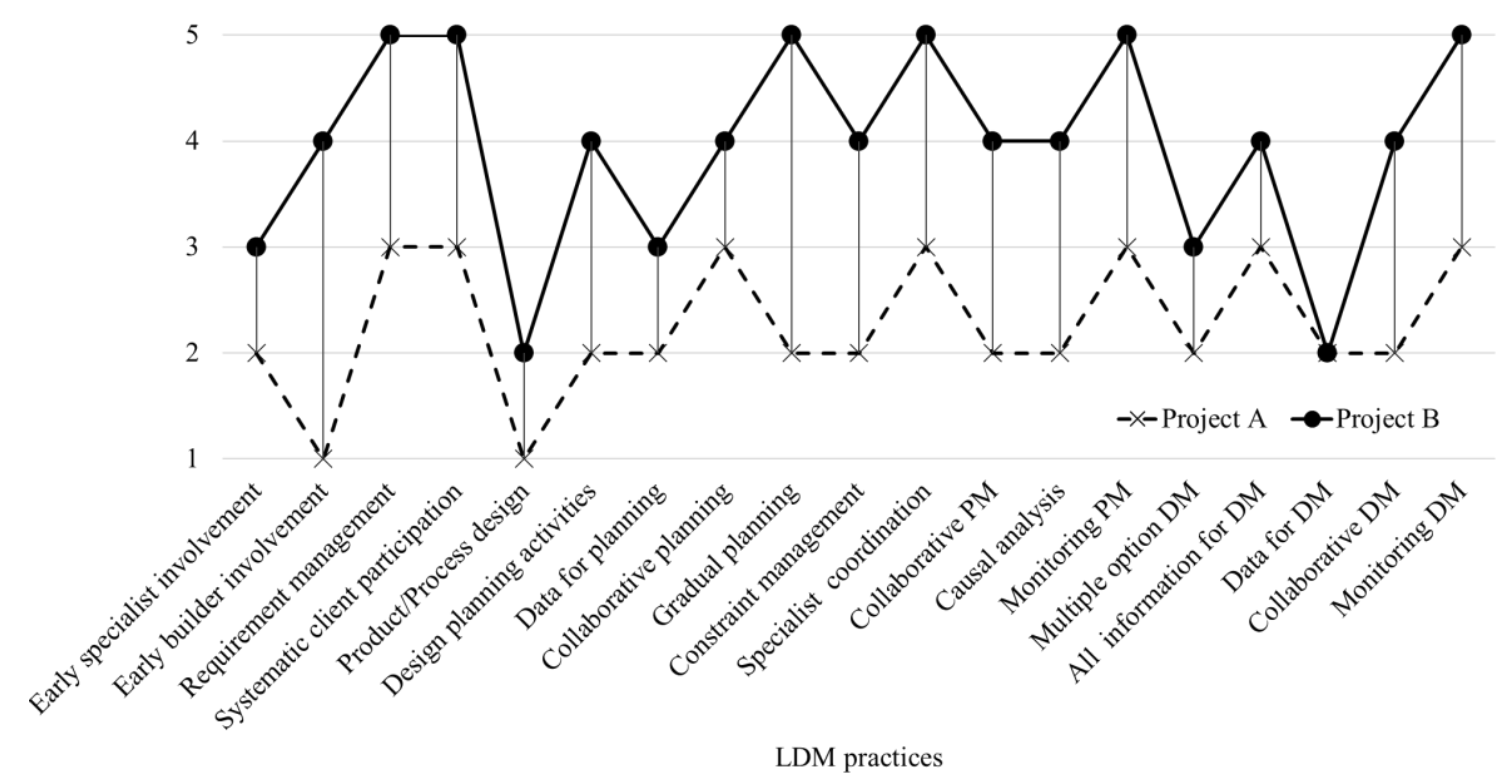

Figure 6-2: LDM practices assessment: project $\mathrm{A}$ and project $\mathrm{B}$ 
Projects A and B can be contrasted with the results of a study regarding 64 projects in Chile, Colombia, and Spain (Herrera et al., 2020a). The levels of LDM practice application in project A are all practice application in the 25th percentile or lower when compared to the projects in the aforementioned study. Additionally, nine of the 19 LDM practices in project B exhibit the best performance among the aforementioned projects, another five are ranked in the 75 th percentile, three are ranked in the 50th percentile, and only two are ranked at the 25 th percentile among these 64 projects. The practices in the last category mentioned consist of the practices related to the simultaneous design of the product and the construction process and the use of databases for decision making. Therefore, the results of the LDM practices assessment demonstrate that project A did not apply LDM practices, while project B applied LDM practices and stood out in its use of these methods even among similar projects.

Interaction analysis was conducted with the survey responses from all members of the project design teams of projects $\mathrm{A}$ and $\mathrm{B}$ (10 and 12 members, respectively); thus, the degree of the node metrics is proportional to the total number of the members of each team. The consistency analysis of the responses using the global interaction network showed that $90.32 \%$ of the interaction in project A was valid, as was $91.18 \%$ of the interaction in project $\mathrm{B}$; therefore, the input data were reliable for performing SNA according to the $80 \%$ limit proposed in this research. To analyze the global interaction network, the collaboration network, the planning and problem-solving network, and the requirement negotiation network, all the nonreciprocal links must first be eliminated because these interactions are undirected networks. Additionally, all links were maintained in the relevant information flow network, the learning network, the trust network, and 
requirement networks because these interactions could occur in only one direction (i.e., directed networks).

The global interaction networks in both projects exhibit connected teams (Figure 6-3), i.e., there is no person or team that is isolated from the others. However, this network shows that the project manager of project A was a bottleneck; i.e., if the project manager was absent or did not engage in an interaction, four specialists of the project team would be isolated (namely, $40 \%$ of the design team). Additionally, project B was a rounded network in which the interactions among the design team members are homogeneous; therefore, if any team member failed to engage in any interaction, other bridges exist that allowed the team to remain cohesive. Figure 6-3 also shows the distribution of the degree of connection among the team members in proportion to the total number of team members. The boxplots illustrate that project B had a higher level of global interaction than does project A. Although the median number of connections of both projects is not very different, the minimum values of connection in project $\mathrm{B}$ are higher, and there is also a more significant number of members with high levels of interaction in project B than there are in project A. This higher interaction level exhibited by project B was initially due to the weekly work sessions and the permanent involvement of the construction company representative and the specialists required for each part of the project. 
Project A

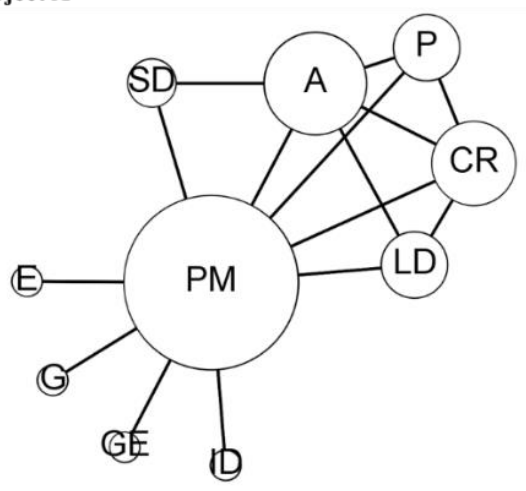

Project B

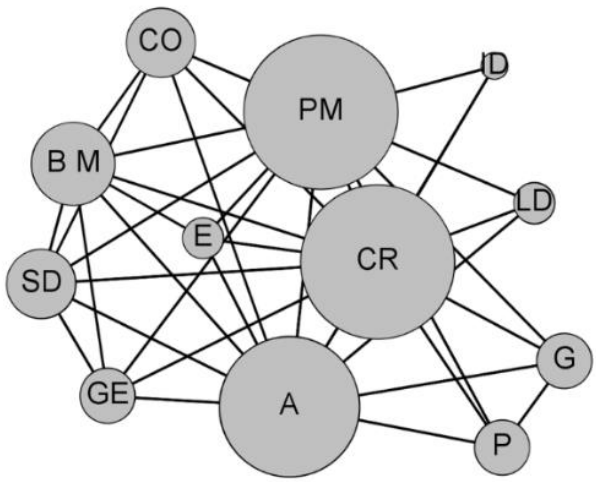

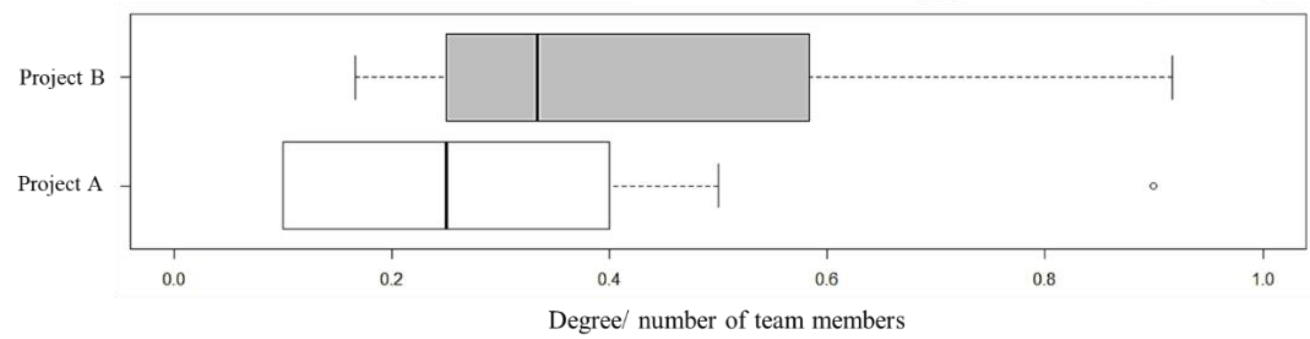

Figure 6-3: Global interaction network and degree: project A and project B

Similar to the global interaction network, the relevant information flow network (Figure 6-4) presents the connections among the teams of both projects; however, in both cases, the management of information remains centralized in the hands of certain stakeholders (PM in project A; and PM, CR, and A in project B). Nevertheless, the number of connections among the teams of project $\mathrm{B}$ is higher than those of project $\mathrm{A}$; this phenomenon is mainly caused by the coordination of specialists via an advanced BIM common data environment where all team members can visualize the building model; add comments, annotations and improvement proposals; and record each information exchange. Additionally, project A used e-mails and phone calls as a means of transferring information to resolve questions or to make comments, leaving no evidence of these communications and failing to clearly manage the supporting documentation. The indegree of both projects is similar; however, the out-degree exhibits major differences. In 
project $\mathrm{A}$, a small number of people did not provide any relevant information during the 12 weeks of the study, demonstrating that the participation of specialists and designers in this project was occasional and not sustained over time. However, in project B, each member provided information to another team member during these 12 weeks, whether it was to support their work, to comment on an aspect of the project, or to communicate some revision of the coordinated model.

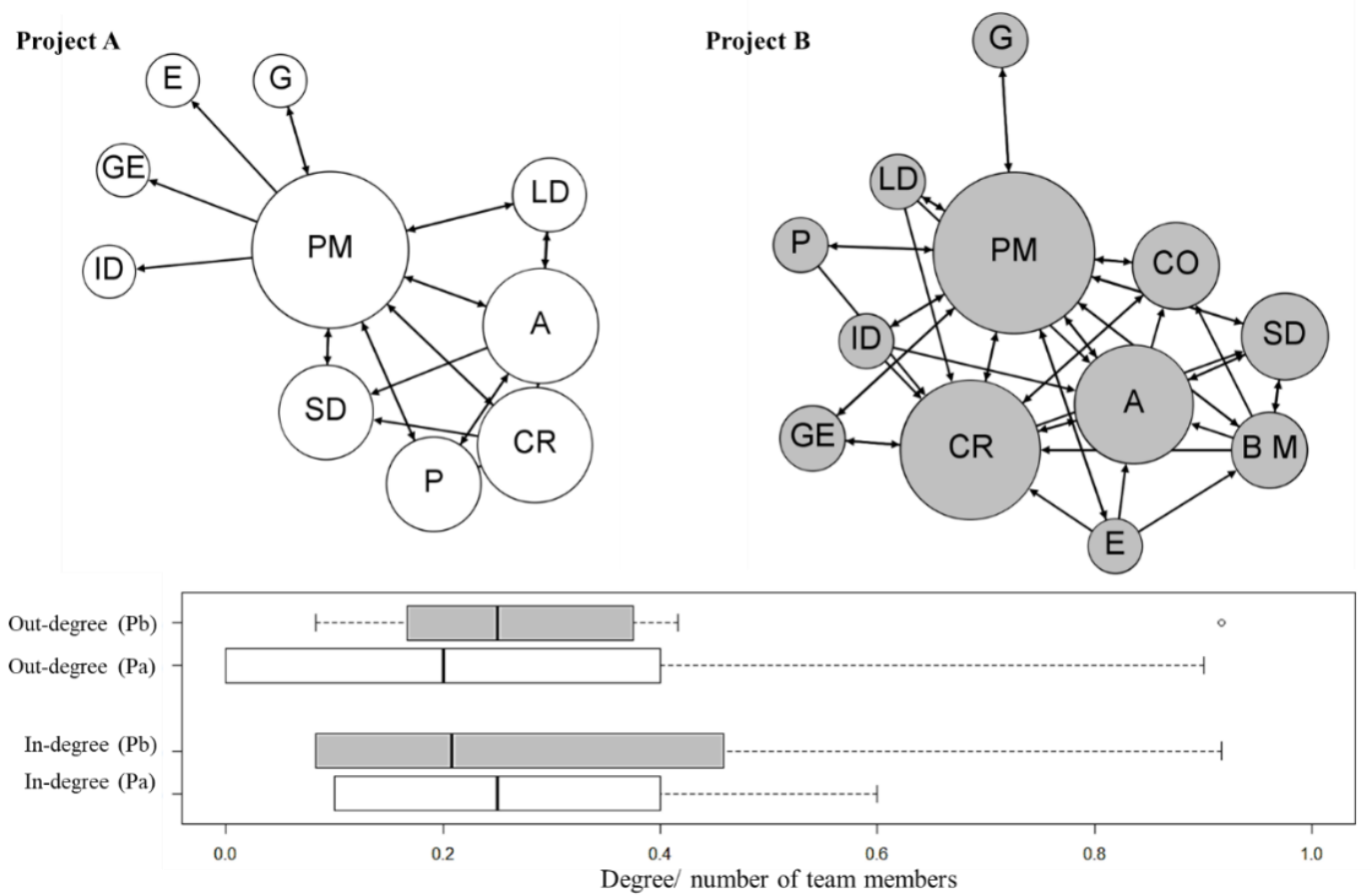

Figure 6-4: Relevant information flow network and degrees: project A and project B

The collaboration network is similar to the planning and problem-solving network of a design team; hence, only collaborative networks will be presented (Figure 6-5). In contrast to the previous networks, this network shows that $40 \%$ of the team of project A was disconnected, meaning that this isolated portion of the team did not participate in any collaborative or work-planning spaces. However, the network shows that the team of project B was connected; in other words, all of its stakeholders collaborated with its team 
members. Project A performed a single, centralized stage of initial planning, while project B engaged in gradual and systematic planning. The project manager of project B conducted a kick-off meeting for the team to become acquainted, and the use of the BIM common data environment was explained during this meeting; thus, this event became the first instance of interactions among the design team. The kick-off meeting generated additional role-knowledge links for this project (not shown in the paper); project B had twice as many role-knowledge links as project A. This is a major difference, considering that project A had only two fewer members than project B. Additionally, in project B, weekly collaborative meetings were organized with a permanent team (namely, PM, CR, CO, and $\mathrm{BM}$ ), and certain designers were invited depending on the topics to be addressed in the meeting. During these meetings, the attendants reviewed the progress of the project, monitored the changes that had been previously made, solved the conflicts between specialties, and replanned the project (not necessarily all in one meeting).

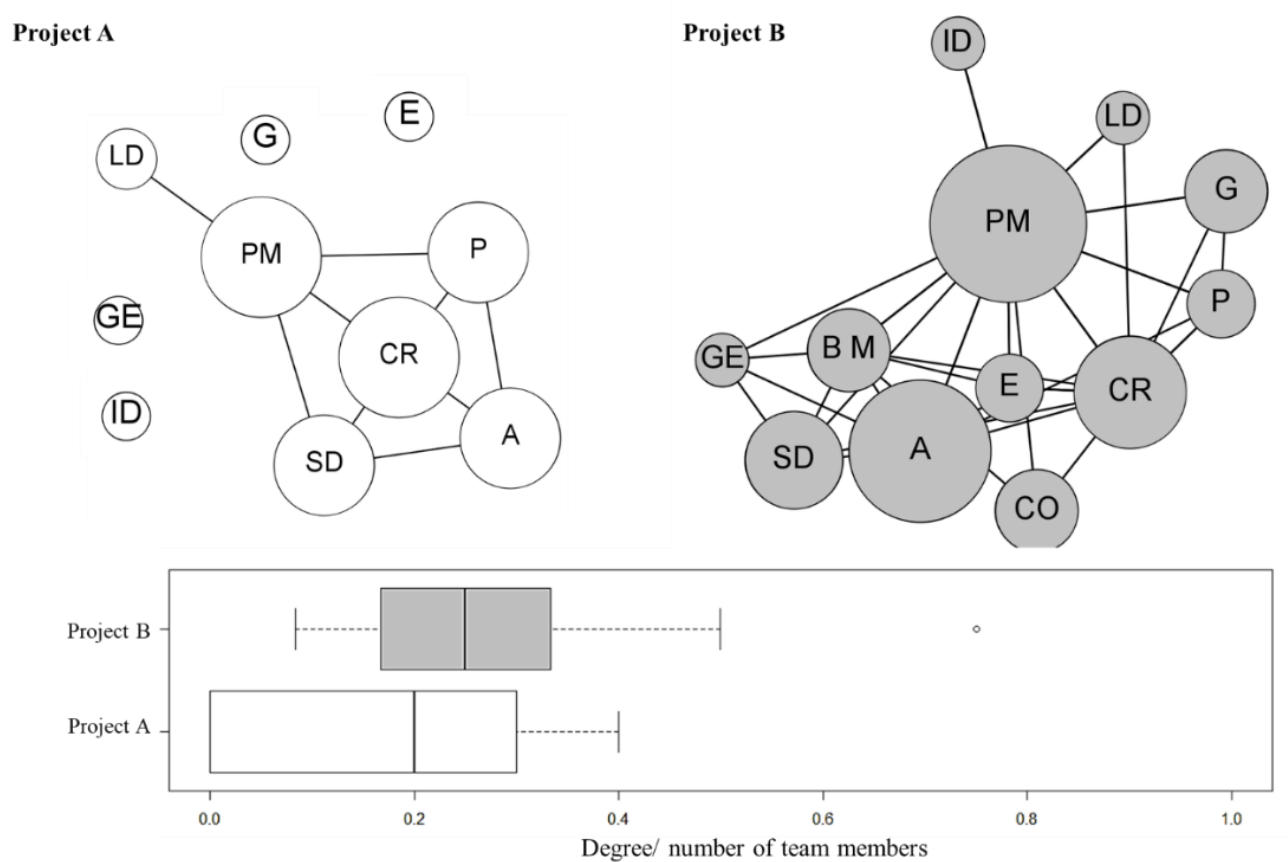

Figure 6-5: Collaboration network and degree: project A and project B 
The boxplot in Figure 6-5 shows that project B, which was the project that applied LDM practices and BIM uses, had more collaboration links among its design team members than did project A. Project B shows more collaboration and lower variability than does project $\mathrm{A}$; therefore, project $\mathrm{B}$ had a less centralized and denser collaboration network (this analysis also applies to the planning and problem-solving network). In conclusion, project B had a greater number of all types of interactions than did project A.

Moreover, in addition to the number of interactions, it is interesting to study how these interactions are distributed with respect to their frequencies. Figure 6-6 presents the frequency of the interactions that occurred in each design team including the relevant information flows, collaboration, and the planning and problem-solving networks. Although the differences are not large, project A exhibits a greater frequency of daily interactions than does project B. This high frequency was limited to a closed group of three members (namely, the PM, CR, and, to a minor degree, A), demonstrating the level of the centralization of the information flow in this project; this phenomenon leads to intensely concentrated interaction due to the lack of bridges among the other team members to decongest the interaction. On the other hand, project B exhibits a low frequency of daily interactions since the project team forced these interactions to occur during the weekly meetings with the appropriate specialists. 
Relevant information flow network

$\square$ Project A $\square$ Project B

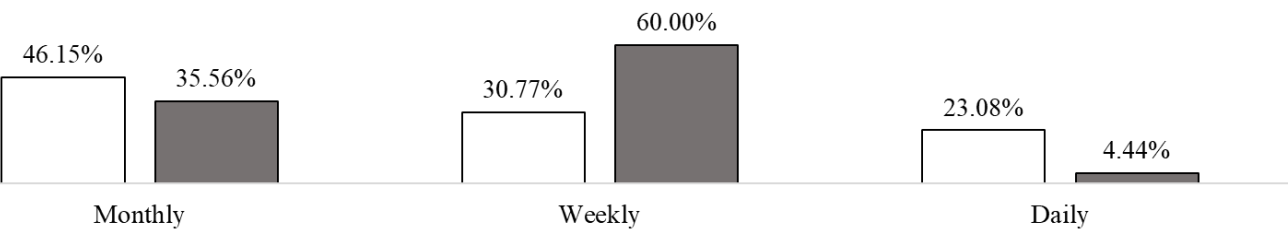

Collaboration network

$\square$ Project A $\square$ Project B
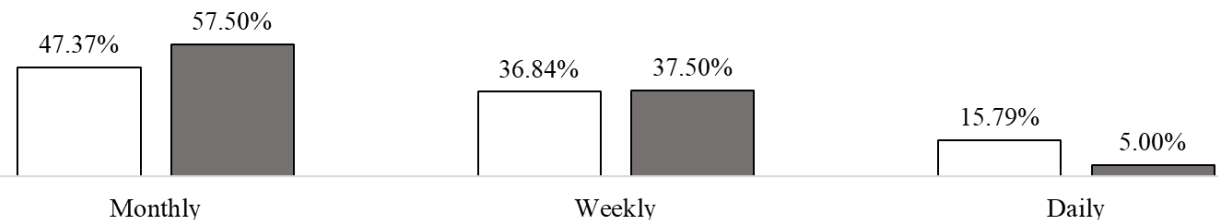

Planning and problem solving network

$\square$ Project A $\square$ Project B

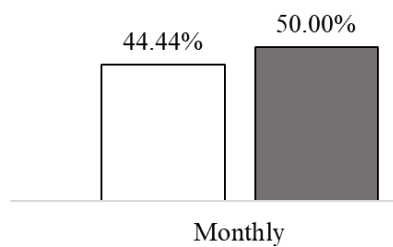

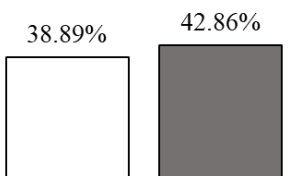

Weekly

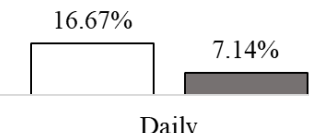

Figure 6-6: Density according to interaction frequency: project A and project B

Another important result of this team analysis is the confidence indicator (Anvuur and Kumaraswamy 2015) (network not shown). The trust network indicator (i.e., the number of trust links/the number of role-knowledge links) of project B is $76.74 \%$ and of project $\mathrm{A}$ is $69.05 \%$. Because project B exhibits twice the role-knowledge links of project A, the trust level of project B is more than double that of project A. In other words, the effort that this team put towards knowing the work team, organizing and standardizing information flows through a BIM common data environment, and collaborating with the team in a formal work environment (weekly meetings) generated greater trust among the team members. Establishing trust among team members is a necessary prerequisite to learning from others in a design team (Herrera et al., 2020b). Additionally, the application of lean practices can 
facilitate learning among team members (Hu, P., Williams, \& Mason, 2016). Figure 6-7 shows the learning network of projects $\mathrm{A}$ and $\mathrm{B}$. The learning network of project $\mathrm{B}$ is significantly more compact and denser than that of project A. This can be seen by simply comparing the sociograms and quantitatively examining the boxplots and the in- and outdegrees of both projects. The fact that the minimum in-degree value of project B is similar to the maximum value of project $\mathrm{A}$ is an indication of this significant difference. In addition, in contrast to the previous networks, the nodes that exhibit the greatest interaction are not those representing the administrative roles but rather the technical roles, especially those of the architect, the structural engineer, the BIM manager, and the construction company's representative. Therefore, this comparison between both projects shows that the application of LDM practices and the implementation of BIM uses promotes organizational learning in design teams, even when they are non-collocated.

Project A

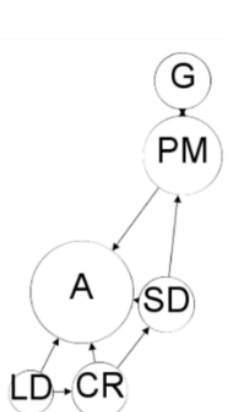

GE

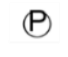

(1)

(E)
Project B

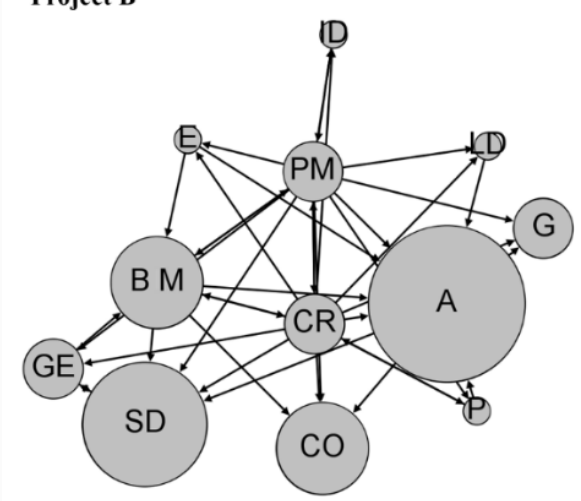

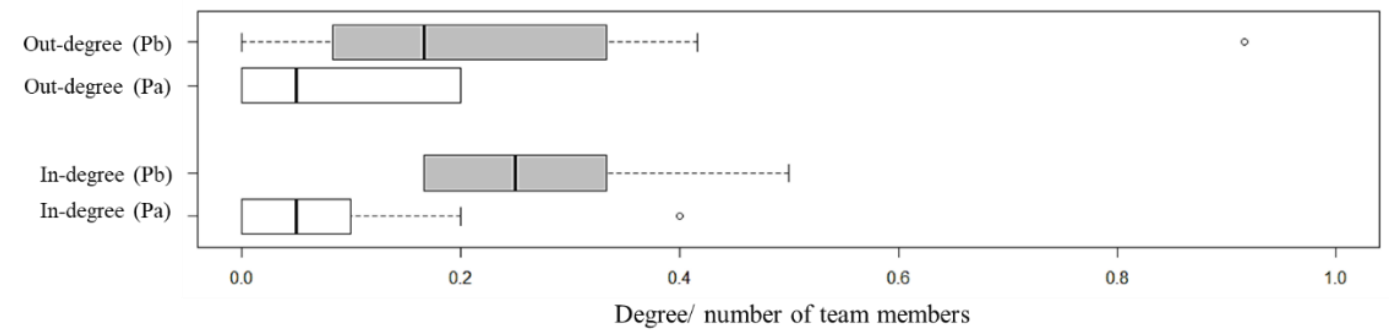

Figure 6-7: Learning network and degrees: project A and project B 
Project $\mathrm{B}$ has better indicators than does project $\mathrm{A}$ in all the traditional interaction dimensions. This effect is similar the effects observed in the types of interaction related to commitment management. During the 12-week evaluation period, project B had 40 links regarding requests for requirements, while project A had 22. This could be attributed to the centralization of these requests for requirements and the information available to all stakeholders. The centralization of requirements produces congestion among the key members of an organization, making them indispensable (i.e., project A), while the creation of additional links among other team members produces a more collaborative, effective, and unmediated flow of information (project B). The information available to all the participants of a BIM common data environment allows problems to be visualized, detected, and solved during the early phases of a project.

The indicators of requirements negotiation, declaration of compliance, and declaration of satisfaction were calculated by considering the frequencies of these interactions (Figure 6-8). The requirements negotiation interaction (i.e., the scope, quality, schedule, and resources of a project) occurred least frequently in both projects, confirming that this is the least-executed interaction in the commitment management cycle of the AEC industry (Salazar, Retamal, Ballard, Arroyo, \& Alarcón, 2019). The declaration of compliance with requirements exhibits the most significant difference between the projects; specifically, this difference occurs between the never and always options of the questionnaire, since the results indicated that more than half of the requirements of project A were not complied with. In project $\mathrm{B}$, this percentage is only $10 \%$. The weekly planning meetings and the BIM common data environment are both spaces in which the compliance with requirements is reported and evidence of this compliance is generated. The interaction of 
declaration of acceptance and satisfaction is also higher in project B; however, a quarter of the requirements do not exhibit this action, though it is fundamental to completing the commitment cycle. Therefore, by applying LDM practices and using BIM methodology, project $\mathrm{B}$ achieves many interactions among the members of its design team; transparent, orderly, and standardized information flows; a collaborative, trusting and learning environment; and commitment management. None of these interaction elements are visible in project $\mathrm{A}$, in which BIM-lean methodologies for design management were not applied.

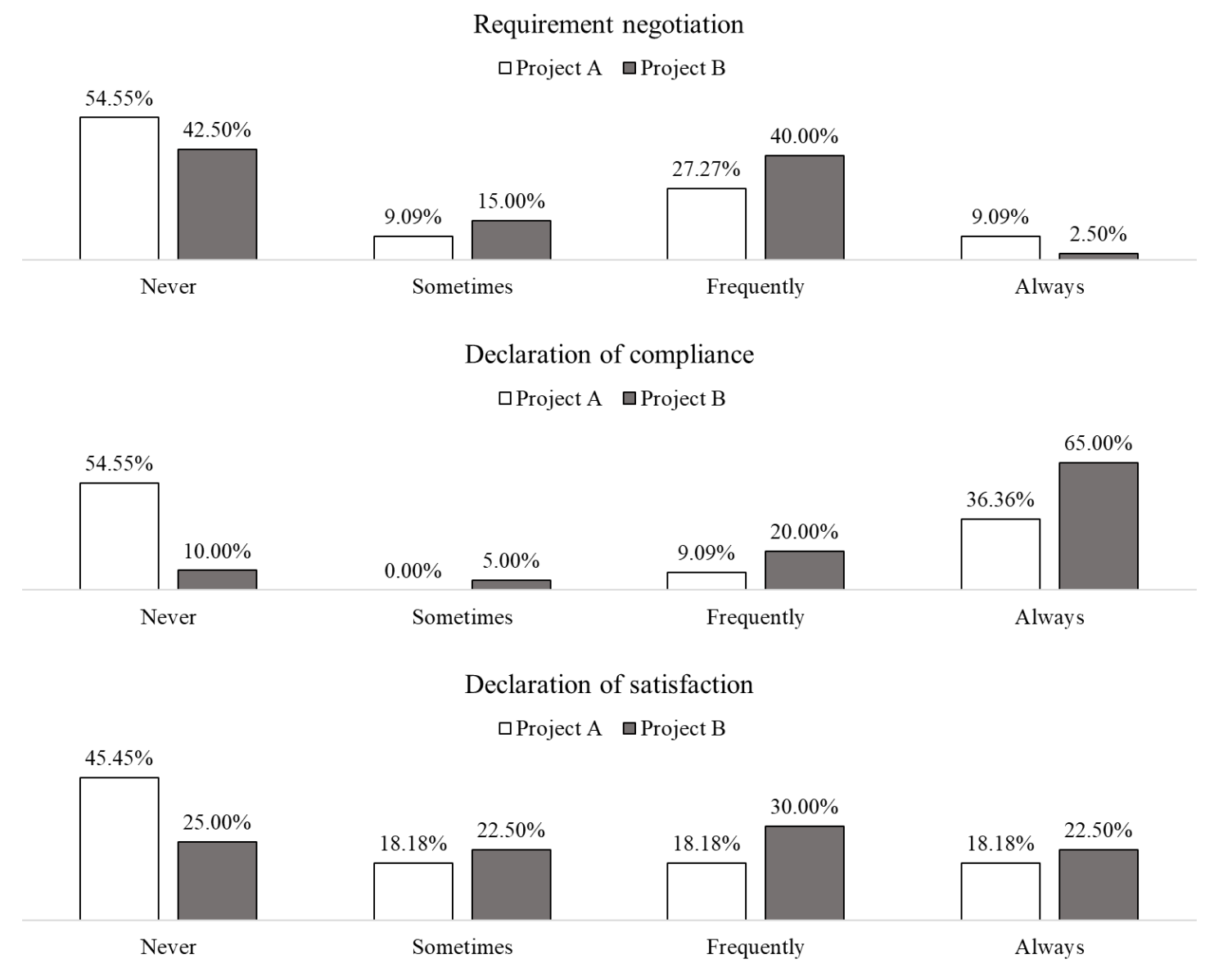

Figure 6-8: Commitment management metrics according to their interaction frequencies: project $\mathrm{A}$ and project $\mathrm{B}$ 


\subsection{Conclusions}

This study presented quantitative evidence of increased team interaction by applying BIM-Lean design management. To achieve this, the authors first evaluated the level of implementation of BIM and Lean principles in two high-rise building projects using the BUA tool and the LDM practices questionnaire, respectively. Then, the different types of interaction produced in both projects were evaluated using social network analysis (SNA) (sociograms and metrics). The results of the BIM-Lean management evaluation showed that one of the projects had a low implementation level of lean practices and had no application of BIM uses during its design and planning phases (project A). The second project had a high implementation level of lean practices, and a high application of BIM uses during its design and planning phases (project B). Project B mainly applied the following practices related to BIM-Lean management: early and systematic involvement of the designers and the representatives of the client and the construction company; gradual, systematic, and collaborative planning during weekly meetings; collaborative and continuously monitored problem-solving and decision making; design reviews and development in a BIM common data environment; and coordination of specialties with the participation of designers in a single federated model.

The design team using BIM-Lean management demonstrated more interactions than did the team using traditional management. The additional interactions between team members allowed for the following: a better understanding of the roles of different team members; a denser, more homogeneous, and more effective flow of relevant information without bottlenecks and indispensable members; planning and collaboration that includes 
all team members; a trusting and learning environment among specialists; and better commitment management during the design process. This study shows clients, designers, and builders of infrastructure projects that a BIM Lean management approach generates higher interaction among members of design teams. Therefore, the different tools presented in this study can be used for the self-analysis of the projects of these professionals and for the assessment of the organizational impact of the management practices, methodologies, and technologies applied in their projects. These concepts apply to any team involved in a construction project but specifically applies to project teams that are temporary organizations and not necessarily collocated (although it could also be used in the context of collocated projects).

The first limitation of this research is that a comparative study of two projects was conducted; thus, for future research, it is recommended that a similar analysis is performed on a representative sample of projects so that conclusive statistical inferences can be drawn about the impact of BIM-Lean management on the interaction of design teams. The second limitation of this research is that project performance, and productivity indicators were not measured; therefore, it is not possible to empirically analyze the impact of a higher level of interaction on a project's performance throughout its life cycle. This type of analysis is particularly complex for two reasons: there is no precedent of measuring indicators during the design phase, and a long period of time is required to evaluate a project's performance throughout its life cycle. However, for future research, it is recommended that performance indicators are evaluated during the design and construction phases so these indicators can be contrasted with the organizational performance of the project during its early phases. 


\section{OVERALL DISCUSSION OF RESULTS}

In this chapter, the main results of the Ph.D. research are discussed as a whole, in an integrated way. Figure 7-1 (developed from Figure 1-1 depicted in the Introduction) presents phase 1 and phase 2, with their respective main results that were described in the five papers, which were presented in the previous chapters (2 to 6). For the reader's better understanding, the first sub-section presents the results of phase 1 of the research method, and the second sub-section presents the results of phase 2 as well as the answers to the research questions.

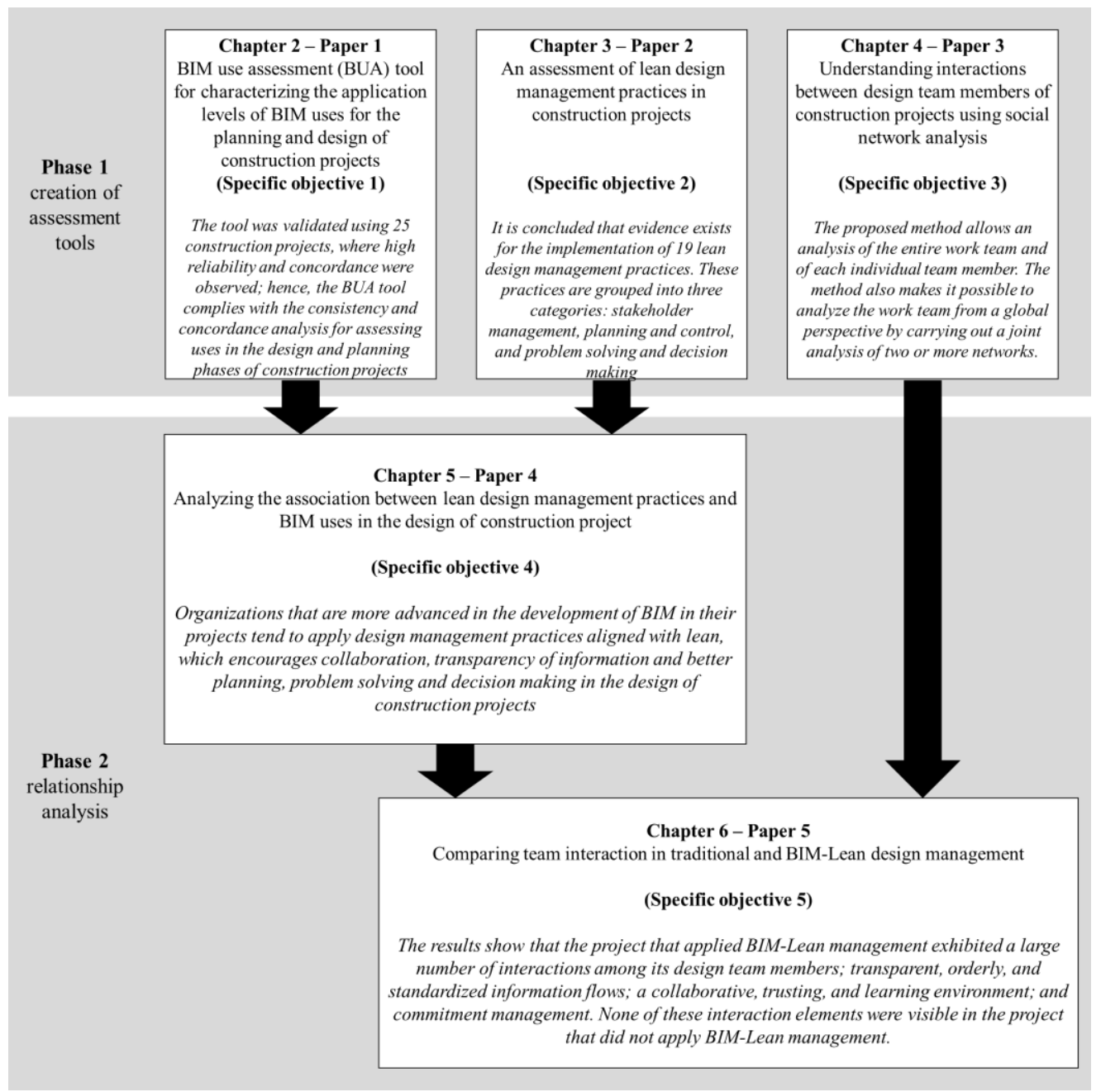

Figure 7-1: Overall main results for each paper 


\subsection{Phase 1: the creation of assessment tools}

Phase 1 of this research developed specific objectives 1,2 and 3 of the thesis (set out in section 1.2.3 of this document). The specific objective 1 was "to devise a tool for assessing the level of implementation of BIM uses in the design phase of construction projects." It was developed and explained in chapter 2 of this document, specifically in the published scientific article "BIM use assessment (BUA) tool for characterizing the application level of BIM uses for the planning and design of construction projects" (Paper 1). The specific objective 2 was "to devise a tool for assessing the degree of adoption of Lean design management (LDM) practices.”. It was developed and explained in the chapter 3 of this document, specifically in the published scientific article "An assessment of lean design management practices in construction projects" (Paper 2). Finally, the specific objective 3 "to understand the phenomenon of interaction between construction project design teams, through the use of Social Network Analysis (SNA)" was developed in Chapter 4 of this document, specifically in the published scientific article "Understanding interactions between design team members of construction project using social network analysis" (Paper 3).

To create the BUA tool, the BIM uses of Penn State University were selected as the baseline of this research, because of the following reasons: most BIM uses are aligned with an objective/application for the project; the classification of lifecycle phase; and that every BIM use definition was strongly supported by scientific literature. Using this guide, an analysis was conducted on each of the uses that were specified in the planning and design phases of a construction project to determine which uses are considered in the evaluation tool. Ten BIM uses were selected for the planning and design phases (Appendix B). Then, 
a definition for each BIM use was proposed, through a literature review of 64 papers from the last ten years that presents evidence of the BIM uses. Later, the definitions were validated by an expert panel.

Once the BIM uses were defined, the characteristics, which are the actions or conditions that are necessary for applying these uses, are identified. Table 2-5 lists the characteristics that are used to assess each use. Additionally, each characteristic use is defined in Appendix B (BUA). Each characteristic is evaluated in various states; for example, in the use "space programming", the characteristic "distribution analysis" has the following states: manuals, consults, reports, and automatic. A characteristic can be evaluated in one or more states since the states are not necessarily mutually exclusive. To validate the consistency resulting from the application of the proposed BUA tool, the first 25 civil infrastructure, and building construction projects were considered, which were all in the first phases of the lifecycle (planning and design) (Paper 1), then 64 projects were evaluated and analyzed with the same tool (Paper 4). It is important to emphasize that the BUA tool should change its content, as additional uses of BIM are implemented in the industry, and the technology and level of automation also rises.

To evaluate each project, interviews were conducted with the BIM manager and/or project manager. All the interviews were recorded with the interviewees' consent so that their answers could be later analyzed by two researchers, who independently evaluated each use of the BUA. Finally, the evaluators held a meeting to decide on the final score of the project for each use; they focused on the categories in which the scores differed between the two evaluators. To validate the BUA tool, a concordance analysis (Cohen's Kappa) and reliability analysis (Cronbach's alpha coefficient) was performed. The results 
show a high level of internal consistency (reliability) and the high level of agreement between the interviewers (concordance); therefore, it is concluded that the BUA is an objective and consistent tool for evaluating the levels of BIM uses in the design and planning phases of construction projects. This validation was repeated with the evaluation of 64 projects presented in Chapter 5 (Paper 4), obtaining similar results of reliability and concordance of the BUA tool. A similar procedure was carried out to apply the LDM practices questionnaire (Paper 2), where a reliability and concordance analysis was also performed.

The BUA tool allows evaluating the level of application and automation of BIM uses in the planning and design phases; therefore, the tool focuses on the BIM uses the application in a specific project. In this way, the BUA tool is a complementary assessment to the existing BIM maturity models in the architecture, engineering, and construction industry (AEC) industry, which aim to facilitate understanding regarding how companies apply the BIM methodology, where the term 'BIM maturity' refers to the quality, repeatability, and degree of excellence within a BIM capability (Succar et al., 2012), but not specifically the BIM uses application. The adoption of BIM has several benefits to the AEC industry (Doumbouya, Gao, \& Guan, 2016); however, to obtain its real potential and make a correct implementation, the organization must also adopt practices associated with the Lean philosophy (Peralta, 2019). The application of Lean practices in the design of construction projects was discussed in Paper 2, the relationship between Lean and BIM in Paper 4, and the impact of both methodologies on the interaction of design teams in Paper 5. 
The application of the Lean philosophy in the design of construction projects has been studied for the last 20 years (Formoso et al., 1998; Koskela et al., 1997). Therefore, there are several case studies where some Lean tools are applied in the design phases of construction projects (Knotten et al., 2016; Musa, Pasquire, \& Hurst, 2019; Rosas, 2013). However, there is not a systematic review that links some best design management practices to the principles of lean construction; consequently, no evaluation tool is available. To create the tool to assess the level of application of the Lean design management (LDM) practices, an extensive literature review was performed, where 19 lean design management (LDM) practices were identified and grouped into three categories, using the affinity method (Carnevalli \& Miguel, 2008; Foster \& Ganguly, 2007): stakeholder management, project planning, and control, and problem-solving and decision making (Paper 2).

The stakeholders' management category includes practices such: specialist designers are involved during early stages of the project; builders are involved during the early stage of the project, the exhaustive identification of requirements from all stakeholders; the systematic participation and support of the client; and the simultaneous design of the product and the construction process (Paper 2). These practices are also associated with various BIM uses at the design phase, which may include design authoring, design review, and cost estimation (Paper 4). The planning and control category includes practices such as: project planning considered delivery dates, phase, milestones, subdivision programs and control instances; use of a database for planning; collaborative planning; gradual planning; constraints management; and coordination of information with technology support (Paper 2). These practices are also associated with various BIM uses at the design 
and planning phases, which may include 4D planning, space programming, site analysis, code validation, sustainability evaluation, and design authoring (Paper 4). Finally, problem-solving and decision-making practices are: solve problems and decision making collaboratively; causal analysis; plan-do-check-act cycle for problem-solving and decision making; make decisions at the last responsible moment; use of learning lessons for decision-making; and use of multi-criteria decision-making methods (Paper 2). These practices are also associated with various BIM uses at the design and planning phases, which may include cost estimation, site analysis, space programming, design review, code validation, sustainability evaluation, design authoring, and 3D coordination (Paper 4).

The 19 defined lean design management practices were subject to at least three principles and a maximum of 10 out of 11 lean construction principles proposed by (Koskela, 1992). On average, each practice contributed to 7.26 principles, and none of the categories dominated over the others, although it was observed that the problem solving, and decision-making category was the least related to the principles of lean construction. Then, a questionnaire was created to assess the level of application of each LDM practice. For each practice, the collaborative team of experts proposed a description was defined for scores 1, 3, and 5, while scores 2 and 4 were defined as an intermediate point between 1-3 and 3-5, respectively: (score 1) a traditional management practice; (score 3) an initial LDM practice; and (score 5). The LDM practice questionnaire was designed and validated (Appendix C). Similarly to the BUA tool (Paper 1), we assessed 64 projects in the design phase; two researchers independently assessed each project, and then the final score was collaboratively defined (Paper 2). In this way, the LDM practices questionnaire covers the knowledge gap to evaluate the level of application of Lean practices in the design of 
construction projects. It is important to emphasize that the LDM practices questionnaire should change its content, as Lean design management best practices evolve in the AEC industry.

The LDM practice questionnaire (Paper 2) and the BUA tool (Paper 1) allow evaluating the level of application of both methodologies in the design phases of construction projects. In this way, it is possible to understand the management of processes, people, and technology, from a BIM-Lean management approach. By creating these two tools, it is possible to assess the synergies between these two methodologies empirically. The synergies between Lean and BIM have been studied for the last ten years (Sacks et al., 2010); therefore, the creation of these two tools contributes to a greater empirical understanding of the level of application of both methodologies. Then, it will be necessary to understand the impact of this management in the interaction of the design teams (Paper 5). Nevertheless, first, it will be necessary to understand how to evaluate the interaction of the design teams of construction projects (Paper 3).

To understand the phenomenon of interaction between construction project design teams, through the use of Social Network Analysis (SNA) (specific objective 3); first, a literature review of the dimensions of interactions evaluated in the AEC industry and different experiences of SNA implementation was performed; and second, an interaction networks method (measurement and analysis) for construction project design teams was proposed (Paper 3).

Two perspectives of interaction were identified: traditional interaction and commitment management. According to the experiences found regarding the use of SNA in the AEC industry, there is evidence of evaluations of dimensions of traditional interaction in this 
industry, for example, global interaction, information flow, problem-solving, planning, innovation, trust, and learning (Alarcón et al., 2013; Castillo, Alarcón, \& Salvatierra, 2018; Herrera et al., 2018; Segarra et al., 2017). However, interactions such as knowledge of roles and collaboration are not explicitly included because these elements have been broadly studied as key elements in the effectiveness of a work team (Baiden et al., 2006; Savolainen et al., 2018; Svalestuen et al., 2015). In addition, Kereri \& Harper (2019) recently proposed to use SNA for the evaluation of collaboration in construction project teams. Furthermore, based on similar experiences in the AEC industry, there is no evidence of interaction assessments associated with the perspective of commitment management, although this element is key to a shared understanding in multidisciplinary teams in which discussion and negotiation are common (Kleinsmann et al., 2012).

For each dimension of interaction, an SNA can be performed; therefore, for each interaction, the links must be defined as directed or undirected, according to the nature of the interaction (Hoppe \& Reinelt, 2010). According to the SNA experiences in the AEC industry, this definition is not explicit; however, it is fundamental to the analysis of metrics and input data filtering because some metric calculations are affected depending on the characteristics of the link (Scott, 2017). Because data capture is conducted through a survey of project team members, there will always be some amount of subjectivity of the input data; therefore, an analysis of the coherence of the input data must be performed before the SNA (Cisterna, 2017). This coherence analysis can be performed in undirected networks in which, theoretically, there is a correspondence between the responses of the people involved, so that if person $\mathrm{A}$ wishes to interact with person $\mathrm{B}$, then person $\mathrm{B}$ must indicate the same (Cisterna, 2017). 
Although there are metrics for SNA that have mathematical interpretations, a practical interpretation should be provided for the construction project design teams (less than 50 people) (Castillo, Alarcón, \& Pellicer, 2018). In addition, new metrics should be proposed for the dimensions of interaction associated with commitment management because these networks interact with each other as part of a cycle, even though there are no SNA metrics linking two or more networks. The definition of the link types (directed or undirected), the coherence analysis to validate the input data, and the definition of new dimensions of interaction, and their metrics and interpretation must be included in the existing SNA methodology (e.g., Alarcón et al., 2013; Flores et al., 2014). The description of each dimension of interaction and the type of link (directed or undirected) was determined by a multidisciplinary team of professionals. This team included engineers, builders, researchers, architects, and linguists; all with experience in SNA and teamwork assessment in the AEC industry. There are three types of answers for each question: yes/no per person, the number of times per person, and frequency per person.

To apply the proposed method in this research (Paper 3), the activities outlined in Figure 4-2 should be carried out. For the creation of the survey, it is first necessary to establish the setting information, such as (1) the definition of the interaction time period; (2) definition of the data collection method; (3) definition of the study participants; (4) definition of the limit for validation of the reliability of the answers obtained; and (5) selection of the software to carry out the SNA. Second, the survey should be created considering all the previous information, the descriptions of the interaction dimensions, and the questions and answers for the evaluation. Third, the survey should be sent to the defined participants and the data collected; for small teams, it is recommended that $100 \%$ 
of the defined participants respond. Then, with the information collected, the data are processed using the selected software, according to the type of link of each interaction dimension, directed or undirected. Then, the metrics are calculated according to the definitions in Table 4-7, and the limit criterion of the coherence analysis is reviewed to determine whether the analysis can continue. If the coherence analysis criterion is satisfied, then the sociograms are created, and the analysis proceeds. Finally, the analysis consists of two parts: an analysis of the metrics and sociograms according to the project context, which can be done between the assessor and project manager, and a comparative analysis with other experiences in the AEC industry reported in the literature.

The SNA is a methodology that has gained strength in recent years in the AEC industry; Pryke, (2012) defines it as a research method advancing in the built environment. Therefore, the proposed methodology contributes to understanding the interactions of design teams, which are usually small teams, using this advanced research method. The method developed to assess the interactions of design team members (Paper 3), gives a holistic analysis of the relationships in a design team, allowing to understand the organizational culture and interactions from multiple dimensions, such as, social interaction, information flow, collaboration, trust, learning, and commitment management that are generated by the design team. Since the AEC industry is still considered a semicraft industry, the subject of "people and culture" has had high developmental interest from the scientific and professional community. In theory, the application of the BIM and Lean methodologies allows improving the interaction of the work teams; therefore, the proposed methodology to assess the interactions (Paper 3) will allow to evaluate this impact (Paper $5)$. 
At the end of phase 1 of the research, specific objectives 1, 2 and 3 were met. In this phase, three methodologies to assess the management of a design team were developed, from a perspective of BIM uses (Paper 1), Lean practices (Paper 2), and interaction (Paper 3). The three evaluation methods provide a complete picture of a design team's work, from a technology, process, and people perspective. Then, to achieve the research goal, it is necessary to do a relationship analysis between these three issues, which will be explained in the next section.

\subsection{Phase 2: relationship analysis}

Phase 2 of this research developed specific objectives 4 and 5 of the thesis (set out in section 1.2.3 of this document). The specific objective 4 was "to understand the relationship between the application of Lean design management (LDM) practices and the implementation of BIM uses during the design phase of construction projects" was developed and latently explained in Chapters 5 of this document, specifically the scientific article under review "Analyzing the association between lean design management practices and BIM uses in the design of construction projects" (Paper 4). Finally, specific objective 5 was "to understand the relationship between the use of LDM practices and BIM uses, and the interaction of design teams of construction projects" was developed in Chapter 6 of this document, specifically in the scientific article under review "Comparing team interaction in traditional and BIM-Lean design management" (Paper 5).

To achieve specific objective 4 of this work and answer the first research question, "what is the relationship between Lean practices and BIM uses in the design phase of construction projects?" the research (Paper 4) was organized into three stages: 
1. An explanation of assessment tools to measure the level of implementation of BIM uses (Paper 1), and the lean design management (LDM) practices (Paper 2).

2. A characterization of the sample of projects and data collection strategy.

3. The data exploration, including reliability analysis, descriptive statistics, association analysis using the Pearson chi-square test, and a causal analysis.

The 64 projects assessed had the following characteristics: (1) the contracting system was design-bid-build; (2) BIM methodology was being used; and (3) the project manager and/or BIM manager agreed to provide actual project information. The assessment of the 64 construction projects was carried out using the LDM practices tool (Paper 2), and the BUA tool (Paper 1).

The chi-square test was performed between the 190 pairs of variables, where the chisquare, the associated p-value, and the standardized contingent coefficient of each pair of variables were calculated. There are 33 significant relationships that are equivalent to $17.36 \%$ of the potential relationships between the 19 LDM practices and the 10 BIM uses. Therefore, in the other $82.64 \%$, it is not possible reject the hypothesis "there is no association between the LDM practice (n) and the BIM use (m)". Each LDM practice is connected on average to two or three BIM uses, and through a clustering analysis, five groupings can be identified that includes one or two BIM uses. Ten years ago, Sacks et al. (2010) proposed a framework with 56 potential interactions between BIM functionalities and Lean Construction principles, where they argued that at that time, companies and professionals were still in the process of learning BIM and Lean. Currently, the actual interaction between Lean and BIM is still low in the planning and design phase of 
construction projects in relation to the potential interactions between Lean and BIM. The analysis of the relationship between LDM practices and BIM uses allows having empirical evidence of the LDM practices that are present in each BIM use in the design phase of construction projects. LDM practices from the categories "planning and control" and "problem-solving and decision making" are more related to BIM uses than LDM practices from the category "stakeholder management" (Paper 4). BIM with its technology capability and Lean with its theoretical foundation can complement each other for better project efficiency and can contribute to other project goals (Al Hattab \& Hamzeh, 2015).

Finally, a necessity and sufficiency analysis was performed to assess the causal relationship between the LDM practices proportion $(\boldsymbol{p l})$, and the BIM uses proportion $\left(\boldsymbol{p}_{\boldsymbol{b}}\right)$ using the data of the 64 evaluated projects. From the consistency analysis, it can be concluded that if a project applies a higher proportion of BIM uses, it will tend to apply a higher proportion of LDM practices; however, this relationship is not as clear in the other way around. The above ratifies the evolution of BIM from a technology to a collaborative methodology with technological support (Olawumi, Chan, \& Wong, 2017), where the LDM practices associated with stakeholder management, planning, and problem-solving are also part of advanced uses of BIM in construction projects (Kapogiannis \& Sherratt, 2018). In this way, we can identify when a project is managed from a BIM-Lean approach. However, it is still necessary to know the impact of this BIM-Lean management on the interaction of the construction project design teams (Paper 5).

To achieve the specific objective 5 of this work and answer the second research question "what is the relationship between Lean and BIM with the interaction of construction project design teams?", quantitative empirical evidence of the differences 
that exist among the various types of interactions of a design team was conducted, through a comparative analysis of two case studies involving high-rise building construction projects in Chile. The BUA tool (Paper 1) and the LDM practices questionnaire (Paper 2) was applied to assess the BIM uses and LDM practices of both projects. Then, the method to understand the interactions among the design teams in construction projects (Paper 3) was applied in both projects. Therefore, this study present the application of a set of tools and methods for assessing the impact of the combined use of Lean design management practices and BIM uses in the interaction between construction project design team members.

The evaluation of project A shows that BIM uses were not applied in this project, as was mentioned by its project manager during the project description. The unique application of BIM at the initial level corresponds to a 3D coordination between the architecture and the structural model. Therefore, project A was entirely designed using traditional methodologies, i.e., the use of CAD and non-BIM technologies. By contrast, project B shows some level of BIM application for each of the BIM uses considered in this study, as mentioned by the project manager and the client representative during the project description. Projects A and B can be contrasted with the results of a study regarding 25 projects in Chile, Colombia, and Spain (Paper 1). Project A consistently corresponded to the minimum application of BIM exhibited by the projects in the study, while project B in the maximum values of application in the BIM uses. Therefore, the results of the BIM use assessment demonstrate that project A did not use BIM methodology in its planning and design; however, project B used BIM methodology and stood out in its use of these methods even among similar projects. 
Neither project explicitly applied lean design methodologies to manage the project during the design stage. However, the researchers assessed the LDM practices in both projects since BIM methodology indirectly involves the application of certain lean principles (Fakhimi et al., 2016); thus, projects that apply BIM methods could be expected to apply some lean practices as well. We assessed the LDM practices using the questionnaire created in this research (Paper 2). Project B had a higher level of implementation of all the LDM practices than did project $\mathrm{A}$, confirming that the application of BIM methodology entails the application of some lean principles as well. Projects A and B can be contrasted with the results of a study regarding 64 projects in Chile, Colombia, and Spain (Paper 2). The levels of LDM practice application in project A are all practice application in the 25 th percentile or lower when compared to the projects in the study. Additionally, nine of the 19 LDM practices in project B exhibit the best performance among the aforementioned projects, another five are ranked in the 75th percentile, three are ranked in the 50th percentile, and only two are ranked at the 25 th percentile among these 64 projects. Therefore, the results of the LDM practices assessment demonstrate that project A did not apply LDM practices, while project B applied LDM practices and stood out in its use of these methods even among similar projects. The results obtained in the cases confirm the outcome of specific objective 3 (Paper 4), i.e., that projects that have a high level of application of BIM uses are at the same time applying many LDM practices.

Then, the interaction analysis of both design teams was conducted through the SNA method (Paper 3). The global interaction networks in both projects exhibit connected teams, i.e., there is no person or team that is isolated from the others. Project B had a 
higher level of global interaction than does project A and without a bottleneck. This higher interaction level exhibited by project B was initially due to the weekly work sessions and the permanent involvement of the construction company representative and the specialists required for each part of the project (Paper 2). Particularly, the relevant information flow network presents the connections among the teams of both projects. Nevertheless, the number of connections among the teams of project $\mathrm{B}$ is higher than those of project $\mathrm{A}$; this phenomenon is mainly caused by the coordination of specialists via an advanced BIM common data environment where all team members can visualize the building model; add comments, annotations and improvement proposals; and record each information exchange (Paper 1), as also mentioned in the study by Shafiq et al., (2013). Additionally, project A used e-mails and phone calls as a means of transferring information to resolve questions or to make comments, leaving no evidence of these communications and failing to manage the supporting documentation (Paper 2).

The collaboration network is similar to the planning and problem-solving network of a design team, similar to the pilot project presented in Paper 3. In contrast to the previous networks, this network shows that $40 \%$ of the team of project A was disconnected, meaning that this isolated portion of the team did not participate in any collaborative or work-planning spaces. While the network shows that the team of project B was connected, in other words, all of its stakeholders collaborated with its team members. Project A performed a single, centralized stage of initial planning, while project $\mathrm{B}$ engaged in gradual and systematic planning (Paper 2). The project manager of project B conducted a kick-off meeting for the team to become acquainted, and the use of the BIM common data environment was explained during this meeting (Paper 1); thus, this event became the first 
instance of interactions among the design team. The kick-off meeting generated additional role-knowledge links for this project; project B had twice as many role-knowledge links as project A. This is a major difference, considering that project A had only two fewer members than project B. Additionally, in project B, weekly collaborative meetings, where the attendants reviewed the progress of the project, monitored the changes that had been previously made, solving the conflicts between specialties, and replanned the project (Paper 2). The project B, which was the project that applied LDM practices and BIM uses, had more collaboration links among its design team members than did project A. Project B shows more collaboration and lower variability than does project $\mathrm{A}$; therefore, project $\mathrm{B}$ had a less centralized and denser collaboration network (this analysis also applies to the planning and problem-solving network). In conclusion, project B had a greater number of all types of interactions than did project $\mathrm{A}$.

Another important result of this team analysis is the confidence indicator (Anvuur \& Kumaraswamy, 2015). The trust network indicator of project B is higher than project A.; because project B exhibits twice the role-knowledge links of project $A$, the trust level of project $\mathrm{B}$ is more than double that of project $\mathrm{A}$. In other words, the effort that this team put towards knowing the work team, organizing and standardizing information flows through a BIM common data environment (Paper 1), and collaborating with the team in a formal work environment (weekly meetings) generated greater trust among the team members. Establishing trust among team members is a necessary prerequisite to learning from others in a design team (Paper 3). Additionally, the application of lean practices can facilitate learning among team members (Hu et al., 2016). The learning network of project $\mathrm{B}$ is significantly more compact and denser than that of project A. The fact that the minimum 
in-degree value of project $\mathrm{B}$ is similar to the maximum value of project $\mathrm{A}$ is an indication of this significant difference. In addition, in contrast to the previous networks, the nodes that exhibit the greatest interaction are not those representing the administrative roles but rather the technical roles, especially those of the architect, the structural engineer, the BIM manager, and the construction company's representative. Therefore, this comparison between both projects shows that the application of LDM practices and the implementation of BIM uses promote organizational learning in design teams, even when they are noncollocated.

Project $\mathrm{B}$ has better indicators than does project $\mathrm{A}$ in all the traditional interaction dimensions. This effect is similar to the effects observed in the types of interaction related to commitment management. This could be attributed to the centralization of these requests for requirements and the information available to all stakeholders (Paper 2). The centralization of requirements produces congestion among the key members of an organization, making them indispensable (project A), while the creation of additional links among other team members produces a more collaborative, effective, and unmediated flow of information (project B). The information available to all the participants of a BIM common data environment allows problems to be visualized, detected, and solved during the early phases of a project (Paper 4).

The requirements negotiation interaction (i.e., the scope, quality, schedule, and resources of a project) occurred least frequently in both projects, confirming that this is the least-executed interaction in the commitment management cycle of the AEC industry (Salazar et al., 2019). The declaration of compliance with requirements exhibits the most significant difference between the projects; specifically, this difference occurs between the 
"never" and "always" options of the questionnaire, since the results indicated that more than half of the requirements of project A were not complied with. The weekly planning meetings (Paper 2) and the BIM common data environment (Paper 1) are both spaces in which the compliance with requirements is reported, and evidence of this compliance is generated. Therefore, by applying LDM practices and using BIM methodology, project B achieves many interactions among the members of its design team; transparent, orderly, and standardized information flows; a collaborative, trusting and learning environment; and commitment management. None of these interaction elements are visible in project A, in which BIM-lean methodologies for design management were not applied (Paper 5). 


\section{CONCLUSIONS}

\subsection{Contributions to knowledge}

The proposed BUA tool that is presented in this study contributes to the diagnosis of the application of BIM uses, thereby enabling companies to identify the way in which the BIM uses are being implemented, and opportunities for improvement. Via this approach, it is possible to realize higher benefits from the BIM methodologies when they are applied in the earliest stages (planning and design) of the projects. With the increasing requirements for the use of BIM methodologies, having a tool that enables the assessment of the application of BIM uses in projects is advantageous for those who are in the process of implementing or are seeking to implement this methodology efficiently. Then, the BUA tool becomes crucial for companies in evaluating how they are utilizing all the "uses" that BIM can offer. Additionally, the BUA tool has high concordance and consistency values; therefore, it is a validated instrument to assess the level of application of the BIM uses in the design and planning phases of construction projects.

Additionally, in this study, evidence was encountered in the literature about the implementation or potential implementation of at least 19 practices of the lean philosophy in the design process of construction projects. These practices were framed in three main areas: stakeholder management, planning and control, and problem-solving and decision making. Each of the 19 practices had a high degree of relation with lean construction principles and revealed a balanced contribution to each of the principles of the lean philosophy; therefore, the defined practices could be regarded as lean practices in the design of construction projects. Furthermore, this research proposed a tool (questionnaire) 
to evaluate the degree of implementation of each of the practices at the project level, defining a taxonomy of lean design management practices. This way, the authors carried out an evaluation of the 19 lean design management practices to 64 construction projects at the design phase, where a high variability in the levels of lean implementations could be observed. The most developed practices are: requirement management and active participation of the client; the least developed are: "builders in early stages", "decisionmaking until the last responsible moment", and "multicriteria decision-making". Therefore, there is a great opportunity to implement these practices in the design process and to continuously improve the implementation of lean design practices that are at the initial levels of development.

For a design team to be successful, the design participants must have high levels of interaction. To evaluate the interaction, a method was proposed to understand the interactions in this type of work team using SNA as a tool and evaluating the interaction from a multidimensional point of view. The key dimensions of interaction in a design team were identified and grouped into two groups: traditional interaction and commitment management. The latter group is fundamental in design teams because there are instances of systematic discussion and negotiation that oblige the team to have a shared understanding of the actions to be followed. In addition, this was the first time that speech acts were modeled using SNA. Each dimension of interaction is represented as a network and may have an individual analysis; however, it is also necessary to perform an analysis between two or more networks.

Then, this study examined the association among BIM uses and LDM practices in the planning and design of construction projects through the BUA tool and the LDM practices 
questionnaire, respectively. The obtained results confirm that the implementation of BIM uses and lean management practices, at the design phase, are at a nascent stage, given that the relationship between Lean and BIM and their potential have not been explored extensively. In this learning phase, BIM uses are still applied as isolated technological implementations of collaborative management and other best management practices aligned with Lean. Therefore, this study reinforces the need to apply BIM as a whole to LDM, and even more at the design and planning phases of the infrastructure lifecycle. Additionally, it is concluded that there is no double implication between BIM uses and the application of LDM, since with the causal analysis, it was found that the application of BIM uses implies a greater application of LDM practices; however, a greater application of such practices does not imply a greater application of BIM uses. This means that organizations that are more advanced in the development of BIM in their projects tend to apply design management practices aligned with lean, which encourages collaboration, transparency of information and better planning, problem-solving and decision making in the design of the construction project.

Finally, this study presented quantitative evidence of increased team interaction by applying BIM-Lean design management. To achieve this, the authors first evaluated the level of implementation of BIM and Lean principles in two high-rise building projects using the BUA tool and the LDM practices questionnaire, respectively. Then, the different types of interaction produced in both projects were evaluated using social network analysis (SNA) (sociograms and metrics). The results of the BIM-Lean management evaluation showed that one of the projects had a low implementation level of lean practices and had no application of BIM uses during its design and planning phases. The second project had 
a high implementation level of lean practices, and a high application of BIM uses during its design and planning phases. The design team using BIM-Lean management demonstrated more interactions than did the team using traditional management. The additional interactions between team members allowed for the following: a better understanding of the roles of different team members; a denser, more homogeneous, and more effective flow of relevant information without bottlenecks and indispensable members; planning and collaboration that includes all team members; a trusting and learning environment among specialists; and better commitment management during the design process.

\subsection{Practical value}

The BUA tool can be used to evaluate companies to be contracted seeking for specific BIM use level expected. Additionally, the BUA tool can be used to benchmarking the BIM uses level in the industry. Also, the BUA can be used as a self-assessment tool if the examiner is knowledgeable regarding BIM. Similarly, the LDM practices questionnaire can be used as a self-assessment tool if the examiner is knowledgeable regarding Lean philosophy. Construction executives, project managers, and designers can benefit from these tools as it helps them to identify the main development gaps in the best practices related to BIM uses and Lean practices of design management. In addition, this evaluation enables the comparison between projects of the same company or of different companies and promotes benchmarking and continuous improvement in organizations.

The proposed method to understand the interaction of design teams has the following practical applications: (a) understanding the interactions of the design team from several perspectives; (b) taking corrective actions to improve the interaction to make it more 
efficient and less dependent on a single person; (c) recognizing the causes that generate a shared misunderstanding among the members of the team; and (d) taking actions in this matter, such as generating knowledge of roles, meetings for collaborative planning, and opportunities for collaborative work. These benefits can improve the common understanding of project requirements, reduce waste, and increase the value of the design process of project teams. The application of the method requires that all the members of the design team respond to the survey; therefore, there must be a commitment from the organization that is being assessed. In addition, respondents should equally understand the questions, so the evaluation team should write the questions in context and verify the PVC limit through coherence analysis. In addition, the evaluation team and the design team should understand this method as a tool for continuous improvement and not as a punitive mechanism.

Since several countries are defining a regulatory framework that promotes the use of $\mathrm{BIM}$, organizations that manage their projects under Lean principles will naturally be able to apply the BIM methodology. The results obtained allow project managers and executives to carry out a benchmark study of the practices and uses of BIM applied in their projects in comparison with other projects in the planning and design phases. Additionally, it allows the identification of sets of design management practices associated with certain BIM uses, allowing the adopter of these methodologies to prioritize efforts in the combined implementation of Lean and BIM in their projects. Construction companies that want to increase the number of BIM uses in their projects, or engineering companies that want to increase their service portfolio, must understand that to reach high levels of BIM application, they must apply Lean management practices. Therefore, companies should 
complement their BIM training plans with a Lean training plan, with the aim of making changes in the management of their projects in a holistic approach, that is, including people, processes, and technology. At the same time, public agencies that are beginning to require the use of BIM in their projects need to be flexible in their contractual frameworks, since these are often at odds with some Lean management practices.

Finally, this study shows clients, designers, and builders of infrastructure projects that a BIM Lean management approach generates higher interaction among the members of design teams. Therefore, the different tools presented in this study can be used for the selfanalysis of the projects of these professionals and for the assessment of the organizational impact of the management practices, methodologies, and technologies applied in their projects. These concepts apply to any team involved in a construction project but specifically applies to project teams that are temporary organizations and not necessarily collocated (although it could also be used in the context of collocated projects).

\subsection{Limitations}

The descriptive analysis and hypothesis tests were conducted with the pilot test of 64 projects. The use of larger sample size is recommended for obtaining more general conclusions according to the characteristics of the project. The BUA defines each level as a combinatorial of states associated with each characteristic of each use. However, this combinatorial could be different. The uses "sustainability analysis" and "engineering analysis" group several specialties, respectively, this simplification could generate an information gap if the objective of the assessment is to understand the use of each specialty individually. The BUA tool does not include BIM uses in the construction and operation phases. In addition, the BIM uses considered as a basis were those proposed by Penn State; 
however, there are other more detailed lists of uses that were not considered in this research. The BUA tool does not evaluate the number of people who will interact with each of the uses; therefore by itself, it does not allow understanding the level of centralization or decentralization of BIM uses.

The identified LDM practices were not necessarily the only ones since the practices associated with information technology were not considered, such as the use of BIM or the cloud. Also, the authors did not assess specific tools, such as the last planner system, target value design, or others. Additionally, this study proposes a quantitative measure of the level of the lean design management practices in each project based on an interview with the project coordinator; this assessment may have a biased view. The qualification of each project has to be done with at least two researchers or specialized consultants to provide higher objectivity of the assessment. Both the BUA tool and the LDM practices questionnaire are evaluated by interviewing the BIM manager and the project manager, respectively. In other words, both evaluation systems do not consider the opinion of other members of the design team regarding BIM uses and LDM practices. Additionally, neither tool requests evidence of the application of MLM practices and BIM uses.

The tool for understanding de design team interaction is used for evaluation over time; therefore, comparisons should be made between projects with similar levels of progress. In addition, the researchers only assessed two projects with the SNA tool. The survey used to evaluate the interaction needs the response of all team members, which is complex in some situations, with some team members not belonging to the same sponsoring organization. Additionally, the survey itself may generate inconsistencies between the responses of the design team members. This research did not consider measuring interactions from other 
data sources such as common data environment, e-mails, etc. The dimensions of interaction evaluated in this method are limited to those that the authors found in the literature and those that we consider relevant; however, other types of interaction that were not considered in this research can be evaluated. In addition, the proposed method to evaluate interactions shows a static network with static indicators and does not evaluate the evolution of interactions during the design process, through dynamic networks, where other metrics and conclusions could be obtained.

To analyze the relationship between LDM practices and BIM uses, we assess a sample of 64 projects. The 64 projects evaluated are not a statistical sample, considering the number of projects in the design process in the countries where they were evaluated; hence, a larger number of projects should be assessed. Given the size of the sample, it was not possible to carry out in-depth studies with other project variables, such as place of origin, size of the project, type of project, number of members of the design team, among others. Because of the low number of projects compared to the number of variables evaluated, the authors did not perform more sophisticated statistical analyses that would allow for more precise statistical inferences. As the origin of the projects evaluated was Chile, Colombia and Spain (countries that are starting to implement BIM and Lean in their projects), no comparisons were made with countries more advanced in the implementation of these methodologies, such as United Kingdom, United States, Australia, among others.

Finally, this study did not measure the effect of the application of LDM practices and BIM uses on the productivity of the 64 projects. There are several difficulties in assessing the productivity impact of implementing Lean BIM management. For example, the impact of the application of these methodologies transcends one phase of the project, that is, the 
application in the design can impact the design, the construction, the operation and maintenance of the infrastructure; therefore the analysis would require having information of all the life cycle of the project. Additionally, in the AIC industry, there is a culture of measuring productivity in the construction phase; however, in the design and planning phases, there is no culture of measuring performance and productivity indicators; therefore, the teams are not used to and do not have the culture of measuring.

\subsection{Futures lines of research}

Future work will focus on the extension of BUA, which was developed for implementation in the planning and design phases, to the other project lifecycle phases, namely, the construction and operation phases. In addition, it would be of substantial value to assess the level of socialization of each BIM use since, for effectively using BIM, the integration of information among all actors of the project is necessary. This would involve assessing the way in which the information is managed, shared, and stored. Additionally, with a greater number of projects, a deeper descriptive analysis can be made of the states in which each feature of each BIM use is located.

Future research should also consider management practices associated with information technology, specifically, the collaborative work in the cloud and the use of BIM, to evaluate a larger number of projects of different types to understand and identify the gaps and opportunities for improvement that exist in the design phase of construction projects and understand the impacts of these practices on the performance of projects. In addition, as future work, it could be interesting to conduct an in-depth study of each project that involves the viewpoint of different actors carrying out a qualitative and quantitative assessment of the project. 
Besides, for future research, it is recommended to perform assessments with the SNA interaction method on a large number of design teams with different compositions, e.g., collocated/non-collocated teams, different numbers of companies, different management systems, and different technology application levels (BIM environments), to understand how the context, management, and technology affects interactions between team members. In addition, it would be interesting to evaluate new dimensions of interaction, study new metrics for small networks, and analyze their quality and evaluate the metrics between different networks. Furthermore, in projects that work in BIM environments, it would be interesting to contrast the networks obtained from the log files and the networks obtained with the proposed method

Additionally, future studies could create a tool that would be used as a self-evaluation for each project. Besides, future research should aim to assess the performance of the design process and the organizational performance of the design team; in this way, it will be possible to identify the effect of LDM practices on the performance of the construction project, both during its design and in its execution. Besides, for future research, it is recommended to perform a similar analysis on a representative sample of projects to make conclusive statistical inferences about the impact of BIM-Lean management on the interaction of design teams. Finally, it is proposed to evaluate performance indicators in the design and construction phases, to contrast it with the organizational performance of the project in the early phases. 


\section{CONCLUSIONES}

\subsection{Contribuciones de la investigación}

La herramienta BUA propuesta que se presenta en este estudio contribuye al diagnóstico de la aplicación de los usos de la BIM, permitiendo así a las empresas y clientes identificar el estado de los usos de BIM del proyecto, la forma en que se están aplicando los usos BIM y las oportunidades de mejora. Mediante este enfoque, es posible obtener mayores beneficios de las metodologías BIM cuando se aplican en las primeras etapas de los proyectos. Dado que los países están fomentando el uso de las metodologías BIM, disponer de un instrumento que permita evaluar la aplicación de los usos de las BIM en los proyectos es ventajoso para los que están en proceso de aplicación o tratan de aplicar esta metodología de manera eficiente. Por consiguiente, el instrumento BUA se vuelve crucial para las empresas al evaluar la forma en que están utilizando todos los "usos" que puede ofrecer la BIM. Además, la herramienta BUA tiene altos valores de concordancia y consistencia, por lo que es un instrumento validado para evaluar el nivel de aplicación de los usos de la BIM en la fase de diseño y planificación de proyectos de construcción.

Adicionalmente, en este estudio, se encontraron evidencias en la literatura sobre la implementación o posible implementación de al menos 19 prácticas de la filosofía Lean en el proceso de diseño de proyectos de construcción. Estas prácticas se enmarcaron en tres áreas principales: gestión de los interesados, planificación y control, y resolución de problemas y toma de decisiones. Cada una de las 19 prácticas tenía un alto grado de relación con los principios de Lean en la construcción y mostraban una contribución equilibrada a cada uno de los principios de la filosofía Lean; por lo tanto, las prácticas

definidas podían considerarse como prácticas Lean en el diseño de proyectos de 
construcción. Además, esta investigación propuso un instrumento (cuestionario) para evaluar el grado de aplicación de cada una de las prácticas a nivel de proyecto, definiendo una taxonomía de las prácticas de gestión de diseño eficiente. De esta manera, los autores realizaron una evaluación de las 19 prácticas de administración de diseño lean a 64 proyectos de construcción en la fase de diseño donde se pudo observar una alta variabilidad en los niveles de implementación lean. Las prácticas más desarrolladas fueron: la gestión de requisitos y la participación activa del cliente; las menos desarrolladas son: "constructores en etapas tempranas", "toma de decisiones hasta el último momento responsable" y "toma de decisiones multicriterio". Por lo tanto, existe una gran oportunidad de aplicar estas prácticas en el proceso de diseño y de mejorar continuamente la aplicación de las prácticas de diseño ajustadas que se encuentran en los niveles iniciales de desarrollo.

Para que un equipo de diseño tenga éxito, los participantes en el diseño deben tener altos niveles de interacción. Para evaluar la interacción, se propuso un método para comprender las interacciones en este tipo de equipo de trabajo utilizando el SNA como herramienta y evaluando la interacción desde un punto de vista multidimensional. Se identificaron las dimensiones clave de la interacción en un equipo de diseño y se agruparon en dos grupos: interacción tradicional y gestión de compromisos. Este último grupo es fundamental en los equipos de diseño porque hay instancias de discusión y negociación sistemáticas que obligan al equipo a tener un entendimiento compartido de las acciones a seguir. Además, esta fue la primera vez que se modelaron actos de habla utilizando el SNA. El SNA es una herramienta que permite el análisis global e individual en un formato visual y con indicadores matemáticos. Cada dimensión de interacción se representa como 
una red y puede tener un análisis individual; sin embargo, también es necesario realizar un análisis entre dos o más redes.

Luego, en este estudio se examinó la asociación entre los usos del BIM y las prácticas de gestión del diseño lean en la planificación y el diseño de proyectos de construcción mediante el instrumento BUA y el cuestionario de prácticas LDM, respectivamente. Los resultados obtenidos confirman que la aplicación de los usos de BIM y las prácticas de gestión lean, en la fase de diseño, se encuentran en una etapa inicial, dado que la relación entre Lean y BIM y su potencial no se han explorado ampliamente. En esta fase inicial de aprendizaje, los usos de BIM se siguen aplicando como implementaciones tecnológicas aisladas de gestión colaborativa y otras mejores prácticas de gestión alineadas con Lean. Por lo tanto, este estudio refuerza la necesidad de aplicar el BIM en su conjunto a LDM, y más aún en las fases de diseño y planificación del ciclo de vida de la infraestructura. Además, se concluye que no hay una doble implicación entre los usos del BIM y la aplicación de LDM, ya que en el análisis causal se encontró que la aplicación de los usos del BIM implica una mayor aplicación de las prácticas de LDM; sin embargo, una mayor aplicación de dichas prácticas no implica una mayor aplicación de los usos del BIM. Esto significa que las organizaciones que están más avanzadas en el desarrollo de BIM en sus proyectos tienden a aplicar prácticas de gestión de diseño alineadas con lean, lo que fomenta la colaboración, la transparencia de la información y una mejor planificación, resolución de problemas y toma de decisiones en el diseño del proyecto de construcción.

Finalmente, este estudio presentó pruebas cuantitativas de una mayor interacción de los equipos al aplicar la gestión de diseño BIM-Lean. Para lograrlo, los autores evaluaron primero el nivel de aplicación de los métodos BIM y Lean en dos proyectos de 
construcción de edificios en altura utilizando la herramienta BUA y el cuestionario de prácticas LDM, respectivamente. A continuación, se evaluaron los diferentes tipos de interacción producidos en ambos proyectos mediante el análisis de redes sociales (SNA) (sociogramas y métricas). Los resultados de la evaluación de la gestión del BIM-Lean mostraron que uno de los proyectos tenía un bajo nivel de aplicación de las prácticas de gestión de Lean y no tenía ninguna aplicación de los usos del BIM durante sus fases de diseño y planificación. El segundo proyecto tenía un alto nivel de aplicación de prácticas Lean y una alta aplicación de usos de BIM durante sus fases de diseño y planificación. El equipo de diseño que utilizó la gestión BIM-Lean demostró más interacciones que el equipo que utilizó la gestión tradicional. Las interacciones adicionales entre los miembros del equipo permitieron lo siguiente: una mejor comprensión de las funciones de los diferentes miembros del equipo; un flujo más denso, homogéneo y eficaz de la información pertinente sin cuellos de botella y sin miembros indispensables; una planificación y colaboración que incluye a todos los miembros del equipo; un entorno de confianza y aprendizaje entre los especialistas; y una mejor gestión del compromiso durante el proceso de diseño.

\subsection{Valor práctico}

El instrumento BUA puede utilizarse para evaluar las empresas que se contraten buscando el nivel de uso específico esperado del BIM. Además, el instrumento BUA puede utilizarse para comparar el nivel de usos del BIM de un proyecto con la industria. Asimismo, la BUA puede utilizarse como instrumento de autoevaluación si el examinador tiene conocimientos sobre la BIM. Del mismo modo, el cuestionario de prácticas LDM puede utilizarse como instrumento de autoevaluación si el examinador tiene conocimientos 
sobre la filosofía Lean. Los ejecutivos de la construcción, los directores de proyectos y los diseñadores pueden beneficiarse de esos instrumentos, ya que les ayudan a identificar las principales deficiencias de desarrollo en las prácticas óptimas relacionadas con los usos del BIM y las prácticas Lean de gestión del diseño. Además, esta evaluación permite la comparación entre proyectos de una misma empresa o de empresas diferentes y promueve la evaluación comparativa y la mejora continua en las organizaciones.

El método propuesto para comprender la interacción de los equipos de diseño tiene las siguientes aplicaciones prácticas: a) comprender las interacciones del equipo de diseño desde varias perspectivas; b) adoptar medidas correctivas para mejorar la interacción a fin de que sea más eficiente y menos dependiente de una sola persona; c) reconocer las causas que generan un malentendido compartido entre los miembros del equipo; y d) adoptar medidas al respecto, como la generación de conocimiento de las funciones, las reuniones para la planificación colectiva y las oportunidades de trabajo en colaboración. Estos beneficios pueden mejorar la comprensión común de las necesidades del proyecto, reducir el desperdicio y aumentar el valor del proceso de diseño de los equipos de proyecto. La aplicación del método requiere que todos los miembros del equipo de diseño respondan a la encuesta; por lo tanto, debe haber un compromiso de la organización que se está evaluando. Además, los encuestados deben comprender igualmente las preguntas, por lo que el equipo de evaluación debe redactar las preguntas en su contexto y verificar el límite de PVC mediante un análisis de coherencia. Además, el equipo de evaluación y el equipo de diseño deben entender este método como una herramienta para el mejoramiento continuo y no como un mecanismo punitivo. 
Dado que varios países están definiendo un marco normativo que promueve el uso de $\mathrm{BIM}$, las organizaciones que gestionan sus proyectos bajo los principios de Lean podrán naturalmente aplicar la metodología BIM. Los resultados obtenidos permiten a los directores y ejecutivos de proyectos realizar un estudio de referencia de las prácticas y usos de la BIM aplicada en sus proyectos en comparación con otros proyectos en las fases de diseño y planificación. Además, permite la identificación de conjuntos de prácticas de gestión del diseño asociadas a determinados usos de BIM, lo que permite al usuario de estas metodologías priorizar los esfuerzos en la aplicación combinada de Lean y BIM en sus proyectos. Las empresas de construcción que deseen aumentar el número de usos de BIM en sus proyectos, o las empresas de ingeniería que quieran aumentar su cartera de servicios, deben entender que para alcanzar altos niveles de aplicación de BIM, deben aplicar prácticas de gestión Lean. Por lo tanto, las empresas deben complementar sus planes de capacitación BIM con un plan de capacitación Lean, con el objetivo de realizar cambios en la gestión de sus proyectos mediante un enfoque holístico, es decir, incluyendo a las personas, los procesos y la tecnología. Al mismo tiempo, los organismos públicos que empiezan a exigir el uso de BIM en sus proyectos deben ser flexibles en sus marcos contractuales, ya que éstos suelen no estar alineados con algunas prácticas de gestión Lean.

Por último, este estudio muestra a los clientes, diseñadores y constructores de proyectos de infraestructura que un enfoque de gestión Lean BIM genera una mayor interacción entre los miembros de los equipos de diseño. Por lo tanto, las diferentes herramientas presentadas en este estudio pueden utilizarse para el autoanálisis de los proyectos de estos profesionales y para la evaluación del impacto organizativo de las prácticas, metodologías y tecnologías de gestión aplicadas en sus proyectos. Estos 
conceptos se aplican a cualquier equipo que participe en un proyecto de construcción, pero se aplican específicamente a los equipos de proyecto que son organizaciones temporales y no necesariamente coubicados (aunque también podría utilizarse en el contexto de proyectos coubicados).

\subsection{Limitaciones}

El análisis descriptivo y las pruebas de hipótesis se realizaron con la prueba piloto de 64 proyectos. Se recomienda el uso de un tamaño de muestra mayor para obtener conclusiones más generales según las características del proyecto. La BUA define cada nivel como una combinación de estados asociados a cada característica de cada uso, sin embargo, esta combinación podría ser diferente. Los usos "análisis de sustentabilidad" y "análisis de ingeniería" agrupan varias especialidades respectivamente, esta simplificación podría generar una brecha de información si el objetivo de la evaluación es comprender el uso de cada especialidad individualmente. El instrumento BUA no incluye los usos de BIM en las fases de construcción y explotación. Además, los usos de BIM considerados como base fueron los propuestos por Penn State, sin embargo, hay otras listas más detalladas de usos que no se consideraron en esta investigación. El instrumento BUA no evalúa el número de personas que interactuarán con cada uno de los usos, por lo tanto, por sí mismo no permite comprender el nivel de centralización o descentralización de los usos del BIM.

Las prácticas de LDM identificadas no son necesariamente las únicas, ya que no se consideraron las prácticas asociadas a la tecnología de la información, como el uso de BIM o la nube. Además, los autores no evaluaron herramientas específicas, como el sistema del último planificador, el diseño del valor objetivo u otros. Además, en este estudio se 
propone una medida cuantitativa del nivel de las prácticas de gestión del diseño lean en cada proyecto a partir de una entrevista con el coordinador del proyecto; esta evaluación puede tener una visión sesgada. La calificación de cada proyecto tiene que hacerse con al menos dos investigadores o consultores especializados para dar mayor objetividad a la evaluación. Tanto el instrumento BUA como el cuestionario sobre prácticas LDM se evalúan entrevistando al gerente del BIM y al gerente del proyecto, respectivamente. En otras palabras, ambos sistemas de evaluación no tienen en cuenta la opinión de otros miembros del equipo de diseño en lo que respecta a los usos de BIM y las prácticas LDM. Además, ninguno de los dos instrumentos solicita evidencia de la aplicación de las prácticas LDM y los usos BIM.

La herramienta para comprender la interacción del equipo de diseño se utiliza para la evaluación en un periodo especifico de tiempo; por lo tanto, se deben hacer comparaciones entre proyectos con niveles de progreso similares. Además, los investigadores sólo evaluaron dos proyectos con la herramienta SNA. La encuesta utilizada para evaluar la interacción necesita la respuesta de todos los miembros del equipo, lo cual es complejo en algunas situaciones en que algunos miembros del equipo no pertenecen a la misma organización patrocinadora. Además, la propia encuesta puede generar incoherencias entre las respuestas de diferentes miembros del equipo de diseño.En esta investigación no se consideró la posibilidad de medir las interacciones de otras fuentes de datos, como el entorno de datos común, los correos electrónicos, etc. Las dimensiones de la interacción evaluadas en este método se limitan a las que los autores encontraron en la literatura y a las que consideramos pertinentes; sin embargo, se pueden evaluar otros tipos de interacción que no se consideraron en esta investigación. Además, el método propuesto para evaluar 
las interacciones muestra una red estática con indicadores estáticos y no evalúa la evolución de las interacciones durante el proceso de diseño, a través de redes dinámicas, donde se podrían obtener otras métricas y conclusiones.

Para analizar la relación entre las prácticas LDM y los usos BIM, evaluamos una muestra de 64 proyectos. Los 64 proyectos evaluados no son una muestra estadística, teniendo en cuenta el número de proyectos en el proceso de diseño en los países en los que se evaluaron; por lo tanto, se debe evaluar un número mayor de proyectos. Dado el tamaño de la muestra, no fue posible realizar estudios en profundidad con otras variables del proyecto, como el lugar de origen, el tamaño del proyecto, el tipo de proyecto, el número de miembros del equipo de diseño, entre otros. Debido al bajo número de proyectos en comparación con el número de variables evaluadas, los autores no realizaron análisis estadísticos más sofisticados que permitieran hacer inferencias estadísticas más precisas. Dado que el origen de los proyectos evaluados fue Chile, Colombia y España (países que están comenzando a implementar BIM y Lean en sus proyectos), no se hicieron comparaciones con países más avanzados en la implementación de estas metodologías, tales como: Reino Unido, Estados Unidos, Australia, entre otros.

Finalmente, este estudio no midió el efecto de la aplicación de las prácticas LDM y los usos BIM en la productividad de los 64 proyectos. Existen varias dificultades para evaluar el impacto en la productividad de la aplicación de la gestión Lean BIM. Por ejemplo, el impacto de la aplicación de estas metodologías trasciende de una fase del proyecto, es decir, la aplicación en el diseño puede repercutir en el diseño, la construcción, la operación y el mantenimiento de la infraestructura; por lo tanto, el análisis requeriría tener información de todo el ciclo de vida del proyecto. Adicionalmente, en la industria AIC 
existe una cultura de medición de la productividad en la fase de construcción; sin embargo, en las fases de diseño y planificación no existe una cultura de medición de indicadores de desempeño y productividad; por lo tanto, los equipos no están acostumbrados y no tienen la cultura de realizar mediciones.

\subsection{Futuras líneas de trabajo}

Los trabajos futuros se centrarán en la ampliación de la BUA, que se elaboró para su aplicación en las fases de planificación y diseño, a las demás fases del ciclo de vida del proyecto, es decir, las fases de construcción y operación. Además, sería de gran valor evaluar el nivel de socialización de cada uso de BIM, ya que para utilizarlo eficazmente es necesario integrar la información entre todos los agentes del proyecto. Ello supondría evaluar la forma en que se gestiona, comparte y almacena la información. Además, con un mayor número de proyectos, se puede hacer un análisis descriptivo más profundo de los estados en que se encuentra cada característica de cada uso del BIM.

Las investigaciones futuras también deberían considerar las prácticas de gestión asociadas con la tecnología de la información, concretamente, el trabajo en colaboración en la nube y el uso de BIM, para evaluar un mayor número de proyectos de diferentes tipos a fin de comprender e identificar las brechas y oportunidades de mejora que existen en la fase de diseño de los proyectos de construcción y comprender los impactos de estas prácticas en el rendimiento de los proyectos. Además, como trabajo futuro, podría ser interesante realizar un estudio a fondo de cada proyecto que implique el punto de vista de diferentes actores que realicen una evaluación cualitativa y cuantitativa del proyecto.

Por otra parte, para futuras investigaciones, se recomienda realizar evaluaciones con el método de interacción del SNA en un gran número de equipos de diseño con diferentes 
composiciones, por ejemplo, equipos colocados/no colocados, diferentes números de empresas, diferentes sistemas de gestión y diferentes niveles de aplicación de la tecnología (entornos BIM), para comprender cómo el contexto, la gestión y la tecnología afectan a las interacciones entre los miembros del equipo. Además, sería interesante evaluar nuevas dimensiones de la interacción, estudiar nuevas métricas para redes pequeñas y analizar su calidad y evaluar las métricas entre diferentes redes. Adicionalmente, en los proyectos que trabajan en entornos BIM, sería interesante contrastar las redes obtenidas de los archivos de registro y las redes obtenidas con el método propuesto

Adicionalmente, en futuros estudios se podría crear un instrumento que se utilizaría como autoevaluación para cada proyecto. También las investigaciones futuras deberían tener por objeto evaluar el rendimiento del proceso de diseño y el rendimiento organizativo del equipo de diseño; de esta manera, será posible identificar el efecto de las prácticas de LDM en el rendimiento del proyecto de construcción, tanto durante su diseño como en su ejecución.

Así mismo, para futuras investigaciones, se recomienda realizar un análisis similar sobre una muestra representativa de proyectos para hacer inferencias estadísticas concluyentes sobre el impacto de la gestión de BIM-Lean en la interacción de los equipos de diseño. Por último, se propone evaluar los indicadores de rendimiento en las fases de diseño y construcción, para contrastarlos con el rendimiento organizativo del proyecto en las fases tempranas. 


\section{REFERENCES}

Abou-Ibrahim, H., \& Hamze, F. (2017). Design Management: Metrics and Visual Tools. In 25th Annual Conference of the International Group for Lean Construction, 465-473. https://doi.org/10.24928/2017/0234

AIA. (2007). Integrated Project Delivery : A Guide. In The American Institute of Architects (Vol. 1). https://doi.org/10.1016/j.autcon.2010.09.002

Akoglu, H. (2018). User's guide to correlation coefficientes. Turkish Journal of Emergency Medicine, 18(3), 91-93.

Al Hattab, M., \& Hamzeh, F. (2015). Using Social Network Theory and Simulation to Compare Traditional versus BIM-Lean Practice for Design Error Management. Automation in Construction, 52(4), 59-69. https://doi.org/10.1016/j.autcon.2015.02.014

Al Hattab, M., \& Hamzeh, F. (2017). A Process-Social Perspective for Understanding Design Information Flow. Lean Construction Journal, 11, 1-11. Retrieved from http://search.ebscohost.com/login.aspx?direct=true $\& d b=b$ th $\& A N=123824110 \&$ site $=e$ host-live

Alarcón, D. M., Alarcón, I. M., \& Alarcón, L. F. (2013). Social Network Analysis : a Diagnostic Tool for Information Flow in the Aec Industry. 21st Annual Conference of the International Group for Lean Construction 2013, IGLC 2013, 947-956. Fortaleza: International Group for Lean Construction.

Alarcón, L. F., Ashley, D. B., Sucre de Hanily, A., Molenaar, K. R., \& Ungo, R. (2011). Risk Planning and Management for the Panama Canal Expansion Program. Journal of Construction Engineering \& Management, 137(10), 762-771. https://doi.org/10.1061/(ASCE)CO.1943-7862.0000317.

Alsehaimi, A. O., Fazenda, P. T., \& Koskela, L. (2014). Improving Construction Management Practice with the Last Planner System: A Case Study. Engineering, Construction and Architectural Management, 21(1), 51-64.

https://doi.org/10.1108/ECAM-03-2012-0032 
Alves, T. da C. L., Lichtig, W., \& Rybkowski, Z. K. (2017). Implementing Target Value Design: Tools and Techniques to Manage the Process. Health Environments Research and Design Journal, 10(3), 18-29. https://doi.org/10.1177/1937586717690865

Anvuur, A. M., \& Kumaraswamy, M. M. (2015). Effects of Teamwork Climate on Cooperation in Crossfunctional Temporary Multi-Organization Workgroups. Journal of Construction Engineering and Management, 142(1), 04015054.

https://doi.org/10.1061/(asce)co.1943-7862.0001029

Arashpour, M., \& Arashpour, M. (2015). Analysis of Workflow Variability and its Impacts on Productivity and Performance in Construction of Multistory Buildings. Journal of Management in Engineering, 31(6), 04015006.

https://doi.org/10.1061/(ASCE)ME.1943-5479.0000363

Arayici, Y., Coates, P., Koskela, L., Kagioglou, M., Usher, C., \& O’Reilly, K. (2011). Technology Adoption in the BIM Implementation for Lean Architectural Practice. Automation in Construction, 20(2), 189-195. https://doi.org/10.1016/j.autcon.2010.09.016

Arbulu, R., \& Soto, J. (2006). A Design Case Study: Integrated Product and Process Management. 14th Annual Conference of the International Group for Lean Construction 2006, IGLC 2006, (511), 107-119. Santiago, Chile.

Arkader, R. (2001). The Perspective of Suppliers on Lean Supply in a Developing Country Context. Integrated Manufacturing Systems, 12(2), 87-93.

https://doi.org/http://dx.doi.org/10.1108/09576060110384280

Arnheiter, E. D., \& Maleyeff, J. (2005). The Integration of Lean Management and Six Sigma. The TQM Magazine, 17(1), 5-18. https://doi.org/10.1108/09544780510573020

Arroyo, P., Fuenzalida, C., Albert, A., \& Hallowell, M. R. (2016). Collaborating in Decision Making of Sustainable Building Design: An Experimental Study Comparing CBA and WRC Methods. Energy and Buildings, 128, 132-142. https://doi.org/10.1016/j.enbuild.2016.05.079 
Arroyo, P., Tommelein, I. D., \& Ballard, G. (2015). Selecting Globally Sustainable Materials : A Case Study Using Choosing by Advantages. Journal of Construction Engineering and Management, 05015015(1), 1-10. https://doi.org/10.1061/(ASCE)CO.1943-7862.0001041.

Austin, R. B., Pishdad-Bozorgi, P., \& de la Garza, J. M. (2015). Identifying and Prioritizing Best Practices to Achieve Flash Track Projects. Journal of Construction Engineering and Management, 142(2), 04015077. https://doi.org/10.1061/(asce)co.1943-7862.0001061

Azhar, S. (2011). Building Information Modeling (BIM): Trends, Benefits, Risks, and Challenges for the AEC Industry. Leadership and Management in Engineering, 11(3), $241-252$.

Aziz, R. F., \& Hafez, S. M. (2013). Applying Lean Thinking in Construction and Performance Improvement. Alexandria Engineering Journal, 52(4), 679-695. https://doi.org/10.1016/j.aej.2013.04.008

Bade, B. M., \& Haas, C. (2015). Using Lean Design and Construction to Get More from Capital Projects. Lean Construction Institute, (April), 39-44.

Baiden, B. K., Price, A. D. F., \& Dainty, A. R. J. (2006). The Extent of Team Integration within Construction Projects. International Journal of Project Management, 24(1), 13-23. https://doi.org/10.1016/j.ijproman.2005.05.001

Ballard, G. (2008). The Lean Project Delivery System: An Update. Lean Construction Journal, 1-19.

Ballard, G., \& Howell, G. (2003). Lean project management. Building Research \& Information, 31(2), 119-133. https://doi.org/10.1080/09613210301997

Ballard, G., Tommelein, I. D., Koskela, L., \& Howell, G. (2002). Lean Construction Tools and Techniques. In Rick Best and Gerard de Valence (Ed.), Design and Construction: Bulding in Value (pp. 227-255). Butterworth-Heinemann and Elsevier Ltd.

Ballard, Glenn. (2002). Managing Work Flow on Design Projects : A Case Study. Engineering, Construction and Architectural Management, 9(3), 284-291. 
Ballard, Glenn, \& Zabelle, T. (2000). Project Definition. In White Paper \#9. USA.

Becerik-Gerber, B., Kihonh, K., Jazizadek, F., Ku, K., \& Jazizadeh, F. (2012). BIM-

Enabled Virtual and Collaborative Construction Engineering and Management.

Journal of Professional Issues in Engineering Education and Practice, 138(3), 234245. https://doi.org/10.1061/(asce)ei.1943-5541.0000098

Bloom, N., \& Van Reenen, J. (2007). Measuring and Explaining Management Practices Across Firms and Countries. Quarterly Journal of Economics, 122(4), 1341-1408.

Bloom, N., \& Van Reenen, J. (2010). New Approaches to Surveying Organizations. American Economic Review, 100(2), 105-109. https://doi.org/10.1257/aer.100.2.105

Bloomberg, D., Bloomberg, M. R., Burney, D. J., \& Resnick, D. (2012). BIM Guidelines $N Y$. New Yor: New York city deparment of design construction.

Bloomberg, M. R., Burney, D. J., \& Resnick, D. (2012). BIM Guidelines. New York. Bryde, D., Broquetas, M., \& Volm, J. M. (2013). The Project Benefits of Building Information Modelling (BIM). International Journal of Project Management, 31(7), 971-980. https://doi.org/10.1016/j.ijproman.2012.12.001

Bryde, D., Unterhitzenberger, C., \& Joby, R. (2018). Conditions of Success for Earned Value Analysis in Projects. International Journal of Project Management, 36, 474484. https://doi.org/10.1016/j.ijproman.2017.12.002

Building and Construction Authority. (2013). Singapore BIM Guide - V2.0. In Cornet. Cambiaghi, H., \& Amá, R. (2006). Manual de Escopo de Projetos e Servicos de Arquitetura e Urbanismo. Sao Paulo.

Carnevalli, J. A., \& Miguel, P. C. (2008). Review, Analysis and Classification of the Literature on QFD-Types of Research, Difficulties and Benefits. International Journal of Production Economics, 114(2), 737-754. https://doi.org/10.1016/j.ijpe.2008.03.006

Cash, P., Dekoninck, E. A., \& Ahmed-Kristensen, S. (2017). Supporting the Development of Shared Understanding in Distributed Design Teams. Journal of Engineering Design, 28(3), 147-170. https://doi.org/10.1080/09544828.2016.1274719 
Castillo, T., Alarcón, L. F., \& Pellicer, E. (2018). Influence of Organizational Characteristics on Construction Project Performance Using Corporate Social Networks. Journal of Construction Engineering \& Management, 34(4), 1-9. https://doi.org/10.1061/(ASCE)ME.1943-5479.0000612.

Castillo, T., Alarcón, L. F., \& Salvatierra, J. L. (2018). Effects of Last Planner System Practices on Social Networks and the Performance of Construction projects. Journal of Construction Engineering and Management, 144(3), 05017120-05017121. https://doi.org/10.1061/(ASCE)CO.1943-7862.0001443.

Cisterna, D. A. (2017). Application of Social Network Analysis in Lean Infraestructure Projects. Universität Stuttgart.

Cohen. (2010). Integrated Project Delibery: Case Studies. Sacramento.

Cohen, J. (1960). A Coefficient of Agreement for Nominal Scales. Educational and Psychological Measurement, 20(1), 37-46. https://doi.org/https://doi.org/10.1177/001316446002000104

Craft, R. C., \& Leake, C. (2002). The Pareto Principle in Organizational Decision Making. Management Decision, 40(8), 729-733. https://doi.org/10.1108/00251740210437699

Czemplik, A. (2014). Application of Earned Value Method to Progress Control of Construction Projects. XXIII R-S-P Seminar, Theoretical Foundation of Civil Engineering, 91, 424-428. https://doi.org/10.1016/j.proeng.2014.12.087

Dainty, A. R. J., Briscoe, G. H., \& Millett, S. J. (2001). Subcontractor Perspectives on Supply Chain Alliances. Construction Management and Economics, 19(8), 841-848. https://doi.org/10.1080/01446190110089727

Dam, R., \& Siang, T. (2019). Affinity Diagrams- Learn How to Cluster and Bundle Ideas and Facts. Retrieved December 8, 2019, from https://www.interactiondesign.org/literature/article/affinity-diagrams-learn-how-to-cluster-and-bundle-ideasand-facts

Dantas-Filho, J. B. P., Lima, M. M. X., Heineck, L. F. M., Tzortzopoulos, P., \& Barros Neto, J. P. (2017). Waiting Times in Design Process: A Case Study. In 25th Annual 
Conference of the International Group for Lean Construction, (July), 483-489. https://doi.org/10.24928/2017/0294

Dave, B. A. (2013). Developing a Construction Management System Based on Lean Construction and Building Information Modelling. University of Salford.

Dave, B., Koskela, L., Kiviniemi, A., Owen, R., \& Tzortzopoulos, P. (2013). Implementing Lean in construction. https://doi.org/Published by Ciria, Classic House, 174-180 Old Street. London, ECIV 9BP, UK

Dave, Bhargav, Kubler, S., Främling, K., \& Koskela, L. (2014). Addressing Information Flow in Lean Production Management and Control in Construction. 22nd Annual Conference of the International Group for Lean Construction, IGLC 2014, 581-592. Oslo: International Group for Lean Construction.

Doumbouya, L., Gao, G., \& Guan, C. (2016). Adoption of the Building Information Modeling (BIM) for Construction Project Effectiveness: The Review of BIM Benefits. American Journal of Civil Engineering and Architecture, 4(3), 74-79. https://doi.org/10.12691/AJCEA-4-3-1

Eastman, C. M., Teicholz, P., Sacks, R., \& Liston, K. (2011). BIM Handbook: A Guide to Building Information Modeling for Owners, Managers, Designers, Engineers and Contractors (2nd ed.). New Jersey: John Wiley \& Sons Ltd.

Eastman, Chuck M., Teicholz, P., Sacks, R., \& Liston, K. (2008). BIM Handbook: A Guide to Building Information Modeling for Owners, Managers, Designers, Engineers and Contractors (1st ed.). https://doi.org/10.1017/CBO9781107415324.004

Elmualim, A. (2010). Culture and Leadership in Stakeholder Management. In E. A. Chinyio \& P. Olomolaiye (Eds.), Constrution stakeholders management (pp. 174192). London: Wiley-Blackwell Publishing.

Elmualim, A., \& Gilder, J. (2014). BIM: Innovation in Design Management, Influence and Challenges of Implementation. Architectural Engineering and Design Management, 10(3-4), 183-199. https://doi.org/10.1080/17452007.2013.821399

European Commission. (2003). Commission Recommendation Concerning the Definition 
of Micro, Small and Medium-Sized Enterprises. Official Journal of the European Union, 361(EC), 1-6. https://doi.org/10.1093/nq/s10-I.5.88-c

Fakhimi, A. H., Majrouhi Sardroud, J., \& Azhar, S. (2016). How Can Lean, IPD and BIM Work Together? 33rd International Symposium on Automation and Robotics in Construction (ISARC), 1-8. https://doi.org/10.22260/isarc2016/0009

Flores, F. (2015). Conversaciones para la Acción y Ensayos Seleccionados (M. Flores, Ed.). Bogotá: Createspace Independent Pub.

Flores, J., Ruiz, J. C., Alarcón, D., Alarcón, L. F., Salvatierra, J. L., \& Alarcón, I. (2014). Improving Connectivity and Information Flow in Lean Organizations - Towards an Evidence-Based Methodology. 22nd Annual Conference of the International Group for Lean Construction 2014, IGLC 2014, 1109-1120. Oslo: International Group for Lean Construction.

Forbes, L. H., \& Ahmed, S. M. (2011). Modern Construction: Lean Project Delivery and Integrated Practices. New York: Taylor \& Francis.

Formoso, C. T., Tzotzopoulos, P., Jobim, M. S., \& Liedtke, R. (1998). Developing a Protocol for Managing the Design Process in the Building Industry. 6th Annual Conference of the International Group for Lean Construction 1998, IGLC 1998. Retrieved from http://icasp9.berkeley.edu/ tommelein/IGLC6/FormosoTzotzopoulosJobimLeidtke.pdf

Fosse, R., \& Ballard, G. (2016). Lean Design Management in Practice. 24th Annual Conference of the International Group for Lean Construction 2016, IGLC 2016, 33 42. Boston.

Foster, S. T., \& Ganguly, K. K. (2007). Managing Quality: Integrating the Supply Chain. New Jersey: Pearson Prentice Hall.

Franco, V., \& Picchi, A. (2016). Lean Design in Building Projects: Guiding Principles and Exploratoyry. 24th Annual Conference of the International Group for Lean Construction 2016, IGLC 2016, 113-122. Boston.

Freire, J., \& Alarcón, L. F. (2002). Achieving Lean Design Process : Improvement 
Methodology. Journal of Construction Engineering and Management, 128(3), 248256. https://doi.org/10.1061/?ASCE?0733-9364?2002?128:3?248? CE

Gambatese, J. A., Pestana, C., \& Lee, H. W. (2017). Alignment between Lean Principles and Practices and Worker Safety Behavior. Journal of Construction Engineering and Management, 143(1). https://doi.org/10.1061/(ASCE)CO.1943-7862.0001209

Gerber, D. J., Becerik-Gerber, B., \& Kunz, A. (2010). Building Information Modeling and Lean Construction: Technology, Methodology and Sdvances from Practices. 18th Annual Conference of the International Group for Lean Construction, 1-11. Haifa, Israel: International Group for Lean Construction.

Gu, N., \& London, K. (2010). Automation in Construction Understanding and facilitating BIM adoption in the AEC industry. Automation in Construction, 19(8), 988-999. https://doi.org/10.1016/j.autcon.2010.09.002

Hamzeh, F. R., Ballard, G., \& Tommelein, I. D. (2009). Is the Last Planner System applicable to design? A case study. 17th Annual Conference of the International Group for Lean Construction 2009, IGLC 2009, 407-416. Taipei.

Hamzeh, F. R., Zankoul, E., \& Rouhana, C. (2015). How can 'Tasks Made Ready’ during Lookahead Planning Impact Reliable Workflow and Project Duration? Construction Management and Economics, 33(4), 243-258.

https://doi.org/10.1080/01446193.2015.1047878

Hannele, K., Reijo, M., Tarja, M., Sami, P., Jenni, K., \& Teija, R. (2012). Expanding Uses of Building Information Modeling in Life-Cycle Construction Projects. Work, 41(1), 114-119. https://doi.org/10.3233/WOR-2012-0144-114

Hansen, G. K., Olsson, N. O. E., Hansen, G. K., \& Olsson, N. O. E. (2011). Layered Project - Layered Process: Lean Thinking and Flexible Solutions. Architectural Engineering and Design Management, 7(2), 70-84.

https://doi.org/10.1080/17452007.2011.582331

Harvard University Construction Management Council. (2010). BIM Uses Guide.

Herrera, R. F., Mourgues, C., \& Alarcón, L. F. (2018). Assessment of Lean Practices, 
Performance and Social Networks in Chilean Airport Projects. 26th Annual Conference of the International Group for Lean Construction 2018, IGLC 2018, 603613. https://doi.org/10.24928/2018/0493

Herrera, R. F., Mourgues, C., Alarcon, L. F., \& Pellicer, E. (2019). Assessing Design Process Performance of Construction Projects. CIB World Building Congress 2019. Hong Kong SAR, China: CIB.

Herrera, R. F., Mourgues, C., Alarcón, L. F., \& Pellicer, E. (2020a). An Assessment of Lean Design Management Practices in Construction Projects. Sustainability, 12(1), 119.

Herrera, R. F., Mourgues, C., Alarcón, L. F., \& Pellicer, E. (2020b). Understanding Interactions between Design Team Members of Construction Projects Using Social Network Analysis. Journal of Construction Engineering and Management, 146(6), 04020053. https://doi.org/10.1061/(asce)co.1943-7862.0001841

Herrera, R. F., Sanz, M. A., Montalbán-Domingo, L., García-Segura, T., \& Pellicer, E. (2019). Impact of Game-Based Learning on Understanding Lean Construction Principles. Sustainability, 11(19), 5294. https://doi.org/10.3390/su11195294

Hickethier, G., Tommelein, I. D., \& Lostuvali, B. (2013). Social Network Analysis of Information Flow in an IPD-Project Design Organization. 21st Annual Conference of the International Group for Lean Construction 2013, IGLC 2013, 319-328. Fortaleza: International Group for Lean Construction.

Hoppe, B., \& Reinelt, C. (2010). Social Network Analysis and the Evaluation of Leadership Networks. The Leadership Quarterly, 21(4), 600-619. https://doi.org/10.1016/j.leaqua.2010.06.004

Hu, Q., P., F., Williams, S., \& Mason, R. (2016). Lean Thinking and Organisational Learning: How Can They Facilitate Each Other? In A. Chiriani, P. Found, \& N. Rich (Eds.), Understanding the Lean Enterprise. Measuring Operations Performance (pp. 61-77). https://doi.org/10.1007/978-3-319-19995-5

Iii, D. W. T. (2010). Qualitative Interview Design : A Practical Guide for Novice 
Investigators Qualitative Interview Design : A Practical Guide for Novice Investigators. 15(3), 754-760.

Jaganathan, S., Nesan, L. J., Ibrahim, R., \& Mohammad, A. H. (2013). Integrated Design Approach for Improving Architectural Forms in Industrialized Building Systems. Frontiers of Architectural Research, 2(4), 377-386.

https://doi.org/10.1016/j.foar.2013.07.003

Jones, S. a, Young Jr., N. W., \& Bernstein, H. M. (2008). Building Information Modeling (BIM): Transforming Design and Construction to Achieve Greater Industry Productivity. In McGraw Hill Construction - SmartMarket Report.

Kalsaas, B. T., \& Sacks, R. (2011). Conceptualization of Interdependency and Coordination. In 19th Annual Conference of the International Group for Lean Construction, 1-11. Lima.

Kapogiannis, G., \& Sherratt, F. (2018). Impact of Integrated Collaborative Technologies to form a Collaborative Culture in Construction Projects. Built Environment Project and Asset Management, 8(1), 24-38. https://doi.org/10.1108/BEPAM-07-2017-0043

Karp, N. C., Hauer, K. E., \& Sheu, L. (2019). Trusted to Learn: a Qualitative Study of Clerkship Students' Perspectives on Trust in the Clinical Learning Environment. Journal of General Internal Medicine, 34(5), 662-668.

https://doi.org/10.1007/s11606-019-04883-1

Kereri, J. O., \& Harper, C. M. (2019). Social Networks and Construction Teams: Literature Review. Journal of Construction Engineering and Management, 145(4), 03119001. https://doi.org/10.1061/(asce)co.1943-7862.0001628

Kestle, L., \& London, K. (2002). Towards the Development of a Conceptual Design Management Model for Remote Sites. 10th Annual Conference of the International Group for Lean Construction 2002, IGLC 2002, 1-14. Sidney: International Group for Lean Construction.

Kestle, L., Potangaroa, R., \& Storey, B. (2011). Integration of Lean Design and Design Management and its Influence on the Development of a Multidisciplinary Design 
Management Model for Remote Dite Projects. Architectural Engineering and Design Management, 7(2), 139-153. https://doi.org/10.1080/17452007.2011.582336

Kleinsmann, M., Deken, F., \& Dong, A. (2012). Development of Design Collaboration Skills. Journal of Engineering Design, 23(7), 485-506.

https://doi.org/10.1080/09544828.2011.619499

Knotten, V., Lædre, O., \& Hansen, G. K. (2017). Building Design Management-Key Success Factors. Architectural Engineering and Design Management, 13(6), 479493. https://doi.org/10.1080/17452007.2017.1345718

Knotten, V., Svalestuen, F., \& Hansen, G. (2016). Improving Design Management. 24th Annual Conference of the International Group for Lean Construction 2016, IGLC 2016, (2), 173-182. Boston.

Ko, C.-H., \& Chung, N.-F. (2014). Making Design Process Lean. In 22nd Annual Conference of the International Group for Lean Construction., 886(8), 463-474. Oslo, Norway: International Group for Lean Construction.

Ko, C., \& Chung, N. (2014). Lean Design Process. Journal of Construction Engineering \& Management, 140(6), 1-11. https://doi.org/10.1061/(ASCE)CO.1943-7862

Koo, C. W., Park, S. H., Yi, J. S., \& Kwon, O. K. (2013). Development of Web-Based Design Management System through User Participatory Design and Use-Case Modeling. International Journal of Civil Engineering, 11(1), 23-32.

Koskela, L. (1992). Application of the New Production Philosophy to Construction. In Center for Integrated Facility Engineering. https://doi.org/Technical Report No. 72

Koskela, L. (2000). An Exploration towards a Production Theory and its Application to Construction. Construction, 298. https://doi.org/10.1073/pnas.1107281109//DCSupplemental.www.pnas.org/cgi/doi/10.1073/pnas.1107281109

Koskela, L., Ballard, G., \& Tanhuanpää, V.-P. (1997). Towards Lean Design Management. 5th Annual Conference of the International Group for Lean Construction 1997, IGLC 1997, 1-13. Gold Coast.

Koskela, L., Huovila, P., \& Leinonen, J. (2002). Design management in building 
construction: From theory to practice. Journal of Construction Research, 3(1), 1-16.

Kreider, R. (2013). An Ontology of the Uses of Building Information Modeling.

Pennsylvania State University.

Kreider, R. G., \& Messner, J. I. (2013). The Uses of BIM: Classifying and Selecting BIM Uses. In The Pennsylvania State University. Pennsylvania.

Lamming, R. (1996). Squaring Lean Supply with Supply Chain Management. International Journal of Operations \& Production Management, 16(2), 183-196. https://doi.org/http://dx.doi.org/10.1108/01443579610109910

Liu, Y., van Nederveen, S., Hertogh, M., Nederveen, S. Van, \& Hertogh, M. (2017). Understanding Effects of BIM on Collaborative Design and Construction : An Empirical Study in China. International Journal of Project Management, 35(4), 686698. https://doi.org/10.1016/j.ijproman.2016.06.007

Long, D., \& Arroyo, P. (2018). Language, Moods, and Improving Project Performance. 26th Annual Conference of the International Group for Lean Construction 2018, IGLC 2018, 495-504. https://doi.org/https://doi.org/10.24928/2018/0541

Love, P. E., Irani, Z., Cheng, E., \& Li, H. (2002). A Model for Supporting Interorganizational Relations in the Supply Chain. Engineering, Construction \& Architectural Management, 9(1), 2-15.

Magalingam, A., Yadav, A. K., \& Varaprasad, J. (2015). Investigating the Role of Lean Practices in Enabling BIM Adoption: Evidence from Two Indian Cases. Journal of Construction Engineering and Management, 141(7). https://doi.org/10.1061/(ASCE)CO.1943-7862.0000982

Mandujano, M. G., Mourgues, C., Alarcón, L. F., \& Kunz, J. (2017). Modeling Virtual Design and Construction Implementation Strategies Considering Lean Management Impacts. Computer-Aided Civil and Infrastructure Engineering, 00, 1-22. https://doi.org/10.1111/mice.12253

Marin, A., \& Wellman, B. (2011). Social Network Analysis: An Introduction. In J. Scott \& P. J. Carrington (Eds.), The SAGE Handbook of Social Network Analysis (pp. 11-25). 
Matta, G., Herrera, R. F., Baladrón, C., Giménez, Z., \& Alarcón, L. F. (2018). Using BIMBased Sheets as a Visual Management Tool for On-site Instructions: A Case Study. IGLC 2018 - Proceedings of the 26th Annual Conference of the International Group for Lean Construction: Evolving Lean Construction Towards Mature Production Management Across Cultures and Frontiers, 1, 144-154.

https://doi.org/10.24928/2018/0520

Mchugh, M. L. (2012). Interrater Reliability: The Kappa Statistic. Biochemia Medica, 22(3), 276-282.

Medina-Mora, R., Winograd, T., Flores, R., \& Flores, F. (1992). The Action Workflow Approach to Workflow Management Technology. CSCW 92 Proceedings, 281-288. https://doi.org/10.1080/01972243.1993.9960152

Mesa, H. A., Molenaar, K. R., \& Alarcón, L. F. (2016). Exploring performance of the integrated project delivery process on complex building projects. International Journal of Project Management, 34(7), 1089-1101. https://doi.org/10.1016/j.ijproman.2016.05.007

Mok, K. Y., Shen, G. Q., \& Yang, J. (2015). Stakeholder Management Studies in Mega Construction Projects: A Review and Future Directions. International Journal of Project Management, 33(2), 446-457. https://doi.org/10.1016/j.ijproman.2014.08.007

Mollasalehi, S., Fleming, A., Talebi, S., \& Underwood, J. (2016). Development of an Experimental Waste Framework Based on Bim / Lean Concept in Construction Design. 24th Annual Conference of the International Group for Lean Construction 2016, IGLC 2016, 193-202. Boston: International Group for Lean Construction.

Molwus, J. J., Erdogan, B., \& Ogunlana, S. (2017). Using Structural Equation Modelling (SEM) to Understand the Relationships Among Critical Success Factors (CSFs) for Stakeholder Management in Construction. Engineering, Construction and Architectural Management, 24(3), 426-450. https://doi.org/https://doi.org/10.1108/ECAM-10-2015-0161

Mostafa, S., Chileshe, N., \& Abdelhamid, T. (2016). Lean and Agile Integration within Offsite Construction using Discrete Event Simulation. Construction Innovation, 
16(4), 483-525. https://doi.org/10.1108/CI-09-2014-0043

Mujumdar, P., \& Maheswari, J. U. (2018). Design Iteration in Construction Projects Review and Directions. Alexandria Engineering Journal, 57(1), 321-329. https://doi.org/10.1016/j.aej.2016.12.004

Munthe-kaas, T. S., Hjelmbrekke, H., \& Lohne, J. (2015). Lean Design versus Traditional Design Approach. 23th Annual Conference of the International Group for Lean Construction 2015, IGLC 2015, 578-588. Perth: International Group for Lean Construction.

Musa, M., Pasquire, C., \& Hurst, A. (2019). Using TVD Simulation to Improve Collaboration. 27th Annual Conference of the International Group for Lean Construction, IGLC 2019, 503-514. https://doi.org/10.24928/2019/0268

Nascimento, D., Caiado, R., Tortorella, G., Ivson, P., \& Meiriño, M. (2018). Digital Obeya Room: Exploring the Synergies between BIM and Lean for Visual Construction Management. Innovative Infrastructure Solutions, 3(19), 1-10. https://doi.org/10.1007/s41062-017-0125-0

NBS National Building Specification. (2018). National BIM Report 2018. Newcastle.

Ng, S., \& Tang, Z. (2010). Labour-intensive Construction Sub-contractors: Their Critical Success Factors. International Journal of Project Management, 28(7), 732-740. https://doi.org/10.1016/j.ijproman.2009.11.005

O’Connor, R., \& Swain, B. (2013). Implementing Lean in construction: Lean tools and techniques-an introduction. London: CIRIA.

Olatunji, O. A. (2011). Modelling the costs of corporate implementation of building information modelling. Journal of Financial Management of Property and Construction, 16(3), 211-231. https://doi.org/10.1108/13664381111179206

Olawumi, T. O., Chan, D. W. M., \& Wong, J. K. W. (2017). Evolution in the Intellectual Structure of BIM Research: A Bibliometric Analysis. Journal of Civil Engineering and Management, 23(8), 1060-1081. https://doi.org/10.3846/13923730.2017.1374301

Oloufa, A. A., Hosni, Y. A., Fayez, M., \& Axelsson, P. (2017). Civil Engineering and 
Environmental Systems Using DSM for modeling information flow in construction design projects. 6608(May). https://doi.org/10.1080/10286600310001638474

Oluwatayo, A. A., \& Amole, D. (2013). Ownership, Structure, and Performance of Architectural Firms. Frontiers of Architectural Research, 2(1), 94-106. https://doi.org/10.1016/j.foar.2012.12.001

Othman, M. Z., Nawi, M. N. M., Nifa, F. A. A., Yaakob, M., Rofie, K., Zan, Z. M., \& Pozin, M. A. .-. (2016). A Atrategy Towards Team Integration Practice for Improving the Design and Construction Process in the Malaysian Industrialized Building Projects. International Review of Management and Marketing, 6(8S), 226-229.

Oviedo-Haito, R. J., Jiménez, J., Cardoso, F. F., \& Pellicer, E. (2014). Survival Factors for Subcontractors in Economic Downturns. Journal of Construction Engineering \& Management, 140(3), 04013056. https://doi.org/10.1061/(ASCE)CO.19437862.0000811.

Paris, C. R., Salas, E., \& Cannon-Bowers, J. A. (2000). Teamwork in Multi-person Systems: A Review and Analysis. Ergonomics, 43(8), 1052-1075. https://doi.org/10.1080/00140130050084879

Pellicer, E., Yepes, V., Teixeira, J. C., Moura, H., \& Catalá, J. (2014). Construction Management. Oxford: Wiley-Blackwell.

Penttilä, H. (2006). Describing the Changes in Architectural Information technology to Understand Design Complexity and Free-form Architectural Expression. Electronic Journal of Information Technology in Construction, 11(1), 395-408.

Peralta, C. I. (2019). BIM Maturity and its relationships with Lean and BIM uses performance. Pontificia Universidad Católica de Chile.

Perez, C., Castro, R., Simons, D., \& Gimenez, G. (2010). Development of Lean Supply Chains: A Case Study of the Catalan Pork Sector. Supply Chain Management: An International Journal, 15(1), 55-68. https://doi.org/10.1108/13598541011018120

Pestana, C., \& Gambatese, J. A. (2016). Lean Practices and Safety Performance. Construction Research Congress, 1710-1719. San Juan, Puerto Rico: ASCE. 
Phelps, A. F. (2012). Behavioral Factors Influencing Lean Information Flow in Complex Projects. 20th Annual Conference of the International Group for Lean Construction 2012, IGLC 2012. San Diego: International Group for Lean Construction.

Porwal, A., \& Hewage, K. N. (2013). Building Information Modeling (BIM) Partnering Framework for Public Construction Projects. Automation in Construction, 31, 204214. https://doi.org/10.1016/j.autcon.2012.12.004

Priven, V., \& Sacks, R. (2013). Social Network Development in Last Planner System Implementations. 21st Annual Conference of the International Group for Lean Construction 2013, IGLC 2013, 474-485. Fortaleza: International Group for Lean Construction.

Project Management Institute. (2017). A Guide to the Project Management Body of Knowledge (PMBOK® Guide) (Sixth Edit; Project Management Institute, Ed.). Project Management Institute.

Pryke, S. (2012). Social Network Analysis in Construction. Wiley-Blackwell.

Ragin, C. C. (2006). Set Relations in Social Research: Evaluating their Consistency and Coverage. Political Analysis, 14(3), 291-310. https://doi.org/10.1093/pan/mpj019

Rahmawati, Y., Utomo, C., Anwar, N., Negoro, N. P., \& Nurcahyo, C. B. (2014). A Framework of Knowledge Management for Successful Group Decision in Design Process. 2014 IEEE Conference on Open Systems (ICOS), 60-65. https://doi.org/10.1109/ICOS.2014.7042410

Reifi, M. H. El, \& Emmitt, S. (2013). Perceptions of Lean Design Management. Architectural Engineering and Design Management, 9(3), 195-208. https://doi.org/10.1080/17452007.2013.802979

Richards, W., \& Macindoe, O. (2010). Characteristics of Small Social Networks. Technical Report, Computer Science and Artificial Intelligence Laboratory, MIT, 40.

Rihoux, B., \& Ragin, C. C. (2009). Introduction. In Configurational Comparative Methods (Thousand O). California: SAGE Publications.

Rojas, M. J., Herrera, R. F., Mourgues, C., Ponz-Tienda, J. L., Alarcón, L. F., \& Pellicer, 
E. (2019). BIM Use Assessment (BUA) Tool for Characterizing the Application Levels of BIM Uses for the Planning and Design of Construction Projects. Advances in Civil Engineering, 2019, 1-9. https://doi.org/10.1155/2019/9094254

Rosas, E. (2013). Integrating the Design Structure Matrix and the Last Planner System Into Building Design. 21th Annual Conference of the International Group for Lean Construction 2013, IGLC 2013, (July), 389-398. Fortaleza.

Sacks, R., Barak, R., Belaciano, B., \& Gurevich, U. (2011). Field Tests of the Kanbim ${ }^{\text {TM }}$ Lean Production Management System. 19th Annual Conference of the International Group for Lean Construction, 1-12. Lima, Perú: International Group for Lean Construction.

Sacks, R., Eastman, C. M., Lee, G., \& Teicholz, P. (2018). BIM Handbook: A Guida to Building Information Modeling for Owners, Designers, Engineers, Contractors and Facility Managers (3rd Editio). New York: John Wiley \& Sons Ltd.

Sacks, R., Koskela, L., Dave, B. A., \& Owen, R. (2010). Interaction of Lean and Building Information Modeling in Construction. Journal of Construction Engineering \& Management, 136(9), 968-980. https://doi.org/10.1061/ASCEீCO.19437862.0000203

Salazar, L. A., Retamal, F., Ballard, G., Arroyo, P., \& Alarcón, L. F. (2019). Results of Indicators from the Linguistic Action Perspective in the Last Planner® System. In C. Pasquire \& F. R. Hamzeh (Eds.), 27th Annual Conference of the International Group for Lean Construction, IGLC 2019 (pp. 1241-1250). https://doi.org/10.24928/2019/0148

Salgin, B., Arroyo, P., \& Ballard, G. (2016). Exploring the Relationship between Lean Design Methods and C\&D Waste Reduction: Three Case Studies of Hospital Projects in California. Revista Ingenieria de Construccion, 31(3), 191-200. https://doi.org/10.4067/S0718-50732016000300005

Salvatierra, J. L., Galvez, M., Bastias, F., Castillo, T., Herrera, R. F., \& Alarcón, L. F. (2019). Developing a Benchmarking System for Architecture Design Firms. Engineering, Construction and Architectural Management, 26(1), 139-152. 
Savolainen, J. M., Saari, A., Männistö, A., \& Kähkonen, K. (2018). Indicators of Collaborative Design Management in Construction Projects. Journal of Engineering, Design and Technology, 16(4), 674-691. https://doi.org/10.1108/JEDT-09-2017-0091

Schimanski, C. P., Monizza, G. P., Marcher, C., \& Matt, D. T. (2019). Conceptual Foundations for a New Lean BIM-Based Production System in Construction. 27th Annual Conference of the International Group for Lean Construction, 877-888. Dublin, Ireland: International Group for Lean Construction.

Schneider, C. Q., \& Wagemann, C. (2012). Set-Theoric Methods for Social Sciences: A Guide to Qualitative Comparative Analysis. Cambridge: Cambridge University Press.

Schöttle, A., Haghsheno, S., \& Gehbauer, F. (2014). Defining Cooperation and Collaboration in the Context of Lean Construction. In 22nd Annual Conference of the International Group for Lean Construction., 49(0), 1269-1280. Oslo: International Group for Lean Construction.

Schröpfer, V. L. M., Tah, J., \& Kurul, E. (2017). Mapping the Knowledge Flow in Sustainable Construction Project Teams using Social Network Analysis. Engineering , Construction and Architectural Management, 24(2), 229-259.

Scott, J. (2017). Social Network Analysis (4th ed.; M. Steele, Ed.). London: SAGE Publications.

Searle, J. R. (1969). Speech acts: An Essay in the Philosophy of Language (Cambridge university press., Ed.). Berkeley.

Segarra, L., Herrera, R. F., Alarcón, L. F., \& Pellicer, E. (2017). Knowledge Management and Information Flow through Social Networks Analysis in Chilean Architecture Firms. 25th Annual Conference of the International Group for Lean Construction, IGLC 2017, 413-420. https://doi.org/10.24928/2017/0244

Shafiq, M. T., Matthews, J., \& Lockley, S. (2013). A study of BIM collaboration requirements and available features in existing model collaboration systems. Journal of Information Technology in Construction, 18, 148-161.

Simons, D., \& Taylor, D. (2007). Lean Thinking in the UK Red Meat Industry: A Systems 
and Contingency Approach. Int. J. Production Economics, 106, 70-81. https://doi.org/10.1016/j.ijpe.2006.04.003

Sødal, A. H., Lædre, O., Svalestuen, F., \& Lohne, J. (2014). Early Contractor Involvement: Advantages and Disadvantages for the Design Team. 22nd Annual Conference of the International Group for Lean Construction 2014, IGLC 2014, 519-531. Oslo.

Sonnenwald, D. H. (1996). Communication Roles that Support Collaboration During the Design Process. Design Studies, 17(3), 277-301. https://doi.org/10.1016/0142694X(96)00002-6

Succar, B. (2016). 211in Model Uses List.

Succar, B., Sher, W., \& Williams, A. (2012). Measuring BIM Performance: Five Metrics. Architectural Engineering and Design Management, 8(2), 120-142. https://doi.org/10.1080/17452007.2012.659506

Svalestuen, F., Frøystad, K., Drevland, F., Ahmad, S., Lohne, J., \& Lædre, O. (2015). Key Elements to an Effective Building Design Team. International Conference on Project Management, 64, 838-843. https://doi.org/10.1016/j.procs.2015.08.636

Sydow, J., \& Braun, T. (2018). Projects as Temporary Organizations: An Agenda for Further Theorizing the Interorganizational Dimension. International Journal of Project Management, 36(1), 4-11. https://doi.org/10.1016/j.ijproman.2017.04.012

Talebi, S. (2014). Exploring Advantages and Challenges of Adaptation and Implementation of BIM in Project Life Cycle. 2nd BIM International Conference on Challenges to Overcome. BIMForum Portugal., 1-20. https://doi.org/10.1002/ejoc.201200079

Tauriainen, M., Marttinen, P., Dave, B., \& Koskela, L. (2016). The effects of BIM and lean construction on design management practices. Procedia Engineering, 164, 567574. https://doi.org/10.1016/j.proeng.2016.11.659

Thangaraj, M., \& Amutha, S. (2018). Mgephi: Modified Gephi for Effective Social Network Analysis. International Journal of Scientific Research in Computer Science, Engineering and Information Technology, 3(1), 39-50. 
Tilley, P. A. (2005). Lean design management - A New Paradigm for Managing the Design and Documentation Process to Improve Quality? 13th Annual Conference of the International Group for Lean Construction 2005, IGLC 2005, 283-295. Sidney.

Tribelsky, E., \& Sacks, R. (2011). An Empirical Study of Information Flows in Multidisciplinary Civil Engineering Design Teams using Lean Measures. Architectural Engineering and Design Management, 7(2), 85-101. https://doi.org/10.1080/17452007.2011.582332

Tsai, M., Mom, M., Hsieh, S., Tsai, M., \& Hsieh, S. (2014). Developing Critical Success Factors for the Sssessment of BIM Technology Adoption: Part I . Methodology and Survey. Journal of the Chinese Institute of Engineers, 37(7), 859-868. https://doi.org/10.1080/02533839.2014.888798

Turner, J. R., \& Müller, R. (2003). On the Nature of the Project as a Temporary Organization. International Journal of Project Management, 21(1), 1-8.

UUsitalo, P., Olivieri, H., Seppänen, O., Pikas, E., \& Peltokorpi, A. (2017). Review of Lean Design Management: Processes, Methods and Technologies. 25th Annual Conference of the International Group for Lean Construction 2017, IGLC 2017, 571578. Heraklion.

Valentine, M., Nembhard, I., \& Edmondson, A. (2015). Measuring Teamwork in Health Care Settings: A Review of Survey Instruments. Medical Care, 53(4), 16-30. https://doi.org/10.1097/MLR.0b013e31827feef6

Viana, D. D., Formoso, C. T., \& Isatto, E. L. (2011). Modelling the Network of Commitments in the Last Planner System. Lean Construction Journal, 7(1), 55-67.

Wesz, J. G. B., Formoso, C. T., \& Tzortzopoulos, P. (2018). Planning and Controlling Design in Engineered-to-Order Prefabricated Building Systems. Engineering, Construction and Architectural Management, 25(2), 134-152. https://doi.org/10.1108/ECAM-02-2016-0045

Whyte, J., \& Tombesi, P. (2013). Challenges of Design Management in Construction. In R. Cooper, S. Junginger, \& T. Lockwood (Eds.), The Handbook of Design Management 
(pp. 202-2013). Bloomsbury Academic.

Wong, P. S. P., Demertjis, M., Hardie, M., \& Lo, C. yiu. (2014). The Effect of Unlearning on Organisational Learning Behaviour and Performance in Construction Contracting Organisations. International Journal of Project Organisation and Management, 6(3), 197. https://doi.org/10.1504/IJPOM.2014.065256

Woodside, A. G. (2010). Case Study Research. Theory, Methods and Practice. Bingley, U.K.: Emerald.

Wu, C., Xu, B., Mao, C., \& Li, X. (2017). Overview of BIM Maturity Measurement Tools. Journal of Information Technology in Construction, 22(March 2016), 34-62. https://doi.org/10.1080/01621459.1951.10500779

Yang, H. L., \& Tang, J. H. (2004). Team Structure and Team Performance in IS Development: A Social Network Perspective. Information and Management, 41(3), 335-349. https://doi.org/10.1016/S0378-7206(03)00078-8

Yin, R. K. (2009). Case Study Research: Design and Methods. New York: SAGE Publications.

Zhang, L., \& Ashuri, B. (2018). BIM Log Mining: Discovering Social Networks. Automation in Construction, 91(3), 31-43. https://doi.org/10.1016/j.autcon.2018.03.009 
A P P E N D I X E S 


\title{
APPENDIX A: PUBLISHED PAPERS FIRST PAGE
}

\section{Hinderi}

Advances in Ovil Engineering

Volume 2019, Article ID 9094254, 9 pages

herps//dni.org/10.1155/2019/909,25/

\section{Research Article}

\section{BIM Use Assessment (BUA) Tool for Characterizing the Application Levels of BIM Uses for the Planning and Design of Construction Projects}

\author{
María J. Rojas, ${ }^{1}$ Rodrigo F. Herrera ${ }^{2,3,4}$ Claudio Mourgues, ${ }^{3}$ José L. Ponz-Tienda, ${ }^{1}$ \\ Luis F. Alarcón, ${ }^{3}$ and Eugenio Pellicer $\odot^{4}$ \\ "Department of Civil and Envirunmental Enginecring Universidad de Los Andes, Bogotif, Colombiu \\ ${ }^{2}$ Sichool of Crvil Enginecringe. Pontificiat Universidad Canbilicat de Valpuratiso, Valpanuiso, Chile \\ ${ }^{3}$ Department of Constnaction Engincering and Management, Pontificiar Universidad Catóticat de Chilc, Santiatgo, Chile \\ 4School of Civil Enginecring Universitat Politácrioa de Valéncia, Valiencia, Spain \\ Correspondence should be addressed to Rodrigo F. Herrera; rodrigo herreraepucv.d \\ Received 1 February 2019, Revised 27 April 2019, Accepted 22 May 2019, Published 9 June 2019 \\ Academic Editor: Reza Akhavian
}

Copyright $\odot 2019$ Maria I. Rojas et al. This is an open access article distributed under the Creative Commons Attribution License, which permits unrestricted use, distribution, and reproduction in any medium, provided the original work is properly cited.

The evaluation of BIM capabilities and repeatability emables a company or project to identify its current status and how to improve continuously, this evaluation can be performed with BIM maturity models. However, these maturity models can measure the BIM state but not specifically the application of BIM uses. Likewise, in interorganizational project teams with a diversity of factors from various companies, it is possible to evaluate the capacity at a specified time with specified factors, but it is not possible to evaluate the repeatability unless the client always works with the same project teams. Therefore, despite the existence of various BIM uses in the literature, there is no instrument to evaluate the level of implementation of them in construction projects. This research proposes a BIM Use Assessment (BUA) tool for characterizing the levels of application of the BIM uses in the planning and design phases of building projects. The research methodology was organized into three stages: (1) identification, selection, and definition of BIM uses, (2) proposal of the BUA tool for charncterizing the level of BIM use application; and (3) validation of the BUA tool. The tool was validated using 25 constroction projects, where high reliability and concordance were observed, bence, the BUA tool complies with the consistency and concondance analysis for assessing uses in the design and planning phases of construction projects. The assessment will emable self-diagnosis, stakeholder qualification' selection, and industry benchmarking.

\begin{abstract}
1. Introduction
Building information modeling (BIM) is becoming an essential methodology in the architecture, engineering, and construction (AEC) industry. Indeed, public agencies from several countries are encouraging the use of this methodology by issuing requirements, user guides, and manuals regarding its use [1]. There are several ways of using BIM (BIM uses), which lead to various benefits; as stated by Kreider and Messner [2], applications of BIM during the infrastructure lifecycle can enable the realization of one of more specific objectives. Therefore, it is important to understand the way that organizations apply BIM uses.
\end{abstract}

BIM uses are defined in various ways the Penn State guide defines BIM use as "a method of applying Building Information Modeling during a facility's life cycle to achieve one of more specific objectives" [2]. According to Succar, BLM uses "identify and collate the information, requirements that need to be delivered as-or embedded within-3D diginal models" [3]. Another definition comes from the New York guide, which defines BIM uses as "the most common applications of BIM on the Department of Design and Construction Projects: BIM uses shall be considered and aligned with proiect goals ${ }^{-}[4]$. Thus, while there is a consensus on the relationship of uses to project objectives, there is no agreement on whether uses are methods.

Paper 1: BIM Use Assessment (BUA) Tool for Characterizing the Application Levels of BIM Uses for the Planning and Design of Construction Projects 


\title{
An Assessment of Lean Design Management Practices in Construction Projects
}

\author{
Rodrigo F. Herrera ${ }^{1, *}$, Claudio Mourgues ${ }^{2}$, Luis Fernando Alarcón ${ }^{2}$ and Eugenio Pellicer ${ }^{3} \odot$ \\ 1 School of Civil Engineering, Pontificia Universidad Católica de Valpuraiso, Pontificia Univensidad Católica \\ de Chile \& Universitat Politèrnica de València, Av Brasil 2147, Valparaiso 2340000, Chile \\ 2 School of Enginerering, Pontificia Universidad Católica de Chile, Vicuña Mackenna 4860, Casilla 306 Correo \\ 22 Santiago, Chile, cmourguetting pucel (C.M.); lalarconeting puc.d (L.F.A.) \\ 3 School of Civil Engineering, Universitat Politrecrica de Valencia, Camino de Vera s/n, 46022 Valencia, Spain; \\ pelliceritupves \\ - Correspondence: rodrigo herreraêpucv.d; Tel + +56-32-227-3882
}

Received: 30 October 2019; Accepted: 16 December 2019; Published: 18 December 2019

\begin{abstract}
Evidence exists for the application of lean management practices in the design process. However, there is no systematic review of this type of practice that links the design management practices to the lean construction principles. There is no tool to assess the level of use of lean design management practices in construction projects either. Therefore, this paper aims to assess the lean management practices that are performed at the design phase of construction projects. The research was divided into a literature review of design management practices; a validation of lean design management practices with a practice-principle relationship, based on an expert survey; the devolvement of a tool (questionnaire) to evaluate the lean design management practices; and an assessment in 64 construction projects (coherence, reliability, correlation, and descriptive analysis). It is concluded that evidence exists for the implementation of 19 lean design management practices. These practices are grouped into three categories: stakeholder management, planning and control, and problem solving and decision making. Additionally, in the assessment of the 64 projects, it can be observed that the lean design management practices are at initial levels of implementations, so there is a significant development gap. This research proposes a tool to assess management practices in the design phase of construction projects; then, the study identifies implementations gaps, it provides benchmarks with other projects, and it improves the design process through a taxonomy of lean design management practices.
\end{abstract}

Keywords: design phase; management practices; construction projects; lean construction

\section{Introduction}

The infrastructure life-cycle has several phases from the inception of the idea to the dismantlement of the facility $[1,2]$. Within this life cycle, the design phase is key because the decisions made during this phase can significantly affect the subsequent phase. In addition, the costs of changes in the design phase are negligible compared to the costs of changes in future phases [3]. Poot interactions within the work teams of the architecture, engineering and construction (AEC) industry can result in poor performances [4]. Poor performance results from activities that do not add value and are considered project losses, such as reworks and waiting times, among others [5]. Therefore, it is essential to appropriately manage the design process. Design management is the discipline of planning. organizing, and managing the design process to meet certain defined objectives [6]. Although there is no tradition of integral management of the design process, in recent years, several options have 


\title{
ASCE \\ Understanding Interactions between Design Team Members of Construction Projects Using Social Network Analysis
}

\author{
Rodrigo F. Herrera'; Claudio Mourgues, Ph.D. ${ }^{2}$; \\ Luis F. Alarcón, Ph.D., M.ASCE ${ }^{3}$; and Eugenio Pellicer, Ph.D., M.ASCE ${ }^{4}$
}

Abstract: Social network analysis (SNA) has not been used to study design project teams in which the full interactions have become more complex (formal and informal) because the team members are from different companies and there is no colocation. This work proposes a method to understand the interactions in the design teams of construction projects using SNA metrics and the sociograms generated within temporary organizations. This study includes three stages: (1) a literature review of the dimensions of interactions with in work teams and the application of SNA to the architecture, engineering, and construction (AEC) industry; (2) a proposal of an interaction network method for construction project design teams; and (3) an analysis of a pilot project. Interaction networks were defined in two categories: general interactions and commitment management. For each network, metric indicators were defined for the analysis The pilot project showed high levels of consistency among team responses. The proposed method allows an analysis of the entire work team and of each individual team member. The method also makes it possible to analyze the work team from a global perspective by carrying out a joint analysis of two or more networks. DOI: 10.1061/(ASCE)CO.1943-7862.0001841. ㅇ 2020 American Saciety of Civil Engineers

Author keywords: Interaction; Interaction metrics; Sociograms; Information flow; Design teams; Social networks

\section{Introduction}

The architecture, engineering, and construction (AEC) industry is fragmented into several specialties that correspond to the different phases of a project (Dainty et al. 2001; Love et al. 2002). A high degree of fragmentation requires better interaction among the specialties ( $\mathrm{Ng}$ and Tang 2010). The interaction of a work team is generated through communication, coordination, and collaboration among the participants (Schßttle et al. 2014). This interaction can be represented as the information flow between the right people at the right time (Dave et al. 2014; Al Hattab and Hamzeh 2015).

Poor interactions in work teams can lead to poor performance both in the implementation of each phase (design, construction, maintenance, operation, and deconstruction) and globally in the life cycle of the project (Baiden et al. 2006). This phenomenon is

${ }^{1}$ Instruckor, School of Civil Engineering, Pontificia Universidad Casblica de Valparaiso, Averida Brasil 2147, Valparaíso 23662504 Chile; Ph.D. Candidate, Dept. of Construction Engineering and Management, Pontificia Universidad Catblica de Chile, Santiago, Chile; Ph.D. Candidate, School of Civil Engineering, Universitat Politècnica de Va. Rencia, Valencia, Spain (corresponding author). ORCID: htps:Norcid org/0000-0001-5186-3154. Email; rodrigo.herrera pucv.cl

${ }^{2}$ Associste Professor, Dept. of Construction Engineering and Management, Pontificia Universidad Catilica de Chile, Vicuña Mackenna 4860, Cavill 306 , Correo 22, Santiago, Chile. Email: cmourgue ing.puc.cl

${ }^{3}$ Professor, Dept. of Construction Engineering and Maragement, Pontificia Universibad Catilica de Chile, Vicuña Mackenna 4860, Cailla 306, Carreo 22 Santiago, Crike, Email: barcon wing pucd

${ }^{4}$ Professor, School of Civil Engineering, Universitat Poliecrica de València, Caminode Vera shn, Valencia46022, Spain. ORCID: hrtps:Norcid arg $0000-0001-9100-0644$. Email: pellicerilip upves

Note. This manuscript was submitted on April 5, 2019; pproved on December 4, 2019; published online on Maxh 25, 2020. Discussion period open urtil Augus 25, 2020); separate discussions must be submittal for individual papers. This paper is part of the Joumal of Construction Enginearing and Management, 0 ASCE, ISSN 0733-9364.

Q ASCE

$04020053-1$ particularly important at the design phase because decisions made at this phase can significantly affect the following phases, and the cost of making changes at this phase are insignificant compared with the cost of implementing changes in future phases (American Institute of Architects Califomia Council 2007).

The client usually chooses a project coordinator or design manager at the design phase of a construction project to lead this phase and manage the interaction among all the specialists, such as architects, structural, electrical and sanitary specialists, and others (Knotten et al. 2017; Oluw atayo and Amole 2013). Because the AEC industry is fragmented, the level of subcontracting of the specialties has been increasing in recent years (Oviedo-Haito et al. 2014).

More fragmentation requires more interaction, which must be approached by considering the social and technological factors. These factors together allow the information flows to be suitable for the desired interaction. A project team with greater interaction may generate an increase in trust and leaming in work teams, achieving high levels of commitment and understanding among participants (Phelps 2012). Flores et al. (2014) claimed that by improving the interaction of information flows among people, improved project performance can be achieved. An interaction in a work team can be represented as a network of commitments among its members, who establish reliable commitments among themselves to achieve the objectives of the project (Viana et al. 2011).

Evaluation of the interactions among members of a work team is challenging. One approach to this issue is to measure teamwork with instruments; Valentine et al. (2015) presented a literature review from 2012 in which 39 instruments were identified for measuring teamwork with surveys. Most of these instruments include dimensions such as communication, coordination, and respect. Although the study by Valentine et al. (2015) included a large number of instruments that evaluate teamwork, these instruments carry out a general evaluation of an organization and thus do not allow the identification of the frequency and dimension of interactions

\section{J. Const. Eng. Manze, 2020, 146(6): 04020053}

Paper 3: Understanding Interactions between Design Team Members of Construction Projects Using Social Network Analysis 
APPENDIX B: BUA TOOL

\begin{tabular}{|c|c|c|c|c|c|c|c|c|c|c|}
\hline \multirow{2}{*}{\multicolumn{2}{|c|}{ Cost Estimation }} & \multicolumn{4}{|c|}{ Source of quantities } & \multicolumn{3}{|c|}{ Type of model } & \multicolumn{2}{|c|}{ Applied Systems } \\
\hline & & Manual & luct view & Renert & Integration & م2 & $3 \mathrm{R}$ & BIM $>$ & $<50 \%$ & $>50 \%$ \\
\hline \multirow{5}{*}{$\begin{array}{l}\text { A BIM model is used to } \\
\text { generate accurate quantity take } \\
\text { offs and cost estimates. }\end{array}$} & 1 & & & & & & & & & \\
\hline & 2 & & & & & & & & & \\
\hline & 3 & & & & & & & & & \\
\hline & 4 & & & & & & & & & \\
\hline & 5 & & & & & & & & & \\
\hline
\end{tabular}

\begin{tabular}{|c|c|c|c|c|c|c|c|}
\hline \multirow{2}{*}{\multicolumn{2}{|c|}{ Phase Planning }} & 4D model & \multicolumn{3}{|c|}{ Type of use } & \multicolumn{2}{|c|}{ Link type } \\
\hline & & $4 \mathrm{D}$ & Communic. & Manual & Auto & Manual & Auto \\
\hline \multirow{5}{*}{$\begin{array}{l}\text { A 4D BIM model is utilized to } \\
\text { effectively plan, especially } \\
\text { spatial planning, including } \\
\text { spatial clashes and paths. }\end{array}$} & 1 & & & & & & \\
\hline & 2 & & & & & & \\
\hline & 3 & & & & & & \\
\hline & 4 & & & & & & \\
\hline & 5 & & & & & & \\
\hline
\end{tabular}

\begin{tabular}{|c|c|c|c|c|c|c|}
\hline \multirow{2}{*}{ Site Analysis } & & \multicolumn{2}{|c|}{ Type of model } & \multicolumn{3}{|c|}{ Type analysis } \\
\hline & & RIMA $>$ & GIS & Location by & Site ontionc & Location by \\
\hline \multirow{5}{*}{$\begin{array}{c}\text { BIM/GIS is used to select and } \\
\text { evaluate a site location and to } \\
\text { select a building position on the } \\
\text { site. }\end{array}$} & 1 & & & & & \\
\hline & 2 & & & & & \\
\hline & 3 & & & & & \\
\hline & 4 & & & & & \\
\hline & 5 & & & & & \\
\hline
\end{tabular}

\begin{tabular}{|c|c|c|c|c|c|c|c|c|}
\hline \multirow{2}{*}{\multicolumn{2}{|c|}{ Space Programming }} & \multicolumn{3}{|c|}{ Type of model } & \multicolumn{4}{|c|}{ Distribution analysis } \\
\hline & & $2 D$ & $3 D$ & BIM & Manual & Consults & Report & Auto \\
\hline \multirow{5}{*}{$\begin{array}{l}\text { A BIM model is used to design } \\
\text { and analyse the project's } \\
\text { spaces and rooms and to assign } \\
\text { to each space a use and its } \\
\text { measurements. }\end{array}$} & 1 & & & & & & & \\
\hline & 2 & & & & & & & \\
\hline & 3 & & & & & & & \\
\hline & 4 & & & & & & & \\
\hline & 5 & & & & & & & \\
\hline
\end{tabular}

\begin{tabular}{|c|c|c|c|c|c|c|c|c|}
\hline \multicolumn{2}{|l|}{ Design Review } & \multicolumn{3}{|c|}{ Type of model } & \multicolumn{2}{|c|}{ Immersive lab } & \multicolumn{2}{|c|}{ List of requirements } \\
\hline & & $2 \mathrm{D}$ & $3 D$ & BIM & No & Yes & Informal & Formal \\
\hline \multirow{5}{*}{$\begin{array}{l}\text { A process in which } \\
\text { stakeholders interact with a } \\
\text { BIM model and provide their } \\
\text { feedback to validate multiple } \\
\text { design aspects. }\end{array}$} & 1 & & & & & & & \\
\hline & 2 & & & & & & & \\
\hline & 3 & & & & & & & \\
\hline & 4 & & & & & & & \\
\hline & 5 & & & & & & & \\
\hline
\end{tabular}

\begin{tabular}{|c|c|c|c|c|c|c|c|c|c|c|c|}
\hline \multirow{2}{*}{\multicolumn{2}{|c|}{ Code Validation }} & \multicolumn{3}{|c|}{ Type of software } & \multicolumn{3}{|c|}{ Type of model } & \multicolumn{2}{|c|}{ Applied system } & \multicolumn{2}{|c|}{ Level of mock-up } \\
\hline & & Manual & Consults & Auto & $2 \mathrm{D}$ & $3 \mathrm{D}$ & BIM & $<50 \%$ & $>50 \%$ & Geometry & Parametric \\
\hline \multirow{5}{*}{$\begin{array}{l}\text { A process in which code } \\
\text { validation software is utilized } \\
\text { to check the model } \\
\text { parameters against project- } \\
\text { specific design or } \\
\text { construction codes or norms. }\end{array}$} & 1 & & & & & & & & & & \\
\hline & 2 & & & & & & & & & & \\
\hline & 3 & & & & & & & & & & \\
\hline & 4 & & & & & & & & & & \\
\hline & 5 & & & & & & & & & & \\
\hline
\end{tabular}




\begin{tabular}{|c|c|c|c|c|c|c|c|c|c|}
\hline \multirow{2}{*}{\multicolumn{2}{|c|}{ Sustainable analysis }} & \multicolumn{3}{|c|}{ Type of model } & \multicolumn{3}{|c|}{ Type of software } & \multicolumn{2}{|c|}{ Applied system } \\
\hline & & \multirow[t]{2}{*}{$2 \mathrm{D}$} & \multirow[t]{2}{*}{$3 \mathrm{D}$} & \multirow[t]{2}{*}{ BIM } & \multirow[t]{2}{*}{ Manual } & \multirow[t]{2}{*}{ Consults } & \multirow[t]{2}{*}{ Auto } & \multirow[t]{2}{*}{$<50 \%$} & \multirow[t]{2}{*}{$>50 \%$} \\
\hline \multirow{5}{*}{$\begin{array}{l}\text { A process in which the } \\
\text { sustainability of a facility is } \\
\text { evaluated and tracked using a } \\
\text { sustainability metric system }\end{array}$} & 1 & & & & & & & & \\
\hline & 2 & & & & & & & & \\
\hline & 3 & & & & & & & & \\
\hline & 4 & & & & & & & & \\
\hline & 5 & & & & & & & & \\
\hline
\end{tabular}

\begin{tabular}{|c|c|c|c|c|c|c|c|c|c|}
\hline \multicolumn{2}{|l|}{ Engineering analysis } & \multicolumn{3}{|c|}{ Type of model } & \multirow{2}{*}{$\begin{array}{l}\text { Compatible } \\
\text { software }\end{array}$} & \multicolumn{2}{|c|}{ Applied systems } & \multicolumn{2}{|c|}{ Documentation } \\
\hline & & 2D & 3D & BIM & & $<50 \%$ & $>50 \%$ & 2D & $3 \mathrm{D}$ \\
\hline \multirow{5}{*}{$\begin{array}{c}\text { A BIM model and specialized } \\
\text { software are used to conduct } \\
\text { an engineering analysis to } \\
\text { identify the most efficient } \\
\text { method or design. }\end{array}$} & 1 & & & & & & & & \\
\hline & 2 & & & & & & & & \\
\hline & 3 & & & & & & & & \\
\hline & 4 & & & & & & & & \\
\hline & 5 & & & & & & & & \\
\hline
\end{tabular}

\begin{tabular}{|c|c|c|c|c|c|c|c|}
\hline \multicolumn{2}{|l|}{ Design Authoring } & \multicolumn{3}{|c|}{ Type of model } & \multirow{2}{*}{$\begin{array}{c}\text { Generative } \\
\text { models }\end{array}$} & \multicolumn{2}{|c|}{ Applied systems } \\
\hline & & 2D & $3 \mathrm{D}$ & BIM & & $<50 \%$ & $>50 \%$ \\
\hline \multirow{5}{*}{$\begin{array}{l}\text { A process in which 3D software is } \\
\text { used to develop a Building } \\
\text { Information Model. A project is } \\
\text { designed in a BIM model, where } \\
\text { the typical iterations of a project } \\
\text { are made, and everything is built } \\
\text { directly in the BIM software. }\end{array}$} & 1 & & & & & & \\
\hline & 2 & & & & & & \\
\hline & 3 & & & & & & \\
\hline & 4 & & & & & & \\
\hline & 5 & & & & & & \\
\hline
\end{tabular}

\begin{tabular}{|c|c|c|c|c|c|c|c|c|}
\hline \multirow{2}{*}{\multicolumn{2}{|c|}{ 3D Coordination }} & \multicolumn{3}{|c|}{ Type of model } & \multicolumn{2}{|c|}{ Type analysis } & \multicolumn{2}{|c|}{ Applied systems } \\
\hline & & $2 D$ & $3 D$ & BIM & Manual & Auto & $<50 \%$ & $>50 \%$ \\
\hline \multirow{5}{*}{$\begin{array}{l}\text { A process in which 3D } \\
\text { coordination software is used } \\
\text { to identify 3D geometric } \\
\text { conflicts by comparing 3D } \\
\text { models of building systems. }\end{array}$} & 1 & & & & & & & \\
\hline & 2 & & & & & & & \\
\hline & 3 & & & & & & & \\
\hline & 4 & & & & & & & \\
\hline & 5 & & & & & & & \\
\hline
\end{tabular}




\title{
APPENDIX C: LPS QUESTIONNAIRE
}

\author{
PRÁCTICAS DE GESTIÓN EN EL DISEÑO DE PROYECTOS DE CONSTRUCCIÓN \\ Dimensiones: \\ 1. Gestión con involucrados \\ 2. Planificación del trabajo y Gestión de la Información \\ 3. Resolución de Problemas de diseño y Toma de decisiones
}

\section{Dimensión 1: Gestión de involucrados}

1. Los diseñadores especialistas se incorporan al proyecto desde:

a. La etapa de diseño de detalle

b. Entre a y c

c. La etapa de diseño de proyecto

d. Entre c y e

e. La etapa de anteproyecto previa al diseño

2. La constructora o un constructor se incorporan al proyecto desde:
a. La etapa de construcción
b. Entre a y c
c. La etapa de diseño de proyecto
d. Entre c y e
e. La etapa de anteproyecto previa al diseño

3. El levantamiento de los requerimientos del proyecto es:

a. Mínimo: necesidades básicas del cliente y condiciones de borde

b. Entre a y c

c. Detallado: programa, capacidades y aspectos técnicos

d. Entre c y e

e. Exhaustivo: programa, capacidades, aspectos técnicos y requerimientos especiales.

4. La participación del cliente en la etapa de diseño es:

a. Para presentar una necesidad, sin una visión de sistema.

b. Entre a y c

c. Para participar en las reuniones con voz informativa, solicitar información y tomar decisiones que influyan directamente en una necesidad específica.

d. Entre c y e

e. Para participar y apoyar de forma sistemática en las reuniones en la toma de decisiones y resolución de problemas 
5. Con respecto al diseño del producto y del proceso constructivo

a. Se realiza primero el diseño del producto y luego se diseña el proceso constructivo

b. Entre a y c

c. El diseño del producto y el proceso productivo se traslapan frecuentemente

d. Entre c y e

e. El diseño del producto y del proceso constructivo se realizan de forma simultanea

\section{Dimensión 2: Planificación del trabajo y gestión de la información}

6. La planificación del proyecto considera

a. La fecha de entrega y la distribución de tareas (programa a nivel global, es decir, fases e hitos principales)

b. Entre a y c

c. La fecha de entrega, fases, hitos, programa de subdivisión de tareas e instancias de control

d. Entre c y e

e. Lo anterior inmerso en un esquema en el cual se clarifiquen las holguras, buffers y puntos en los cuales puedan realizarse acciones de Pull/Push dentro del programa.

7. Para planificar se considera ...

a. Solo la información que maneja el jefe de proyecto.

b. Entre a y c

c. La información de proyectos internos proveniente de una base de datos interna

d. Entre c y e

e. La información de proyectos internos y/o externos de la organización, generada a través de un ejercicio de Benchmarking.

8. Los actores y las instancias para planificar el trabajo son las siguientes:

a. Planificación centralizada ( 1 actor)

b. Entre a y c (igual que la anterior, pero revisa en conjunto)

c. Planificación descentralizada pero no integrada. Planifica más de 1 persona de forma aislada.

d. Entre c y e (lo anterior, pero con instancias de revisión)

e. Planificación descentralizada, colaborativa y sistemática.

9. Los niveles de planificación son

a. Solo global

b. Entre a y c

c. Global e hitos intermedios

d. Entre c y e

e. Global, por fase, intermedia y a corto plazo 
10. Las restricciones que se asocian al proceso de diseño son:

a. Identificadas solo cuando se presentan y no se puede avanzar en la tarea.

b. Entre a y c

c. Identificadas para que una persona se haga responsable de liberarla.

d. Entre c y e

e. Identificadas, registradas y se asigna un compromiso de liberación asociado a un responsable del equipo. Luego se les hace un seguimiento

11. Para la coordinación de información del proyecto con los especialistas:

a. Se utilizan distintas plataformas

b. Entre a y c

c. Se utiliza la misma plataforma, con diferentes archivos que deben superponerse o transformarse por un servicio externo

d. Entre c y e

e. S utiliza la misma plataforma con un archivo único respaldable.

\section{Dimensión 3: Resolución de problemas de diseño y toma de decisiones}

12. Los problemas que se generan en el proyecto.

a. Se destacan y se espera hasta que alguien los resuelva

b. Entre a y c

c. Se hacen evidentes y se designa un responsable quien busca forma de resolverlos

d. Entre c y e

e. Existe un protocolo para resolver los problemas en forma colaborativa

13. Para resolver problemas

a. El superior identifica el problema y da instrucciones

b. Entre a y c

c. El grupo de trabajo identifica el problema y el superior da las instrucciones

d. Entre c y e

e. El último planificador identifica el problema y se realiza un análisis causal, a través de una técnica, como los 5 por qué u otra similar, para dar solución a la causa raíz.

14. Después de haber decido la solución del problema

a. Se implementa la solución

b. Entre a y c

c. Se implementa y se realiza un monitoreo de las acciones de la solución, para verificar que el problema fue resuelto

d. Entre c y e

e. Se implementa y se realiza un monitoreo de las acciones de la solución, para verificar que el problema fue resuelto. Además, se documentan los resultados de la solución para contar con el antecedente, si es que se vuelve a generar un problema similar 
15. El proceso de toma de decisiones es:

a. Se reacciona ante los eventos y las decisiones se toman rápidamente y se implementan testeando si funciona o no la solución

b. Entre a y c

c. Se evalúan opciones y se realizan pruebas antes de su implementación

d. Entre c y e

e. Se evalúan opciones, se planifican, se realizan pruebas, se validan sus resultados y se aplican (PDCA)

16. El momento para tomar las decisiones en el proyecto es

a. Lo más rápido posible para ofrecerle la solución al cliente

b. Entre a y c

c. Cuando se conocen todas las variables de las opciones que se barajan

d. Entre c y e

e. Decidir tan tarde como sea posible, definiendo previamente cuál es el último momento responsable y actuar antes de ese momento y con toda la información que se pueda reunir para ese instante.

17. Para tomar decisiones se considera ...

a. Solo la información que maneja el jefe de proyecto.

b. Entre a y c

c. La información de proyectos internos proveniente de una base de datos interna

d. Entre c y e

e. La información de proyectos internos y/o externos de la organización, generada a través de un ejercicio de Benchmarking.

18. El mecanismo que se utiliza para tomar decisiones es:

a. En una reunión entre el jefe de proyecto y el cliente, en donde analizan la solución

b. Entre a y c

c. En una reunión entre el jefe de proyecto, el cliente y el especialista que corresponda, en donde analizan todas las opciones y sus implicancias con una lluvia de ideas.

d. Entre c y e

e. En una reunión con todos los implicados, en donde se utiliza un mecanismo de toma de decisiones, tales como, WRC, AHP, CBA u otro.

19. Luego de tomar las decisiones

a. Se realizan acciones para concretar la decisión.

b. Entre a y c

c. Se realizan acciones para concretar la decisión y se verifica si la decisión tuvo resultados satisfactorios

d. Entre c y e

e. Se realizan acciones para concretar la decisión y se verifica si la decisión tuvo resultados satisfactorios. Además, se identifican y documentan las lecciones aprendidas como antecedentes para una nueva toma de decisión. 